Portland State University

PDXScholar

Winter 1-6-2016

\title{
Exploratory Study of the Adoption and Use of the Smartphone Technology in Emerging Regions: Case of Saudi Arabia
}

Fahad Abdulaziz Aldhaban

Portland State University

Follow this and additional works at: https://pdxscholar.library.pdx.edu/open_access_etds

Part of the Communication Technology and New Media Commons, Other Operations Research, Systems Engineering and Industrial Engineering Commons, and the Science and Technology Studies Commons

Let us know how access to this document benefits you.

\section{Recommended Citation}

Aldhaban, Fahad Abdulaziz, "Exploratory Study of the Adoption and Use of the Smartphone Technology in Emerging Regions: Case of Saudi Arabia" (2016). Dissertations and Theses. Paper 2651.

https://doi.org/10.15760/etd.2647

This Dissertation is brought to you for free and open access. It has been accepted for inclusion in Dissertations and Theses by an authorized administrator of PDXScholar. Please contact us if we can make this document more accessible: pdxscholar@pdx.edu. 
Exploratory Study of the Adoption and Use of the Smartphone Technology in Emerging Regions: Case of Saudi Arabia

$$
\text { by }
$$

Fahad Abdulaziz Aldhaban

A dissertation submitted in partial fulfillment of the requirements for the degree of

\author{
Doctor of Philosophy \\ in \\ Technology Management
}

Dissertation Committee:

Tugrul U. Daim, Chair

Robert L. Fountain

Robert Harmon

Kenny Phan

Portland State Universtiy

2016 


\begin{abstract}
Users' acceptance of a new information technology (IT) is considered to be a key determinant factor of its success. Also, studying users' adoption and use of new IT plays an important role in determining users' needs and reducing business risk, especially in industry segments with rapid changes in IT such as Smartphone technology. Such rapid evolution is influencing consumers' behaviors, their daily lifestyle, the manner of conducting their activities and their ways of consuming and using information.

Smartphone technology holds a promising future with an expected global market that could reach US $\$ 258$ billion by the end of year 2015 [1]. Besides the mobile industry, Smartphone technology introduces a wide range of opportunities and challenges for many related industries that participate directly or indirectly in producing and providing Smartphone services/products to the end users. Moreover, the Smartphone technology is relatively new technology with plenty of room for improvement.
\end{abstract}

Better understanding of users' intentions and their behaviors regarding the adoption and use of the Smartphone technology plays a critical role in determining its success and benefiting all stakeholders. Significant efforts have been made to study and explain users' adoption and use of Smartphone technology. However, most of the empirical research focused on only a limited number of Smartphone aspects or on a 
specific profession such as doctors and nurses which may neglect other important factors.

In emerging regions such as Jordan and China, cultural and social influence showed significant relationships with users' adoption and use of the Smartphone and its related technologies. Saudi Arabia is a developing country that has different cultural and social contexts that could influence users' intention to adopt and use the Smartphone technology. The key factors that influence general users' intention to adopt and use Smartphone technology in Saudi Arabia have not yet been studied and explored in a comprehensive manner. Therefore, the main purpose of this dissertation is to empirically study and explore the key factors that influence general users' adoption and use of the Smartphone in a comprehensive manner in Saudi Arabia.

This dissertation starts with a literature review of existing research related to the adoption and use of Smartphone technology. Taxonomy is developed that includes factors that were identified as important in previous research and related to the adoption and use of the Smartphone technology. By using the developed taxonomy and reviewing literature related to the IT adoption theories, a preliminary theoretical research model is developed based on the Unified Theory of Acceptance and Use of Technology (UTAUT). A number of qualitative methods, namely brainstorming, focus group and individual interviews, have been conducted to evaluate, select and validate the existing factors, as well as introduce new factors, and to identify only the most related factors to be included in the preliminary research model. A survey questionnaire 
has been developed and validated to survey general users of the Smartphone in Saudi Arabia. A web-based survey has been designed and sent through email to 5,000 randomly selected smartphones users in Saudi Arabia. Data has been statistically analyzed using Structural Equation Modeling (SEM). The results indicate that performance expectancy factor, effort expectancy factor, brand influence factor, perceived enjoyment factor and design factor have a positive and significant relationship with users' intention to adopt and use smartphones in Saudi Arabia. Also, the results indicate that the social influence factor has a significant and positive relationship with use behavior or actual use of smartphones in Saudi Arabia. The results of this dissertation provide more insights to practitioners in the smartphones domain and information that contributes to the body of knowledge regarding information technology adoption and its related research, especially in Saudi Arabia. 


\section{Dedication}

To my father Sheikh Abdulaziz Aldhaban and Mother Fatima Althobait, for their unlimited love and support throughout my life, my brothers Dr. Saud Aldhaban and Muhammad Aldhaban for their inspiration and continued support. To my beloved wife Ebtesam Alasbli and my children, Melaf, Shodoown, Lamar and Abdulaziz who are my strength, inspiration and joy of my life. 


\section{Acknowledgments}

I would like to express my sincere gratitude to my advisor and committee chair Dr. Tugrul Daim and committee members Dr. Robert Fountain, Dr. Robert Harmon and Dr. Kenny Phan for their continuous efforts in encouraging and guiding me throughout my dissertation. From the first day I arrived at ETM, Dr. Daim's vision, experience, and guidance contributed generously to my work and research.

Dr. Fountain's experience, useful comments and feedback helped me to better understand and use analytical methods in my dissertation and greatly enhanced my experience with statistical analysis. His detailed comments and feedback contributed highly to my dissertation. Dr. Harmon's positivity, continued encouragement, and contributions guided me and enhanced my dissertation process. Dr. Phan's encouragement useful feedback, support and advice were invaluable.

I sincerely thank all of my committee members for their time, effort and patience, throughout my research. They are all always positive and ready to help in any way. Their experience, knowledge, and vision contributed to my success. I would also like to thank all of ETM faculty, staff and students for making my experience at the ETM one of the best chapters in my life. 


\section{Table of Contents}

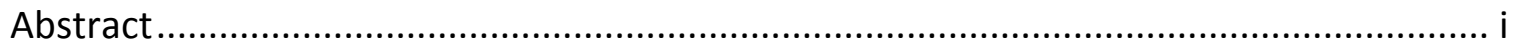

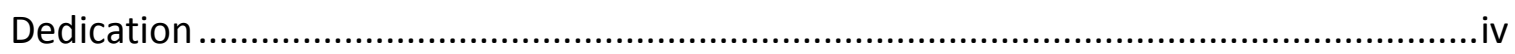

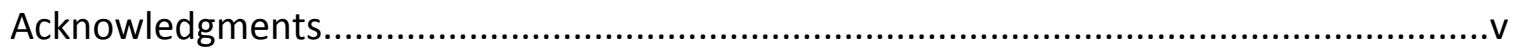

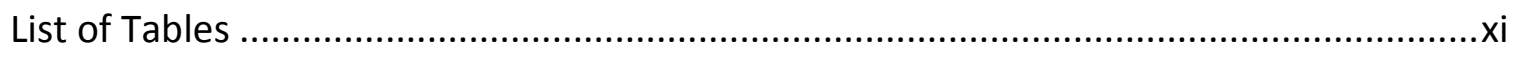

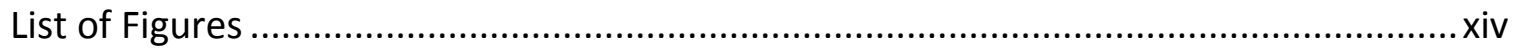

1 Chapter One: Research Objectives and Overview .................................................. 1

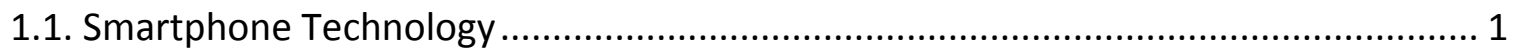

1.2 Users' adoption and use of the Smartphone technology ......................................... 3

1.3 Studying the adoption and use of Smartphone and its related technologies in

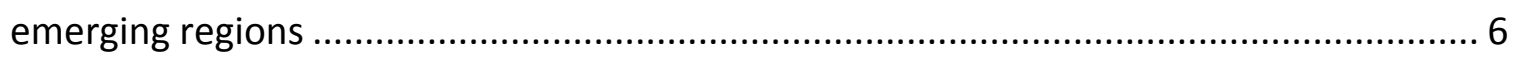

1.4 Saudi Arabia; its Economy and Telecom Sector .................................................. 9

1.5 Language, Cultural differences and the Needs for Graduate Level Research ............ 12

1.6 Research related to Smartphone technology in Saudi Arabia ................................. 14

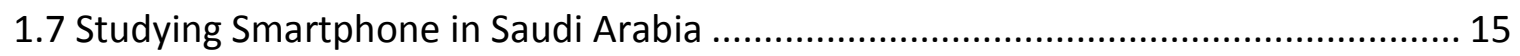

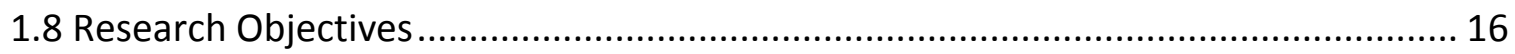

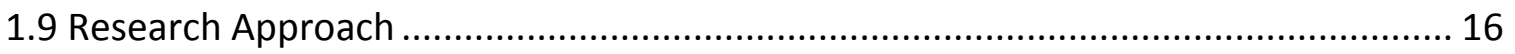

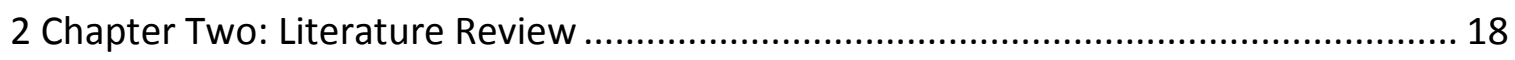

2.1 Relevant Theories Used to Study the Adoption and Use of (IT) .............................. 19

2.2 Research Related to the Adoption and Use of Smartphone ................................. 27

2.3 Taxonomy of Factors Related to The Adoption and Use of Smartphones ................ 46

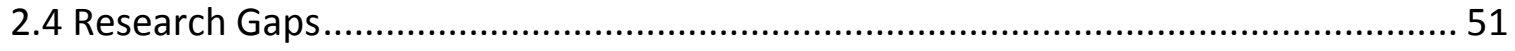

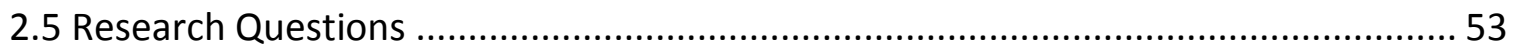

3 Chapter Three: Developing Research Model and Research Hypotheses .................... 56

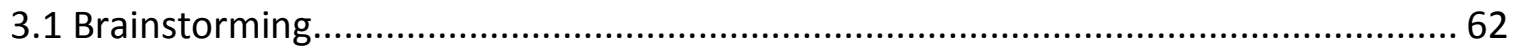




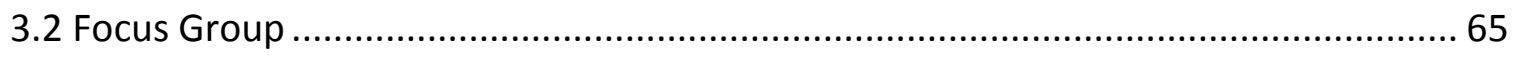

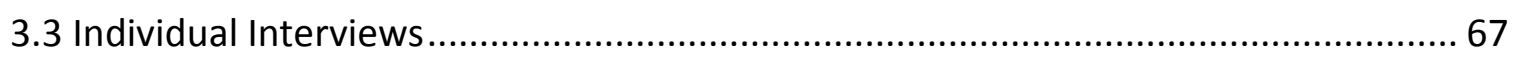

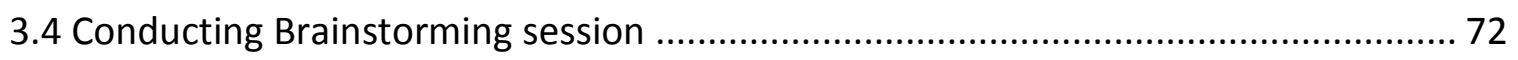

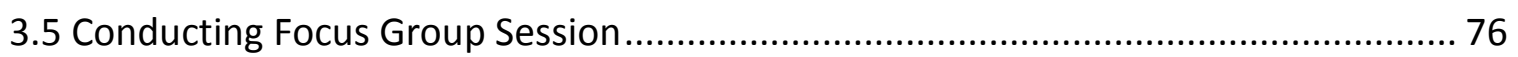

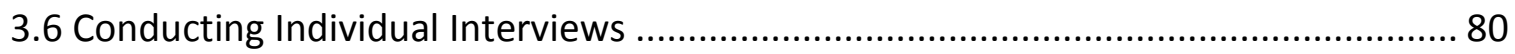

3.7 Results of the Qualitative methods that have been conducted................................ 83

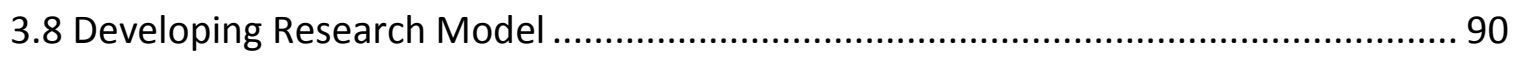

3.9 Developing Research hypotheses ..................................................................... 96

4 Chapter Four: Research Approach .................................................................. 110

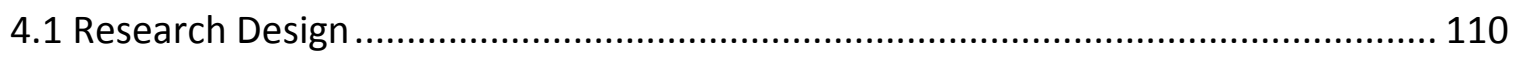

4.2 Survey Instrument Development...................................................................... 110

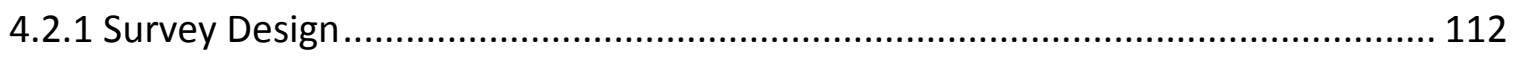

4.2.2 Developing the survey instrument ................................................................ 113

4.2.3 Questionnaire Design................................................................................... 113

4.2.4 Designing the type and form of the survey questions........................................ 114

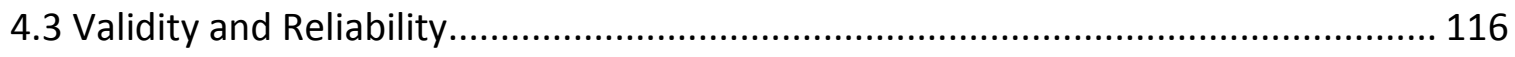

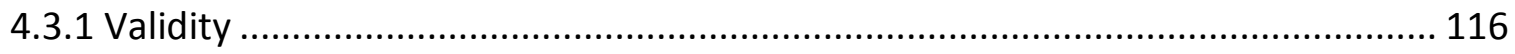

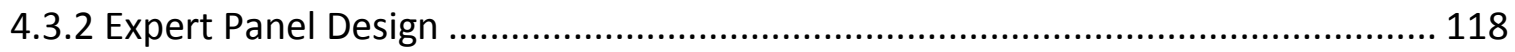

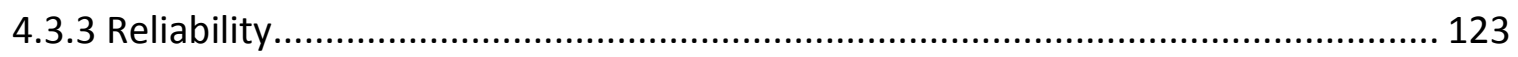

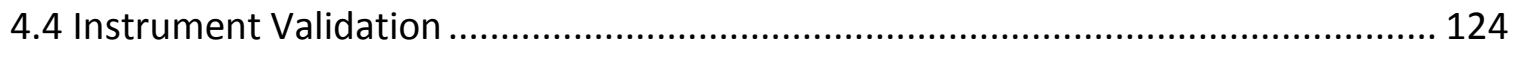

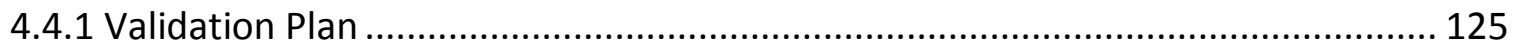

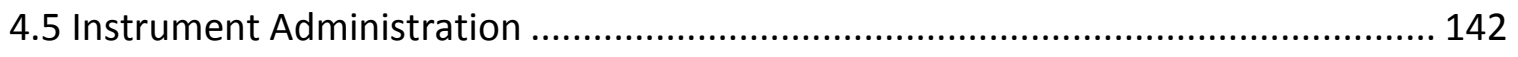

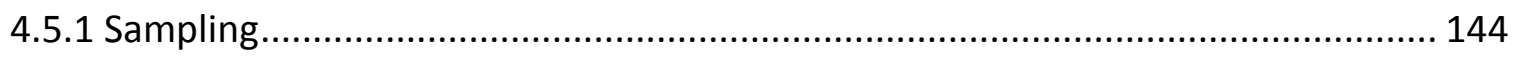




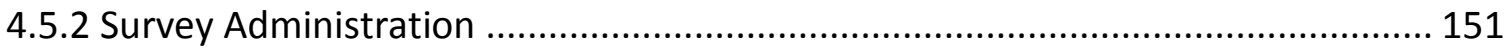

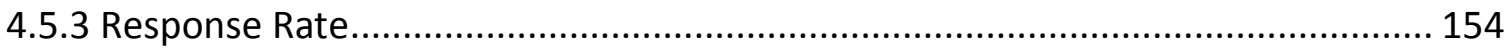

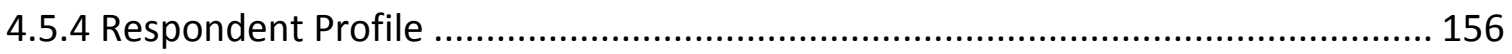

4.5.5 Non-Response Error: Wave Analysis................................................................. 157

4.5.6 Nonresponse Error: Item Nonresponse ........................................................... 159

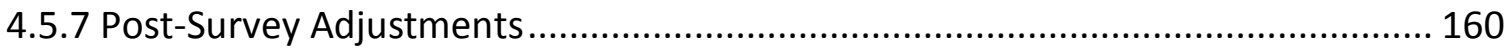

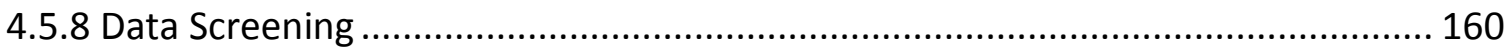

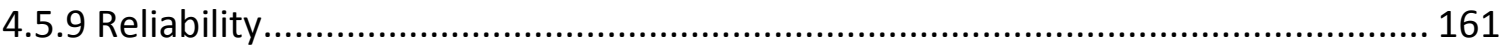

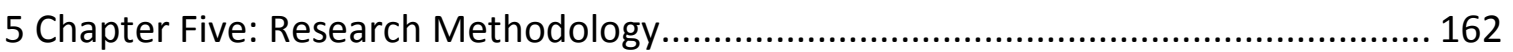

5.1 Structural Educational Modeling (SEM) ................................................................ 162

5.2 Reflective Measurement...................................................................................... 165

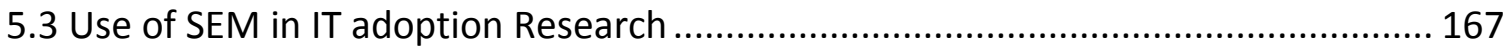

5.3 SEM Process, Assumptions and Limitations …….................................................. 167

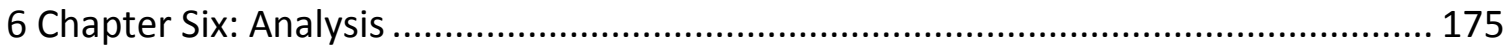

6.1 Measurement Model ................................................................................... 176

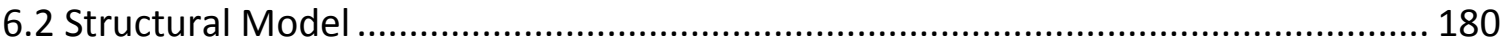

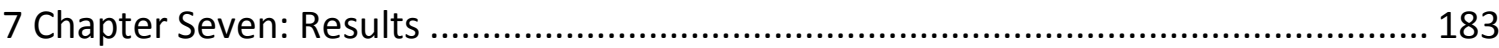

7.1 Performance Expectancy Factor ........................................................................... 183

7.2 Effort Expectancy Factor ................................................................................. 184

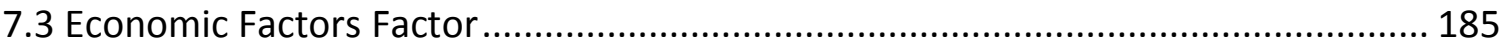

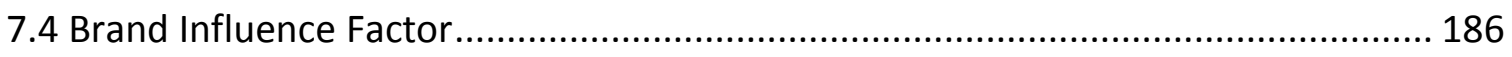

7.5 Perceived Enjoyment Factor ........................................................................... 187

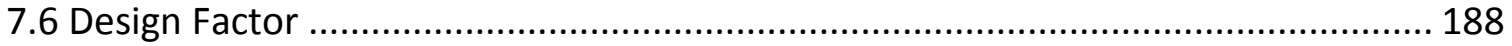

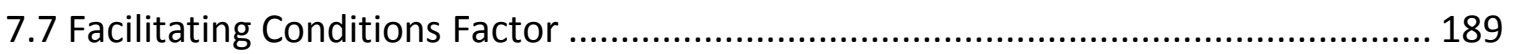


7.8 Social Influence Factor

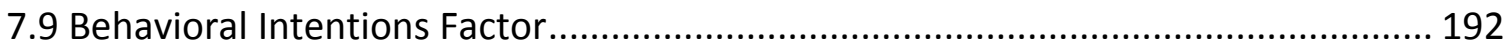

8 Chapter Eight: Hypotheses Testing and Discussion ............................................. 193

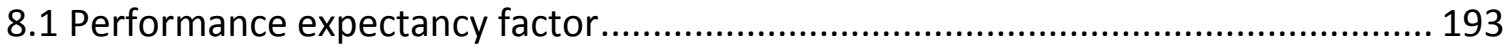

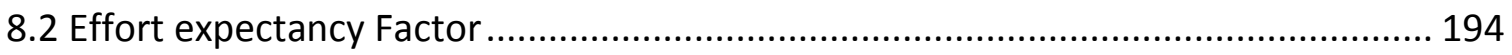

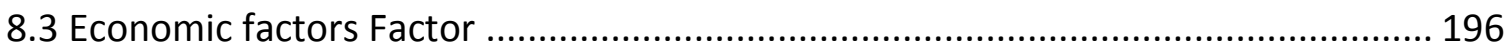

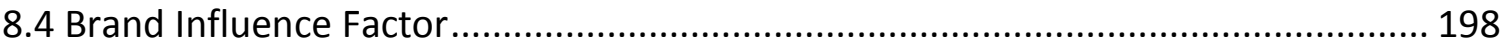

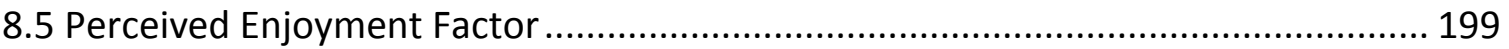

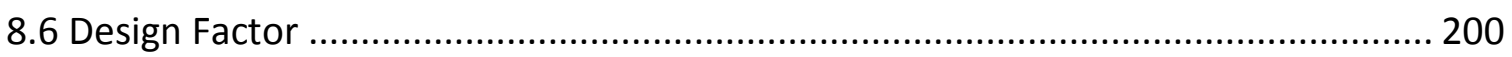

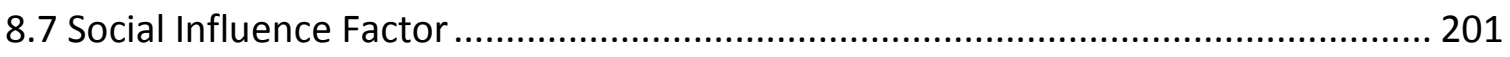

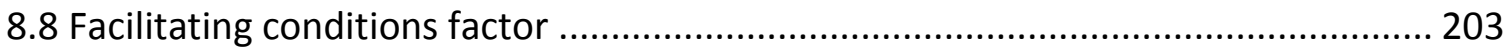

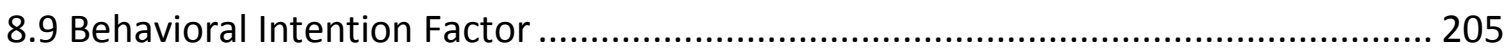

9 Chapter nine: Conclusion, Research Contribution, Limitation and Future Research .. 210

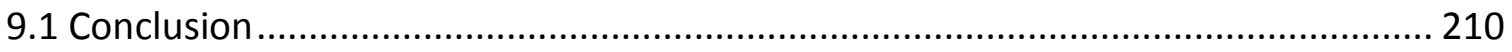

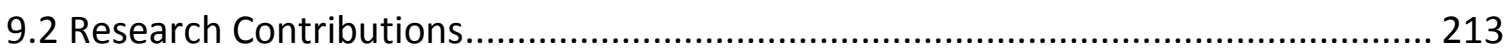

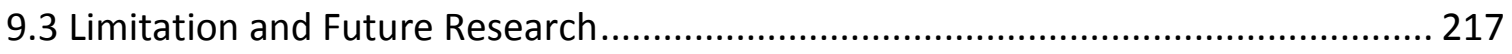

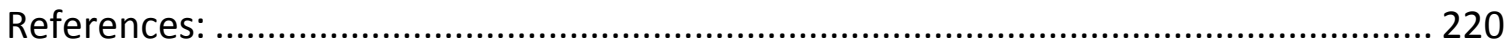

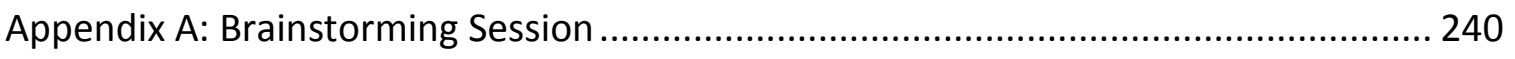

invitation for targeted participants in brainstorming session .................................... 240

Main question for the brainstorming session................................................... 247

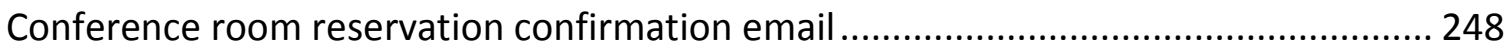

sample slides of the presentation in the brainstorming session ................................. 249

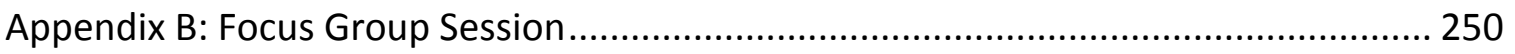

Details provided to participants in the focus group session ..................................... 251 


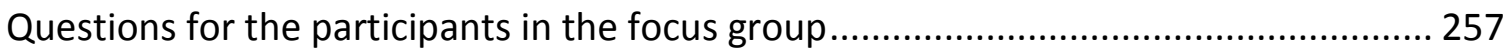

Example of the slides of the presentation presented in the focus group session ........ 258

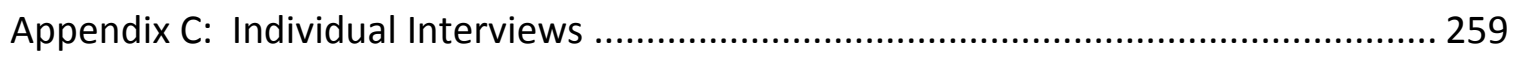

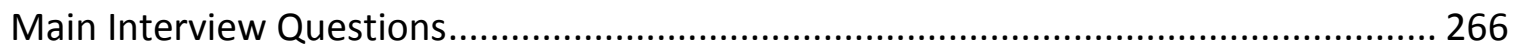

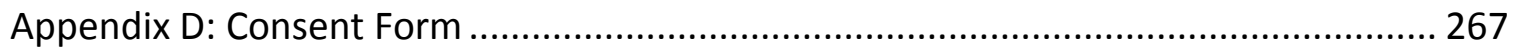

Appendix E: An Example of the Validation Tool Developed to be Used by Experts....... 269

Appendix F: Example of the Translation Validation Tool........................................... 279

Appendix G: Email Invitation Sent to Invite Participants to Participate in the Survey ... 286

Appendix H: Examples of Proportion of Respondent to Items and Items Statistics ...... 287

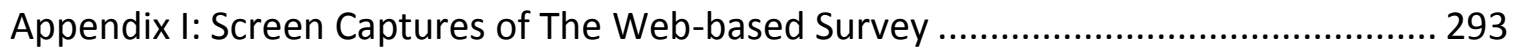

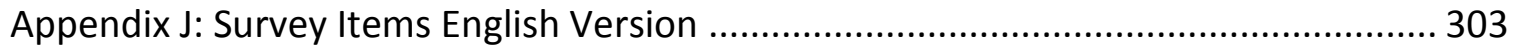

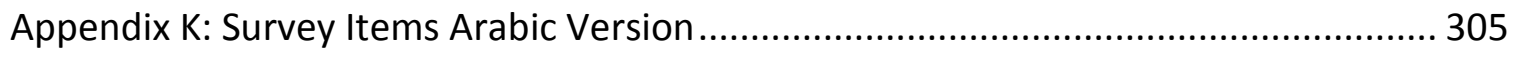




\section{List of Tables}

Table 1: Summary of relevant IT theoretical models

Table 2: Summary of empirical research related to the adoption of Smartphone technology

Table 3 Definitions and explanations for the main factors that were identified through literature

Table 4: Summary of the Research Gaps, Objectives and Questions (explained in more

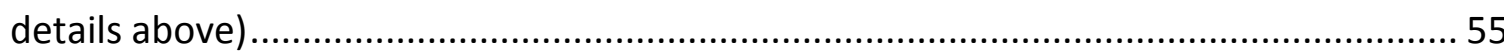

Table 5: Adoption factors derived through literature review ................................... 57

Table 6: Summary of descriptions steps conducted to develop the research model ...... 60

Table 7: Summary of the steps conducted to develop the research model ................... 72

Table 8: Participants in the Brainstorming session................................................... 75

Table 9: Participants in the focus group session .......................................................... 79

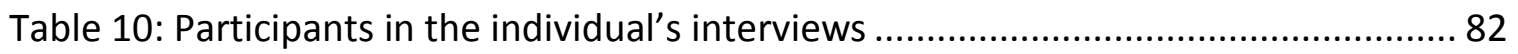

Table 11: Factors related to the adoption smartphones derived from literature............ 84

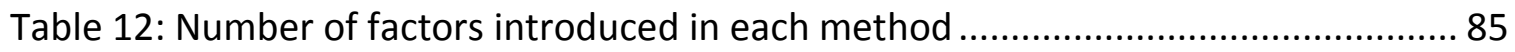

Table 13: New factors introduced by participants in the qualitative methods................ 86

Table 14: Factors selected by participants in the qualitative methods........................... 88

Table 15: Definition of the main research model' factors.......................................... 92

Table 16: Origin models used to develop the UTAUT model \& the specific factors that

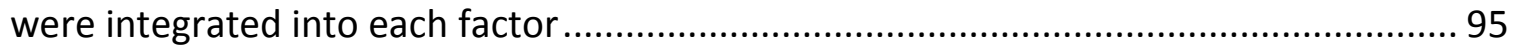

Table 17: Research Questions and the preliminary hypotheses ............................... 109

Table 18: An example of the Survey Testing and Validation Tool .............................. 118

Table 19: An example of translation validating tool................................................. 122 
Table 20: Developing and validating the English version of the survey instrument ...... 125

Table 21: Developing and validating the Arabic version of the survey instrument ....... 126

Table 22: Content Validation Results............................................................... 132

Table 23: Experts participated in the first expert panel .......................................... 133

Table 24: Experts participated in the second expert panel - validating survey translation

Table 25: Experts panel 3 - validating survey translation back to English .................... 139

Table 26: Example of scenarios to Estimate the minimum sample size required for this

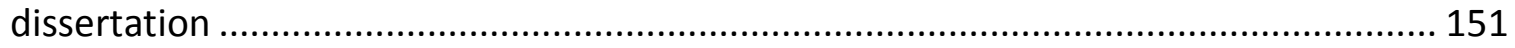

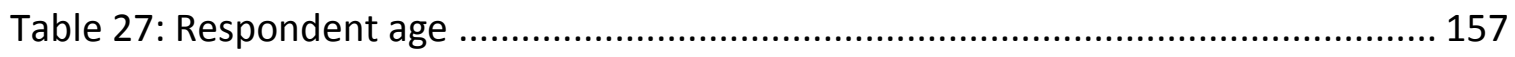

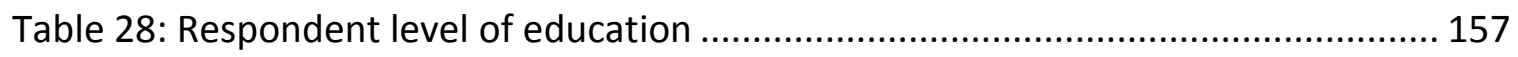

Table 29: Performance Expectancy (PE) item (PE1) ................................................. 158

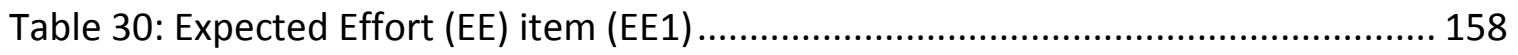

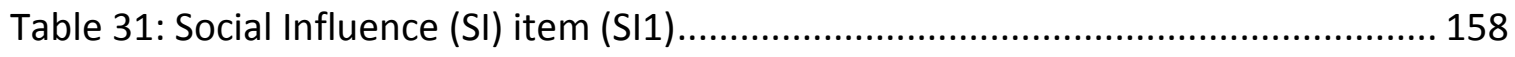

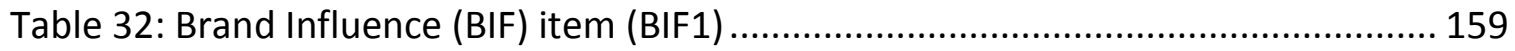

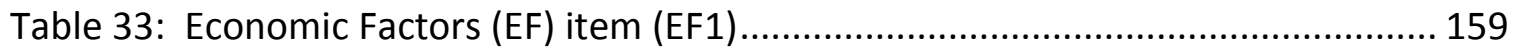

Table 34: Reliability of factors and its specification ............................................ 161

Table 35: Recommended indices to obtain a goodness of model fit indicators ............ 176

Table 36: Model fit indices - Results of the model measurement fit ........................... 178

Table 37: Proportion of respondent for item PE1 ................................................. 183

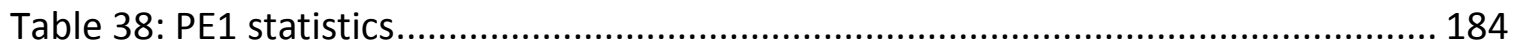

Table 39: Proportion of respondent for item EE1 ................................................. 184

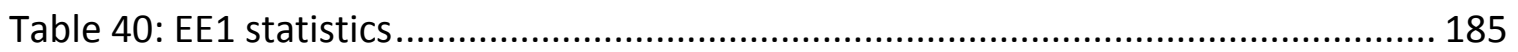

Table 41: Proportion of respondent for item EF1 ................................................. 186 


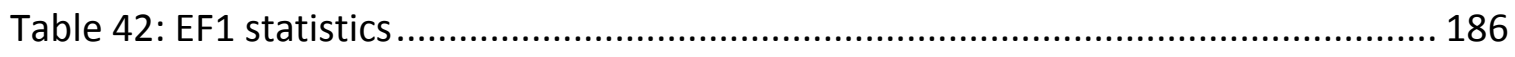

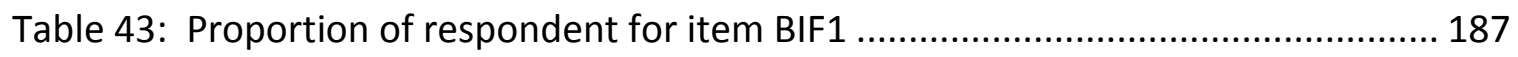

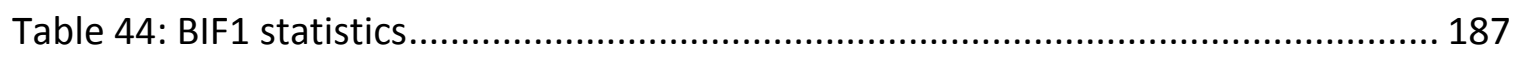

Table 45: Proportion of respondent for item PJ1 .................................................. 188

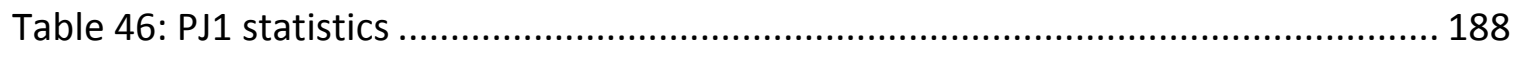

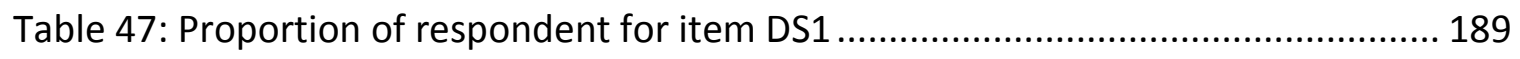

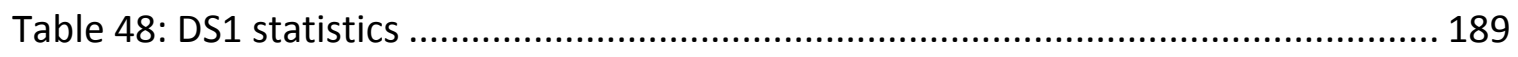

Table 49: Proportion of respondent for item FC1 ................................................ 190

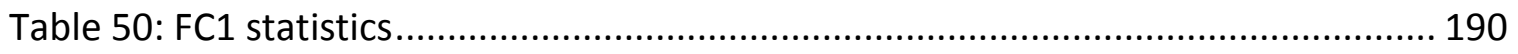

Table 51: Proportion of respondent for item SI1 ............................................... 191

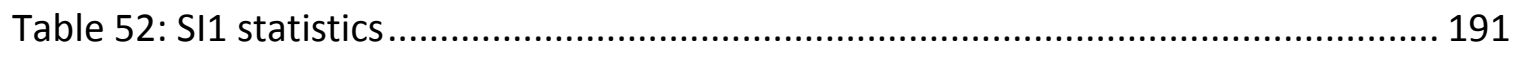

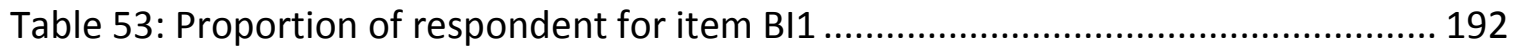

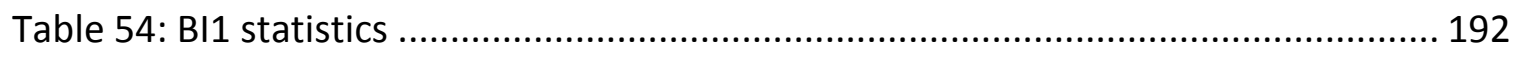

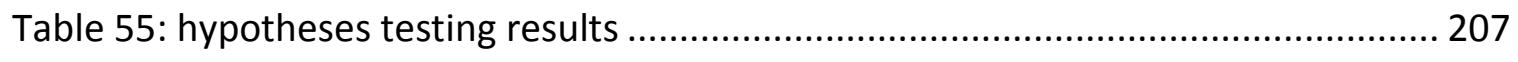

Table 56: Hypotheses testing results - Standardized Regression Weights.................... 208

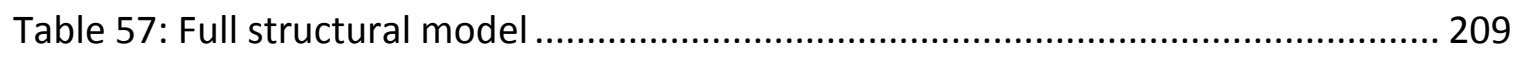




\section{List of Figures}

Figure 1: Smartphones global market share competition by operating system ............... 3

Figure 2: Theory of Reasoned Action (adapted from Ajzen) [75] ................................ 22

Figure 3: Technology Acceptance Model (TAM) (adopted from Davis) [3, 75, 76] ......... 23

Figure 4: Theory of Planned Behaviors (TPB) (adopted from Ajzen) [73] ....................... 24

Figure 5: Taxonomy of factors related to the adoption and use of the Smartphone ...... 48

Figure 6: Factors selected by participants in the qualitative methods ......................... 89

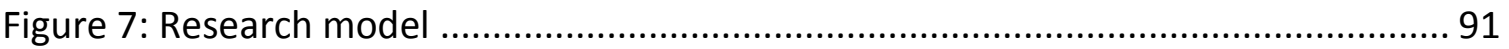

Figure 8: A Screen-shot of the Pilot Test of the survey questionnaire - English version.

Figure 9: A Screen-shot of the web based survey questioner the Arabic version ......... 141

Figure 10: Effect of sample size on fit indices CFI [235] ........................................ 149

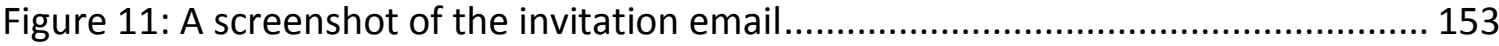

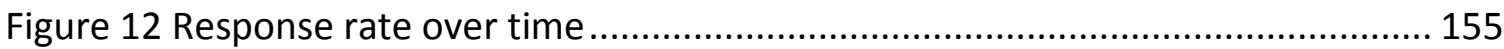

Figure 13: An example of measurement model (CFA) model [214] ........................... 171

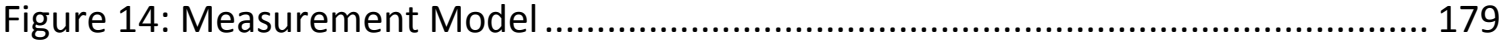

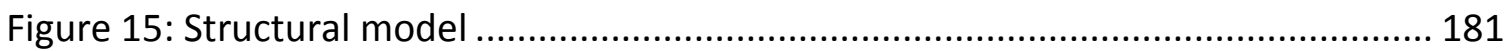

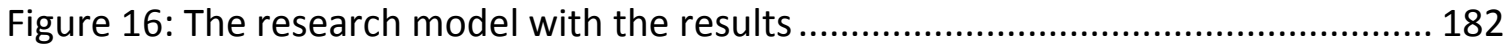




\section{Chapter One: Research Objectives and Overview}

\subsection{Smartphone Technology}

Smartphone technology is defined in two ways: 1) as "a hand-held computer capable of multiple functions in addition to placing calls" [2]; and 2) as "a mobile phone offering advanced capabilities, often with PC-like functionality (PC mobile handset convergence)" [3]. Smartphone technology is based mainly on a well-integrated combination of hardware, software and network.

Blackberry mobile was introduced by Research In Motion (RIM) in 1999 [4]. It enabled users to send and receive email which appealed to business users as a productive tool [4]. In 2000, Microsoft realized that the smartphone could be a real competitor to the laptop and it released its first operating system (OS), the Pocket 2000, for mobile devices [5]. The introduction of Microsoft Pocket 2000 OS for mobile devices is considered to be the first major move by a software company into the mobile market $[6,5]$. To compete in the early smartphones market, a number of hardware manufacturers, namely Nokia, Ericsson, Panasonic, and Samsung collaborated on a single operating system called Symbian OS to be used in their devices [6].

In 2007, Apple released the iPhone, which provided more and advanced options such as an adjustable touch screen interface, music, and a gaming platform, which appealed to the general community [7]. Google noticed the trend of internet search by mobile devices [6] and quickly decided to enter the mobile market by acquiring a 
company that develops software for mobile devices called Android [6]. They decided to adopt a different strategy than Apple OS's 'closed source policy' and built an open source operating system based on Linux $[8,6]$. Google embedded its own search site into its OS, provided its OS free for manufacturers and enabled any application developer to develop applications [6]. Researchers credited the success of the Google OS (Android) to Google's ability to better understand their customers and provide them with products/services accordingly [6].

Smartphone technology is a relatively new technology that is rapidly evolving and gradually impacting consumers' behavior, their daily activities, their social activities, the mobile industry, business activities, marketing, education, healthcare and more [911]. Smartphone technology offers the potential to improve efficiency and productivity, reduce cost, improve users' satisfactions and enhance their experience in a number of related industries including, healthcare, finance, ecommerce, education, entertainment, tourism [12-14]. The Smartphone market is expected to reach $\$ 258$ billion globally by the end of year 2015 [1]. Company spending on mobile promotions and advertisement is expected to increase sharply to reach more than US\$50 billion by year 2015 [11]. Competition among manufacturers, developers and providers in the Smartphone industry is still very intense. Device manufacturers such as Apple, Samsung and LG are competing to gain market share. Global competition for manufacturing Smartphone operating system is still fierce. There are many competitors including Apple, Android, Microsoft, Symbian, and RIM as indicated in the figure below [15-17]. 


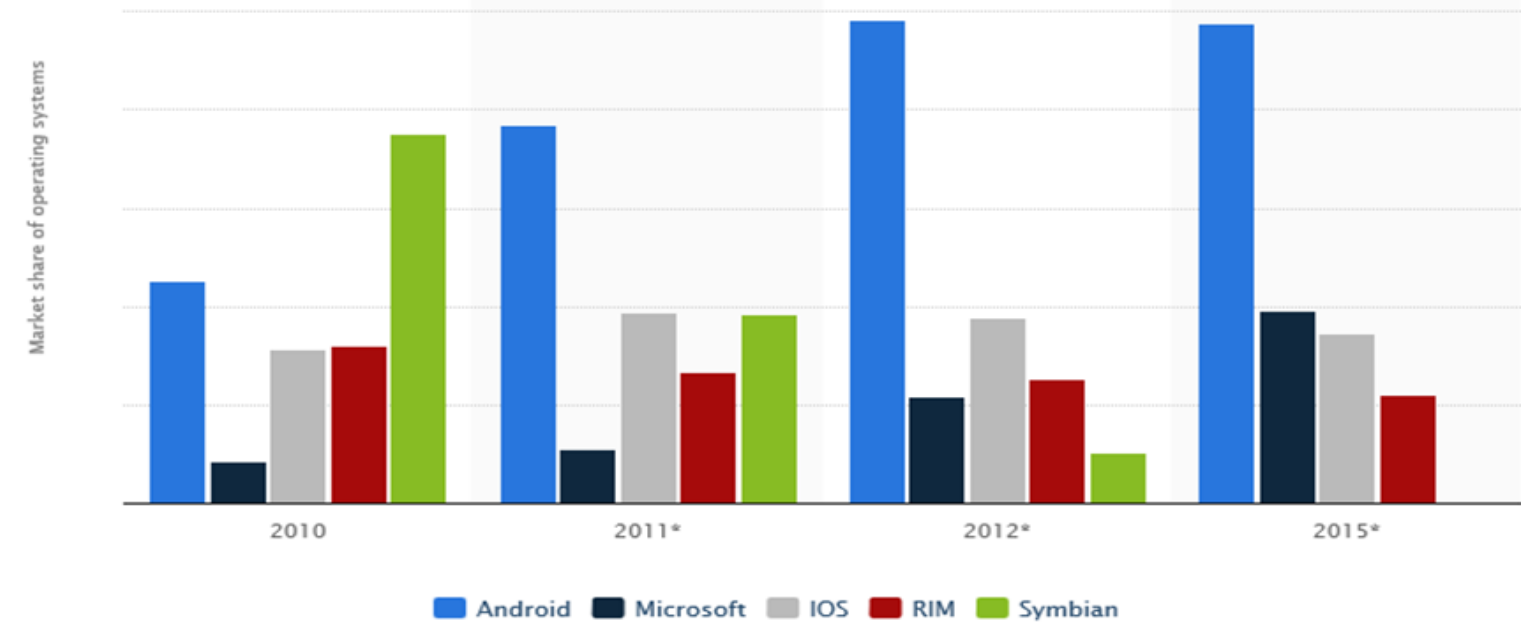

Figure 1: Smartphones global market share competition by operating system

Other segments of manufacturing and providing the Smartphone technology such as software development, application development, service providers and more are still competing intensely to survive and gain more market share. Users' acceptance and their use behavior are key factors that help to determine success in this intense competition. As mentioned above company strategy and policy can make a big difference.

\subsection{Users' adoption and use of the Smartphone technology}

Studying and understanding users' adoption and use of new technologies is very critical for both researchers and practitioners [18]. Studying the key factors that influence adoption of a new Information technology helps to explain and predict users' 
attitudes toward adopting or rejecting that new technology. Users' acceptance of a new information technology (IT) is considered to be a key determinant of its success and their lack of acceptance is considered to be an obstacle to its success [19]. Moreover, understanding users' adoption and use of new IT plays an important role in determining users' needs and reducing business risk, especially with rapid changes in IT such as Smartphone technology [20].

Smartphone users' acceptance and behavior are considered to be key factors to continue successful growth for the Smartphone technology and its stakeholders [21, 22]. Consequently, evaluating and better understanding the key factors that influence users' adoption and use of Smartphone technology has become more important to all stakeholders. Designers, developers, and manufacturers need to improve related products/services, and to meet consumers' expectations [21, 23]. Scholars from different fields and interests agree on the importance of Smartphone technology as a critical part of the evolution of the information technology domain [24].

A number of research studies have been conducted to explore users' adoption and use of Smartphone technology. However, most of the existing empirical research focused on only a limited number of factors such as the fun aspects of using the Smartphone [24] or the effect of the enjoyment aspect on the adoption of the Smartphone [25]. Moreover, a number of empirical studies considered the Smartphone as if it were a tool to be used in executing a specific task such as using the Smartphone in the healthcare sector [26]. Other researchers focused on a specific profession such 
studying adoption of smartphones among doctors and nurses [27, 28], studying the adoption of smartphones among employees in delivery services [29] or studying the adoption and use of smartphones among college students [30].

Studying only one or few factors that influence users' adoption of Smartphone technology will result in neglect of other important factors and make it harder to gain a complete perspective. It is more appropriate to examine and compare all related characteristics within the same research in a holistic and comprehensive manner [31]. In a number of studies, scholars pointed out the important role of cultural and social factors and their influence on the adoption and use of new information technologies [32-36]. Saudi Arabia is a developing country and it has different social and cultural contexts. It can be characterized as a society that is relatively collectivist in nature as individuals have closer ties and high influence among and between them [32]. In a number of empirical studies, scholars studied the adoption and use of Smartphone technologies in Saudi Arabia, including the adoption of mobile internet [9], adoption and use of e-services [37], and acceptance and use of Information Technology (IT) [32]. Their results showed that a number of factors, namely social influences, facilitating conditions and language, showed significant relationships with users' adoption and use of IT in Saudi Arabia. In emerging regions, specifically Saudi Arabia, little or no effort has been made to study and explore the key factors that influence users to adopt and use the Smartphone technology. The Saudi Arabian economy is growing fast and it is supporting the significant expansion of its telecommunication sector which has had less than ten 
years of experience in an open competition market [38]. With this environment, understanding users' intention to adopt and use the Smartphone technology has become a very important factor that needs to be better understood, especially when creating and providing mobile products, services, contents, applications and its related products [39]. However, there has been very little effort to empirically study the factors that influence the adoption and use of the Smartphone technology in Saudi Arabia. In fact, there does not appear to be any research that studied these in a holistic manner.

Therefore, the main purpose of this dissertation is to develop a research model and to conduct empirical research to advance existing knowledge toward a better understanding of the key factors that influence users' adoption and use of the Smartphone technology in Saudi Arabia.

\subsection{Studying the adoption and use of Smartphone and its related technologies in emerging regions}

Arpaci et al. [40] investigated the impacts of cultural differences on Smartphone adoption by organizations in Canada and Turkey. Their finding showed that cultural differences have a significant influence on adoption behavior. Their results indicated that there are significant differences in factors that influence the adoption of Smartphone between countries [40]. Alnajjar et al. [41] studied the influence of cultural and social factors on individuals' intention to adopt and use mobile commerce in Jordan. Their finding showed that cultural and social factors have positive and significant relationship with individuals' intention to adopt and use m-commerce in Jordan. A 
number of empirical research studies were conducted to study the key factors that influence users' adoption and use of the Smartphone and its related technologies in China, also an emerging region. In most of these studies, cultural and social influences showed a significant relationship with users' adoption and use the Smartphone and its related technologies.

Pan et al. [42] empirically investigated the key factors that influence the adoption of the Smartphone among college students in China. Their results showed that social influence has a significant and positive influence on users' adoption of the Smartphone [42]. Ling and Yuan [43] utilized the Theory of Reasoned Action (TRA) to empirically study the factors that influence users' adoption and use of the Smartphone in China and found that subjective norms were among the significant factors that have positive effects on the use of the Smartphone [43]. Lai and Lai studied the factors that influence users' adoption and use of mobile commerce in China [44]. Their results show that social influences were among the significant factors that influence users to adopt and use mobile commerce in China-Macau [44]. Park et al. [45] empirically studied the factors that influence users' adoption of mobile technologies in China. They found that social influence shows a significant influence on users' adoption of mobile technology in China [45]. Pan and March [46] studied the factors that influence the older adults' adoption of the internet in China. Subjective norms were among the significant factors that influence the adoption of the internet [46]. 
Zhou et al. [127] integrated the Technology Task Fit (TTF) model with the Unified Theory of Acceptance and Use of Technology (UTAUT) model to explain the key factors that influence users' adoption of mobile banking in China. Their finding indicated that social influence was among the key factors that have significant effects on user adoption of mobile banking in China [127]. Lu et al. [47] conducted an empirical study to explore the key factors that influence users' acceptance of wireless internet via mobile technology in China. Social influence and facilitating conditions were among the significant factors that influenced users' acceptance of the wireless internet via mobile technology [47]. Dai and Palvia [21] conducted a cross cultural empirical research to study the factors that influence users' adoption of mobile commerce in the United States and China. Their results showed a number of significant differences among factors that influence users' adoption of mobile commerce which include that subjective norms showed more influence on users' adoption in China than in the United States [21].

\section{In Summary:}

Hill et al. [48] stated: "As most technology is designed and produced in developed countries, it is culturally-biased in favor of those developed countries' social and cultural systems." Also, they indicated that differences in Arabic culture and society have an influence on how new IT is accepted, viewed and utilized among users [48]. Factors that influenced users' adoption and use of the Smartphone and its related technologies in other emerging regions, such as China, showed significant differences 
among factors based on the users' perspective and their cultural and regional differences. As mentioned in the previous paragraph, cultural and social factors showed a significant influence on users' adoption and use of Smartphone and its related technologies in China. Saudi Arabia is a country that is witnessing rapid development and has different cultural and social contexts, which may influence users' adoption and use of the Smartphone and its related technologies. Moreover, it has been indicated that there is a need for more empirical research to identify the key factors that influence users' behavioral intention to adopt and use the Smartphone technology in a comprehensive manner [49-51]. A number of scholars mentioned the lack of research investigating the key factors that influence the acceptance and use of Smartphone technology in Saudi Arabia [52, 53, 14, 54]. To date, there is no holistic and comprehensive empirical research regarding the key factors that influence general users' intention to adopt and use the Smartphone. Therefore, this dissertation aims to identify and explore the key factors that influence general users' adoption and use of the Smartphone technology in Saudi Arabia.

\subsection{Saudi Arabia; its Economy and Telecom Sector}

Saudi Arabia is considered to be a central pillar of Arab nations. It is located in the Arabian Peninsula in the Middle East [53] and is the largest state of the Gulf Cooperation Council (GCC) with a total area of 2,149,690 square kilometers and a population of about 21 million $[55,53,56]$. Saudi Arabia is one of the world's largest oil producers and it has about twenty percent of the world's proven oil reserves [57]. Oil 
export accounts for about $90 \%$ of the country's revenue, and the economy continues to improve, especially with the increase in the price of oil and the rise in demand for oil worldwide $[58,59]$. The government is working toward diversifying the economy away from its reliance on oil; therefore, it is encouraging and supporting growth in the private sector [60].

The Saudi government is focusing on a number of sectors to play a critical role in the economic diversification effort including the telecommunications sector [60]. Due to the continued increase in its oil production, Saudi Arabia is witnessing a continuous growth in gross domestic product (GDP) accompanied by noticeable increase in its population [61]. The growth of GDP and the increases in population in Saudi Arabia indicates a healthy economy that holds a promising future, especially for the mobile industry.

The Saudi government's long-term vision is to transform into an information society with a global, modernized and digital economy [59, 62]. Competition in the mobile market is a relatively new trend in Saudi Arabia as the market was monopolized by a government-owned company, Saudi Telecommunication Company (STC), until it was changed into partial competition in 2005 [38]. With this new, relatively open competition in the Saudi telecom market, understanding users and their preferences has become a very important factor that needs to be carefully considered and better understood when creating and providing mobile products, services, contents, applications and any related products [39]. Telecommunication companies in Saudi 
Arabia have started to partner with companies from other countries to gain competitive advantage and increase their revenue [55].

Even though Saudi Arabia's telecommunications industry is growing, it still needs improvement in many of the mobile services provided compared to other GCC countries. Saudi Arabia is the largest telecom market of all the GCC states; however, Saudi consumers spend less on telecom services compared to other countries in the GCC region as a trade-off for the limits on services [39].

There are a number of existing challenges in the Saudi Arabian telecom industry. For instance, only around eight percent of commercial organizations have online purchase channels that consumers can use to buy their product online, which indicates a challenge for electronic commerce including mobile commerce [63]. To improve its performance, enhance users' experience and reduce cost, the government of Saudi Arabia is attempting to provide its services electronically in a number of its sectors; however, this is still in a very early stage of adoption [53]. According to the Saudi Communications and Information Technology Commission (CITC) mobile payments are considered a key challenge for electronic payment systems in Saudi Arabia [64]. Moreover, English language content is still considered as a challenge and the lack of Arabic content is seen as a barrier for many Saudi users to use the internet [64].

With the continuous evolution of Smartphone technology, mobile industry revenue has been changing: revenue from voice and texting services are shrinking while revenue from value added services and data services are rising $[65,66]$. Data revenue in 
Saudi telecom companies accounts for only about 15 percent of total revenues, which is still low compared to 40 percent in the developed market [67]. Electronic government services are still a new trend and it still has a number of challenges to deal with such as the lack of training and the lack of information security [68]. Better understanding of smartphones' users and their use behavior will provide meaningful advantages that can help the government, private sector and all stakeholders to provide users with better services/products and improve their experience.

\subsection{Language, Cultural differences and the Needs for Graduate Level Research}

Arabic is the main language of Saudi Arabia's population. Numerous scholars mentioned that lack of English language was one of the major holdups in the adoption and use of the internet and e-services in Saudi Arabia [37]. The majority of IT services' contents are designed with English version interfaces and intended mostly for English speaking consumers [37]. Even though many Saudis are eager to study and speak English, only about ten percent of the Saudi population presently speaks English [69]. In many studies, scholars pointed out the important role of cultural factors and their influence on the adoption and use of new information technologies [32-36]. Saudi Arabia has different cultural contexts than Western nations. It is characterized as society that is more collectivist in nature. Individuals and family have closer ties resulting in high influence among and between them [32]. Gahtani et al. [32] studied the effects of 
the cultural aspects on the acceptance and use of IT in Saudi Arabia. They found that subjective norms positively influence users' intention to use IT.

Around $22 \%$ of Saudi people have a bachelor's degree, approximately $1 \%$ have a master's degree and about .5\% have a Doctorate [70]. Higher education and academic research are very important aspects that the government of Saudi Arabia is pursuing and highly encouraging, especially in recent years [71]. Nevertheless, there is less effort spent on academic research at the graduate level and the connection between the private sector and academic institutions in Saudi Arabia is very poor [72]. There is an obvious need for academic research at the graduate level that addresses the problems, challenges and benefits in Saudi society [71].

In recent years, the government is working to fulfill the need for graduate level research in Saudi Arabia with special emphasis on science and technology. This can be seen in a number of steps taken by the government to encourage and obtain good quality research, including starting the King Abdullah Program for Scholarship in countries around the world [73]. There are around 111,000 Saudi students in the United States [74]. Moreover, Saudi Arabia established a new graduate level research university, King Abdullah University of Science and Technology (KAUST). It's budget is only exceeded by that of Harvard University and it has gained a well-known reputation in specific research fields around the world in a short time [75].

Adams et al. [76] explored the research challenges in a number of Middle Eastern countries including Saudi Arabia. They indicated that there is a notable growth 
in academic research in a number of countries in the region including Turkey and Iran. However, in Saudi Arabia, academic research activity is still very low and there is a need for improvement. Also, some of these sources mentioned the importance of strong research to improve and develop a more robust education system that benefits the society, especially with the availability of rich human capacity and other resources [76].

\subsection{Research related to Smartphone technology in Saudi Arabia}

Numerous studies have been conducted in subjects related to the Smartphone technology in Saudi Arabia. Al-Meshal and Almotairi [52] studied the factors that influence users' acceptance of mobile marketing among female users in Saudi Arabia including: providing information, sharing content, accessing content, personal attachments and perceived value. Alwahaishi and Snasel studied the factors that influenced users to adopt mobile internet in Saudi Arabia [9]. They indicated that the Smartphone represented about 12 percent of the total handset traffic worldwide. They found that performance expectancy and perceived playfulness are the strongest influential factors on users' behavioral intention to use mobile internet.

Seliaman and Al-Turki [54] studied mobile learning in Saudi Arabia. They mentioned the lack of published research that studied adoption of mobile technology in Saudi Arabia. Saddik et al. [14] studied the adoption of PDA and the Smartphone among physicians and dentists in King Saud Medical Hospital in Saudi Arabia. Also, they mentioned the need for research to study the adoption of the Smartphone, which may 
help to increase users' productivity and decrease costs, especially in the healthcare sector.

\subsection{Studying Smartphone in Saudi Arabia}

Smartphone technology proposes to contribute to Saudi society and its economy by improving users' efficiency and productivity. Also, it can play a critical role in reducing cost, improving electronic communication channels and enhancing users' experience in Saudi Arabia. Providing Smartphone technology to end users requires a great deal of cooperative work and effort that involves many stakeholders, including services providers, device providers, software developers, contents developers operating systems/platforms developers and more. Even with highly designed and advanced technology, users' acceptance is still a very important key that determines its success [77]. Saudi Arabia has different cultural and social contexts which many influence users differently, therefore understanding users' perspectives of the Smartphone plays a key role in developing and providing more successful and more valuable Smartphone products and services [39]. Numerous scholars mentioned the lack of research that investigates and explores the key factors that influence the acceptance and use of Smartphone technology in Saudi Arabia in a holistic manner [52, 53, 14, 54]. Therefore, the aim of the dissertation is to explore and study the key factors that influence general users' adoption and use of the Smartphone technology in Saudi Arabia. 


\subsection{Research Objectives}

This dissertation intends to conduct empirical research to advance existing knowledge toward a better understanding of the key factors that influence general users' intention to adopt and use Smartphone technology in Saudi Arabia. A research model will be developed and utilized in this research to obtain a better understanding and more insight into the key factors that are associated with this process. The research surveyed general users of the Smartphone in Saudi Arabia. The objectives of this dissertation can be summarized into the following main goals:

G1- Developing a research model that can be used to obtain a better understanding and more insight regarding the key factors that are associated with users' adoption and use of the Smartphone in Saudi Arabia. This research model is developed based on the existing IT theoretical adoption models, related adoption factors' taxonomy developed based on previous related research and opinions of experienced users and those who work in sectors related to Smartphone technology.

G2- Explore and better understand the key factors that may have relationships with general users' adoption and use the Smartphone technology in Saudi Arabia based on users' perspectives.

\subsection{Research Approach}

This dissertation is conducted in a number of steps summarized below: 
- An overview of the importance of studying users' adoption and use of IT in general and the Smartphone in particular. Research objective and the purpose of this dissertation as to why adoption of Smartphone technology in Saudi Arabia is important. Background about Saudi Arabia and its IT and mobile sector.

- A literature review on research related to the adoption and use of Smartphones to review and obtain more insight on: existing research and scope; factors related to the adoption and use of the Smartphone identified in literature; and, the IT theories and methodology used in existing research. Also, research gaps and questions that have been identified in, and regarding, past research.

- The development of hypotheses and a research model. The research model has been developed based on review of the existing IT theoretical adoption models, plus factors identified and classified from existing literature review. Moreover, a number of qualitative methods have been conducted: brainstorming sessions, focus groups and individual interviews to introduce new factors, evaluate, validate and select the most important factors to be included in the research model.

- The research methodology, Structural Equation Modeling (SEM), has been discussed in more details. 
- Research design has been discussed and a survey instrument has been developed, tested and validated. A web-based survey has been developed and administered to a randomly selected sample of Smartphones users in Saudi Arabia. Data has been collected and statistically analyzed using SEM.

- Results and hypotheses testing have been provided. Conclusions and potential contributions of future research are discussed and provided.

\section{Chapter Two: Literature Review}


The purpose of this chapter is to provide a comprehensive review of the existing research related to the adoption and use of the Smartphone technology. Based on the literature review, taxonomy has been developed to classify factors that were identified in the literature as important and related to the adoption and use of Smartphone technology. Additionally, this chapter provides a review of the IT theoretical models that are related to the adoption of IT.

\subsection{Relevant Theories Used to Study the Adoption and Use of (IT)}

Scholars' interest in studying and understanding users' adoption and use of new IT at both the organizational level and the individual level has been evolving for decades [78]. With the evolution of IT, a number of theories have been developed and modified to better study and understand users' acceptance and use of new IT. Dillon and Morris [77] defined users' acceptance as "the demonstrable willingness within users group to employ information technology for the tasks it is designed to support." Rogers [79] defined diffusion of innovation as "Diffusion is the process by which an innovation is communicated through certain channels over time among the members of a social system. " Also, Rogers [70] highlights four elements of diffusion namely innovation, time communication channels and social systems. Rogers stated that: "Innovations that are perceived by individuals as having greater relative advantage, compatibility, trialability, and observability, and less complexity will be adopted more rapidly than other innovation" [79]. Innovation diffusion theory (IDT) was introduced in 1995 by Rogers 
and it specifies five characteristics of innovation (relative advantage, compatibility, complexity, observability, and trialability) that influences diffusion of innovation [79]. Rogers also mentioned that these five attributes are very important explaining an innovation adoption. He defined them as follows [79]:

(1) Relative advantage: refers to the level to which an innovation is perceived by an individual to be a superior option among other available options.

(2) Compatibility: refers to the level to which an innovation is perceived by an individual as being in line with his or life style.

(3) Complexity: refers to the level of difficulty which individuals perceived to be associated with innovation or use and understanding of the innovation.

(4) Observability: refers to the level of benefits or attributes of an innovation that is visible to other possible adopters.

(5) Trialability: refers to the level of ease for individuals to experience the innovation before they adopt it.

In Rogers' definition of diffusion he identified four main elements: innovation, time, communication channels and social systems. Each of these elements play a role in the adoption of technology [79]. Moreover ten characteristics were specified by Tornatzky and Klein [31], including the five that were identified by Rogers. They added five more attributes namely: cost, communicability, divisibility, profitability, and social approval. Alavi and Joachimsthaler mentioned that cognitive style, personality, demographic and user situational variables are the most relevant user factors that can help to determine 
the acceptance of technology [80]. Rogers categorized adopters into five categories with regard to the time in which they take to adopt new technology; innovators, early adopters, early majority, late majority and laggards. Each of those users has distinct characteristics that were identified by Rogers [79]. As information technologies evolve and the nature of each technology changes, theories of IT adoption evolve as well. In attempt to better understand, predict and explain users' adoption and use of new technologies at both the organization's level and the individual's level, a number of theoretical models were introduced, developed and tested including the following:

The Theory of Reasoned Action (TRA), developed by Fishbein and Ajzen in 1975, explains users' intention to commit a behavior that is influenced by both attitude and subjective norm. Attitude was defined as "an individual positive and negative attitude towards performing the target behaviors" [81]. Subjective norm is defined as "the person's perception that most people who are important to him think he should or should not perform the behavior on question" [77]. As shown in figure 2 below TRA suggested that users' attitude and subjective norm predicts behavioral intention which intern predict users' behavior [77]. TRA could be one of the most influential theoretical models to predict and explain users' behavior [82]. A number of scholars utilized TRA to developed a number of theoretical models that are well established and widely utilized to explain users' behavior intention to adopt information technology including the Technology Acceptance Model (TAM), the Theory of Planned Behaviors (TPB) and the Unified Theory of Acceptance and Use of Technology (UTAUT) [83, 84, 82]. 


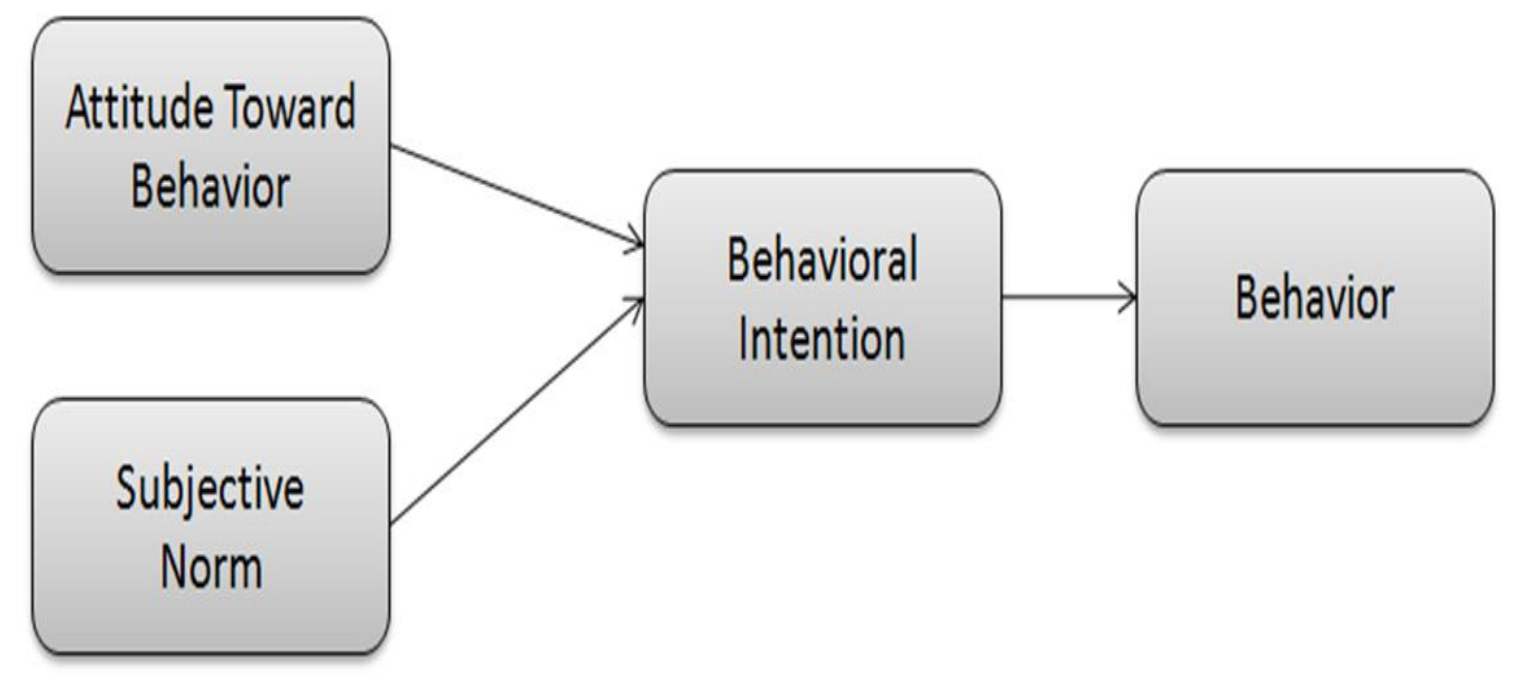

Figure 2: Theory of Reasoned Action (adapted from Ajzen) [75]

Technology acceptance model (TAM) introduced by Davis in 1989, TAM model was adopted from TRA Model. TAM model is a very popular model among researchers and it is the most widely used and cited theoretical model $[19,85,86]$. TAM model introduced (as show in figure 3 below) two variables namely; perceived ease of use and perceived usefulness, which mostly can explain and determine users' attitude and behaviors toward accepting new technology $[87,88]$. Perceived ease of use is defined as "the degree to which a person believes that using a particular system would be free of effort" and usefulness is identified as "the degree to which a person believes that using a particular system would enhance his or her job performance." [89]. TAM model is one of the most widely used models to study and explain users' intention to use Smartphone technology and its related technology. Kang et al. [49] used TAM model to analyze factors affecting adoption of Smartphone. Verkasalo, et al. [90] used TAM model to 
study users' intention to use specific Smartphone' applications. Kim [91] extended TAM model to study users' intention to adopt mobile wireless technology (MWT) Smartphone. Chen et al. [29] combined IDT and the TAM model to explain the users' adoption of Smartphone. However, TAM model is able to explain only about $40 \%$ of variances of technology acceptance [82]. Moreover, scholars have specified a number of limitations in the TAM model and highlighted the need for adding more variables to the model especially related to human and social factors [92].

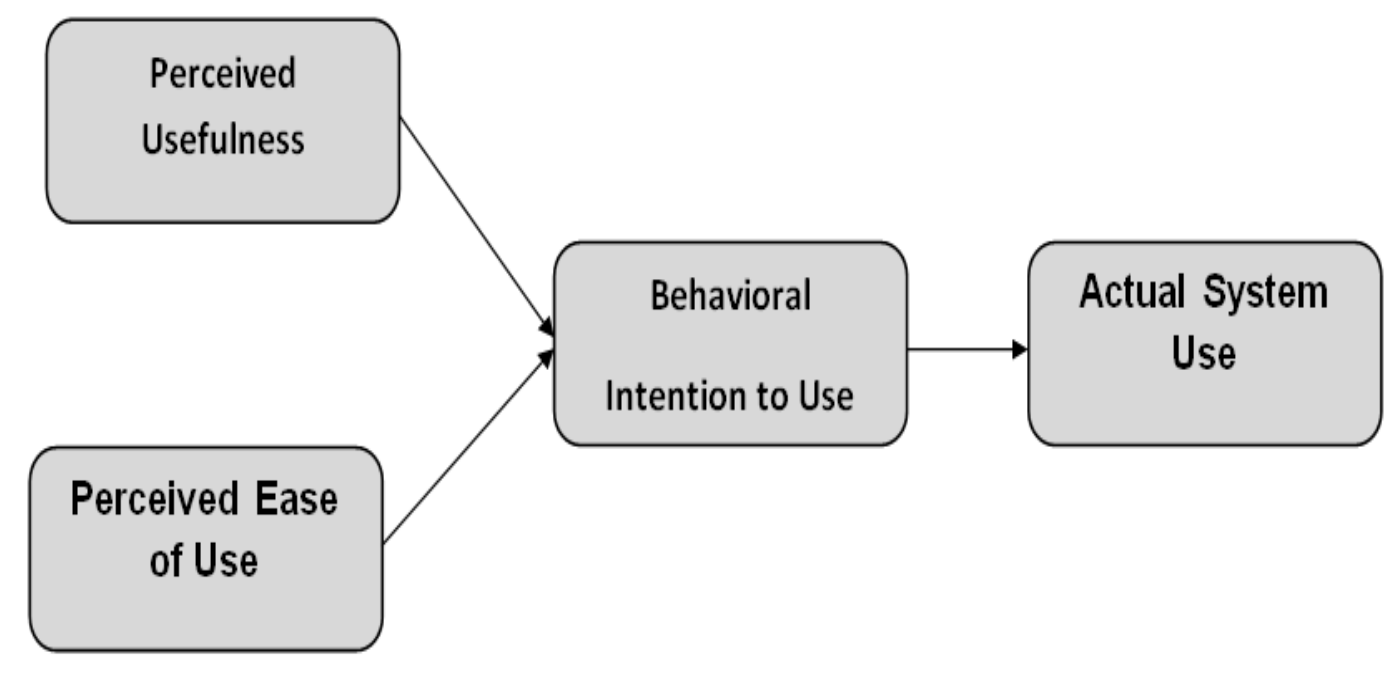

Figure 3: Technology Acceptance Model (TAM) (adopted from Davis) [3, 75, 76]

The Theory of planned behaviors (TPB) was introduced in 1991 by Ajzen, and it was a derivation of TAR. Psychology is the origin field for the TPB theory and it is used to explain users' behavior. As shown in figure 4 below, TPB theory states that subjective norms, attitude and perceived behavioral control determine behavior intention and therefore behavior $[83,19,93]$. Theory of planned behaviors was used to develop a number of IT theories including the Unified Theory of Acceptance and Use of Technology. A number of scholars studied the TPB and suggests extending the TPB 
model as a way that will improve the outcome and help to obtain better explanation of the relationship of intentions to behavior [94].

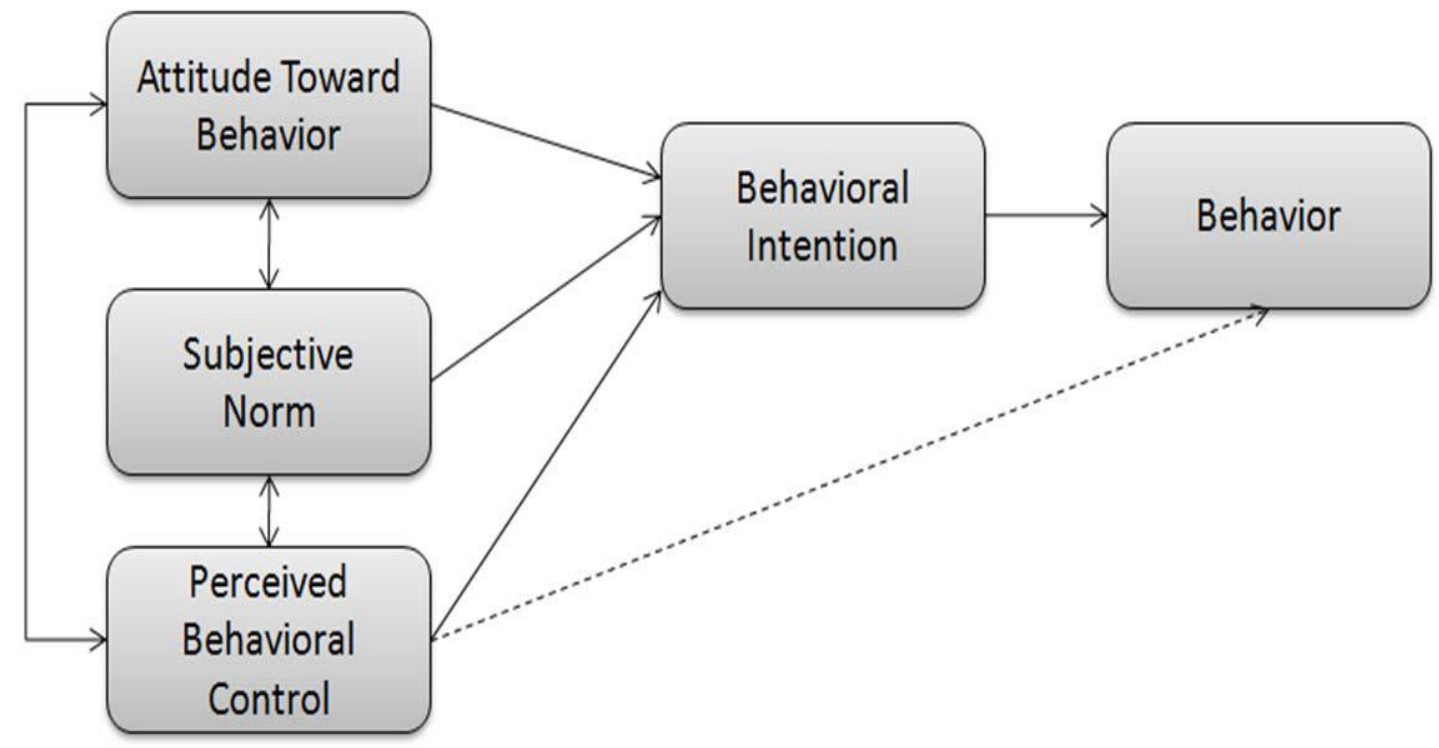

Figure 4: Theory of Planned Behaviors (TPB) (adopted from Ajzen) [73]

Goodhue and R. L. Thompson [95] develeped the Technology Task Fit (TTF) to explain the impact of information technology on users' performance. TTF was defined as "the degree to which a technology assists an individual in performing his or her portfolio of tasks" [95]. TTF models have five main factors namely: Task Characteristics, Technology Characteristics, Task Technology Fit, Performance and Utilization [95]. TTF model suggests that Task Characteristics and Technology Characteristics, together predict the Task Technology Fit factors, which in turn predict individual's Performance and Utilization [95]. Goodhue and Thompson [95] suggested that, TTF could be used as an effective tool to evaluate if an information system is meeting users' needs. Moreover, they mentioned that when an information system has correspondence 
between its functionality and users' task requirements it positively affects their performance [95]. Task Technology Fit factors found to have a positive and significant relationship with individual's Performance [95].

Venkatesh [82] introduced the Unified Theory of Acceptance and Use of Technology (UTAUT) which is based on the integration of TRA, TAM, TPB, motivational Model (MM), model of PC Utilization (MPCU) IDT and Social Cognitive Theory (SCT). UTAUT is been used to study and explain users' acceptance of information technology in many fields. UTAUT consists of four main factors namely: performance expectancy, effort expectancy, social influence and facilitating conditions that can explain and predict an individual's behavioral intention and use behavior [82]. Performance expectancy is defined as the degree to which an individual believes that using a Smartphone will help him or her to attain benefits in their overall performance. Effort expectancy is defined as the degree of ease associated with the use of the Smartphone. Social influence is defined as the extent to which an individual perceives that important others to believe he or she should use a Smartphone. Facilitating conditions are defined as the degree to which an individual believes that technical and infrastructure supports are available to support the use of a system. UTAUT suggest that performance expectancy, effort expectancy, and social influence factors can predict behavior intention factor which in return predict the use behavior factor.

Today's information technologies such as the Smartphone and its related technologies are developing at a fast rate. Thus a great effort has been made to develop 
a more reliable and comprehensive theoretical model that can explain and predict users' adoption and use of IT. It is observed from this literature review that theoretical models have been developed to gain better results and account for the changes in technologies and users' behaviors. Older model such as TRA play a big role in the development of the next models as shown in table 1 below. As shown in Table 1 below many of the newer IT theoretical models such as UTAUT are based on derivations from older models and consist of more and improved factors which make them more mature and more suitable to study the newer technologies such as the Smartphone and its related technologies. Table 1 below lists a number of relevant IT adoption theoretical models.

Table 1: Summary of relevant IT theoretical models

\begin{tabular}{|c|c|c|c|c|c|}
\hline Theory/model & $\begin{array}{l}\text { Main } \\
\text { Dependent } \\
\text { Factors }\end{array}$ & $\begin{array}{l}\text { Main } \\
\text { Independent } \\
\text { Factors }\end{array}$ & Origin & $\begin{array}{l}\text { Originating } \\
\text { Area }\end{array}$ & Introduced \\
\hline $\begin{array}{l}\text { Theory of } \\
\text { Reasoned Action } \\
\text { (TRA) }\end{array}$ & $\begin{array}{l}\text { Behavioral } \\
\text { Intention, } \\
\text { Behavior }\end{array}$ & $\begin{array}{l}\text { Attitude Toward } \\
\text { Behavior, } \\
\text { Subjective } \\
\text { Norm, }\end{array}$ & & $\begin{array}{l}\text { Social } \\
\text { psychology }\end{array}$ & $\begin{array}{l}\text { Fishbein and } \\
\text { Ajzen (1975) } \\
{[96]}\end{array}$ \\
\hline $\begin{array}{l}\text { Technology } \\
\text { Acceptance } \\
\text { Model (TAM) }\end{array}$ & $\begin{array}{l}\text { Behavioral } \\
\text { Intention to } \\
\text { Use, } \\
\text { System } \\
\text { Usage }\end{array}$ & $\begin{array}{l}\text { Perceived } \\
\text { Usefulness, } \\
\text { Perceived Ease } \\
\text { of Use }\end{array}$ & $\begin{array}{l}\text { adopted } \\
\text { from TRA }\end{array}$ & $\begin{array}{l}\text { Information } \\
\text { Systems }\end{array}$ & $\begin{array}{l}\text { Davis (1989) } \\
{[84]}\end{array}$ \\
\hline $\begin{array}{l}\text { Theory of } \\
\text { Planned } \\
\text { Behavior (TPB) }\end{array}$ & $\begin{array}{l}\text { Behavioral } \\
\text { Intention, } \\
\text { Behavior }\end{array}$ & $\begin{array}{l}\text { Attitude Toward } \\
\text { Behavior, } \\
\text { Subjective } \\
\text { Norm, Perceived } \\
\text { Behavioral } \\
\text { Control } \\
\end{array}$ & $\begin{array}{l}\text { derivation of } \\
\text { TRA }\end{array}$ & $\begin{array}{l}\text { Social } \\
\text { psychology }\end{array}$ & $\begin{array}{l}\text { Ajzen (1991) } \\
\text { [83] }\end{array}$ \\
\hline $\begin{array}{l}\text { Unified Theory } \\
\text { of Acceptance } \\
\text { and Use of } \\
\text { Technology } \\
\text { (UTAUT) }\end{array}$ & $\begin{array}{l}\text { Behavioral } \\
\text { intention, } \\
\text { Usage } \\
\text { behavior }\end{array}$ & $\begin{array}{l}\text { Performance } \\
\text { expectancy, } \\
\text { Effort } \\
\text { expectancy, } \\
\text { Social } \\
\text { influence, } \\
\text { Facilitating } \\
\text { conditions, }\end{array}$ & $\begin{array}{l}\text { Adopted } \\
\text { from: TRA, } \\
\text { TAM, TPB, } \\
\text { motivational } \\
\text { Model (MM), } \\
\text { model of PC } \\
\text { Utilization } \\
\text { (MPCU) IDT } \\
\text { and Social } \\
\text { Cognitive } \\
\text { Theory }\end{array}$ & $\begin{array}{l}\text { Information } \\
\text { Systems }\end{array}$ & $\begin{array}{l}\text { Venkatesh et } \\
\text { al. (2003) [82] }\end{array}$ \\
\hline
\end{tabular}




\begin{tabular}{|l|l|l|l|l|l|}
\hline & & & (SCT). & & \\
\hline Task-technology & Performance & Task & & Information & Goodhue and \\
& & Characteristics & & Systems & Thompson, \\
& & Technology & & & (1995) [95] \\
& & Characteristics & & \\
& & & & \\
& & & & \\
& & & & \\
\end{tabular}

\subsection{Research Related to the Adoption and Use of Smartphone}

Smartphone technology evolves even more quickly than other types of IT, and its popularity has gained attention among scholars in both academia and industry. Publication of research in subjects related to adoption and use of Smartphone technology is increasing continuously which indicates the importance of studying and understanding adoption and use of Smartphone technology among scholars in various fields [97]. Significant effort has been made by scholars with different interests, using different approaches, methods, and theories to study various aspects related to Smartphone technology to explore and better understand users' adoption and use of this technology.

Kang et al. [49] applied the TAM model in their research to analyze factors affecting adoption of Smartphone technology. Their research model included five derived primary function attributes (wireless internet, design, multimedia, application, and after service). They indicated that most research on adoption of Smartphone assumed that the Smartphone is a tool used for specific purpose such as medical usage. Also, they emphasized the need for studying adoption of Smartphone in a holistic approach that covers general consumers and usage. 
Verkasalo, et al. [90] studied adoption of Smartphone' applications using the TAM model to understand users' intention to use specific Smartphone's applications including internet access, mapping services, and games. Their research model included the following variables: behavioral control, technical barriers, social norms, perceived enjoyment. They highlighted the needs for further research that investigate the impacts of social norms factors on adoption of Smartphone adoptions. Kim [91] indicated that even though the mobile wireless technology (MWT) market is rapidly growing, studies on key factors affecting its adoption are limited. They extended the TAM model to study users' intention to adopt MWT - Smartphone. This research model tested the effect of perceived cost saving, company's willingness to fund, job relevance and experience factors on users adoption of Smartphone. The study focused on a group of employees in an organization.

Combining IT theoretical models was an approach that numerous researchers used in an attempt to more comprehensively study and predict adoption of Smartphone technology. Chen et al. [29] combined Innovation Diffusion Theory (IDT) and TAM models to study and explain the adoption of Smartphone. Their study was limited to the logistics industry, specifically on delivery employees in a delivery service company. Their research model tested the effects of self-efficacy, compatibility, observable, testability, task, individual, and organization environment factors on adoption of Smartphones. Choudrie et al. [98] combined a number of theories namely: Unified Theory of Acceptance and Use of Technology (UTAUT), the Diffusion of Innovations theory (Dol), 
and TAM to study the adoption and use of the Smartphone by older adults in the United Kingdom. Also, Ho et al. [99] combined the TAM model and Status Quo Theory to build a theoretical framework that considers technological and economic perspectives that explain users' intention to continue using mobile data services MDS. This framework included factors such as perceived service availability, switching benefits and switching cost. Their research did not study the effects of psychological factor on adoption of MDS which they considered as research' limitation that can be further studied.

Based on adopter categories in diffusion models, Aarnio et al. [100] analyzed survey using the clustering process in an SPSS statistical package to explore adoption of mobile services focusing on a specific group of users in a certain age cohort. Their findings highlighted the importance of pricing as a crucial factor for higher diffusion. Moreover, Kargin et al. [101] used conjoint analysis to studied user' adoption of mobile Value Add Services (VAS) and to identify important factors affecting users' intention to adopt VAS. They analyzed factors influencing adoption of VAS including personalization, content, cost, screen size and service speed.

In a qualitative research approach that was based on interviews, Kargin and Basoglu [65] studied factors affecting users' adoption of mobile' Value Added Services. They proposed a mobile services adoption' taxonomy that include two aspects: Service characteristics (content, cost, enjoyment and mobility) and social factors (social influences and user characteristics). Swar et al. [102] used the Bass Diffusion Model to investigate the effect of national cultural factors on adoption of mobile phone services 
by studying the pattern of mobile phones' service adoptions in different counties and comparing them to observe the effect of cultural differences on adoption of mobile services.

Other approaches to studying and understanding the adoption and use of Smartphone were introduced. Verkasalo [51] introduced MobiTrack, a framework to conduct real-life data to analyze Smartphone users' behaviors. MobiTrack is a research application that Smartphone users' download into their Smartphone to monitor and collect data on device and services usage such as: communication usage, multimedia usage, apps usage, and internet traffic. He indicated the need for more comprehensive data on Smartphone users and their behavior in using it that can be used to develop better products. The MobiTrack approach seems to focus on people who had already adopted Smartphone technology and monitoring their behavior in usage of Smartphone device and services.

Also, Cherubini et al. [103] conducted an ethnographic observation study to explore the adoption and refusal of mobile contextual services. They identified 24 user needs that can be fulfilled by these applications and they discussed nine barriers of adoption of contextual services. Moreover, Huang et al. [104] believe that a Smartphone could become a suitable substitute for a traditional computer, yet the performance of Smartphone applications is poorly understood. So, they used systematic methodology to study and to better understand factors that impact users' perceived performance of some Smartphone applications. 
Kim and Garrison [105] investigated key factors that influenced users' adoption of mobile wireless technology (MWT). MWT is used by mobile users as a vehicle to surf the web, text message, perform mobile commerce activities, and more. They extended TAM by incorporating three variables, namely: job relevance, perceived reachability and perceived ubiquity. Moreover, they indicated the need for further studies to identify more new key factors that influence adoption of MWT as it advanced.

Studying adoption and use of Smartphone technology by focusing on just one Smartphone device or brand such as the Apple iPhone was an approach that a number of scholars used in their research $[106,107]$. Based on Ganesh and Kumar's work, Chris Maloney [107] developed a framework to explore the learning effects' influence on the rate of adoption in the market to better explain the impact of the learning effect on adoption rate of the iPhone [107].

Also, Kim and Song [106] investigated the adoption and use of Blueberry Smartphone. They developed their own research model that investigated the social, economic, and technological characteristics that influence individuals' attitude toward adoption of a specific Smartphone device, namely Blueberry. Even though Smartphone device brands such as Nokia, HTC, and Samsung have their own unique differences in their combination of hardware/software, and they may influence user's acceptance and attitude toward adoption of Smartphone differently, the iPhone was the most studied Smartphone device by scholars in articles reviewed [108-111, 7]. 
Focusing on or studying only a single factor or aspect that impacts users' adoption and use of Smartphone technology was an approach that a number of scholars used. Chtourou and Souiden [24] used the TAM model to study the effect of one factor, namely the entertainment of using the Smartphone in browsing the internet. They found that pleasure is an important factor that affects user attitudes toward the use of the mobile internet. Moreover, they emphasized the importance of including emotional motivations when studying users' adoption of innovation. Their study was limited to the use of mobile internet and they suggested a further study to modify and include other products/services.

Also, Song and Han [25] used UTAUT to study the importance of the enjoyment aspect of the users' adoption of new technology in mobile services. They examined the relationship between content quality and perceived enjoyment. Also they examined the effect of social influence and the quality system on behavior intention of the user. They emphasized on the importance of the enjoyment aspect on mobile services acceptance. Moreover, Yoo et al. [112] identified the Smartphone device based on its characteristics as a convergence device; therefore, users experience on Smartphone devices play a crucial role in their adoption. They conducted a conjoint analysis using SPSS to investigate the factor or aspect of positive reputation on adoption of smartphones. They studied four groups of consumers (personal, expert, consumers, and mass media) as their source of the external reputation of Smartphone. Also, a single factor or aspect, 
namely aesthetic design, was studied to observe how it affects users' emotional reaction towards adoption of the Smartphone device[113].

Adoption and usage of Smartphone multimedia' services and applications were studied and investigated in number of articles. Bouwman et al. [114] used a sampling and measurement model to study users' intention to adopt mobile TV application for Smartphones. They studied the effect of four variables (being alone, social, transit and personal innovativeness) that initiate the use of Mobile TV.

In an empirical observational study, Verkaslo [115] studied consumers' real usage patterns of mobile multimedia' services and application to understand users' behaviors toward multimedia adoption in Smartphones. In another study, using survey and cluster analysis, scholars explored the usages and adoption rates of Smartphone multimedia in four clustered users: youngster, female, male and the older users [116].

In a number of articles scholars studied the mobile learning aspect. They believe that mobile learning is a revolutionary technology that can open advanced avenues to reach education and can influence the use and adoption of smartphones. Liu et al. [117] indicated the lack of understanding factors affecting adoption of $\mathrm{m}$-learning. They applied the TAM model to explore factors influencing the adoption of mobile learning. Factors identified and studied in their model included personal innovation, near-term usefulness and long-term usefulness.

Usability of an object could be defined as "the quality of use that a user experiences when in contact with the object" [118]. Page, [118] studied the usability of 
text input interfaces in smartphones. He reviewed and compared a number of smartphone typing methods to evaluate their usability. He indicated that there is a lack of innovative soft keyboard development which he considered as a weak point of smartphones when compared to laptops.

Also, Shin et al. [119] indicated that Smartphone technology is not yet ubiquitous in the educational sector. They also mentioned the limitations of academic research on Smartphone technology as a learning tool. They examined factors that influence users' intentions to use smartphones as a ubiquitous learning tool. In their research model, they modified unified theory of acceptance and use technology (UTAUT) and they used factors from Expectation Confirmation Theory (ECT).Their research focused on ten universities where a survey was distributed to faculty, staff and students. They highlighted that limited aspects of users' experience with Smartphones were reflected upon, also they suggested that including additional factors in future research would enable better understanding of Smartphone users' behaviors.

In an observational study, Schepman et al. [95] explored the adoption of mobile note-taking software that can be used on smartphones. Their research was focused on undergraduate students who were observed over a period of eight weeks.

Adoption of Smartphone technology is a popular subject among researchers in the healthcare industry. Researchers in a number of articles looked at Smartphone technology as a very useful tool that could be utilized to improve performance and 
quality of work in that environment. Park and Chen [27] used the TAM model to study the adoption of Smartphone technology in the healthcare sector and they investigated the factors that affect the adoption of Smartphone technology among doctors and nurses. Their research model included the following factors: compatibility, observability, trialability, and task individual organization environment factors. They indicated the need for further research to investigate the adoption of Smartphone technology.

Also, Putzer and Park [28] investigated factors that affect individuals' decision in healthcare profession to adopt Smartphone. Their research model incorporated aspects of the TAM model and DOI theory. The effects compatibility, observability, job relevance, personal demographics, personal experience, internal environment, and external environment on adoption of Smartphone technology among nurses were investigated. The study focused on nurses in two community hospitals and it included organizational factors that may affect adoption of Smartphone in healthcare environments.

In a descriptive approach, Boulos et al. [120] discussed barriers of adoption to smartphones applications in healthcare, including cost, network bandwidth, battery efficiency, privacy and usability. Moreover, numerous scholars in descriptive approaches recognized and discussed medically-related factors affecting adoption of Smartphone technology in the healthcare industry where it is used as a tool to enable better services and practices such as using the smartphones to help in obesity prevention [121], patients' activity recognizer while in the go [122], and as a suitable 
platform to act as the real time assessment for cardiovascular disease [123]. Also scholars recognize the benefits of Smartphone technology in the healthcare industry. They discussed the critical factors that influence its success in healthcare as well as the challenges facing its adoption in the healthcare sector [124].

Other important aspects of Smartphone technology that scholars looked at as critical to affecting adoption are networking and connectivity. Researchers proposed solutions to improve connectivity and performance as an important factor supporting Smartphone capabilities with the increasing use of internet and computing on Smartphone [125]. Shin [126] applied the TAM model to study factors effecting the adoption of mobile internet. Factors, including perceived availability, quality, enjoyment, and social pressure, were analyzed to explain users' behavioral intention to adopt and use mobile internet. Also, WiMAX is a promising technology to support the growing demands for high speed and cost effective broadband mobile services, A number of scholars looked at the adoption and diffusion of mobile WiMAX using scenario planning and Bass Model methods [127]. Researchers utilized the Bass Model to examine the market acceptance of the satellite digital multimedia broadcasting DMA, a mobile communication service [89].

In descriptive approaches, a number of networking and connectivity issues were discussed including IEEE 802.11g WLAN [128], and adoption of Delay/DisruptiveTolerant Networking (DTN) architecture as an ideal for Smartphone' connectivity, providing more robust network security [129]. Also, researchers discussed and 
evaluated challenges facing Smartphone connectivity that impact the user's adoption of smartphones [130-133] and barriers to wider adoption of Voice over Internet Protocols (VoIP) over Wi-Fi in Smartphone [134]. Challenges coming with wide adoption of mobile broadband services by users of Smartphones and users' expectations were identified and discussed [135]. Moreover, scholars discussed challenges facing the diffusion of 3G, and pricing models of data services and the impact on usages of mobile data services[136].

With regards to security and other related supporting software, scholars discussed and explained a number of factors that directly and indirectly effect adoption of Smartphone technology. Researchers proposed architecture on management of service in an Intelligent Environment (IE) to make the Smartphone aware of its surroundings [137]. Also, scholars introduced a strategy to better detect malware in smartphones [138]. Moreover, versatile reconfigurable architecture to reduce some technical and usability limitation was proposed [139].

A number of researchers discussed the improvements of Smartphone users' privacy and data sensitivity and proposed DiffUser; a differentiated user access control model [140]. Also, researchers proposed a common visual representation protocol to help overcome challenges that international users face with Smartphone [141]. Scholars described Qplus, a middleware, and applications that make it easier for users to operate Smartphone' functions [142]. Scholars proposed an automated system to support Smartphone live memory dynamic properties analysis on applications [143]. Moreover, 
scholars identified and proposed solutions to some security challenges in mobile devices to improve users' acceptance of Smartphone devices [144].

Scholars presented Quality of Service (QoS), a model that improves the quality of service as an important factor affecting Smartphone adoptions [145]. Scholars also investigated the increase in diffusion of mobile internet and its impact on other mobile services [146].

Smartphone technology is evolving rapidly, providing users with more solutions, and enhancements of their experiences such as improved performances, more tools/features, solutions, and applications. Consequently, in a number of research papers, researchers studied and tried to explain the effects of such improvements and enhancements on users' acceptance and use of Smartphone technology.

Jeong and Yoo [147] compared the TAM model and Warshaw's purchase intention model to explore users' intention to buy mobile RFID-tag reader' services. According to this research model, perceived need and purchasability factors could collectively explain user intention to purchase mobile RFID services. Their study focused on graduate students in two universities in Korea.

Cherubini et al. [103] conducted ethnographic observations to study the adoption and refusal of mobile contextual services. They identified 24 users' needs that can be fulfilled by these applications and discussed nine barriers of adoption of contextual services. Also, some scholars Introduced a nomadic device in a vehicle 
environment telemetric to enhance and evaluate users' acceptance of Smartphone technology [148].

Many new applications of Smartphone technology are being discussed and tested. Some scholars proposed a Smartphone-based system that gives users' authority to access rooms using their Smartphone and tested users' behaviors [149]. Other scholars proposed a smart phone system that automatically chooses the right channel and device to reach their callee [150]. Other scholars proposed a novel system, SMART, that is meant to improve the accuracy of indoor maps [151]. Also, to assist users' experience, a middleware platform was proposed that enhances Smartphone' internet connectivity while in the go [152]. Moreover, a machine using learning techniques called Darwin was proposed to improve Smartphone' performance and therefore boost its adoption [153].

Many scholars looked at the adoption of Smartphone with regards to their roles in finance, marketing and business activities. Smartphone technology can be utilized to improve company to customer relationships. Marketing applications are still in the early stage of adoptions [13]. With the advancement of Smartphone technology and its ability to handle data and commercial transactions, banks have become aware of Smartphone advancements and popularity among consumers and started to act accordingly. In a number of articles, scholars tried to study and understand consumers' adoption of mobile banking and related issues. Many banks started to have mobile banking options 
for their customers to insure better future position as the popularity of Smartphone increase.

Zhou et al. [154] integrated the task technology fit (TTF) model and the unified theory and use technology (UTAUT) to study the adoption of mobile banking. They analyzed the following factors: task characteristics, technology characteristic, performance expectancy, effort expectancy, social influence, and facilitating conditions to determine users' adoption of mobile banking. They highlighted the importance of the task technology fit where a new technology has to fulfill users' task requirements in order to be adopted by that user.

Koenig-Lewis et al. [155] examined adoption of mobile banking using the TAM model. They investigated the influence of trust, credibility, compatibility, perceived risk and cost factors on users' behavioral intention to adopt mobile banking services. Their study targeted groups of individuals in Germany who are mostly going to adopt mobile banking. Their research indicated that trust and risk factors can be more or less influential depending on other factors such as technological infrastructure that was not included in their study. Moreover, in a qualitative approach, Mallat [156] used focus group interviews to explore factors that influence adoption of mobile payments. He studied the following adoption factors: relative advantage, compatibility, complexity, costs, network externalities, trust, perceived security and risk.

Bauer et al., [157] highlighted the lack of academics research that allowed for better understanding of mobile marketing as new trend in marketing. They used the 
Theory of Reasoned Action (TRA) to investigate factors influencing users to adopt mobile marketing. Their research model include the following factors: innovativeness, perceived utility, existing knowledge, information seeker-behavior, attitude toward advertising, and perceived risk. Also, users' acceptance of mobile commerce were considered to be a predictor of its success, Tao and Zhou [158] used the UTAUT model to examine key factors that influence users' acceptance and use of mobile commerce. In their research model they examine the influence of the following factors: contextual offering' performance expectancy, effort expectancy, social influence and facilitating conditions on the users' intention to use m-commerce. Also, Wu and Wang, in an empirical study, [159] utilized the TAM model to investigate factors that determine users' acceptance of mobile commerce. Their research model examines compatibility, perceived risk and cost.

Scholars discussed and explored mobile ecosystem from a business perspective [160]. Sawng and Han [89] used the Bass model to examine and measure market acceptance of the satellite digital multimedia broadcasting (DMB) where they attempt to estimate the level and nature of acceptance for each user categories. Also, scholars explained the ecosystem of Smartphone and analyzed Smartphone' operating systems market under a uniform framework [161]. A number of scholars analyzed the adoption barriers of business to employee (B2e) mobile internet applications focusing their study on corporate environment [162]. Finally, scholars explored how smartphones influence work processes and attitudes toward technology as it can boost performance, also how 
adoption of Smartphone technology improved collaboration between the workforce and their organization [163].

Based on the research reviewed in the above literature review, taxonomy has been developed that includes examples of the related research reviewed earlier as shown it in Table 2 below. It presents research topics, theory or model used, variables identified in the research, and a summary of the results. As mentioned earlier in the literature review, a number of points can be recognized in Table two below such as:

- The Technology Acceptance Model is one of the most used models in research that studies the adoption and use of smartphones and its related technology.

- A number of researchers who studied smartphones focused only on one profession such as physicians, dentists, nurses and employees in delivery services.

- A number researchers studied smartphones as if they were a tool to be used in executing a specific task such as the use of smartphones in healthcare, electronic learning or delivery services. 
Table 2: Summary of empirical research related to the adoption of Smartphone technology

\begin{tabular}{|c|c|c|c|c|}
\hline $\begin{array}{l}\text { Research } \\
\text { topic }\end{array}$ & $\begin{array}{c}\text { Theory - } \\
\text { Model }\end{array}$ & $\begin{array}{c}\text { Independent } \\
\text { Variables }\end{array}$ & $\begin{array}{c}\text { Dependent } \\
\text { Variables }\end{array}$ & Results \\
\hline $\begin{array}{l}\text { Analyze } \\
\text { factors } \\
\text { affecting } \\
\text { adoption of } \\
\text { Smartphone } \\
\text { [49], } \\
\text { The research } \\
\text { focused on } \\
\text { undergraduat } \\
\text { e and } \\
\text { graduate } \\
\text { students in } \\
\text { Korea. }\end{array}$ & TAM & $\begin{array}{l}\text { Wireless Internet } \\
\text { Design } \\
\text { Multimedia } \\
\text { Applications } \\
\text { After service } \\
\text { perceived usefulness } \\
\text { (PU) } \\
\text { perceived ease of } \\
\text { use (PEOU) }\end{array}$ & $\begin{array}{l}\text { Behavior } \\
\text { Intention }\end{array}$ & $\begin{array}{l}\text { They found that: } \\
\text { Wireless } \\
\text { Internet, multimedia, } \\
\text { application, and after } \\
\text { services were found to } \\
\text { affect PU and PEOU } \\
\text { Design affected only } \\
\text { PU. } \\
\text { PU significantly affects } \\
\text { BI, while PEOU does } \\
\text { not. }\end{array}$ \\
\hline $\begin{array}{l}\text { Investigate } \\
\text { factors that } \\
\text { may affect } \\
\text { the intention } \\
\text { to use } \\
\text { Smartphone' } \\
\text { applications } \\
\text { across users } \\
\text { and non- } \\
\text { users [90]. }\end{array}$ & TAM & $\begin{array}{l}\text { Perceived enjoyment } \\
\text { Behavior control } \\
\text { Social norm } \\
\text { perceived usefulness }\end{array}$ & $\begin{array}{l}\text { Intention to } \\
\text { Use }\end{array}$ & $\begin{array}{l}\text { Their results included } \\
\text { that: } \\
\text { Perceived enjoyment } \\
\text { and usefulness were } \\
\text { generically } \\
\text { found to explain } \\
\text { intention to use } \\
\text { applications }\end{array}$ \\
\hline $\begin{array}{l}\text { Identify the } \\
\text { important } \\
\text { factors that } \\
\text { influence } \\
\text { users' } \\
\text { intention to } \\
\text { adopt mobile } \\
\text { Value Add } \\
\text { Services } \\
\text { (VAS) [101] }\end{array}$ & $\begin{array}{l}\text { Conjoint } \\
\text { analysis } \\
\text { using SPSS }\end{array}$ & $\begin{array}{l}\text { Personalization } \\
\text { Content } \\
\text { Cost } \\
\text { Screen size } \\
\text { Service speed }\end{array}$ & Preference & $\begin{array}{l}\text { Their results include } \\
\text { that: speed, cost and } \\
\text { content are the most } \\
\text { important factors to } \\
\text { overall mobile service } \\
\text { preference. }\end{array}$ \\
\hline $\begin{array}{l}\text { Study factors } \\
\text { that predict } \\
\text { the adoption } \\
\text { of } \\
\text { Smartphone } \\
\text { among } \\
\text { employees in } \\
\text { delivery } \\
\text { services [29]. }\end{array}$ & $\begin{array}{l}\text { Innovation } \\
\text { Diffusion } \\
\text { Theory (IDT) } \\
\text { and TAM }\end{array}$ & $\begin{array}{l}\text { Self efficacy } \\
\text { Compatibility } \\
\text { Observable, } \\
\text { Testability, } \\
\text { Task, } \\
\text { Individual, } \\
\text { Organization } \\
\text { environment } \\
\text { Attitude }\end{array}$ & $\begin{array}{l}\text { behavioral } \\
\text { intention }\end{array}$ & $\begin{array}{l}\text { Their finding include } \\
\text { that: } \\
\text { Self-efficacy was a } \\
\text { strong predictor of } \\
\text { Behavioral intention } \\
\text { through attitude. } \\
\text { Attitude towards smart } \\
\text { phone adoption was } \\
\text { found to be affected } \\
\text { mainly by testability } \\
\text { and organizational and } \\
\text { environmental factors }\end{array}$ \\
\hline
\end{tabular}




\begin{tabular}{|c|c|c|c|c|}
\hline $\begin{array}{l}\text { To } \\
\text { investigated } \\
\text { the key } \\
\text { factors that } \\
\text { influence the } \\
\text { adoption of } \\
\text { the } \\
\text { Smartphone } \\
\text { among } \\
\text { college } \\
\text { student in } \\
\text { China [42] }\end{array}$ & TAM & $\begin{array}{l}\text { Self-efficacy } \\
\text { Attitude to use } \\
\text { Perceived ease of use } \\
\text { Social influence } \\
\text { Perceived usefulness } \\
\text { Entertainment utility } \\
\text { Compatibility }\end{array}$ & $\begin{array}{l}\text { Behavioral } \\
\text { intention }\end{array}$ & $\begin{array}{l}\text { Their results indicated } \\
\text { that: social influence, } \\
\text { entertainment utility, } \\
\text { compatibility all had a } \\
\text { significant positive } \\
\text { impact on } \\
\text { user's perceived } \\
\text { usefulness of } \\
\text { smartphone }\end{array}$ \\
\hline $\begin{array}{l}\text { To studied } \\
\text { the adoption } \\
\text { and use of } \\
\text { the } \\
\text { Smartphone } \\
\text { by older } \\
\text { adults in the } \\
\text { United } \\
\text { Kingdom [98] }\end{array}$ & $\begin{array}{l}\text { TAM, UTAUT, } \\
\text { DOI }\end{array}$ & $\begin{array}{l}\text { Observability, } \\
\text { Compatibility, Social } \\
\text { influence, Facilitating } \\
\text { conditions, } \\
\text { Effort expectancy } \\
\text { Enjoyment }\end{array}$ & $\begin{array}{l}\text { Behavioral } \\
\text { intention and } \\
\text { use behavior }\end{array}$ & $\begin{array}{l}\text { Their founding includes } \\
\text { that: observability, } \\
\text { compatibility, social } \\
\text { influence, facilitating } \\
\text { conditions, effort } \\
\text { expectancy and } \\
\text { enjoyment are } \\
\text { important to the } \\
\text { adoption and use of } \\
\text { Smartphone among } \\
\text { older adults in UK. }\end{array}$ \\
\hline $\begin{array}{l}\text { Examining } \\
\text { users' } \\
\text { Behavioral } \\
\text { Intention } \\
\text { toward using } \\
\text { mobile } \\
\text { wireless } \\
\text { technology } \\
{[105] .}\end{array}$ & TAM & $\begin{array}{l}\text { Perceived ubiquity } \\
\text { Perceived } \\
\text { reachability } \\
\text { Job relevance } \\
\text { Perceived ease } \\
\text { of use } \\
\text { Perceived usefulness }\end{array}$ & $\begin{array}{l}\text { Behavioral } \\
\text { intention }\end{array}$ & $\begin{array}{l}\text { They found that: All } \\
\text { five variables have a } \\
\text { positive relationship } \\
\text { with Behavioral } \\
\text { Intention and } \\
\text { Perceived usefulness } \\
\text { variable is the most } \\
\text { significant one }\end{array}$ \\
\hline $\begin{array}{l}\text { To study } \\
\text { users' } \\
\text { behavioral } \\
\text { intention } \\
\text { to use mobile } \\
\text { wireless } \\
\text { technology } \\
\text { and the } \\
\text { affect of } \\
\text { using the } \\
\text { Smartphone } \\
\text { [91]. }\end{array}$ & TAM & $\begin{array}{l}\text { Perceived cost } \\
\text { saving, Company's } \\
\text { willingness to fund } \\
\text { Perceived ease } \\
\text { of use (PEOU) } \\
\text { Perceived usefulness } \\
\text { (PU) } \\
\text { Behavioral intention } \\
\text { (BI) }\end{array}$ & $\begin{array}{l}\text { Actual use of } \\
\text { Smartphone }\end{array}$ & $\begin{array}{l}\text { Finding include that : } \\
\text { PU was significantly } \\
\text { related to users' } \\
\text { intention to use the } \\
\text { Smartphone } \\
\text { PEU had a significant } \\
\text { impact on BI and PU } \\
\text { BI was significantly } \\
\text { related to actual usage } \\
\text { of a Smartphone }\end{array}$ \\
\hline $\begin{array}{l}\text { Study the } \\
\text { adoption of } \\
\text { Smartphone } \\
\text { among } \\
\text { medical } \\
\text { doctors and }\end{array}$ & TAM & $\begin{array}{l}\text { compatibility, } \\
\text { observability, } \\
\text { trialability, task } \\
\text { individual } \\
\text { organizational } \\
\text { environment }\end{array}$ & $\begin{array}{l}\text { Behavioral } \\
\text { intention to use }\end{array}$ & $\begin{array}{l}\text { Finding includes that: } \\
\text { PEOU and attitude } \\
\text { toward using } \\
\text { Smartphone } \\
\text { significantly influence } \\
\text { behavioral intention to }\end{array}$ \\
\hline
\end{tabular}




\begin{tabular}{|c|c|c|c|c|}
\hline nurses [27]. & & $\begin{array}{l}\text { Perceived ease } \\
\text { of use (PEOU) } \\
\text { Perceived usefulness } \\
\text { (PU) } \\
\text { Attitude }\end{array}$ & & $\begin{array}{l}\text { use it. } \\
\text { PU and PEOU positively } \\
\text { determine uses' } \\
\text { attitude toward using } \\
\text { the Smartphone }\end{array}$ \\
\hline $\begin{array}{l}\text { Study the } \\
\text { factors that } \\
\text { influence } \\
\text { users' } \\
\text { intention to } \\
\text { use the } \\
\text { Smartphone } \\
\text { in China [43] }\end{array}$ & $\begin{array}{l}\text { Theory of } \\
\text { Reasoned } \\
\text { Action (TRA) }\end{array}$ & $\begin{array}{l}\text { Comparative } \\
\text { advantages } \\
\text { Compatibility } \\
\text { Trialability } \\
\text { Innovativeness } \\
\text { Subjective norms } \\
\text { attitude }\end{array}$ & Intention & $\begin{array}{l}\text { They found that: } \\
\text { innovativeness, } \\
\text { comparative } \\
\text { advantages, } \\
\text { compatibility, } \\
\text { entertainment have } \\
\text { significant positive } \\
\text { impact on users' } \\
\text { attitude } \\
\text { Also, attitude and } \\
\text { subjective norms have } \\
\text { significant positive } \\
\text { effects on using } \\
\text { intention }\end{array}$ \\
\hline $\begin{array}{l}\text { Study key } \\
\text { factors the } \\
\text { influence } \\
\text { users' } \\
\text { intentions to } \\
\text { continue } \\
\text { using the } \\
\text { Smartphone } \\
\text { as a } \\
\text { ubiquitous } \\
\text { learning (u- } \\
\text { learning) tool } \\
\text { [119]. }\end{array}$ & UTAUT & $\begin{array}{l}\text { Perceived content } \\
\text { quality } \\
\text { Perceived service } \\
\text { quality } \\
\text { Confirmation } \\
\text { Perceived } \\
\text { ease of use } \\
\text { Perceived usefulness } \\
\text { Satisfaction } \\
\text { Intimacy } \\
\text { Previous experience }\end{array}$ & $\begin{array}{l}\text { Continuance } \\
\text { intention }\end{array}$ & $\begin{array}{l}\text { The results indicated } \\
\text { that: } \\
\text { satisfaction factors was } \\
\text { the most significant } \\
\text { determinant of } \\
\text { users' continuance } \\
\text { intention for the } \\
\text { Smartphone }\end{array}$ \\
\hline $\begin{array}{l}\text { To examine } \\
\text { the factors } \\
\text { that } \\
\text { Influence the } \\
\text { Thai elderly } \\
\text { Intention to } \\
\text { use } \\
\text { Smartphone } \\
\text { for e-Health } \\
\text { services [164] }\end{array}$ & UTAUT & $\begin{array}{l}\text { Performance } \\
\text { expectancy } \\
\text { Effort expectancy } \\
\text { Social influence } \\
\text { Facilitating } \\
\text { conditions } \\
\text { Perceived Value }\end{array}$ & $\begin{array}{l}\text { Behavioral } \\
\text { intention }\end{array}$ & $\begin{array}{l}\text { The results indicated } \\
\text { that: Perceived } \\
\text { Value' has a strong } \\
\text { significance on the } \\
\text { elderly intention to use } \\
\text { smartphone, followed } \\
\text { by Facilitating } \\
\text { Conditions and Effort } \\
\text { Expectancy. }\end{array}$ \\
\hline $\begin{array}{l}\text { Analyze } \\
\text { users' } \\
\text { acceptance of } \\
\text { mobile } \\
\text { Internet } \\
{[126] .}\end{array}$ & TAM & $\begin{array}{l}\text { perceived } \\
\text { availability, } \\
\text { perceived quality } \\
\text { perceived, } \\
\text { enjoyment, social } \\
\text { pressure } \\
\text { perceive usefulness, } \\
\text { Attitude }\end{array}$ & Intention & $\begin{array}{l}\text { Their results include } \\
\text { that: Perceived quality } \\
\text { and perceived } \\
\text { availability significantly } \\
\text { affect users' attitude } \\
\text { and intention }\end{array}$ \\
\hline
\end{tabular}




\begin{tabular}{|c|c|c|c|c|}
\hline $\begin{array}{l}\text { Examine the } \\
\text { effect of the } \\
\text { fun aspect on } \\
\text { users' } \\
\text { attitude to } \\
\text { use mobile } \\
\text { internet [24]. }\end{array}$ & TAM & $\begin{array}{l}\text { Fun } \\
\text { Market } \\
\text { Usefulness } \\
\text { Ease of Use }\end{array}$ & Users' Attitude & $\begin{array}{l}\text { fun aspect effects } \\
\text { users' attitude toward } \\
\text { the use of mobile } \\
\text { internet }\end{array}$ \\
\hline $\begin{array}{l}\text { Investigate } \\
\text { the barriers } \\
\text { for adopting } \\
\text { mobile } \\
\text { banking } \\
\text { services [155] }\end{array}$ & TAM and IDT & $\begin{array}{l}\text { trust, } \\
\text { credibility, } \\
\text { compatibility, } \\
\text { perceived risk cost } \\
\text { Perceived ease } \\
\text { of use (PEOU) } \\
\text { Perceived usefulness } \\
\text { (PU) }\end{array}$ & $\begin{array}{l}\text { Users' } \\
\text { behavioral } \\
\text { intention }\end{array}$ & $\begin{array}{l}\text { The results includes } \\
\text { that: Compatibility, PU } \\
\text { and risk are Significant } \\
\text { indicators of users' } \\
\text { adoption of mobile } \\
\text { banking services }\end{array}$ \\
\hline $\begin{array}{l}\text { Study the } \\
\text { adoption of } \\
\text { PDA and } \\
\text { smartphones } \\
\text { among } \\
\text { physicians } \\
\text { and dentists } \\
\text { at } \\
\text { King Saud } \\
\text { Medical City } \\
\text { Hospitals } \\
\text { (KSMCH) in } \\
\text { Saudi Arabia }\end{array}$ & $\begin{array}{l}\text { Statistical } \\
\text { Package for } \\
\text { Social } \\
\text { Sciences } \\
\text { (SPSS) } \\
\text { software }\end{array}$ & $\begin{array}{l}\text { Usefulness (PU), } \\
\text { Perceived ease of use } \\
\text { (PEOU),performance } \\
\text { and productivity }\end{array}$ & $\begin{array}{l}\text { Adoption and } \\
\text { Use of PDA and } \\
\text { smartphones }\end{array}$ & $\begin{array}{l}\text { The results show that: } \\
\text { the adoption and use of } \\
\text { PDA and smartphones } \\
\text { improved their } \\
\text { performance and their } \\
\text { productivity. }\end{array}$ \\
\hline
\end{tabular}

\subsection{Taxonomy of Factors Related to The Adoption and Use of Smartphones}

According to Sekaran [165], identifying factors that were determined as important in previous research accompanied with rational relationships and connections that can be logically conceptualized, form the basis of a theoretical research framework or model. Thus, factors that were determined in previous research to be important and related to the adoption and use of the Smartphone and its related technologies have been logically conceptualized, evaluated, validated and utilized to develop a research model in this dissertation. A taxonomy of factors related to the 
adoption and use of smartphone technology has been developed which classifies related factors under five main factors/variables as shown in figure 5 below.

Each of the five main factors identified in the taxonomy have a theoretical basis and were determined to have a relationship with the users' intention to adopt and use a new IT such as Smartphone technology $[166,82]$. A number of factors are classified under the technology characteristics and performance because they were associated with it either directly or through other factors such as perceived usefulness and relative advantage [156], which may improve users' performance when using the Smartphone technology [82]. The factors that are classified under technology characteristics and performance include: perceived usefulness $[29,167,49,155,126,25,82]$, Job relevancies [105, 126], relative advantage [156], perceived ubiquity [168, 105], perceived reachability [105], mobility [65], accuracy [168], security [156], perceived availability [167, 126], perceived quality [126], content $[101,65]$, screen size [101], service speeds [65], multimedia [49], applications [49], and wireless Internet [49]. These factors are related to technology characteristics and performance; therefore, they are classified under it in the developed taxonomy. Further evaluations, validating and selecting of only the most important factors, have been conducted using brainstorming sessions, focus group sessions and individual interviews. Table 3 below provides definitions and explanations for the main factors that were identified through literature. (More details are provided in later chapter of this dissertation). 


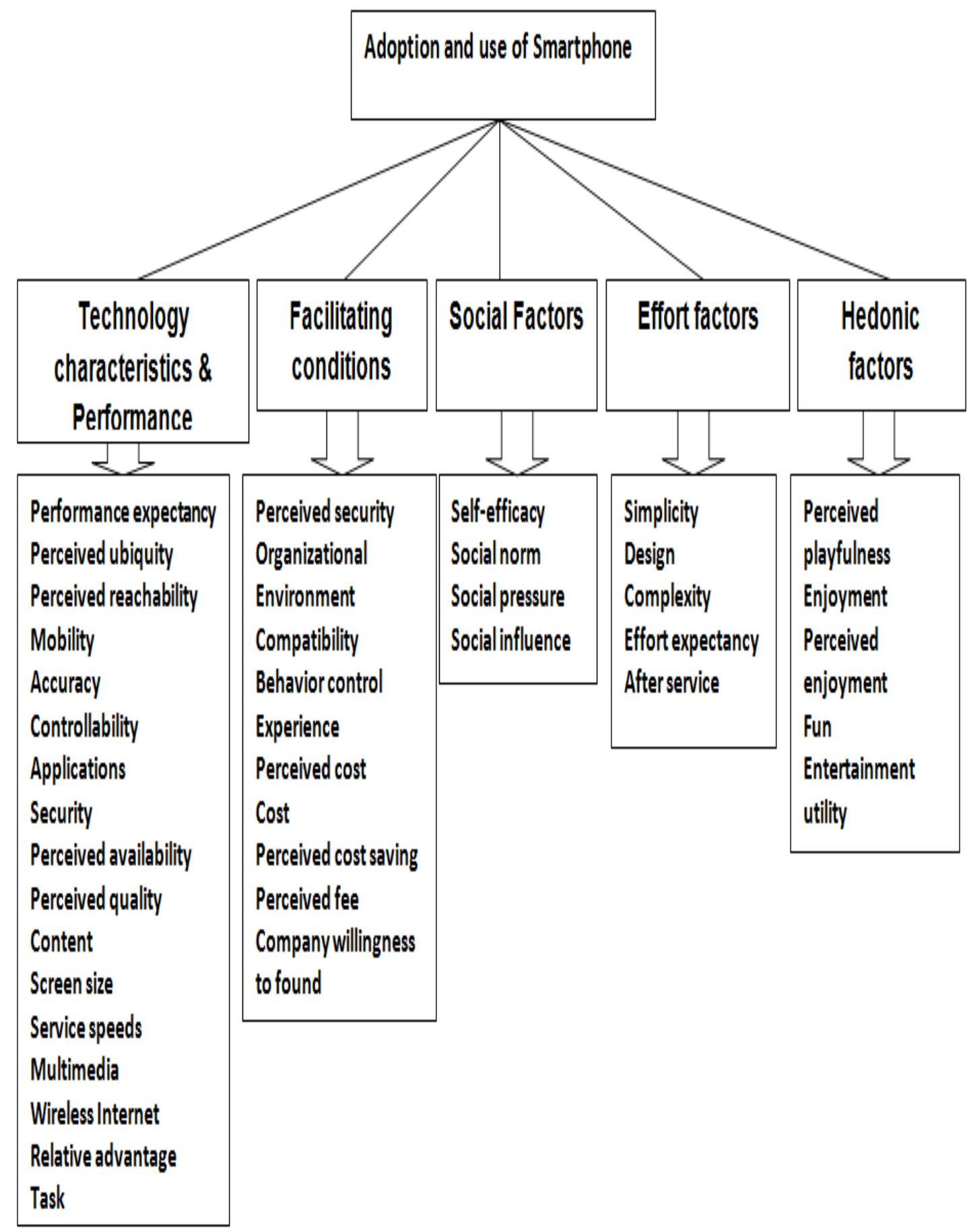

Figure 5: Taxonomy of factors related to the adoption and use of the Smartphone 
Table 3 Definitions and explanations for the main factors that were identified through literature

\begin{tabular}{|c|c|}
\hline Factors & Definition/Explanation \\
\hline mobility [65] & $\begin{array}{l}\text { To have access in real time for information and } \\
\text { communications. Mobility provides users more freedom, as } \\
\text { they can access information and services without having to } \\
\text { find a physical place. }\end{array}$ \\
\hline $\begin{array}{l}\text { perceived } \\
\text { ubiquity or } \\
\text { reachability } \\
{[168,105]}\end{array}$ & $\begin{array}{l}\text { Perceived service availability is defined as "the consumers' } \\
\text { perception of whether mobile services are able to provide } \\
\text { widely accessible services and timely connections" }\end{array}$ \\
\hline $\begin{array}{l}\text { perceived } \\
\text { quality [126] }\end{array}$ & $\begin{array}{l}\text { Perceived quality has been defined "as one of the consumer } \\
\text { satisfaction over content or services provided by technologies" }\end{array}$ \\
\hline $\begin{array}{l}\text { content }[101, \\
65]\end{array}$ & $\begin{array}{l}\text { "Content correctness, content delivery time, content quality, } \\
\text { content quantity, and content provider are the ingredients of } \\
\text { content" }\end{array}$ \\
\hline screen size [101] & The size of smartphones screen small, big \\
\hline Design [49] & $\begin{array}{l}\text { The design has two aspects: (1) inherent design and colors of } \\
\text { mobile phones, and (2) detailed elements of design regarding } \\
\text { the entire appearance, color, harmony of appearance, shape of } \\
\text { keypads, etc. }\end{array}$ \\
\hline Speed [65] & Time it takes to function \\
\hline Multimedia [49] & $\begin{array}{l}\text { "The multimedia refers to the various media functions, such as } \\
\text { camera, mp3, and games." }\end{array}$ \\
\hline applications [49] & $\begin{array}{l}\text { "The application refers to contents that are executed in the } \\
\text { mobile equipment, and we can determine the supply of } \\
\text { diverse applications that meet users' BI." }\end{array}$ \\
\hline $\begin{array}{l}\text { wireless Internet } \\
\text { [49] }\end{array}$ & $\begin{array}{l}\text { "The wireless Internet can be defined as the services that } \\
\text { provide digitized information or contents to users, which can } \\
\text { eliminate time constraints or spatial constraints." }\end{array}$ \\
\hline accuracy [168] & $\begin{array}{l}\text { The quality or state of being correct or precise. } \\
\text { The level or degree of accuracy that can be achieved by using } \\
\text { smartphones in a specific task. }\end{array}$ \\
\hline simplicity [101] & The simplicity of understanding and using the system \\
\hline complexity [156] & $\begin{array}{l}\text { "Degree to which an innovation is perceived as difficult to } \\
\text { understand and use" }\end{array}$ \\
\hline $\begin{array}{l}\text { Switching cost or } \\
\text { benefits [99] }\end{array}$ & $\begin{array}{l}\text { "Switching benefits mean that the perceived utility that a user } \\
\text { gains in switching from the status quo to the new situation" }\end{array}$ \\
\hline self-efficacy [27] & $\begin{array}{l}\text { "An individual's perception of his or her ability to use a } \\
\text { computer in the accomplishment of a job task". }\end{array}$ \\
\hline social norms [90] & "Social norms, also referred to as subjective norms or social \\
\hline
\end{tabular}




\begin{tabular}{|c|c|}
\hline & $\begin{array}{l}\text { influence, represent a factor that is assumed to have a direct } \\
\text { impact on perceived utility" }\end{array}$ \\
\hline $\begin{array}{l}\text { Behavior control } \\
{[90]}\end{array}$ & $\begin{array}{l}\text { Perceived behavioral control refers to people's perception of } \\
\text { the ease or difficulty with which they can perform a certain } \\
\text { task. } \\
\text { Also, perception of the availability of knowledge, resources, } \\
\text { and opportunities needed to carry out the specific task. }\end{array}$ \\
\hline $\begin{array}{l}\text { social pressure } \\
{[126]}\end{array}$ & $\begin{array}{l}\text { Normative pressure as "the person's perception that most } \\
\text { people who are important to him think he should or should not } \\
\text { perform the behavior in question" }\end{array}$ \\
\hline $\begin{array}{l}\text { perceived } \\
\text { security [156] }\end{array}$ & $\begin{array}{l}\text { Feeling the risk of unauthorized use of mobile devices and the } \\
\text { concerns of the following: } \\
\text { Transaction errors, lack of transaction record and } \\
\text { documentation, privacy and device and network reliability }\end{array}$ \\
\hline $\begin{array}{l}\text { environments } \\
{[29,27]}\end{array}$ & $\begin{array}{l}\text { "Environmental factors are: competitor pressure, customer } \\
\text { satisfaction, and marketing approach" }\end{array}$ \\
\hline $\begin{array}{l}\text { organizational } \\
{[29,27]}\end{array}$ & $\begin{array}{l}\text { "Organizational factors include top management support, size, } \\
\text { user involvement, and product champion" }\end{array}$ \\
\hline $\begin{array}{l}\text { compatibility } \\
{[29,155,27]}\end{array}$ & $\begin{array}{l}\text { "Compatibility captures the consistency between an } \\
\text { innovation and the values, experiences, and needs of potential } \\
\text { adopters" } \\
\text { "The more an innovation is recognized as compatible with the } \\
\text { system, the more it would be adopted" }\end{array}$ \\
\hline $\begin{array}{l}\text { perceived cost } \\
{[155]}\end{array}$ & Premium pricing, services and transaction costs \\
\hline Costs [101] & Premium pricing, services and transaction costs \\
\hline $\begin{array}{l}\text { Perceived cost } \\
\text { saving [91] }\end{array}$ & $\begin{array}{l}\text { "Referred to an individual's perception about the way that } \\
\text { mobile wireless technology (MWT) provided cost-effective } \\
\text { communication and information exchange. Costs include more } \\
\text { than monetary factors, e.g., time and emotional effort" }\end{array}$ \\
\hline $\begin{array}{l}\text { company } \\
\text { willingness to } \\
\text { fund }[91]\end{array}$ & $\begin{array}{l}\text { "Defined here as the degree to which a company believes that } \\
\text { funding would enhance an individual's adoption of MWT" }\end{array}$ \\
\hline Task [29]. & $\begin{array}{l}\text { Task was defined broadly as "the action carried out by } \\
\text { individuals in turning inputs into outputs" }\end{array}$ \\
\hline $\begin{array}{l}\text { Task-technology } \\
\text { fit [95] }\end{array}$ & $\begin{array}{l}\text { Task-technology fit TTF is defined as the degree to which a } \\
\text { technology assists an individual in performing his or her } \\
\text { portfolio of tasks. }\end{array}$ \\
\hline Enjoyment [166] & \multirow{2}{*}{$\begin{array}{l}\text { Perceived enjoyment is defined as the extent to which the } \\
\text { activity of using a specific system is perceived to be enjoyable } \\
\text { in its own right, aside from any performance consequences }\end{array}$} \\
\hline $\begin{array}{l}\text { Perceived } \\
\text { enjoyment [166] }\end{array}$ & \\
\hline
\end{tabular}


resulting from system usage [166].

\subsection{Research Gaps}

Research objectives were identified and explained in Chapter One of this dissertation. The research gaps and questions are clarified below. As explained in the literature review (Chapter Two) scholars from different fields and with diverse interests recognize the important role of the Smartphone technology in the evolution of information technology and its related domains. Many research studies have been conducted to explain the adoption and use of the Smartphone technology as shown in the literature review provided earlier in this chapter. However, a number of research gaps were identified including those described below:

- Most of the empirical research that was previously reviewed in the literature review mentioned earlier focused only on limited aspects of the factors that influence users' adoption and use of the Smartphone technology, such as studying only the fun aspects of using the Smartphone [24], or only the effects of the enjoyment aspect on the adoption of the Smartphone [25]. Moreover, many of the empirical research studies that were previously reviewed focused only on one specific type of users such as studying the adoption of smartphones among medical doctors and nurses[27, 169], among college students [42] and among older adults [98].

- Many researchers studied the Smartphone as if it were a tool to be used in executing a specific task; i.e., the use of smartphones in the healthcare sector 
and in delivery services $[164,29,26,123]$. It is felt that studying only a limited number of factors that influence users' adoption and use of Smartphone technology will result in neglecting other important factors that may have an equally important influence. The literature indicates that examining only limited characteristics of a technology makes it harder to gain a complete perspective and it is more appropriate to examine and compare as many characteristics as reasonable within the same research [31]. Therefore, it is appropriate to study the key factors that influence general users' adoption and use of the Smartphone in a holistic and comprehensive manner.

- Researchers have mentioned the important influence of characteristics of both the individual and the innovation on the users' acceptance and use of a technology [77]. The literature indicates that there is a lack of theoretical models, which can provide an appropriate link between individual and innovation to offer a better perspective of the links between user acceptance and use of technology [77]. Most of the empirical research studies related to the adoption of the Smartphone technology have applied the Technology Acceptance Model (TAM). However, a number of scholars indicated that TAM is able to explain only about $40 \%$ of variances in technology acceptance [82]. Moreover, several researchers have specified some limitations in the 
TAM model and highlighted the need for adding more variables to the model, especially as related to human and social factors[92].

- It has been indicated that there is a need for more empirical research to identify the key factors that influence user behavioral intention to adopt and use the Smartphone technology in a comprehensive manner [49-51]. Moreover, there is a lack of research that studies and investigates the key factors that influence the acceptance and use of Smartphone technology, particularly in Saudi Arabia [52, 53, 14, 54].

\subsection{Research Questions}

The impacts of the Smartphone technology on the way that information is distributed, consumed, and created are obvious. They affect the IT domain and its ecosystem. The previous discussion makes it clear that there is an increased need for more empirical research to better understand general users and identify the key factors that influence users' intention to adopt and use the Smartphone technology, and that this information is especially limited in Saudi Arabia. To address some of these research gaps, the author is interested in conducting empirical research to explore the key factors that influence users' adoption and use of Smartphone technology, with a focus on the Saudi Arabian market.

Based on an extensive literature review and existing theoretical models a research model was developed. The model was then modified based on the utilization of qualitative methods including a brainstorming session, a focus group and individual 
face-to-face interviews. This modified model was used in this dissertation to better explore and understand key factors that may have a relationship with users' intention to adopt and use Smartphone technology, especially in Saudi Arabia. The following research questions have been identified to address the research gaps:

Q1: What are the key factors that are associated with general users' behavioral intention to adopt and use the Smartphone technology in Saudi Arabia?

Q2: How can general users' experience with the Smartphone technology be enhanced in Saudi Arabia?

Table 4 (below) provides a summary and shows connections between research gaps, objectives and questions which was explained in more detail above. 
Table 4: Summary of the Research Gaps, Objectives and Questions (explained in more details above)

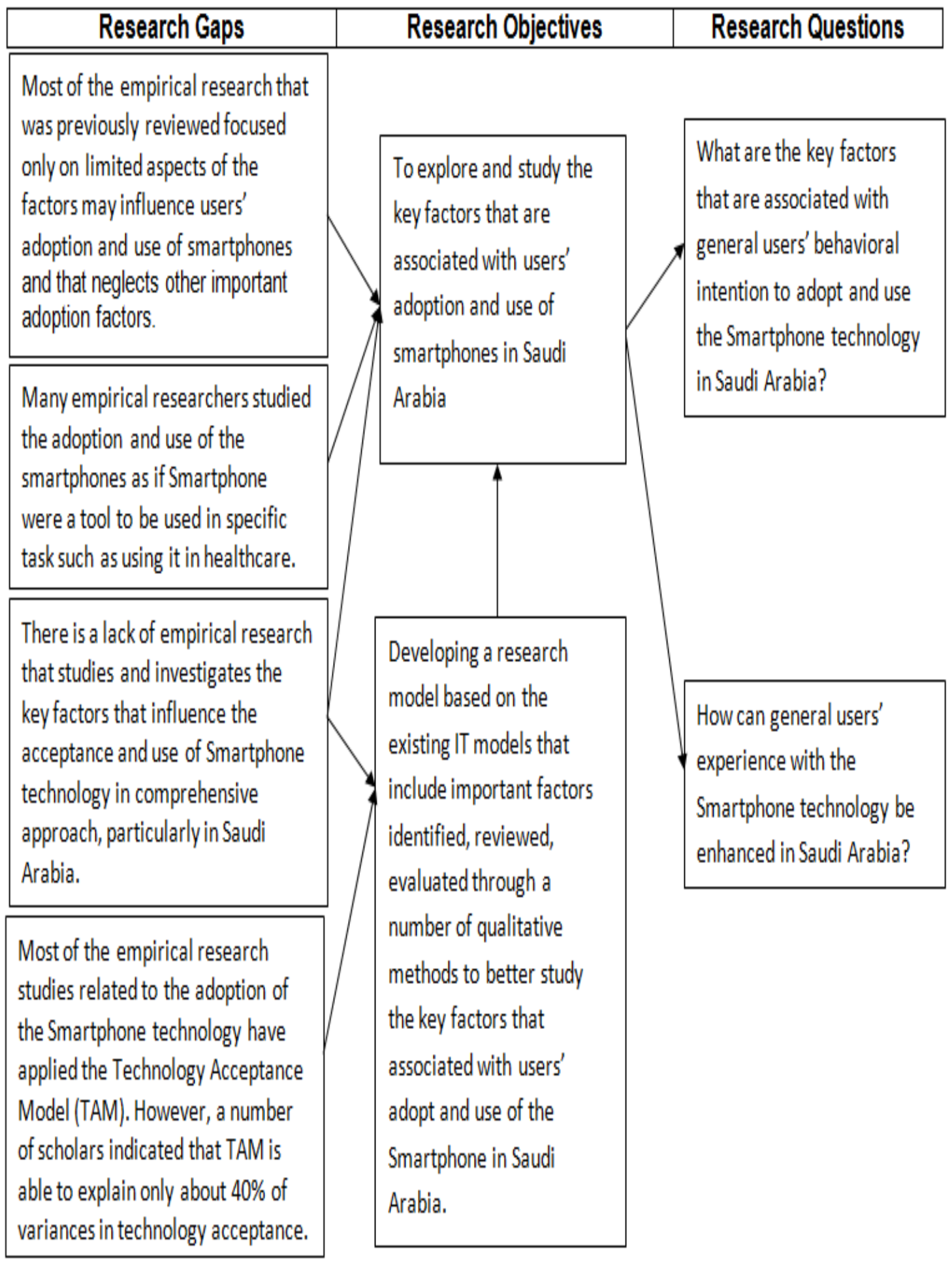




\section{Chapter Three: Developing Research Model and Research Hypotheses}

Sekaran suggested identifying factors that were determined as important by previous research, accompanied with rational relationships and connections that can be logically conceptualized [165]. These factors should be used to form the basis of a theoretical research framework or model with taxonomy of factors identified in previous research as important, and which may have relationships with the users' adoption and use of Smartphone technology. These factors were classified under five main factors, namely: technology characteristics and performance, effort factors, social influence factors, facilitating condition, and hedonic factors. Table 5 below presents the five main factors and the factors that were integrated directly or indirectly into each main factor from previous model. 
Table 5: Adoption factors derived through literature review

\begin{tabular}{|c|c|c|}
\hline Main Factors & $\begin{array}{l}\text { Attributes integrated into } \\
\text { the main factors from } \\
\text { previous models }\end{array}$ & $\begin{array}{l}\text { Factors related to adoption and user } \\
\text { of Smartphone that were identified } \\
\text { in previous research }\end{array}$ \\
\hline $\begin{array}{l}\text { Technology } \\
\text { Characteristics } \\
\text { \& Performance }\end{array}$ & $\begin{array}{l}\text {-Perceived usefulness [29, } \\
167,49,155,126,25,82] \\
\text {-Job Relevancies }[105,126] \\
\text {-Relative advantage [156]. }\end{array}$ & $\begin{array}{l}\text { Perceived ubiquity [168, 105]. } \\
\text { Perceived reachability [105]. } \\
\text { Mobility [65]. } \\
\text { Accuracy [168]. } \\
\text { Controllability [156]. } \\
\text { Security [156]. } \\
\text { Perceived availability [167, 126]. } \\
\text { Perceived quality [126]. } \\
\text { Content [101, 65]. } \\
\text { Screen size [101]. } \\
\text { Service speeds [65]. } \\
\text { Multimedia [49]. } \\
\text { Applications [49]. } \\
\text { Wireless Internet [49]. } \\
\text { Task [29, 27, 154]. }\end{array}$ \\
\hline Effort Factors & $\begin{array}{l}\text {-Ease of Use }[167,49,155, \\
27,126] . \\
\text {-Effort expectancy [156]. }\end{array}$ & $\begin{array}{l}\text { Simplicity [101]. } \\
\text { Design [49]. } \\
\text { Complexity [156]. }\end{array}$ \\
\hline $\begin{array}{l}\text { Social Influence } \\
\text { Factors }\end{array}$ & & $\begin{array}{l}\text { Self-efficacy [27]. } \\
\text { Social norm [90]. } \\
\text { Social pressure [126]. }\end{array}$ \\
\hline $\begin{array}{l}\text { Facilitating } \\
\text { Conditions }\end{array}$ & $\begin{array}{l}\text {-Compatibility [27, 126]. } \\
\text {-Behavior control [90]. }\end{array}$ & $\begin{array}{l}\text { Perceived security [156]. } \\
\text { Environments }[29,27] . \\
\text { Organizational }[29,27] . \\
\text { Compatibility }[29,155,27] . \\
\text { Internal environment }[126] . \\
\text { External environment [126]. } \\
\text { Perceived cost [155]. } \\
\text { Cost [101]. } \\
\text { Perceived cost saving [91]. } \\
\text { Perceived fee [170] } \\
\text { Company willingness to found [91]. }\end{array}$ \\
\hline $\begin{array}{l}\text { Hedonic } \\
\text { Factors }\end{array}$ & & $\begin{array}{l}\text { Enjoyment [65]. } \\
\text { Perceived enjoyment [126, 171, 90]. } \\
\text { Fun [24]. } \\
\text { Entertainment utility [42]. }\end{array}$ \\
\hline
\end{tabular}


Two primary steps have been conducted in this research to develop a suitable research model:

(1) To build the research model based on a suitable existing adoption model that has an adequate theoretical basis; and

(2) To identify related factors that may have associations with users' adoption of smartphone technology and can be used to modify the research model.

After reviewing many related research studies and theoretical models, the UTAUT appeared to be the most suitable theoretical model as a basis for this research model. Through an extensive literature review, more than forty Smartphone adoptionrelated factors were initially identified. These factors were quantitatively and qualitatively reviewed, evaluated, filtered and validated to select the factors to be included in this research model.

There are a number of methods that have been used to help researchers evaluate, validate and select the most important factors out of a list of factors. Quantitative approaches such as statistical analysis, including factor analysis, can be used to select and reduce the number of factors. A factor analysis technique, such as exploratory factor analysis (EFA), can be utilized to filter and reduce the set of factors identified. Scholars recommend using EFA when trying to work with variables/factors that have no theoretical or hypothesis basis [172]. However, when the source of factors 
under consideration is based on existing theory or a literature review, such as the set of factors identified in this dissertation, EFA may not be an effective approach to reducing and selecting the more important factors [173]. Scholars indicated that, to overcome some of the EFA limitations, the researcher must thoughtfully apply sound judgment to factor reduction and selection [174].

Qualitative analysis is another method that can be used to filter and select the more important factors among a set of factors. Qualitative methods such as brainstorming, focus groups, and individual interviews have been widely used to obtain an individual's personal perspective and opinions regarding an issue under consideration [175]. Qualitative methods can be very useful to obtain opinions and perspectives of users' experience with smartphones, for both personal and work sectors. This is the preferred method of selecting the more related factors to be used in developing and modifying the research model, since the factors identified are based on existing theories and identified through the literature review. Therefore, qualitative methods such as brainstorming sessions, focus groups and individual interviews were conducted to aid in reviewing, evaluating, validating and selecting the more related factors to be used in modifying the research model.

A theoretical model can be developed through a literature review of the previous research related to the subject under consideration and through conducting interviews with people who are knowledgeable of the specific subject [165]. In the present case, a literature review was conducted to explore research related to the 
adoption of the Smartphone technology. A number of factors related to the adoption and use of the Smartphone were identified. In addition to the literature review, the researcher employed a number of qualitative methods namely: brainstorming, a focus group, and individual interviews as summarized in Table 6 below.

Table 6: Summary of descriptions steps conducted to develop the research model

\begin{tabular}{|c|c|c|c|}
\hline Research step & $\begin{array}{l}\text { Number of } \\
\text { Participants }\end{array}$ & Description & Targeted participants \\
\hline $\begin{array}{l}\text { Literature } \\
\text { Review }\end{array}$ & & $\begin{array}{l}\text { Extensive literature review } \\
\text { conducted and taxonomy of } \\
\text { factors related to the adoption } \\
\text { and use of Smartphone } \\
\text { developed. }\end{array}$ & \\
\hline Brainstorming & 6 & $\begin{array}{l}\text { A brainstorming session was } \\
\text { conducted with experienced } \\
\text { users of smartphones and } \\
\text { individuals who have work } \\
\text { experience in organizations and } \\
\text { sectors related to smartphone } \\
\text { technology. }\end{array}$ & $\begin{array}{l}\text { Experienced users of } \\
\text { Smartphone and } \\
\text { individuals who have } \\
\text { work experience in } \\
\text { organizations and } \\
\text { sectors related to } \\
\text { Smartphones }\end{array}$ \\
\hline Focus Group & 7 & $\begin{array}{l}\text { A focus group session was } \\
\text { conducted with experienced } \\
\text { users of smartphones and } \\
\text { individuals who have work } \\
\text { experience in organizations and } \\
\text { sectors related to smartphone } \\
\text { technology. }\end{array}$ & $\begin{array}{l}\text { Experienced users of } \\
\text { Smartphone and } \\
\text { individuals who have } \\
\text { work experience in } \\
\text { organizations and } \\
\text { sectors related to } \\
\text { smartphone } \\
\text { technology. }\end{array}$ \\
\hline Interviews & 20 & $\begin{array}{l}\text { The interviews conducted were } \\
\text { face-to- face, semi-structured, } \\
\text { individual interviews. They were } \\
\text { conducted with experienced } \\
\text { users of the smartphones and } \\
\text { individuals who have work } \\
\text { experience in organizations and } \\
\text { sectors related to smartphone } \\
\text { technology. }\end{array}$ & $\begin{array}{l}\text { Experienced users of } \\
\text { Smartphone and } \\
\text { individuals who have } \\
\text { work experience in } \\
\text { organizations and } \\
\text { sectors related to } \\
\text { smartphones } \\
\text { technology. }\end{array}$ \\
\hline
\end{tabular}

The objective of using these qualitative methods is to explore and introduce new factors that may not have been covered in the literature review, and to review, 
evaluate, validate and select the factors that are most associated with users' adoption and use of the Smartphone. These qualitative methods have been used in many studies in different disciplines including research related to IT adoption [176], in research related to the healthcare sector [177] , in research related to the education sector [178] and many more.

Experienced users of the Smartphone with different education levels and different working backgrounds can be valuable sources providing more insight into the factors that may have a relationship with users' adoption and use of the Smartphone. Also, individuals who work in the Smartphone industry and its related sectors can be a valuable source that could provide useful information about factors associated with users' adoption and use of the Smartphone. Therefore, the researcher has targeted experienced users of the Smartphone from different backgrounds and individuals who work in the Smartphone industry and its related sectors. They have been invited to participate in the brainstorming, focus group and individual interviews based on the need for each method. The researcher used a number of approaches to identify and find possible participants including visiting related organizations, sectors, and industries as well as other options such as the Snowball method [179]. The researcher has identified a number of sectors related to the Smartphone industry and visited them in person. The Snowball method is a popular approach that has frequently been used in research which involved individual experts who identify or refer other experts [179]. 


\subsection{Brainstorming}

Brainstorming is defined as "group sessions in which people share ideas on some issue or problem" [180]. Brainstorming can be thought of as a means to increase creativity by generating a wide range of ideas regarding solving or discussing a particular issue $[181,182]$. Brainstorming approaches have been used by a number of scholars to introduce and evaluate factors related to mobile technologies [176]. The brainstorming session aims to gather as many ideas and thoughts as possible related to the issue under consideration [183]. There are a number of general rules usually applied in the process of conducting a brainstorming session including [183]:

- Focus on quantity: Participants are encouraged to come up with any thoughts or ideas related to the issue.

- Withhold criticism: Participants should not be judged or criticized on their ideas and thoughts.

- Welcome unusual ideas.

- Combine and improve ideas: All ideas and thoughts should be combined, discussed and improved.

The aim of this brainstorming session was to obtain experienced users' creative ideas and thoughts regarding introduction of new factors that may have a relationship with users' adoption and use of the Smartphone and to evaluate the identified factors. 


\section{Brainstorming plan}

Experienced Smartphone users from different backgrounds, who have been using the Smartphone for at least three years, and individuals who have work experience in sectors related to smartphones technology have been targeted, contacted and invited to participate in this brainstorming session. (Please see invitation in Appendix A). The researcher has contacted all individuals who agreed to participate in the brainstorming session and provided them with all details related to the issue under consideration to ensure that all participants understand and agree with the aim of the brainstorming session (please see the email of the details in Appendix A).

Experts recommend having six to ten participants in a brainstorming group to obtain a balance between control and productivity $[184,175]$. Therefore, this researcher recruited six participants when conducting the brainstorming session. Scholars mentioned the value of having participants with diversified backgrounds, which could bring alternative views and more insight into the issue under consideration [180]. Therefore the researcher targeted experienced users of Smartphones with varied backgrounds. All participants were contacted to schedule a convenient meeting time and place. Once all participants agreed on the time and place for the meeting, the researcher contacted each participant to confirm the date, time and place for the brainstorming session. The brainstorming session was expected to take about an hour to be completed. All needed material such as pencils, papers and light refreshments were 
provided and distributed among participants by the researcher. A brief presentation was prepared, which included an introduction to the research, issues to be discussed, and brief descriptions of the brainstorming session and what is expected of participants. The researcher provided participants with a hard copy that included more explanation of the subject under consideration as well as the process of brainstorming and how it should proceed. The researcher developed a tool to be used by participants to provide their answers, ideas and point of view.

Participants in the brainstorming session were expected to share thoughts and ideas regarding important factors that they believe are associated with users' adoption and use of the Smartphone as well as review, evaluate and validate the existing factors provided to them. Discussion and thoughts in the brainstorming session revolved around three main questions that were provided to the participants:

Q1: Participants were asked take around five minutes to review the list of factors that were provided to them. After the five minutes, participants were asked (1) to state their thoughts and opinions about these factors; and, (2) if they knew of any new relevant factors that may have a relationship with users' intention to adopt and use Smartphone technology that are not mentioned on the provided list.

Q2: Participants were then asked to review the list of factors provided including the new factors generated from step one, and remove any factors that they believe are similar or duplicated to narrow the list down to only the more important factors. 
Q3: Participants were asked to brainstorm further in order to re-evaluate and validate all factors including those originally provided to them in the preliminary research model. They were then asked to link the selected most important factors.

\subsection{Focus Group}

Scholars indicate that there is value in using a variety of qualitative approaches. Also, they mentioned the usefulness of combining in-depth interviews and focus group approaches [175]. The focus group interview technique can be utilized as a way to raise and explore relevant key issues related to the subject under consideration and has been used extensively in many fields. The identified issues can then be discussed more fully using in-depth individual interviews $[185,175]$. Therefore, the author conducted a focus group session to obtain participants' opinions and perspective about factors that are closely associated with users' intentions to adopt and use Smartphone technology and explore new factors that are not found in the list of factors derived from literature. The focus group session is typically conducted to obtain participants' impressions, points of view, and opinions as the participants are invited to discuss and talk about a specific issue [165].

\section{Styles of focus group and preparations [186]:}

Moderators use a variety of styles when conducting focus groups. These styles may differ based on the degree of control used, ranging from nondirective to extremely 
directive. In the nondirective style the moderator or researcher starts the discussion and only participates when necessary to make sure that the discussion is kept on track. In contrast, in the extreme directive style the only exchange is between the moderator or researcher and one group participant at a time. In this study, the researcher acted as moderator for the focus group and used a moderate control approach or style rather than the extreme. The researcher started the discussion, introduced the topic and talked about the aim of the focus group session and what information was needed.

A brief presentation was prepared that included a brief introduction to the research, issues to be discussed and brief descriptions of the focus group session and the expectations of participants in this session. The researcher provided each participant with a hard copy document with information related to the subject under concentration, the main questions that focus groups should be discussing, and space to write notes regarding their final selections.

\section{Size of the focus group $[184,175]$ :}

It is recommended that a focus group have between six to ten participants to allow the researcher or moderator to have reasonable control on the discussion and sustain the discussion. Having more than ten participants may negatively affect the moderator's ability to maintain firm control of the group discussion, while having less than six may not support a sustained discussion. As recommended, the author obtained six participants when conducting the focus group session for this research. 
The researcher targeted experienced users of Smartphone and individuals who have work experience in organizations and sectors related to smartphone technology. Targeted potential participants were contacted and invited to participate in the focus group session. Participants who agreed to participate were provided with more details related to the research and the issue to be discussed in the focus group session as shown in Appendix B.

\subsection{Individual Interviews}

After completing the focus groups, in-depth individual interviews were conducted. The target participants were experienced users of Smartphone technology and individuals who were currently working in organizations and sectors related to smartphone technology. Each interviewee was provided with the list of factors that were developed through the literature review, brainstorming sessions and focus group sessions. They were asked a number of questions regarding their perspective about the identified factors and they were asked to carefully review, filter, select and validate the most important factors that are most associated with users' intentions to adopt and use the Smartphone.

Interviews are a qualitative research method used to collect data and are defined as a type of conversation with purpose [175]. Individual in-depth interviews primarily provide an opportunity for the researcher to obtain more detailed investigation on each individual's personal perspective about the issue under consideration and are one of the most widely used methods in qualitative research 
[175]. There are two main types of interviews, unstructured and structured. There are a number of ways that interviews can be conducted including, face-to-face, telephone, chat/messaging, and online, and so on [165].

Unstructured interviews aim to introduce new issues so that the researcher can determine what aspects need more in-depth exploration [165]. When conducting unstructured interviews, usually the researcher begins the interview with no specific sequence of questions to ask the participant and uses answers to guide the interview content towards new material [165]. In structured interviews, the researcher knows what information is needed and uses predetermined questions to explore certain areas of content that are specifically interesting to the study [165]. The interviews conducted for this research study were semi-structured in that the researcher had a number of questions that were the focus of the interviews but allowed for follow-up on any new thoughts uncovered in the interview process. (Please see the questions as shown in Appendix C). The interviews were intentionally more flexible so that the interviewee had the time and opportunity to reflect on the whole issue and on each question as needed.

Scholars mentioned a number of stages that are usually followed when conducting interviews including [175]:

\section{- Arrival}

The arrival stage can be a very important, allowing the researcher to welcome the interviewee and establish a good relationship. The researcher's role at this stage is 
to try to make the interviewee feel more comfortable, confident and relaxed. He should avoid any conversation about the research topic until the interview begins.

\section{- Introducing the Research}

At this stage the researcher starts introducing the research topic, background, purpose, and making sure that the environment is appropriate and quiet so the interview can be conducted without any distractions.

\section{- Beginning the Interview}

Most interviews begin by asking personal demographic questions such as age and status. These first questions can be an opportunity to obtain important contextual information. In this stage it is possible for the researcher to set the scene of the interview and get a sense of the background and skills the interviewee brings to the table along with the possibility of more detailed information.

\section{- During the Interview}

The researcher should guide the interviewee through the issues under consideration and their key themes. Any interesting point can be explored in more depth by asking the interviewee additional questions and requiring more details.

\section{- Ending the Interview}

It is important at this stage to check for anything related to the issue under consideration that was not mentioned during the interview. A few minutes before the end of the interview, the researcher can start gradually bringing the conversation into a general conversational level as a signal that the interview is ending. 
The researcher followed these recommended stages when conducting individual interviews for this research, anticipating an optimal outcome of the interviews.

\section{- Forming the interview questions [175]:}

The objective of conducting in-depth interviews is to obtain wider coverage of and deeper insights into the key issues under consideration. To achieve this, two main types of questions are recommended: content mapping questions and content mining questions, which can be combined and used in conducting the interview. Content mapping refers to questions that aim to define the territory of the issue, identify the issue boundaries and raise related (possibly new) issues. Content mining questions aim to explore key issues in more detail.

The aim of the interviews in this research was to obtain the participants' deep perspectives and thoughts about the key factors they believe are associated with adoption and use of Smartphone technology. Experienced users of the Smartphone and individuals working in sectors related to the Smartphone industry have been targeted and invited to participate in this interview (please see the invitation presented in Appendix C). The targeted participants were contacted by phone, email or in person and invited to participate. The time and place of the interview was scheduled at their convenience. Documents that include all related details have been handed to each interviewee in person or sent by email. The researcher thanked each participant for participating in the interview process and provided them with details about the issues 
discussed (please see email presented in Appendix C). They may also be provided with results when the study is complete, if desired.

Based on the literature review, results of the brainstorming session, focus group and the individual interviews, the preliminary research model was modified. Factors that were selected as important by at least two thirds of the participants in the brainstorming, focus group and interviews were included in the research model and the research model has been modified accordingly [187].

A theoretical model can be developed through a literature review of previous research related to the subject and through conducting interviews with the people who are knowledgeable of the specific subject under consideration [165]. Such a literature review was conducted to identify and explore research related to the adoption of Smartphone technology as shown earlier in this research. In addition, the researcher employed a number of qualitative methods namely: brainstorming, focus groups and individual interviews as shown in Table 7 below. The purpose of using these methods was to explore and introduce new factors that were not covered in the literature review and to review, filter and select the important factors that are most closely associated with users' adoption and use of Smartphone technology. Qualitative methods have been used by many researchers in different disciplines including research related to IT adoption [176], healthcare [177], education, and many other disciplines [178].

Experienced users of the Smartphone with different work backgrounds are a valuable resource that can provide more insight into the factors that may have a 
relationship with users' adoption and use of the Smartphone. Also, individuals who work in the Smartphone industry and its related sectors can be a valuable source of valuable information about factors associated with users' adoption and use of the Smartphone. Therefore, the researcher targeted experienced users of the Smartphone from different backgrounds and individuals who work in the Smartphone industry and its related sectors.

Table 7: Summary of the steps conducted to develop the research model

\begin{tabular}{|c|c|c|}
\hline Research step & Description & Targeted participants \\
\hline $\begin{array}{l}\text { Literature } \\
\text { Review }\end{array}$ & $\begin{array}{l}\text { An extensive literature review has } \\
\text { been conducted and taxonomy of } \\
\text { factors related to the adoption and } \\
\text { use of Smartphone technology was } \\
\text { developed. }\end{array}$ & \\
\hline Brainstorming & $\begin{array}{l}\text { A } 70 \text {-minute brainstorming session } \\
\text { was conducted with six participants. }\end{array}$ & \multirow{3}{*}{$\begin{array}{l}\text { Experienced users of } \\
\text { Smartphone ( with at } \\
\text { least } 3 \text { years of usage) } \\
\text { and individuals who } \\
\text { work in Smartphone } \\
\text { industry and its related } \\
\text { sectors }\end{array}$} \\
\hline Focus Group & $\begin{array}{l}\text { A } 1 \text { hour focus group session was } \\
\text { conducted with } 7 \text { participants. }\end{array}$ & \\
\hline Interviews & $\begin{array}{l}\text { Face to face individual interviews } \\
\text { were conducted with } 20 \text { participants. } \\
\text { Interviews took } 15 \text { to } 50 \text { minutes } \\
\text { each. }\end{array}$ & \\
\hline
\end{tabular}

\subsection{Conducting Brainstorming session}

Brainstorming is a useful approach that has been used as a means to initiate and establish creativity and stimulate thinking to generate a wide range of ideas. It is used to explore potential solutions, discuss options and consequences, or deal with a given 
issue [181, 182]. Researchers have utilized brainstorming to introduce and evaluate factors related to mobile technologies [176]. Conducting a brainstorming session is a great approach to gather a wide range of ideas and thoughts regarding an issue under consideration [183]. The purpose of conducting the brainstorming session in this research is: 1) to obtain experienced users' opinions, creative ideas and thoughts; 2) to introduce new factors that may have relationship with users' adoption and use of the Smartphone; and to evaluate and validate factors identified in the literature review.

After inviting participants and obtaining their agreement on the time and place, the researcher visited the Hillsboro main library and reserved a conference room to conduct the brainstorming session (see reservation conformation email in Appendix A). However, the first attempt to form and conduct a brainstorming session had to be cancelled and postponed because of unexpected changes in a number of participants' schedules. The second attempt was successful and the number of participants was sufficient to accomplish a productive session. The researcher arrived at the reserved conference room one hour before the starting time to prepare all needed materials and set up a selection of light beverages for the participants.

The brainstorming session started with a brief presentation in which the researcher welcomed the participants and introduced himself and his research (Appendix A). A brief explanation of the main purpose of the brainstorming session was given and the participants were asked to introduce themselves before starting the actual discussion. 
The three main research questions mentioned earlier were the focus of the discussion. These questions helped define the boundaries of the discussion. The researcher led the group discussion, working to maintain productivity, focus and group synergy during the session. An interesting and informative interaction took place among the participants as they shared thoughts and ideas regarding factors that could influence users' adoption and use of Smartphone technology. Participants reviewed and evaluated a list of factors developed from the literature review combined with some factors newly introduced through the discussion process. They selected and validated specific factors for inclusion in the research model.

During the meeting a white board had been used to outline participants' statements, comments, agreements, and disagreements. This visual aid helped to keep the discussion on track and assisted in reaching conclusions. All participants participated actively in the discussion. The hard copy of the questions and lists provided to each participant plus notes of additional factors were then used to identify their selections for the final cut. Each participant made his/her own final decision as to which factors to validate and select. The researcher took notes during the whole meeting and documented the final conclusions.

The researcher closed the session by asking the participants if they had any final thoughts or comments and then he thanked them and expressed his appreciation for their participation in the session. Participants seemed very excited to participate and showed their interest in the Smartphone technology and how it is rapidly evolving. The 
brainstorming session was conducted with six participants and it took around an hour and ten minutes. Table 8 below presents participants in brainstorming session.

Table 8: Participants in the Brainstorming session

\begin{tabular}{|c|c|c|c|}
\hline Participants & $\begin{array}{c}\text { Affiliation/ } \\
\text { Title/Experience }\end{array}$ & $\begin{array}{l}\text { Years of using } \\
\text { Smartphone }\end{array}$ & Method \\
\hline 1 & $\begin{array}{l}\text { Tyfone Corporate/ } \\
\text { Electrical engineer, Software } \\
\text { designer. /Developing } \\
\text { hardware and software related } \\
\text { to security of mobile devices } \\
\text { including smartphones }\end{array}$ & $\begin{array}{l}\text { More than } 5 \\
\text { years }\end{array}$ & $\begin{array}{l}\text { Brainstorming } \\
\text { Session }\end{array}$ \\
\hline 2 & $\begin{array}{l}\text { Anonymous / } \\
\text { Marketing Analyst./ Knowledge } \\
\text { related to marketing of } \\
\text { portable devices including of } \\
\text { tablets smartphones }\end{array}$ & $\begin{array}{l}\text { More than } 4 \\
\text { years }\end{array}$ & $\begin{array}{l}\text { Brainstorming } \\
\text { Session }\end{array}$ \\
\hline 3 & $\begin{array}{l}\text { Anonymous / } \\
\text { Retail Store Associate/ } \\
\text { smartphone sale consultant }\end{array}$ & $\begin{array}{l}\text { More than } 5 \\
\text { years }\end{array}$ & $\begin{array}{l}\text { Brainstorming } \\
\text { Session }\end{array}$ \\
\hline 4 & $\begin{array}{l}\text { Anonymous / Software } \\
\text { developers- mobile banking } \\
\text { apps. / Software validation; } \\
\text { Quality Assurance Engineer. }\end{array}$ & $\begin{array}{l}\text { More than } 5 \\
\text { years }\end{array}$ & $\begin{array}{l}\text { Brainstorming } \\
\text { session }\end{array}$ \\
\hline 5 & $\begin{array}{l}\text { Healthcare IT. Kaiser } \\
\text { Permanente / IT specialist }\end{array}$ & $\begin{array}{l}\text { More than } 5 \\
\text { years }\end{array}$ & $\begin{array}{l}\text { Brainstorming } \\
\text { Session }\end{array}$ \\
\hline 6 & $\begin{array}{l}\text { IT support sector / Product } \\
\text { Development Engineer Work } \\
\text { with applications related to } \\
\text { smartphone }\end{array}$ & $\begin{array}{l}\text { More than } 5 \\
\text { years }\end{array}$ & $\begin{array}{l}\text { Brainstorming } \\
\text { session }\end{array}$ \\
\hline
\end{tabular}

* Some participants would like to keep their name and their affiliation anonymous 
An example of the discussion during brainstorming session:

Participants thought:

"Durability of the smartphones can be a factor that would be related to users' intention to adopt and use smartphones. Durability of the technology can be a factor that encourage more people adopt it and use it"

Another participant replied, "I think durability and quality are the same and quality is mentioned here in the list of the factors provided to us" the first participant agreed with the thought that quality is the same is durability.

Another participant thought "Social networking is one factor that may drive many people to adopt and use smartphones, smartphones provide users with many way of connecting and networking with other"

A number of participants in the brainstorming session agreed with this thought.

The researcher added this thought into the list and included it in the discussion in the focus group session and the individuals' interviews.

\subsection{Conducting Focus Group Session}

Focus group is a useful qualitative method that can help the researcher obtain valuable data. It is a very valuable approach combined with in-depth individual interviews and focus group approaches [175]. Scholars support the use of focus groups to raise and explore relevant key issues related to the subject and then these key issues can be discussed in more depth using individual interviews [185, 175]. In this research, the focus group session was implemented to obtain participants' opinions and perspectives about identified factors that are associated with users' adoption and use of 
smartphones as well as giving them the chance to introduce new related factors. Focus groups are used extensively in research studies and typically used to obtain participants' impressions, points of view and opinions as the participants are invited to discuss and talk about a specific issue [185] [165].

The researcher targeted possible participants and invited them to this focus group session. The nine individuals who agreed were contacted to set a time and place that was convenient for them; however, two eventually opted out for personal reasons, leaving seven participants. The researcher reserved a conference room the Hillsboro Main Library. He arrived one hour before the starting time, prepared all needed materials, and provided water and light beverages for participants.

The session started with a brief presentation in which the researcher welcoming the participants, introducing himself and his research and giving a brief description of the main aim of conducting the focus group session (see Appendix A). The researcher asked the participants to briefly introduce themselves and their background.

In a group discussion, participants exchanged thought and ideas, reviewed, evaluated and discussed the list of factors provided to them. An interesting, energetic and informative discussion was unleashed among participants that included all factors in the list provided to them. Participants reviewed, evaluated and expressed their thoughts and ideas regarding each of the factors provided to them. The three main questions mention earlier were the focus of the discussion and they helped to create a boundary for the session. 
Participants reviewed and evaluated the list of factors provided to them. They selected and validated a number of factors that they believed were most important to be included in the research model. All participants actively participated, sharing thoughts and ideas. Each participant made his/her final decision to which factors to validate and select, using the hard copy of the focus group questions and factors provided to each participant. The selected factors were included in the research model.

During the focus group session, in addition to the hard copy documents provided to each participant, a whiteboard was used to note participants' statement, comments, agreement, and disagreement and record their conclusions. The researcher also took personal notes during the meeting and documented the final conclusions of the group. The researcher led the group discussion, trying to make it easier and working to maintain productivity and focus and to create group synergy during the session.

The session was closed by asking the participants if they had any final thoughts or comments. The researcher then thanked them and expressed his appreciation for their time and effort. This session took around an hour. The seven participants seemed very excited to participate and showed their interest in the Smartphone technology and its rapid evolution. (See the table 9 of participants below).

An example of a statement by a participant to support his idea:

Performance expectancy factor is certainly one of the most important factors that can influence users' intention to adopt and use smartphones. Smartphones have become more efficient and allow users to do many things without the need for a laptop. 
Many participants agreed. One reply was "I depend on my smartphone to do many things while in the go such as using my email, surfing the net and keeping myself updated constantly"

The final results of focus group session shows that, all participants in the focus group have selected performance expectancy as an important factor that may have an influence on users' intention to adopt and use smartphone technology.

Table 9: Participants in the focus group session

\begin{tabular}{|c|c|c|c|}
\hline Participant & $\begin{array}{l}\text { Affiliation/ } \\
\text { Title / Experience }\end{array}$ & $\begin{array}{l}\text { Years of using } \\
\text { the } \\
\text { Smartphone }\end{array}$ & Method \\
\hline 1 & $\begin{array}{l}\text { Anonymous/(mobile service provider) } \\
\text { Customer services/ smartphones sale } \\
\text { and support }\end{array}$ & $\begin{array}{l}\text { More than } 5 \\
\text { years }\end{array}$ & Focus group \\
\hline 2 & $\begin{array}{l}\text { Tyfone Corporate/ } \\
\text { Electrical engineer, Software } \\
\text { designer/ Developing hardware and } \\
\text { software related to security of } \\
\text { mobile devices including } \\
\text { Smartphones }\end{array}$ & $\begin{array}{l}\text { More than } 5 \\
\text { years }\end{array}$ & Focus group \\
\hline 3 & $\begin{array}{l}\text { Intel Corp. / Manufacturing Tech. / } \\
\text { equipments testing and sorting. }\end{array}$ & $\begin{array}{l}\text { More than } 5 \\
\text { years }\end{array}$ & Focus group \\
\hline 4 & $\begin{array}{l}\text { Anonymous/ IT services - software } \\
\text { analysis- / with background on } \\
\text { software development }\end{array}$ & $\begin{array}{l}\text { More than } 6 \\
\text { years }\end{array}$ & Focus group \\
\hline 5 & $\begin{array}{l}\text { Anonymous / } \\
\text { Marketing Analyst. Knowledge related } \\
\text { to marketing of portable devices }\end{array}$ & $\begin{array}{l}\text { More than } 5 \\
\text { years }\end{array}$ & Focus group \\
\hline 6 & $\begin{array}{l}\text { Intel Corp. } \\
\text { Manufacture Tech. research \& } \\
\text { development }\end{array}$ & $\begin{array}{l}\text { More than } 5 \\
\text { years }\end{array}$ & Focus group \\
\hline 7 & $\begin{array}{l}\text { (Anonymous)/Smartphone devise } \\
\text { Manufacturer/software developer/ } \\
\text { develop and test software for } \\
\text { smartphone }\end{array}$ & $\begin{array}{l}\text { More than } 8 \\
\text { years }\end{array}$ & Focus group \\
\hline
\end{tabular}

*some participants would like to keep their name and their affiliation anonymous 


\subsection{Conducting Individual Interviews}

Individual interviews are a popular qualitative method that has been used widely to conduct in-depth discussions in which more detailed information can be obtained [175]. It is known that in-depth interviews provide an opportunity for researchers to obtain more detailed investigation of each individual's personal perspective about the issue under consideration [175]. After conducting a brainstorming session and a focus group session, as mentioned earlier, the researcher followed up with in-depth individual interviews to obtain more details that could provide a better outcome as recommended by a number of scholars $[185,175]$.

Experienced users of the Smartphone and individuals who work in sectors related to the Smartphone were invited to participate in these individual interviews. The aim of conducting the individual interviews is to obtain participants' deep perspectives, opinions, and evaluations about factors identified in this research and ask them to select and validate the factors that they believe are more associated with users' adoption and use of the Smartphone technology. The place and the time of each interview have been arranged based on the participant's preference.

Each interview started with a brief introduction in which the researcher introduced himself and his research with a brief description of the main aim of conducting the interview. The researcher politely asked each participant to briefly introduce him/herself and give some background information in return. Individual interviews allowed the researcher to engage in a relaxed but in-depth, interesting, and 
informative discussion that included all factors in the list that had been provided to each participant in advance. The three main research questions mentioned earlier helped put boundaries of the discussion; however, getting each participant's personal reactions and conclusions as to which factors were more valid and should be included in the research model was the ultimate goal. A number of participants introduced new factors that they believed had a strong relationship with users' adoption and use of smartphones and had not been previously considered.

The researcher closed the interview by asking the participants if they had any final thoughts or comments on the subject and then he thanked them and expressed his appreciation for their participation in the interview. A total of twenty individual face-toface interviews were conducted ranging from about 20 minutes to 35 minutes each.

An example of one of the individual interviewees' comments:

One interviewee, in supporting his view and explaining the importance of including the brand influence factor into the research model stated: "I believe that brand influence is very important and should be included in the model. A number of smartphone users come to us asking about some features that they are looking for and we told them that the Smartphone device that [you] have does not have or support this feature but if you want to change, and get a smartphone device which is another brand, that device has and supports this feature that you looking for.' Their answer was NO; they are willing to wait for the next generation of the brand that they like, hoping that the new generation of the same brand will have that feature. They would rather wait a longer time on a hope and they are not willing to use any brand other than the one that they believe in". 
Table 10 below presents participants in the individual interviews.

Table 10: Participants in the individual's interviews

\begin{tabular}{|c|c|c|c|}
\hline participants & Affiliation/ Title / Experience & $\begin{array}{l}\text { Years of } \\
\text { using the } \\
\text { Smartphone }\end{array}$ & Method \\
\hline 1 & $\begin{array}{l}\text { (anonymous)Smartphones' software } \\
\text { and applications provider/ tech. } \\
\text { support }\end{array}$ & $\begin{array}{l}\text { More than } \\
10 \text { years }\end{array}$ & $\begin{array}{l}\text { Individual } \\
\text { interview }\end{array}$ \\
\hline 2 & $\begin{array}{l}\text { Sprint Corporation /sale } \\
\text { representative/ Smartphone sales } \\
\text { consultant }\end{array}$ & $\begin{array}{l}\text { More than } 5 \\
\text { years }\end{array}$ & $\begin{array}{l}\text { Individual } \\
\text { interview }\end{array}$ \\
\hline 3 & $\begin{array}{l}\text { T-Mobile/ Retails Store associate/ } \\
\text { Smartphone sales \& customer } \\
\text { supports }\end{array}$ & $\begin{array}{l}\text { More than } 5 \\
\text { years }\end{array}$ & $\begin{array}{l}\text { Individual } \\
\text { interview }\end{array}$ \\
\hline 4 & $\begin{array}{l}\text { T-Mobile/ Retails Store associate/ } \\
\text { Smartphone sales and customer } \\
\text { support }\end{array}$ & $\begin{array}{l}\text { More than } 5 \\
\text { years }\end{array}$ & $\begin{array}{l}\text { Individual } \\
\text { interview }\end{array}$ \\
\hline 5 & $\begin{array}{l}\text { (anonymous)/ Smartphones device } \\
\text { manufacture/ software developer/ } \\
\text { develop and test software for } \\
\text { Smartphones }\end{array}$ & $\begin{array}{l}\text { More than } 8 \\
\text { years }\end{array}$ & $\begin{array}{l}\text { Individual } \\
\text { interview }\end{array}$ \\
\hline 6 & $\begin{array}{l}\text { T-Mobile/ Retails Store associate/ } \\
\text { tech. support }\end{array}$ & $\begin{array}{l}\text { More than } 4 \\
\text { years }\end{array}$ & $\begin{array}{l}\text { Individual } \\
\text { interview }\end{array}$ \\
\hline 7 & $\begin{array}{l}\text { T-Mobile/Associate Retailer, tech. } \\
\text { support sale representative }\end{array}$ & $\begin{array}{l}\text { More than } 5 \\
\text { years }\end{array}$ & $\begin{array}{l}\text { Individual } \\
\text { interview }\end{array}$ \\
\hline 8 & $\begin{array}{l}\text { Wireless Advocates/ sale } \\
\text { representative/ customer support and } \\
\text { consultant }\end{array}$ & $\begin{array}{l}\text { More than } 4 \\
\text { years }\end{array}$ & $\begin{array}{l}\text { Individual } \\
\text { interview }\end{array}$ \\
\hline 9 & $\begin{array}{l}\text { Wireless Advocates/ Customer } \\
\text { services, sales }\end{array}$ & $\begin{array}{l}\text { More than } 5 \\
\text { years }\end{array}$ & $\begin{array}{l}\text { Individual } \\
\text { interview }\end{array}$ \\
\hline 10 & $\begin{array}{l}\text { Wireless Advocates } \\
\text { Customer services/tech. support }\end{array}$ & $\begin{array}{l}\text { More than } 3 \\
\text { years }\end{array}$ & $\begin{array}{l}\text { Individual } \\
\text { interview }\end{array}$ \\
\hline 11 & $\begin{array}{l}\text { AT\&T Mobility/ Store Manager/ } \\
\text { customer consultant }\end{array}$ & $\begin{array}{l}\text { More than } 5 \\
\text { years }\end{array}$ & $\begin{array}{l}\text { Individual } \\
\text { interview }\end{array}$ \\
\hline 12 & $\begin{array}{l}\text { (Anonymous)/ Electrical engineering, } \\
\text { equipment testing and evaluation }\end{array}$ & $\begin{array}{l}\text { More than } 4 \\
\text { years }\end{array}$ & $\begin{array}{l}\text { Individual } \\
\text { interview }\end{array}$ \\
\hline 13 & $\begin{array}{l}\text { (anonymous)/Smartphones' software } \\
\text { and application provider/ tech. } \\
\text { support }\end{array}$ & $\begin{array}{l}\text { More than } 6 \\
\text { years }\end{array}$ & $\begin{array}{l}\text { Individual } \\
\text { interview }\end{array}$ \\
\hline 14 & T-Mobile/ Retail Store Associate/ & More than 5 & Individual \\
\hline
\end{tabular}




\begin{tabular}{|c|l|l|l|}
\hline & smartphone sale and support & years & interview \\
\hline 15 & $\begin{array}{l}\text { (Anonymous)/smartphone device } \\
\text { manufacture/ customer service, tech. } \\
\text { support }\end{array}$ & $\begin{array}{l}\text { More than 5 } \\
\text { years }\end{array}$ & $\begin{array}{l}\text { Individual } \\
\text { interview }\end{array}$ \\
\hline 16 & $\begin{array}{l}\text { (Anonymous)/ smartphones device } \\
\text { manufacturer/ Retails associate/ } \\
\text { customer service }\end{array}$ & $\begin{array}{l}\text { More than 5 } \\
\text { years }\end{array}$ & $\begin{array}{l}\text { Individual } \\
\text { interview }\end{array}$ \\
\hline 17 & $\begin{array}{l}\text { AT\&T Mobility/ sales representative, } \\
\text { tech support customer consultant }\end{array}$ & $\begin{array}{l}\text { More than 5 } \\
\text { years }\end{array}$ & $\begin{array}{l}\text { Individual } \\
\text { interview }\end{array}$ \\
\hline 18 & $\begin{array}{l}\text { AT\&T Mobility/ sales representative, } \\
\text { customer support }\end{array}$ & $\begin{array}{l}\text { More than 5 } \\
\text { years }\end{array}$ & $\begin{array}{l}\text { Individual } \\
\text { interview }\end{array}$ \\
\hline 19 & $\begin{array}{l}\text { Sprint Corporation /store Manager/ } \\
\text { customer support and consultant }\end{array}$ & $\begin{array}{l}\text { More than 6 } \\
\text { years }\end{array}$ & $\begin{array}{l}\text { Individual } \\
\text { interview }\end{array}$ \\
\hline 20 & $\begin{array}{l}\text { Sprint Corporation /sale } \\
\text { representative/ Smartphone sales \& } \\
\text { tech. support }\end{array}$ & $\begin{array}{l}\text { More than 6 } 6 \\
\text { years }\end{array}$ & $\begin{array}{l}\text { Individual } \\
\text { interview }\end{array}$ \\
\hline
\end{tabular}

*Some participants would like to keep their name and their affiliation anonymous

\subsection{Results of the Qualitative methods that have been conducted}

More than forty factors related to the users' adoption and use of Smartphones have been identified through a literature review conducted for this research as shown in table 11 below: 
Table 11: Factors related to the adoption smartphones derived from literature.

\begin{tabular}{|l|}
\hline Factors derived from literature \\
\hline$>$ Performance expectancy \\
\hline$>$ Task Technology Fit \\
\hline$>$ Perceived ubiquity \\
\hline$>$ Perceived reachability \\
\hline$>$ Mobility \\
\hline$>$ Accuracy \\
\hline$>$ Controllability \\
\hline$>$ Security \\
\hline$>$ Perceivedavailability \\
\hline$>$ Perceived quality \\
\hline$>$ Content \\
\hline$>$ Screensize \\
\hline$>$ Servicespeeds \\
\hline$>$ Design \\
\hline$>$ Multimedia \\
\hline$>$ Applications \\
\hline$>$ Wireless Internet \\
\hline
\end{tabular}

\begin{tabular}{|c|c|}
\hline Effort expectancy & \multirow[b]{2}{*}{ Perceivedenjoyment } \\
\hline Simplicity & \\
\hline$>$ Social influence & Computer playfulness \\
\hline Complexity & $>$ Fun \\
\hline Self-efficacy & Entertainmentutility \\
\hline Socialnorm & $>$ After service \\
\hline$>$ Social pressure & Resource capability \\
\hline$>$ Facilitating conditions & \\
\hline$>$ Environments & Experience \\
\hline$>$ Organizational & \\
\hline$>$ Compatibility & \\
\hline$>$ Behavior control & \\
\hline$>$ Pricevalue & \\
\hline$>$ Perceived cost & \\
\hline$>$ Cost & \\
\hline$>$ Perceived costsaving & \\
\hline Company willingness to fund & \\
\hline$>$ Enjoyment & \\
\hline
\end{tabular}

Participants in the qualitative methods that have been conducted have introduced a number of new factors which they believe may have a relationship with users' adoption and use of smartphones. Tables 12 and 13 below summarize methods used, its objectives and factors introduced in each method. 
Table 12: Number of factors introduced in each method

\begin{tabular}{|c|c|c|c|}
\hline Method & Objectives & $\begin{array}{l}\text { Number } \\
\text { of factors }\end{array}$ & $\begin{array}{l}\text { Total of } \\
\text { factors } \\
\text { introduced in } \\
\text { each method }\end{array}$ \\
\hline $\begin{array}{l}\text { Literature } \\
\text { review }\end{array}$ & $\begin{array}{l}\text { Explore, review and Identify factors that } \\
\text { have been identified in previous related } \\
\text { research. }\end{array}$ & 42 & 42 \\
\hline $\begin{array}{l}\text { Brainstorming } \\
\text { session }\end{array}$ & $\begin{array}{l}\text { Gather as many ideas and thoughts that } \\
\text { can introduce new factors. Also, } \\
\text { evaluate, review validate and select the } \\
\text { more related factors that should be } \\
\text { included in the research model. }\end{array}$ & 6 & 48 \\
\hline $\begin{array}{l}\text { Focus group } \\
\text { session }\end{array}$ & $\begin{array}{l}\text { The main objective of conducting a } \\
\text { focus group is to obtain participants' } \\
\text { impressions, feelings, points of view and } \\
\text { opinions on the factors identified } \\
\text { through literature review and } \\
\text { brainstorming session. Discussion } \\
\text { among participants should encourage } \\
\text { participants to refine their perception } \\
\text { Also, they were asked to introduce new } \\
\text { factors if they have any. }\end{array}$ & 1 & 49 \\
\hline $\begin{array}{l}\text { Individual } \\
\text { interviews }\end{array}$ & $\begin{array}{l}\text { To obtain individuals' perspective, point } \\
\text { of view, and opinion on the factors } \\
\text { identified through literature review, } \\
\text { brainstorming and focus group. Also, } \\
\text { participants were asked to introduce } \\
\text { new factor that were not previously } \\
\text { identified. }\end{array}$ & 3 & 52 \\
\hline
\end{tabular}


Table 13: New factors introduced by participants in the qualitative methods

\begin{tabular}{|c|c|c|}
\hline Method & New factors introduced & $\begin{array}{c}\text { Number of } \\
\text { participants selected } \\
\text { the same factor }\end{array}$ \\
\hline $\begin{array}{l}\text { Brainstorming } \\
\text { session }\end{array}$ & Reliability & 18 \\
\hline $\begin{array}{l}\text { Brainstorming } \\
\text { session }\end{array}$ & Social networking & 7 \\
\hline $\begin{array}{l}\text { Brainstorming } \\
\text { session }\end{array}$ & Marketing (advertisement) & 5 \\
\hline $\begin{array}{l}\text { Brainstorming } \\
\text { session }\end{array}$ & Usability & 10 \\
\hline $\begin{array}{l}\text { Brainstorming } \\
\text { session }\end{array}$ & Integration & 3 \\
\hline $\begin{array}{l}\text { Brainstorming } \\
\text { session }\end{array}$ & Operating System & 8 \\
\hline Focus group session & perceived convenience & 8 \\
\hline Individual interview & connectivity & 1 \\
\hline Individual interview & Screen Type & 1 \\
\hline Individual interview & Innovation & 2 \\
\hline
\end{tabular}

Table 13 and Figure 6 below show each participant's selection in each method of the three qualitative methods conducted. In the qualitative methods conducted herein each participant is allowed to select any factor only once. When a participant selects a 
factor it is counted number one and factors that are not selected are counted as zero or left empty. (Table 14 and figure 6 below present experts' selections).

There were a total of thirty three participants; six participants in the brainstorming session, seven participants in the focus group session and twenty participants in the individual face-to-face interviews. Eight factors that were selected by at least two-thirds (22) of the participants in the qualitative methods have been included in the research model: performance expectancy, effort expectancy, social influence, brand influence, economic factors, facilitating conditions, perceived enjoyment and design. After obtaining the results of the qualitative methods mentioned above, the research model was modified accordingly. 
Table 14: Factors selected by participants in the qualitative methods

\begin{tabular}{|c|c|c|c|c|c|c|c|c|c|c|c|c|c|c|c|c|c|c|c|c|c|c|c|c|c|c|c|c|c|c|c|c|c|c|}
\hline \multirow[t]{2}{*}{ Factors } & \multicolumn{20}{|c|}{ Participants in the individual interviews } & \multicolumn{6}{|c|}{$\begin{array}{l}\text { Participants in the } \\
\text { Brainstorming } \\
\text { session }\end{array}$} & \multicolumn{7}{|c|}{$\begin{array}{l}\text { Participants in the focus } \\
\text { group session }\end{array}$} & \multirow[t]{2}{*}{ Total } \\
\hline & $\# 1$ & $\# 2$ & $\# 3$ & & $\# 5$ & $\# 6 \mid \#$ & $\# 7 \mid \#$ & $\# 8$ & $\# 9$ & $\# 10$ & $\# 11$ & & $\# 13$ & $\# 14$ & $\# 15$ & $\# 16 \mid \#$ & |\#17 & $\# 18$ & $\# 19$ & $\# 20 \mid \#$ & $\# 1$ & $\# 2$ & $\# 3$ & $\# 4$ & $\# 5$ & $\# 6$ & $\# 1$ & $\# 2$ & $\# 3$ & $\# 4$ & $\# 5$ & $\# 6$ & $\# 7$ & \\
\hline \begin{tabular}{|l} 
Performance \\
Expectancy
\end{tabular} & 1 & 1 & 1 & \begin{tabular}{l|l}
1 & \\
\end{tabular} & 1 & 1 & 1 & 1 & 1 & 1 & 1 & 1 & & 1 & 1 & 1 & & 1 & 1 & 1 & 1 & 1 & 1 & 1 & 1 & 1 & 1 & 1 & 1 & 1 & 1 & 1 & 1 & 31 \\
\hline Task Technology Fit & & 1 & 1 & 1 & & 1 & & & 1 & & & & & & & & & & 1 & & & & 1 & & & & & & & & & & & 7 \\
\hline \begin{tabular}{|l} 
perceived \\
Reachability \\
\end{tabular} & 1 & & & & & 1 & & & & & & & 1 & & & & & & 1 & & & & & & & & & & & & & & & 4 \\
\hline Mobility & 1 & & & \begin{tabular}{|l|l|}
1 & \\
\end{tabular} & & 1 & 1 & & & 1 & \begin{tabular}{|l|}
1 \\
\end{tabular} & & & 1 & & & & & 1 & & 1 & & & & & & & & & & & 1 & & 10 \\
\hline Accuracy & & & & & 1 & 1 & & & & 1 & 1 & & 1 & & & & & & 1 & & & & & & & & & & & & & & & 6 \\
\hline Controllability & & & & & 1 & & & & & & & & & & & & & & & & & & & & & & & & & & & & & 1 \\
\hline Security & 1 & & & & & 1 & 1 & & 1 & & & & & & & & & 1 & & 1 & & & & & & & 1 & & & & & & & 7 \\
\hline $\begin{array}{l}\text { perceived } \\
\text { availability }\end{array}$ & & & & & & 1 & & & & & & & & & & & 1 & & 1 & & & & & & & & & & & & & & & 3 \\
\hline Perceived Quality & & 1 & & & & 1 & & & & & & & & & & & 1 & & 1 & & 1 & & & & 1 & & & & 1 & & & & 1 & 8 \\
\hline Content & 1 & 1 & & & & & & & & 1 & & & 1 & 1 & & & & & & 1 & & 1 & & & & 1 & & & & & & & 1 & 9 \\
\hline screen size & & 1 & & & & 1 & 1 & & 1 & \begin{tabular}{l|l}
1 \\
\end{tabular} & & 1 & & 1 & & & & 1 & 1 & & & & & & & & & & & & & & & 9 \\
\hline Services Speeds & 1 & & & & & 1 & & & & & & & & & & & & 1 & & & & & 3 & & & & & & & & & 1 & & 7 \\
\hline Design & 1 & 1 & & & 1 & 1 & 1 & 1 & 1 & 1 & \begin{tabular}{|l|l}
1 & \\
\end{tabular} & 1 & & 1 & & 1 & & 1 & 1 & 1 & \begin{tabular}{|l|l}
1 & \\
\end{tabular} & & 1 & \begin{tabular}{|l|l}
1 & \\
\end{tabular} & & & 1 & 1 & & 1 & & & 1 & 22 \\
\hline Multimedia & 1 & 1 & & & & 1 & & & & & & & & & & & & & 1 & & & & & & & & & & & & & & & 4 \\
\hline Applications & & 1 & & & 1 & 1 & 1 & & & & 1 & 1 & & & 1 & & & 1 & 1 & & & 1 & & & & & & & & & & & & 10 \\
\hline Wireless Internet & 1 & & & & & 1 & & & & 1 & & & & & & & & & 1 & & & & & & & & & & & & & & & 4 \\
\hline Effort Expectancy & & 1 & & \begin{tabular}{|l|l|}
1 & \\
\end{tabular} & 1 & & 1 & 1 & 1 & & & 1 & 1 & & & 1 & 1 & & 1 & 1 & 1 & 1 & 1 & 1 & 1 & 1 & 1 & 1 & 1 & 1 & 1 & & 1 & 24 \\
\hline Simplicity & 1 & 1 & & 1 & & 1 & 1 & & 1 & & 1 & & 1 & & & 1 & & & 1 & & & & & & & & 1 & 1 & 1 & & & & , & 13 \\
\hline Social Influence & & 1 & $1 \mid$ & & 11 & 1 & 1 & & 1 & 1 & 1 & 1 & 1 & 1 & 1 & 1 & 1 & 1 & 1 & & 1 & 11 & 1 & \begin{tabular}{|l|l}
1 \\
\end{tabular} & 1 & & 1 & 1 & & 1 & 1 & & 1 & 26 \\
\hline $\begin{array}{l}\text { Facilitating } \\
\text { Conditions }\end{array}$ & 1 & 1 & 1 & 1 & & 1 & & 1 & 1 & & \begin{tabular}{|l|}
1 \\
\end{tabular} & 1 & 1 & & 1 & & & 1 & 1 & 1 & 1 & & 1 & & 1 & 1 & 1 & 1 & & 1 & 1 & & 1 & 23 \\
\hline environments & & & & & & & & & & & & & 1 & & & & & 1 & 1 & & & & & & & & & & & & & & & 3 \\
\hline Organizational & & & & & & & & & & & 1 & & & & & & & & & & & & & & & & & & & & & & & 1 \\
\hline Compatibility & 1 & & & & 1 & & & & & & & & 1 & & & & & & 1 & 1 & & & & & 1 & & & & & & & & 1 & 7 \\
\hline Economic Factors & & & & 1 & & 1 & & 1 & 1 & 1 & 1 & 1 & 1 & & 1 & 1 & 1 & 1 & 1 & 1 & 1 & & 1 & 1 & 1 & 1 & 1 & 1 & 1 & 1 & 1 & & & 24 \\
\hline \begin{tabular}{|l|} 
Perceived \\
Enjoyment
\end{tabular} & 1 & & 1 & & 1 & 1 & & & 1 & & \begin{tabular}{|l|l|}
1 \\
\end{tabular} & 1 & 1 & & 1 & 1 & 1 & 1 & 1 & 1 & 1 & 1 & 1 & 1 & 1 & & 1 & & 1 & & 1 & & 1 & 23 \\
\hline Fun & 1 & & & & & 1 & & & & \begin{tabular}{l|l}
1 \\
\end{tabular} & 1 & & 1 & & & & & 1 & 1 & & & & & & 1 & & & & 1 & & & & 1 & 10 \\
\hline $\begin{array}{l}\text { Entertainment } \\
\text { Utility } \\
\end{array}$ & 1 & & 1 & & & & & & & & 1 & & 1 & & & 1 & & 1 & & & & & & & & & & & & & 1 & 1 & & 8 \\
\hline After Services & & & & & & & & & & & & & & & & & & & 1 & & & 1 & & & & & & & & 1 & & & & 3 \\
\hline Brand Influence & & 1 & 1 & 1 & 1 & 1 & 1 & 1 & 1 & 1 & 1 & 1 & 1 & 1 & 1 & & 1 & 1 & 1 & 1 & 1 & & 1 & & 1 & 1 & & & 1 & 1 & & & 1 & 25 \\
\hline $\begin{array}{l}\text { Perceived } \\
\text { Convenience }\end{array}$ & & & & 1 & & 1 & & & & 1 & \begin{tabular}{|l|l|l|}
1 &
\end{tabular} & & & & & & & & 1 & & & & & & & & & & & 1 & 1 & & & 7 \\
\hline Reliability & 1 & & & 1 & & 1 & & & 1 & 1 & 1 & & & & 1 & 1 & & 1 & 1 & 1 & 1 & & & 1 & & 1 & 1 & & 1 & 1 & & & 1 & 18 \\
\hline \begin{tabular}{|l} 
Marketing ( \\
advertisement)
\end{tabular} & & & & 1 & & 1 & & & & 1 & \begin{tabular}{|l|l|}
1 & \\
\end{tabular} & & & & & & 1 & 1 & & & & 1 & & & 1 & & 1 & & \begin{tabular}{|l|}
1 \\
\end{tabular} & 1 & & & & 11 \\
\hline $\begin{array}{l}\text { Operating System } \\
\text { (OS) }\end{array}$ & & 1 & & & & 1 & 1 & & & & & & & 1 & & & & & & & 1 & & & & & 1 & 1 & 1 & & & & & 1 & 9 \\
\hline Integration & & 1 & & & & & & & & & & & & & & & & & & & & & & 1 & & & & & & & & & & 2 \\
\hline Usability & & 1 & & & 1 & 1 & & & 1 & & 1 & & & & & & & & 1 & & 1 & & & 1 & & & & & & & 1 & & 1 & 10 \\
\hline Social Network & & & & & & 1 & & & & 1 & 1 & & & & & & & & . & & & 1 & & 1 & & 1 & & 1 & & 1 & & & & 8 \\
\hline Experience & & & & & & & & & & & & & 1 & & & & & & 1 & 1 & & & & & & & & & & & & & & 3 \\
\hline Type of screen & & 1 & & & & & & & & & & & & & & & & & & & & & & & & & & & & & & & & 1 \\
\hline connectivity & & & & & & & & & & & & & & \begin{tabular}{|l|}
1 \\
\end{tabular} & & & & 1 & & & & & & & & & & & & & & & & 2 \\
\hline Innovation & & & & & & & & & 1 & & & & & & & 1 & & & & & & & & & & & & & & & & & & 2 \\
\hline
\end{tabular}




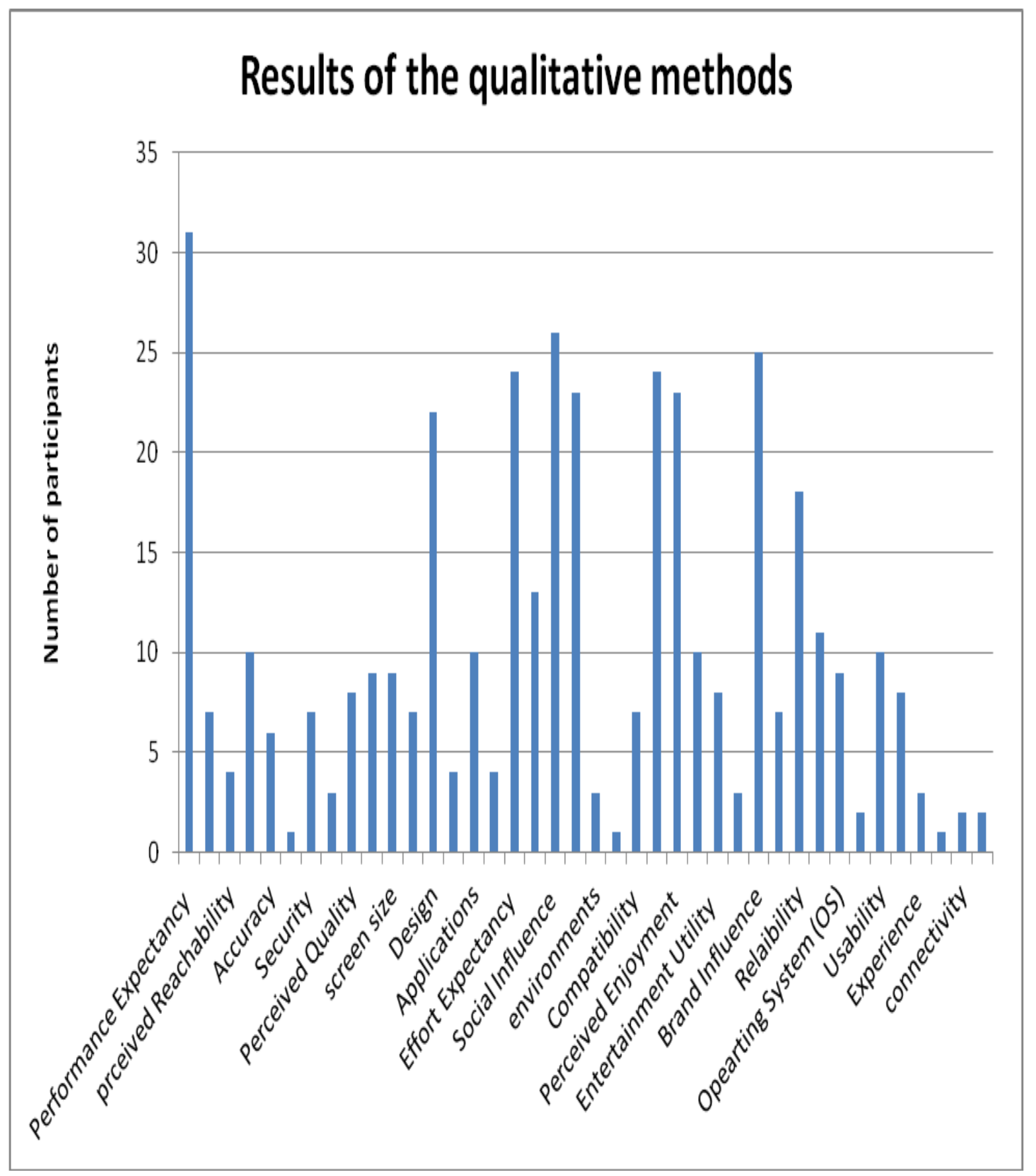

Figure 6: Factors selected by participants in the qualitative methods 


\subsection{Developing Research Model}

Sekaran [165] defined a theoretical framework or model as "a conceptual model for how one theorizes or makes logical sense of the relationships among the several factors that have been identified as important to the research problem." Also, he mentioned that identifying factors that were determined as important factors by previous research accompanied with rational relationships and connections can be logically conceptualized to form the basis of a research theoretical framework or model [165]. The research model for this dissertation (as shown in Figure 6 below) is developed based on modification of the UTAUT model. Besides using the taxonomy developed through the literature review, a number of qualitative methods have been conducted to help in developing the final research model. Table 15 below summarizes the definition of each factor in the preliminary research model.

Research model modification based on the literature review and qualitative methods that have been conducted for this research

Factors that are selected by at least two-third of participants have been included in the research model as show in figure 7 below. 


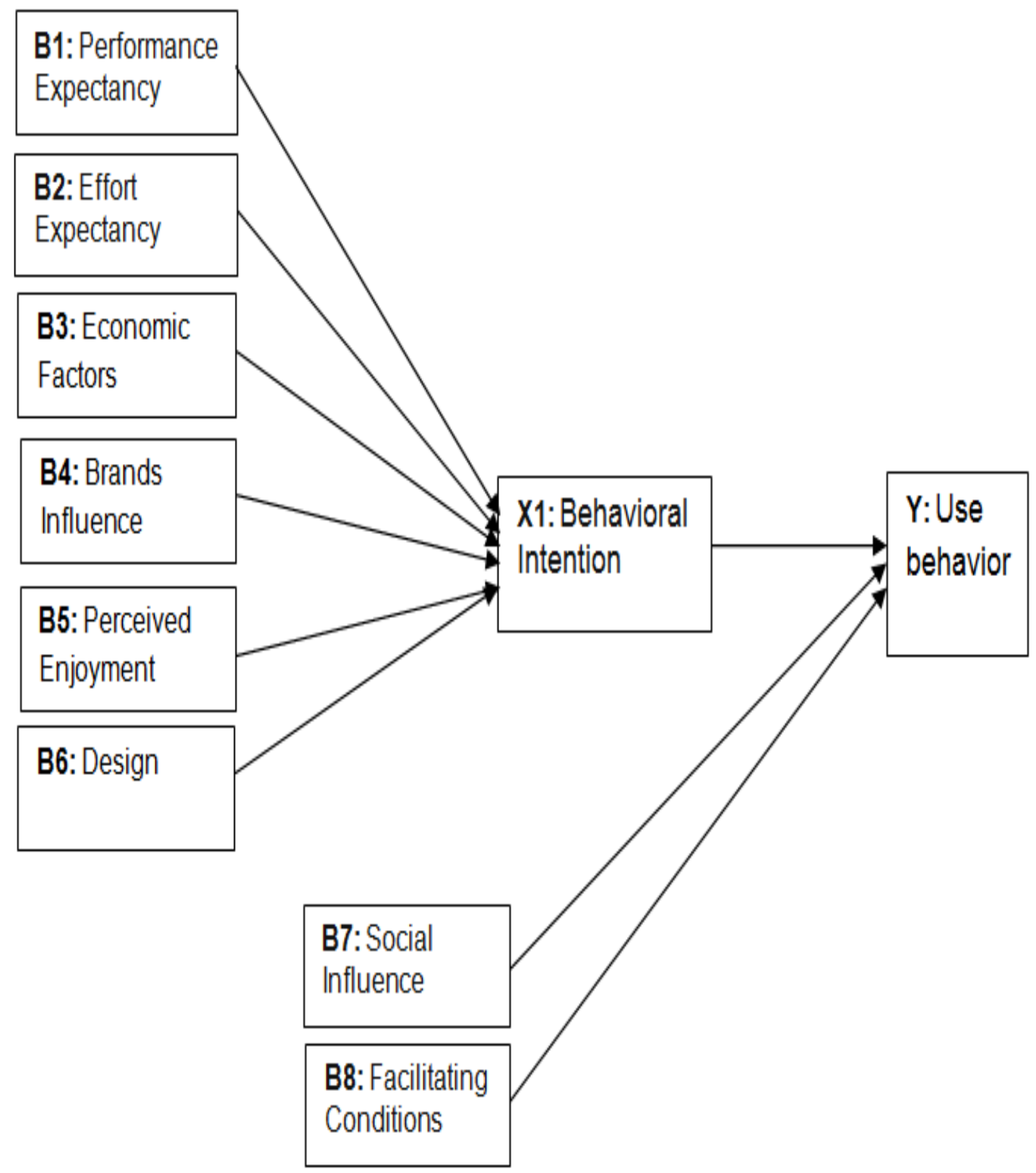

Situational factors

Figure 7: Research model 
Table 15: Definition of the main research model' factors

\begin{tabular}{|l|l|}
\hline Factors & Definition \\
\hline $\begin{array}{l}\text { Performance } \\
\text { Expectancy }\end{array}$ & $\begin{array}{l}\text { Performance expectancy is defined as the degree to which an } \\
\text { individual believes that using a Smartphone will help him or her to } \\
\text { attain benefits in their overall performance. }\end{array}$ \\
\hline $\begin{array}{l}\text { Effort } \\
\text { Sxpectancy }\end{array}$ & $\begin{array}{l}\text { Effort expectancy was defined as the degree of ease associated } \\
\text { with the use of the Smartphone. }\end{array}$ \\
\hline $\begin{array}{l}\text { Facilitating } \\
\text { Conditions }\end{array}$ & $\begin{array}{l}\text { Social influence is defined as the extent to which an individual } \\
\text { perceives that important others believe he or she should use a } \\
\text { Smartphone. }\end{array}$ \\
\hline $\begin{array}{l}\text { Economic } \\
\text { Factors }\end{array}$ & $\begin{array}{l}\text { Econdividual believes that technical and infrastructure supports are } \\
\text { available to support the use of Smartphones." } \\
\text { tradeoff between the perceived benefits of the technologies and } \\
\text { the cost for acquiring and using it. }\end{array}$ \\
\hline $\begin{array}{l}\text { Brand } \\
\text { Influence }\end{array}$ & $\begin{array}{l}\text { Brand is an exclusive name, symbol that distinguishes a product or } \\
\text { services. Brand name is a unique status symbol of a product that } \\
\text { can influence consumers adoption of technology [188]. }\end{array}$ \\
\hline Design & $\begin{array}{l}\text { Design has two aspects: (1) inherent design and colors of mobile } \\
\text { phones, and (2) detailed elements of design regarding the entire } \\
\text { appearance, color, harmony of appearance, shape of keypads, etc. }\end{array}$ \\
\hline $\begin{array}{l}\text { Perceived } \\
\text { Enjoyment }\end{array}$ & $\begin{array}{l}\text { the extent to which the activity of using a specific system is } \\
\text { perceived to be enjoyable in its own right, aside from any } \\
\text { performance consequences resulting from system usage [166]. }\end{array}$ \\
\hline
\end{tabular}

Developing a suitable and adequate research model is a critical step to obtaining better results in this research. Thus, as mentioned earlier, the research model has been developed and modified based on a review of existing related IT adoption theoretical models, factors identified in related literature, and the results of the qualitative methods research that has been conducted. The literature identified five main factors that are related to the adoption of Smartphone technology: technology characteristics and performance, facilitating conditions, social factors, effort factors, and enjoyment 
factors. Each one of the five factors has a number of sub-factors that contribute to its influence on the adoption and use of Smartphone technology. All factors presented in this taxonomy were identified in previous research as related to the adoption and use of the Smartphone technology. One brainstorming session, one focus group session and 20 individual interviews with experienced users and industry insiders were conducted to explore and add new factors that were not covered in the literature review. All factors were then evaluated and filtered to select the most important factors that are associated with users' intention to adopt and use the Smartphone. The factors that were selected have been included in the research model and the model has been modified and finalized accordingly.

This dissertation aims to explore the key factors that influence general users' intention to adopt and use the Smartphone technology in Saudi Arabia with a more comprehensive approach. Therefore, a literature review of related IT adoption theoretical models has been conducted (as mentioned in Chapter Two of this dissertation) including TRA, TAM, TPB, IDT, TTF and UTAUT. UTAUT is an established model with four main factors that determine users' intentions towards and use of a new technology [82].

Venkatesh et al. [82] empirically tested the UTAUT model and confirmed that UTAUT outperforms each of the eight prominent models initially used in forming UTAUT. In order to make UTAUT a more comprehensive model, the developer of the UTAUT model integrated a number of important factors under each main factor of the 
UTAUT model (table 16 present the origin models used to develop the UTAUT model and the specific factors that were integrated into each factor in the UTAUT model). For example, integrating the perceived usefulness factor under the performance expectancy factor, which indicates that any factor that contributes to the perceived usefulness factor can perhaps contribute to the performance expectancy factor. UTAUT proposed a better unified view of the users' acceptance of a technology and it is expected to explain about $70 \%$ of variances [82].

The survey in this dissertation has been translated into Arabic language and it has been administered to smartphones users in Saudi Arabia. Therefore, to obtain better results it is appropriate to base the dissertation research model on a suitable and robust model such as UTAUT. A number of scholars have tested the robustness of UTAUT and its ability to withstand translation and use in countries different than its original country and language of origin [189]. Their finding showed that UTAUT is a robust model and can withstand translation and use in a different country such as Saudi Arabia [189].

The UTAUT model has been modified, extended and integrated with other IT theoretical models to study and explain adoption and use of technology related to the Smartphone technology. Choudrie et al. [98] combined UTAUT with TAM and DOI to study the adoption and use of the Smartphone by older adults in the United Kingdom. Shin et al. [119] extended the UTAUT model study key factors that influence users' intentions to continue using the Smartphone as a ubiquitous learning (u-learning) tool. 
Boontarig et al. [164] extended UTAUT to examine the factors that Influence the Thai elderly's intention to use Smartphone for e-Health services. Tao and Zhou [158] modified the UTAUT model to study the key factors that influence users' acceptance and use of mobile commerce. Yun et al. [168] extended UTAUT to explain and predict users intention to use the location-based services (LBS) application used on Smartphone technology. Therefore, the UTAUT model is highly suitable and it has been selected as a base for the research model in this dissertation. It has been modified based on a literature review related to Smartphones and the results of the qualitative methods that have be conducted to evaluate, validate and select the related factors to be included in the final research model.

Table 16: Origin models used to develop the UTAUT model \& the specific factors that were integrated into each factor

\begin{tabular}{|c|c|c|}
\hline UTAUT & $\begin{array}{l}\text { Pertain factors from previous } \\
\text { models }\end{array}$ & Original Models \\
\hline $\begin{array}{l}\text { Performance } \\
\text { Expectancy }\end{array}$ & $\begin{array}{l}\text {-Perceived usefulness } \\
\text {-extrinsic motivation } \\
\text {-Job-fit } \\
\text {-relative advantage } \\
\text {-outcome expectation }\end{array}$ & $\begin{array}{l}-(\text { TAM/TAM2 and C-TAM- TPB) } \\
-(\mathrm{MM}) \\
-(\mathrm{MPCU}) \\
-(\text { IDT) } \\
-(\mathrm{SCT})[12]\end{array}$ \\
\hline $\begin{array}{l}\text { Effort } \\
\text { Expectancy }\end{array}$ & $\begin{array}{l}\text {-Ease of Use } \\
\text { - Complexity } \\
\text {-Effort expectancy }\end{array}$ & $\begin{array}{l}-(\text { TAM/TAM2) } \\
-(\text { MPCU) } \\
-(\text { IDT) [12] }\end{array}$ \\
\hline $\begin{array}{l}\text { Social } \\
\text { Influence }\end{array}$ & $\begin{array}{l}\text {-Subjective norm } \\
\text {-Social factors } \\
\text {-Image }\end{array}$ & $\begin{array}{l}\text { (TRA,TAM2, TPB, AND C-TAM- } \\
\text { TPB) } \\
\text { (MPCU) } \\
\text { (IDT) [12] }\end{array}$ \\
\hline $\begin{array}{l}\text { Facilitating } \\
\text { Conditions }\end{array}$ & $\begin{array}{l}\text {-Compatibility } \\
\text {-Perceived behavior control } \\
\text {-Facilitating conditions }\end{array}$ & $\begin{array}{l}\text { (IDT) } \\
\text { (TPB/DTPB, C-TAM-TPB) } \\
\text { (MPCU) [12] }\end{array}$ \\
\hline
\end{tabular}




\subsection{Developing Research hypotheses}

B1: Performance expectancy factor: defined as "the degree to which an individual believes that using an information system will help him or her to attain benefits in job performance" [82]. Smartphone technology can benefit users in their job as well as other environments. Therefore, for the purposes of this research, the original definition of performance expectancy will be modified to be "the degree to which an individual believes that using the Smartphone technology will help him or her to attain benefits in their overall performance."

The performance expectancy factor has a strong relationship with intention and it is a key predictor of the users' intention to adopt and use a technology [82]. The Smartphone provides users with many features and benefits that can help to improve their overall performance. Choudrie et al. [98] studied the adoption and use of the Smartphone by older adults in the United Kingdom. Their findings showed that the performance expectancy factor has the strongest influence on intention to adopt and use Smartphone technology [98].

As explained previously, a number of qualitative methods have been conducted to review, evaluate, validate and select factors that may have a relationship with users' adoption and use of Smartphone technology. The performance expectancy factor was selected by at least two-thirds of the participants in the brainstorming, focus group and 
interview sessions as an important factor that may have a relationship with users' adoption and use of the smartphone and should be included in the research model. Therefore, the following hypothesis has been developed to test the relationship between the performance expectation factor and the users' intention to adopt and use Smartphone technology.

H1: The performance expectancy factor will have a positive relationship with the users' behavioral intention to use the Smartphone technology.

B2: Effort expectancy factor: defined as "the degree of ease associated with the use of systems" [82], the effort expectancy factor reflects users' views or perceptions of the level or degree of ease of use or simplicity associated with the use of Smartphone technology. There are three factors that were identified in previous research that are associated with the level of effort expectancy when using the Smartphone and its related technologies namely simplicity [101], design [49], and complexity [156]. These factors were either directly associated with the effort expectancy factor or through other factors such as the ease of use factor $[167,49,155,27,126]$.

Boontarig et al. [164] studied the key factors that influence the elderly's intention to use the Smartphone for e-Health services in Thailand. Their finding includes that effort expectancy factor has a significant influence on the Thai elderly's intention to use the Smartphone for e-health services [164]. Choudrie et al. [98], in their investigation of factors that influence adoption and use of Smartphone among older 
adults, found that effort expectancy factor has a significant influence on users' intention to adopt and use the Smartphone.

As previously explained, a number of qualitative methods have been conducted to review, evaluate, validate and select factors that may have relationships with users' adoption and use of Smartphone technology. The effort expectancy factor has been selected by at least two-thirds of the participants in the brainstorming, focus group and interviews as an important factor that may have a relationship with users' adoption and use of the smartphone and should be included in the research model. Therefore, the following hypothesis has been created to test the relationship between the effort expectancy factor and users' intention to adopt and use the Smartphone technology.

H2: The effort expectancy factor will have a positive relationship with the users' behavioral intention to adopt and use the Smartphone technology.

B3: Economic factors factor: Individual users usually pay close attention to the price and cost of a technology before considering adopting and using that technology. Economic factors can be defined as the perceived value of the tradeoff between the perceived benefits of the technologies and the cost for acquiring and using it [190, 191]. Economic factors were identified as a factor that can predict users' behavioral intention to adopt and use new IT [191]. When the apparent benefits of acquiring and using a technology are perceived to be greater than the cost, the economic factors are expected to have a positive relationship with users' intention to adopt and use a technology [191]. 
The price of the Smartphone's devices and its services can be costly for some users, which can negatively influence their intention to adopt and use the Smartphone [192]. If users perceive Smartphone technology as cost effective, they may be more willing to adopt and use it. In a number of empirical research studies related to the adoption and use of Smartphone technology, price or cost of the technology showed a significant relationship with users' intention to adopt and use it. Kim [91] studied the factors that influence users to adopt and use mobile wireless technology (MWT) via the Smartphone technology. In his results, perceived cost saving showed a positive relationship with users' behavioral intention to use the MWT via Smartphone.

Kim et al. [170] also investigated factors that influence the adoption and use of the mobile internet. They found that, cost, or the price of mobile internet, had a significant relationship with users' intention to adopt mobile technology [170]. A number of factors related to economic factors, perceived cost [155], perceived cost saving [91], and company willingness to fund [91] were determined as important factors that are associated with users' adoption and use of the Smartphone.

As explained previously, a number of qualitative methods were conducted to review, evaluate, validate and select factors that may have relationships with users' adoption and use of Smartphone technology. The economic factors factor has been selected by at least two-thirds of the participants in the brainstorming, focus group and interviews as an important factor that may have relationships with users' adoption and use of the smartphone and should be included in the research model. Therefore, an 
economic factors factor is added to the research model as a predictor of users' behavioral intention to adopt and use the Smartphone. Thus, the following hypothesis is created to test the relationship between the economic factors factor and users' intention to adopt and use the Smartphone technology.

H3: The economic factors factor will have a positive relationship with the users' behavioral intention to adopt and use the Smartphone technology.

B4: Brand influence factor: Studying the brand influence on the adoption and use of Smartphone technology was an approach that a number of scholars used in their research [106, 107]. Based on Ganesh and Kumar's work, Chris Maloney [107] developed a framework to explore the learning effects' influence on the rate of adoption in the market and to explain the impact of the learning effect on the adoption rate of the iPhone [107].

Osman et al. [192] studied users of smartphones in Malaysia and their usage behaviors. Their results indicated that the brand of smartphones has relationships with users' adoption and their usage behaviors [192]. Also, Kim and Song [106] investigated the adoption and use of the Blueberry Smartphone. They developed their own research model that investigated the social, economic, and technological characteristics that influence individuals' attitude toward adoption of a Blueberry. Even though Smartphone device brands such as Nokia, HTC, and Samsung have their own unique differences in 
their combination of hardware/software, and this may influence user's acceptance and attitude toward the adoption of smartphones differently.

The iPhone was the most studied Smartphone device in articles reviewed [108$111,7]$. As explained previously, a number of qualitative methods have been used to review, evaluate, validate and select factors that are more related and may have relationships with users' adoption and use of Smartphone technology. The brand influence factor has been selected by at least two-thirds of the participants in the brainstorming, focus group and interviews as an important factor that may have relationship with users' adoption and use of the smartphone and should be included in the research model. Therefore, the following hypothesis has been developed to test the relationship between the brand influence factor and users' intention to adopt and use the Smartphone technology.

H4: The brand influence factor will have a positive relationship with the users' behavioral intention to adopt and use the Smartphone technology.

B5: Perceived enjoyment: perceived enjoyment is defined as the extent to which the activity of using a specific system is perceived to be enjoyable in its own right, aside from any performance consequences resulting from system usage [166]. Perceived enjoyment has been found to be a significant predictor of users' intention to adopt and use information technology $[193,194]$. Perceived enjoyment has become a key factor 
that is associated with individuals' intention to adopt and use technologies related to the smartphones.

In a number of previous research studies, scholars studied and explored the relationship between the perceived enjoyment factor and users' intention to adopt and use smartphones and their related technologies. Their findings indicated that the perceived enjoyment factor was found to be a positive and significant predictor of users' behavioral intention to adopt and use technology related to the Smartphone [98, 166, 90].

As explained previously, a number of qualitative methods have been conducted to review, evaluated, validate and select factors that may have relationships with users' adoption and use of Smartphone technology. The perceived enjoyment factor has been selected by at least two-thirds of the participants in the brainstorming, focus group and interviews as an important factor that may have relationships with users' adoption and use of the smartphone and should be included in the research model. Therefore, the following hypothesis is created to test the relationship between the perceived enjoyment factor and users' intention to adopt and use the Smartphone technology.

H5: The perceived enjoyment factor will have a positive relationship with users' behavioral intention to adopt and use the Smartphone technology.

B6: Design: Aesthetic design of smartphones has been studied to observe how it affects users' emotional reaction towards adoption of the Smartphone device [113]. Osman et 
al. studied users of smartphones in Malaysia and their usage behaviors [192]. Their results indicated that design of smartphones was an important factor that user considers when buying a smartphone [192]. In research focused on undergraduate and graduate students in Korea, Kang et al. [49] analyzed the factors that may affect the adoption of Smartphone. Their findings indicated that design factor has a positive relationship with perceived usefulness, which, in return, has an effect on behavioral intention.

As explained previously, a number of qualitative methods have been conducted to review, evaluate, validate and select factors that may have relationships with users' adoption and use of Smartphone technology. The design factor has been selected by at least two-thirds of the participants in the brainstorming, focus group and interviews as an important factor that may have a relationship with users' adoption and use of the smartphone and should be included in the research model. Therefore, the following hypothesis is created to test the relationship between the design factor and users' intention to adopt and use the Smartphone technology.

H6: The design factor will have a positive relationship with the users' behavioral intention to adopt and use the Smartphone technology.

\section{Situational factors}

The consumer or users' situation can be viewed as comprising "of all those factors particular to a time and place of observation which do not follow from knowledge of 
personal (infra-individual) and stimulus (choice alternative) attributes and which have a demonstrable and systematic effect on current behavior" [195]. Accounting more clearly for situational variables can greatly improve the researcher's ability to predict and understand consumers' actual behavior [196]. Ward and Robertson stated that "situational variables may account for considerably more variance than actor related variables" [197]. it was indicated that key situational variables have shown significant effects on behavior and it is important to consider it with other related factors to obtain a better explanation of consumers' behavior [196]. Both individual and situational factors must be considered in order to explain consumers' choices[196]. It was mentioned that both individual and situational factors must be accounted for to better explain users' actual use[196].

Actual behavior of buying or using a technology usually happens within a situational context and that situation may act as a means to facilitate or to inhibit the occurrence of that actual behavior or it may not affect it at all [198]. A number of scholars identified a number of general variables that can be characterized as situational factors including $[196,198]:$

- Physical surroundings;

- Social influence or social surroundings such as other persons present, their characteristics, their apparent roles, and their interpersonal Interactions;

- Time horizon; and

- Past experience. 
Alavi and Joachimsthaler mentioned user situational variables as one of the most relevant user factors that can help to determine the acceptance of technology [80]. A number of situational factors are presented in the primarily research model, namely facilitating condition and social influence. Two hypotheses are developed. "Key situational variables have been demonstrated to have significant effects on behavior." Situational variables include the following:

- Users' task requirements

- Users' resource capability

- Users' experience with related products

- Organizational/Social influences on users

B7: Social influence factor: Social influence is defined as "the extent to which a person perceives that important others believe he or she should use a new information system" [82]. Subjective norms and social influence have been recognized as important aspects that influence users' adoption of a new technology [96]. A number of factors, namely self-efficacy [27], social norms [90], and social pressure [126] were determined in previous research as important factors that are related to social influence on users' adoption of and use of the Smartphone.

Pan et al. [42] studied the key factors that influence the adoption of the Smartphone among college students in China and they indicated that social influence has a significant and positive influence on users' adoption of the Smartphone [42]. Ling 
and Yuan [43] empirically studied the factors that influence users' adoption and use of smartphones in China and they found subjective norms were among the significant factors that have positive effects on users' adoption and use of the smartphones [43]. Scholars pointed out the important role of cultural factors and their influence on the adoption and use of new information technologies [32-36].

Saudi society has different cultural contexts in that it is characterized as a society that is more collectivist in nature in which individuals have closer ties and influential effects among them [32]. As explained previously, a number of qualitative methods have been conducted to review, evaluate, validate and select factors that may have relationships with users' adoption and use of Smartphone technology. The social influence factor has been selected by at least two-thirds of the participants in the brainstorming, focus group and the interviews as an important factor that may have relationships with users' adoption and use of the smartphone and should be included in the research model. Therefore, the following hypothesis is created to test the relationship between the social influence factor and users' intention to adopt and use the Smartphone technology.

H7: The social influence factor will have a positive relationship with the use behavior factor.

B8: Facilitating conditions factor: defined as "the degree to which an individual believes that an organizational and technical infrastructure exists to support use of the 
system" [82]. In Smartphone technology, facilitating conditions can include connectivity and internet service availability, services support, usage information, system compatibility, individual financial resource, and more factors that facilitate better use of this technology. A number of factors that are related to facilitating conditions including perceived security [156], environments $[29,27]$, organizational $[29,27]$, compatibility $[29,155,27]$, internal environment [126], and external environment [126], were determined in previous research as important factors that are associated with users' adoption and use of the Smartphone.

Boontarig et al. [164] investigated the key factors that influence the Thai elderlys' intention to use the Smartphone for e-Health services. They found that the facilitating conditions factor has a significant influence on the Thai elderlys' intention to use the Smartphone for e-health services [164]. Choudrie et al. [98], in their study of factors that influence adoption and use of Smartphone among older adults, found that the facilitating conditions factor is an important factor that has a significant influence on users' intention to adopt and use the Smartphone.

As explained previously, a number of qualitative methods have been conducted to review, evaluate, validate and select factors that may have relationships with users' adoption and use of Smartphone technology. The facilitating conditions factor has been selected by at least two-thirds of the participants in the brainstorming, focus group and interviews as an important factor that may have relationships with users' adoption and use of the smartphones and should be included in the research model. Therefore, the 
following hypothesis is created to test the relationship between the facilitating conditions factor and the use behavior.

H8: Facilitating conditions factor will have a positive relationship with the use behavior regarding the Smartphone technology.

X1: Behavioral Intention: the behavioral intention factor has been indicated to be a key predictor of use behavior or actual use of technology [82].

In a number of previous studies, researchers examined the relationship between the behavioral intention factor and the use behavior factor. They found the behavioral intention factor to be a strong and important predictor of use behavior (actual use) of smartphones and their related technologies $[199,82,159]$. Use behavior or actual use of smartphones is expected to be associated with users' behavioral intention. Therefore, in this research, behavioral intention is expected to have a positive relationship with use behavior factor. Thus, the following hypothesis is created.

H9: The behavioral intentions factor will have a positive relationship with the use behavior factor.

Table 17 below presents the research questions and the research hypotheses for this dissertation. 
Table 17: Research Questions and the preliminary hypotheses

\begin{tabular}{|c|c|}
\hline $\begin{array}{l}\text { Research } \\
\text { Questions }\end{array}$ & Hypotheses \\
\hline $\begin{array}{l}\text { Research } \\
\text { Question 1: } \\
\text { What are the key } \\
\text { factors that } \\
\text { influence users' } \\
\text { intention to } \\
\text { adopt and use } \\
\text { the Smartphone } \\
\text { technology in } \\
\text { Saudi Arabia? }\end{array}$ & $\begin{array}{l}\text { The author has developed a research model based on literature } \\
\text { review, the UTAUT model, and use of a number of qualitative } \\
\text { methods. Also, a number of hypotheses have been developed to } \\
\text { explore and test the type of relationships and the level of } \\
\text { significance among factors in the research model. Based on } \\
\text { collecting data from the targeted sample (users of Smartphone } \\
\text { in Saudi Arabia) and conducting statistical analysis, the results } \\
\text { have indicated the type of relationships and the level of } \\
\text { significance of each factor with the users' intention to use and } \\
\text { adopt the Smartphone. } \\
\text { The hypotheses that were developed to test key factors } \\
\text { associated with users' adoption and use of the Smartphone are } \\
\text { listed below: } \\
\text { Hypothesis1: Positive relationship: as performance expectancy } \\
\text { factor increases the Behavioral intention will increase. } \\
\text { Hypothesis 2: Positive relationship: as effort expectancy factor } \\
\text { increases the behavioral intention factor will increase. } \\
\text { Hypothesis 3: Positive relationship: as economic factors } \\
\text { increases the use behavior factor will increase. } \\
\text { Hypothesis 4: Positive relationship: as brand influence factor } \\
\text { increase the behavioral intention factor will increase. } \\
\text { Hypothesis 5: Positive relationship: as perceived enjoyment } \\
\text { factor increases the behavioral intention factor will increase. } \\
\text { Hypothesis 6: Positive relationship: as design factor increases the } \\
\text { behavioral intention factor will increase. } \\
\text { Hypothesis 7: Positive relationship: as behavioral intention factor } \\
\text { increases the use behavior factor will increase. } \\
\text { Hypothesis 8: Positive relationship: as facilitating conditions } \\
\text { factor increases the use behavior factor will increase. } \\
\text { Hypothesis 9: Positive relationship: as social influence factor } \\
\text { increases the use behavior factor will increase. }\end{array}$ \\
\hline $\begin{array}{l}\text { Research } \\
\text { Question 2: How } \\
\text { to enhance users' } \\
\text { experience of } \\
\text { using } \\
\text { Smartphone } \\
\text { technology? }\end{array}$ & $\begin{array}{l}\text { The results of testing the mentioned hypotheses will indicate the } \\
\text { key factors that have positive and significant relationships with } \\
\text { users' adoption and use of Smartphone technology. Reviewing } \\
\text { these key factors, which are more important to the Smartphone } \\
\text { users can be improved to enhance users' experience with } \\
\text { Smartphone technology. }\end{array}$ \\
\hline
\end{tabular}




\section{Chapter Four: Research Approach}

\subsection{Research Design}

The research hypotheses have been developed based on related literature, modification of the UTAUT theoretical model, and the results of a number of qualitative methods mentioned earlier in this research. Hypotheses' testing is mostly associated with the survey approach which is followed by collecting data for this research. Gable defined the survey approach as "a group of methods which emphasize quantitative analysis, where data for a large number of organizations are collected through methods such as mail questionnaires, telephone interviews or published statistics, and these data are analyzed using statistical techniques" [200] In order to examine and analyze each of the hypothesized relationships among factors in the research model, data from Smartphone' users have been collected. To collect the needed data, analyze the data and obtain results, a series of steps have been conducted including the following:

- Development of a survey instrument

- Validation and testing of the survey instrument

- Administration of the survey

- Analysis of the data

- Providing results

\subsection{Survey Instrument Development}

A survey is defined as "gathering information about the characteristics, actions, or opinions of a large group of people, referred to as a population" [201]. In survey 
research there are a number of options for data collection which can be categorized under self-completion or interviewer-assisted [202-204]. Under the interviewer-assisted category are personal interviews and telephone interviews. Under the self-completion type are mail surveys, electronic surveys, or web surveys. In an electronic survey, which is based on web survey, the researcher can email the electronic link of the electronic survey to the targeted participants or upload the link into a social network and desired web sites [202, 205]. An electronic survey is cheaper than alternative methods of survey distribution and it can be sent to a greater number of participants in a shorter time [202]. There are some limitations to the electronic survey that need to be considered when using this method such as getting responses from outside the research sample frame, especially when uploading the link into a social network or a web site [202].

\section{Survey purpose}

There are many objectives or purposes of conducting a survey including description, explanation and exploration [206, 201]:

- Descriptive surveys usually aim to describe a specific distribution about a population. The researcher is mostly concerned about what the observed distribution is rather than being concerned about why the distribution exists.

- Exploration surveys usually have a loosely structured questionnaire which tends to be more applicable for researchers just at the start of an exploration or have limited inquiry about a specific topic that will need additional exploration. 
- In an explanation or explanatory survey, the researchers usually aim to make an assertion or explanation about a specific population.

The explanatory purpose survey mostly requires multivariate analysis and the simultaneous examination of multiple variables. Usually the researcher aims to explain, for example, why some individuals prefer one choice while other has different preferences.

In this dissertation, the survey objective is explanatory since the purpose of the research is to explain the users' behaviors and their preference of choices with regards to the Smartphone technology.

\subsubsection{Survey Design}

There are many survey designs including cross sectional survey and longitudinal survey $[206,201,207]$ :

- Longitudinal Survey is to collect data at different points in time so the researcher can report, and describe the changes.

- Cross Sectional Survey is to collect of data at one point of time and from a selected sample which can describe the larger population at that specific time. This survey design can also be used to determine a relationship between variables at the time of conducting the study.

This dissertation studies the relationships between variables that may have an association with users' adoption and use of smartphones in Saudi Arabia at the time of conducting the research. Therefore, for this dissertation, the survey design is a cross 
sectional survey that collect data from smartphone users at one point in time and analyze it accordingly.

\subsubsection{Developing the survey instrument}

The process of developing the survey instrument for this dissertation required a number of steps including the following:

- Generating the questions and designing the item scales based on a literature search and in accordance with research questions.

- Evaluating and validating the survey questions using experts and modifying the questions accordingly.

- Translating the survey questions into Arabic language.

- Validating the translation using experts in both languages then modifying the questions accordingly.

- Testing the survey instrument with a small group of smartphones users and modifying it as necessary.

- Final review, establishing the final version and launching the survey

\subsubsection{Questionnaire Design}

When writing survey questions it is recommended to use a previously tested survey instrument and build upon it $[202,204]$. To generate survey questions for this dissertation, a review of the related literature was conducted to study prior questionnaires and to gain more insight from related studies that gathered data using 
similar instruments. There are a number of possible types of research that can be useful as a base in developing the survey questions including theoretical research which discusses the developments and validation of the IT adoption theoretical models. For instance, Venkatesh et al. in their research of user acceptance of new IT, developed a new IT adoption theoretical model of the UTAUT [82]. In their research, they developed items (questions) to measure a number of variables such as the performance expectancy variable, and the social influence variable. These mentioned items can be useful as a base to develop new questions (items) to measure variables that influence users' adoption and use of Smartphone, especially when the research model is based on UTAUT. Another type of research is empirical research that utilizes similar variables to study topics related to the adoption and use of Smartphone technology. For instance, Carlsson et al., in their study of adoption of mobile devices and services, developed a survey questionnaire that includes questions (items) developed to measure similar variables such as the performance expectancy variable [208]. Therefore, for this dissertation, the similar tested survey instruments in previous related research have been reviewed and built upon to develop survey questions.

\subsubsection{Designing the type and form of the survey questions}

Survey questions can be grouped under two main types: Open-ended questions and closed-ended questions [202, 209, 210]. Open-ended questions do not limit participants in their answer; however, they provide subjects with a frame of reference 
for their answers [203]. Closed-ended questions limit the participant's answer to a fixed possible answer $[202,203]$.

Since the nature of this dissertation is quantitative, the appropriate type of questions that have been utilized are structured closed-ended questions. Closed-ended questions present a fixed set of possible answers for the participants to choose from [203]. Closed-ended questions include single answer, multiple answer rank order and Likert-type scale [202, 204]. The Likert-type scale was introduced by Rensis Likert in 1932 as a technique to assess the measurement of survey respondents' attitudes [211]. Likert-type scale is one of the most used in survey research Likert's scale is usually ordinal and each individual item has a range of alternative responses within a five point scale [212]. For example:

1. Strongly disagree

2. disagree

3. natural

4. agree

\section{Strongly agree}

The survey questions in this dissertation are based on a 5 point Likert-type scale with possible answers ranging from 1 to 5 . Each question has taken the form of a statement where the participants are given five possible answers to choose from. Their answers have been recorded and analyzed on an ordinal scale. An ordinal scale "consists of a set of categories that are organized in an ordered sequence" [213]. 


\subsection{Validity and Reliability}

To assess the accuracy of measurement and account for any error that may present in any measure, two characteristics of a measure have been conducted for this dissertation instrument namely: validity and reliability [203, 214].

\subsubsection{Validity}

Validity is defined as "the degree to which a measure accurately represents what it is supposed to"[214]. There are three major approaches to measure instrument validity - content validity, criterion-related validity and factor validity [203, 204]:

- Content validity measures the degree to which the content of the instrument items appropriately and comprehensively represents the content to be assessed. One way to measure the content validity is through the use of experts' judgments. An expert panel was formed and the experts' judgments and opinions were obtained to help in assessing the measurement of content validity for the research instrument. More details are provided later in this chapter.

- Criterion-related validity measures how a predictor is appropriate in capturing the relevant aspects of the criterion. The researcher compares the performance on the instrument under consideration with the performance on some other criterion, usually using correlation.

- Construct validity aims to "identify the underlying constructs being measured and how well the test represent them" [203] so that the factor 
that is being measured is very clearly defined. Experts' judgment can be utilized to assess the factors' validity. An expert panel was formed to obtain experts' judgment to test construct validity for the research instrument. More details are provided later in this chapter.

In order to validate the survey instrument of this dissertation as mentioned above, an expert panel was formed to assess and validate the survey instrument. An expert panel is a widely-used method to validate survey instruments used in many research studies. Ho et al., in their study of the factors influencing the adoption of mobile data services, used expert judgment to evaluate and validate their research questionnaire items [167]. An initial version of survey questions has been developed based on previously related research that used a similar survey instrument. Then a number of expert panels were used to validate the survey instrument. It is critical to make sure that the survey instrument is validated and has both construct and content validity [203, 204]. Based on experts' opinions and judgments, the survey has been modified as necessary. A survey testing tool, similar to the one shown in Table 18, was developed and provided to participants be used in validating the survey instrument. 
Table 18: An example of the Survey Testing and Validation Tool

\begin{tabular}{|c|c|c|c|c|}
\hline $\begin{array}{l}\text { Question } \\
\text { (Item) }\end{array}$ & $\begin{array}{l}\text { Intention of the } \\
\text { Question }\end{array}$ & Relevance & $\begin{array}{l}\text { Ease of } \\
\text { answering the } \\
\text { question }\end{array}$ & $\begin{array}{l}\text { Comment } \\
\text { s }\end{array}$ \\
\hline $\begin{array}{l}\text { Question text } \\
\text { (stating the } \\
\text { question) }\end{array}$ & $\begin{array}{l}\text { Indicating the } \\
\text { information } \\
\text { intended to get } \\
\text { through this } \\
\text { question }\end{array}$ & $\begin{array}{l}\text { Answer will be, } \\
\text { as indicated } \\
\text { above, 1-to-5 }\end{array}$ & $\begin{array}{l}\text { Answer will be, } \\
\text { as indicated } \\
\text { above, 1-to-5 }\end{array}$ & \\
\hline $\begin{array}{l}\text { (an example) } \\
\text { 1- Using the } \\
\text { Smartphon } \\
\text { e would } \\
\text { improve } \\
\text { my overall } \\
\text { performan } \\
\text { ce. }\end{array}$ & $\begin{array}{l}\text { To obtain } \\
\text { information to test } \\
\text { the relationship } \\
\text { between } \\
\text { performance } \\
\text { expectancy factor } \\
\text { and users' } \\
\text { behavioral } \\
\text { intention to adopt } \\
\text { and use the } \\
\text { Smartphone. }\end{array}$ & $(1)(2)(3)(4)(5)$ & $(1)(2)(3)(4)(5)$ & \\
\hline
\end{tabular}

\subsubsection{Expert Panel Design}

An expert panel was formed to evaluate and validate the survey instrument. Having between six to twelve experts is recommended as an ideal number in an expert panel to achieve manageable results while having diverse perspectives [215]. It is recommended to obtain experts with different backgrounds to ensure a better base of 
expertise and knowledge [216]. It is very critical to select experts who have a sufficient level of experience and knowledge on the subject under consideration. Also, it is important that the experts are willing and able to provide a useful point-of-view in the issue under consideration. Scholars provide numerous criteria that can be utilized when selecting experts and forming an expert panel $[217,218]$ :

- Knowledge and experience in the subject under consideration.

- Willingness and availability to participate in the research.

- Providing diversity among experts with the field of interest.

- Obtaining a balanced viewpoint among experts to compensate for individual biases on the outcome.

- Insuring absence of obvious conflicts among experts and insuring absence of influence of personality and position.

When selecting individuals to form the expert panel for this research, the above recommended criteria were considered and utilized to gain better results. Moreover, to insure diversity and gain better points of view, the experts were selected from related academia, the mobile industry, mobile services providers and experienced - Smartphone users. Initially around twenty experts were invited to participate in evaluating and validating the research survey instrument. A total of nine experts actually participated in this expert panel. 
This dissertation aims to study and explore the factors that influence users to adopt and use the smartphones, especially in Saudi Arabia. Therefore, the survey questionnaire has been translated from the English into Arabic. After experts evaluated and validated the survey questionnaires, any suggested modifications were implemented. A pilot test was then conducted. A web survey was developed and administered to a group of $\mathrm{PhD}$ students from the engineering and technology management (ETM) department who are smartphones users as well. After the modifications of the English version, the survey questionnaires were translated from English into Arabic. In order to validate the translation of the survey questions, a second group of experts were selected to form an expert panel. These experts were asked to evaluate and validate the translation of the survey questionnaire from English into Arabic to insure that the survey is clear and has an equivalent norm. When selecting the experts for validating the translation of the survey questions, the same criteria that were used in forming the first expert panel were applied in addition to the following criteria:

- Experts should be knowledgeable and fluent in both English and Arabic.

- Experts should be willing to participate in the panel.

- Experts should have knowledge about terminology involved in the subject that will be translated.

- Experts should be familiar with Smartphone technology 
There are many ways that experts can be contacted and invited to participate in survey activities such as email, phone calls, or in-person face-to-face invitations. Electronic mail is considered as quicker, cheaper and usually more effective as a means of communication $[219,203,220]$. For this study, a combination of these methods were used to approach and invite participants in the expert panels and provide them with related information.

It was anticipated that a number of the experts who initially agreed to participate in the panel would not actually be able to participate. Therefore, twenty experts were initially invited with the goal of having six to twelve experts actually participate. Those who agreed to participate were provided with all information related to the survey questionnaire. Also, the participants were provided with a validation tool, such as the one shown in Table 19, to be used in validating the translation of the questions (validating tool in Appendix E). They were asked to review the translation of each question and make sure it accurately reflected the English version of the question.

After validating the translation of the survey questionnaire from English into Arabic, the survey questionnaire was translated back into English and experts were asked to validate the translation back to English to insure the equivalence norm once again. Based on the experts' review, comments and validation regarding the question, the translation was modified accordingly. A tool was developed and provided to the experts for use in validating the questions' translation. It is similar to the questions translation tool in Table 19 (please see Appendix E). The validation tool was utilized to 
help in testing and validating the translation of the survey questions into Arabic. A similar validation tool was utilized to help in testing and validating the translation of the survey questionnaire back into English.

After the survey instrument was translated into Arabic and validated, an initial web survey was developed and a pilot test was conducted. The pilot test targeted a small number of smartphones users from Saudi Arabia and asked them to test and evaluate the survey instrument. Based on the outcome of the pilot test and feedback from participants the survey instrument was modified as needed.

Table 19: An example of translation validating tool

\begin{tabular}{|c|c|c|}
\hline Variables & Items & Comments \\
\hline $\begin{array}{l}\text { Performance } \\
\text { Expectancy }\end{array}$ & $\begin{array}{l}\text { Q1- The question text in English for example (PE1: } \\
\text { Using the Smartphone would improve my overall } \\
\text { performance.) } \\
\text { The question text in Arabic } \\
\qquad \text { (استخدام الهاتف الذكي يحسين من أدائي العام ) }\end{array}$ & \\
\hline $\begin{array}{l}\text { Editing the } \\
\text { question as } \\
\text { needed }\end{array}$ & & \\
\hline
\end{tabular}




\subsubsection{Reliability}

To test and assess the reliability of the survey instrument, a number of measurement methods have been utilized. Reliability refers to "the consistency of the scores obtained," it is concerned with evaluation of how each individual administration of the survey instruments maintains consistency to another and how consistency is maintained from one set of items to another set [204]. A number of commonly used methods are recommended to measure instrument reliability namely the test-retest method, the equivalent forms method, and the internal consistency method $[203,204]$ :

- The test-retest method tests the reliability of the instrument by testing the effect in a different time period $[203,204]$. Using this method, the same test will be administrated a second time to the same subjects after a specific interval of time $[203,204]$.

- Equivalent forms method measures the "degree to which alternative forms of the same measure produce the same or similar results" [203]. Two identical forms of an instrument are administrated simultaneously to the same groups of individual [204].

- Internal consistency is the measurement of to what degree an instrument's items are homogeneous and reflect the same underlying factor or variable [203]. Internal consistency can be measured using a split-half, KR20 or Cronbach's alpha $[203,204]$. The Cronbach's alpha coefficient was developed by Lee Cronbach in 1951 to assess the 
reliability measurement [221]. It is a widely-utilized measure to determine the internal consistency in a survey instrument to test its reliability [204, 222]. In a Cronbach's alpha measurement, values range from 0.0 to 1.0 and a value closer to 1 indicates a higher level of reliability among the indicators. A Cronbach's Alpha value greater than 0.7 indicates that the factor and indicators have good and acceptable levels of internal consistency and reliability $[214,223]$. To assess the reliability of the survey instrument in this dissertation, Cronbach's alpha measurement was conducted to test the internal consistency for each factor.

\subsection{Instrument Validation}

To insure the quality and validity of the survey for this dissertation, the survey instrument has been reviewed and validated. Content validation has been assessed an expert panel in which experts were asked to provide their judgment and opinions about the survey items regarding two main aspects:

- The first aspect was how well each item represents the intention of the variable/factor it intended to measure.

- The second aspect was how easy it was for the targeted participants to answer each survey item. A tool was developed to obtain experts' judgments regarding survey instrument content validation. 


\subsubsection{Validation Plan}

The validation process was conducted in two main phases, which included a number of steps to develop and validate the survey instrument as shown in Table 20 and 21 below:

\section{Phase one:}

Table 20: Developing and validating the English version of the survey instrument

\begin{tabular}{|c|c|c|c|}
\hline \multicolumn{2}{|r|}{ Step } & Description & outcome \\
\hline 1 & $\begin{array}{l}\text { Developing the } \\
\text { preliminary } \\
\text { version based } \\
\text { on previous } \\
\text { related survey }\end{array}$ & $\begin{array}{l}\text { The preliminary version of this survey } \\
\text { questionnaire has been developed based on } \\
\text { previous related surveys obtained from existing } \\
\text { research }\end{array}$ & Version 1 \\
\hline 2 & $\begin{array}{l}\text { Pre-validate } \\
\text { (Read-aloud) }\end{array}$ & $\begin{array}{l}\text { Using the read-aloud method, version one of } \\
\text { the survey was administered to a group of Ph.D. } \\
\text { students in the Department of Engineering and } \\
\text { Technology Management to obtain their } \\
\text { feedback and comments. }\end{array}$ & Version 2 \\
\hline 3 & Pilot test 1 & $\begin{array}{l}\text { Version } 2 \text { of the survey was administered to a } \\
\text { group of graduate students at Portland State } \\
\text { University to obtain their feedback and } \\
\text { comments. }\end{array}$ & Version 3 \\
\hline 4 & Expert Panel 1 & $\begin{array}{l}\text { A validation tool was been developed, based on } \\
\text { survey version 3, to obtain experts' judgment on } \\
\text { the relevance of each question and the ease of } \\
\text { answering each question. } \\
\text { The expert panel was formed and the }\end{array}$ & Version 4 \\
\hline
\end{tabular}




\begin{tabular}{|l|l|l|l|}
\hline & & $\begin{array}{l}\text { developed validation tool was administered to } \\
\text { nine the experts in the panel. }\end{array}$ & \\
\hline 5 & Pilot test 2 & $\begin{array}{l}\text { Version 4 of the survey was incorporated into a } \\
\text { web-based survey and linked emails have been } \\
\text { sent to a group of Smartphones users to obtain } \\
\text { their comments and feedback. }\end{array}$ & Version 5 \\
\hline
\end{tabular}

Phase Two: includes a number of steps to translate and validate the survey instrument as shown in Table 21 below:

Table 21: Developing and validating the Arabic version of the survey instrument

\begin{tabular}{|c|c|c|c|}
\hline \multicolumn{2}{|r|}{ Step } & Description & Result \\
\hline 1 & $\begin{array}{l}\text { Translating } \\
\text { the survey } \\
\text { from English } \\
\text { into Arabic }\end{array}$ & $\begin{array}{l}\text { Version } 5 \text { of the survey was translated from English into } \\
\text { Arabic }\end{array}$ & Version 6 \\
\hline 2 & $\begin{array}{l}\text { Pre-validate } \\
\text { (Read-aloud) }\end{array}$ & $\begin{array}{l}\text { A read-aloud session was conducted. Version } 6 \text { of the } \\
\text { survey was administered to a group of PSU students } \\
\text { who are smartphone users and speak Arabic }\end{array}$ & Version 7 \\
\hline 3 & $\begin{array}{l}\text { Expert panel } \\
2\end{array}$ & $\begin{array}{l}\text { A validation tool was developed, based on survey } \\
\text { version 7, to obtain experts' judgment on the } \\
\text { translation of the survey questions from English into } \\
\text { Arabic. } \\
\text { An expert panel was developed and the validation tool } \\
\text { was administered to an expert panel of } 7 \text { members. }\end{array}$ & Version 8 \\
\hline 4 & $\begin{array}{l}\text { Translate the } \\
\text { Arabic } \\
\text { Version back } \\
\text { into English }\end{array}$ & $\begin{array}{l}\text { Version } 7 \text { of the survey has been translated from Arabic } \\
\text { back into English. }\end{array}$ & Version 9 \\
\hline 5 & Expert panel & Version 8 of the survey has been administered to an & Version \\
\hline
\end{tabular}




\begin{tabular}{|l|l|l|l|}
\hline 2 & $\begin{array}{l}\text { expert panel of 7 members to validate the translation } \\
\text { back to English to insure that the meaning of questions } \\
\text { did not change and that the factor that is being } \\
\text { measured is very clearly defined. }\end{array}$ & 10 \\
\hline 6 & Pilot test 3 & $\begin{array}{l}\text { Version 9 of the survey was incorporated into a web- } \\
\text { based survey and linked emails were sent to a group of } \\
\text { Smartphones' users, (Arabic speakers) to test the survey } \\
\text { and obtain their comments and feedback. }\end{array}$ & 11 \\
\hline
\end{tabular}

\section{Phase one:}

\section{Step one:}

Scholars have suggested that, when writing survey questions, it is recommended to build upon an existing previously tested and validated survey instrument [202, 204]. To generate survey questions for this dissertation, a review of the literature was conducted to review prior related research that collected data using similar survey instruments. There are a number of possible types of research that could be useful as a basis to develop survey questions (including empirical research as discussed) and to develop and validate IT theoretical adoption models. For instance, Venkatesh et al., in their research of user acceptance of new information technology, developed a new IT theoretical adoption model, the Unified Theory of Acceptance and Use of Technology (UTAUT) [82]. In their research, they developed items (questions) to measure a number of variables such as performance expectancy and social influence. These items can be useful as a 
basis to build upon and develop new questions (items) to measure similar variables. Another type of research is empirical research that utilizes similar variables to study topics related to the adoption and use of Smartphone technology. For instance, Carlsson et al., in their study of adoption of mobile devices and services, developed a survey questionnaire that included questions (items) developed to measure similar variables such as performance expectancy [208]. Therefore, for this research, a similarly tested survey instrument used in previous related research was reviewed and utilized to survey questions. The questions in the initial survey questionnaire were adopted from a number of survey instruments that were developed and validated in previous related research [164, 208, 171, 82, 191].

\section{Step Two:}

The read-aloud method is a useful approach that has been used to obtain participants' opinions and comments in order to develop a survey instrument [219]. In this case, the read-aloud method has been utilized to obtain participants' opinions and help in developing the initial version of the survey instrument for this dissertation. A group of Ph.D. students from the Department of Engineering and Technology Management at Portland State University have been invited to participate in a read-aloud session. Six students choose to participate. The first version of the survey that was developed in this process was administrated to the participants. 
The researcher prepared a conference meeting room at the department of Engineering and Technology Management and provided the needed materials to conduct the read-aloud session. A hard copy of the first modified version of the survey questionnaire was provided to each participant. The researcher asked participants to voluntarily read aloud each question in the survey and provide their comments. Participants read each question, discussed it with the rest of the group and provided their comments accordingly. The session took around 45 minutes to complete.

The outcome of this read aloud session was reviewed and applied into the survey questionnaire as applicable. The comments and feedback from each participant were also reviewed and applied into the survey questionnaire. Version 2 of the survey was established.

\section{Step Three}

The researcher contacted a number of graduate students at Portland State University and invited them to participate in a pilot test for a survey questionnaire. The researcher explained to the participants that as a smartphone user he or she would be given a hard copy of the survey and asked to read the survey questions and provide their feedback about the survey questionnaire. Thirteen students participated in this pilot test, reviewing version 2 of the survey questionnaire. Based on participants' preference and availability, a soft copy of the survey was emailed or a hard 
copy of the survey was provided in person to each of them. The feedback from each participant was reviewed. The survey questionnaire was modified accordingly and version 3 of the survey was established.

\section{Step Four}

Experts' panels are a very popular method that has been used in many previous research studies to assess and validate survey questionnaires. Six to twelve experts are recommended as an ideal number to achieve manageable results while having diverse perspectives [215]. Moreover, scholars suggested obtaining experts with different backgrounds to ensure a better base of expertise and diversified knowledge [216].

An expert panel was developed and formed to review and validate the survey questionnaire. The researcher targeted 21 experts from the academic and industry sectors related to the smartphones industry and invited them to participate in this expert panel, insuring diverse background and knowledge. Thirteen experts agreed to participate in the expert panel and nine ended up as the actual participants (See Table 23 below). Version 3 of the survey questionnaire was used in developing a tool designed to be used by experts to review, modify and validate the survey instrument (see Appendix E). 
The feedback from each expert has been reviewed and applied. The survey questionnaire has been modified accordingly and version 4 has been established.

In a number of previous desertions the acceptable score is 4 Somewhat Closely for relevance and 4- Somewhat Easy for ease of answering questions [219, 224]. Accordingly, after incorporating experts' feedback, the goal in this dissertation is to have all surrey questions score above 4 - Somewhat Closely for relevance and 4- Somewhat Easy for ease of answering questions.

Meeting these goals could help demonstrate that the survey is well developed, suited for the research objective, and easy to answer the questions. As shown in Table 22, the results were encouraging.

The validation results show that the average relevance score was (4.50) out of 5 and the average ease of answering was (4.36) of 5. To be consistent with the goal of having scores above 4 points for both indicators, relevance and ease of answering question, ease of answering question 9 (3.78), question 14 (3.67) and relevance question 8 (3.89) were identified for improvement and modification. 
Table 22: Content Validation Results

\begin{tabular}{|c|c|c|c|c|}
\hline \multirow{2}{*}{ Question } & \multicolumn{2}{|c|}{ Relevance } & \multicolumn{2}{c|}{$\begin{array}{c}\text { Ease of answering } \\
\text { Questions }\end{array}$} \\
\cline { 2 - 5 } & Mean & SD & Mean & SD \\
\hline Q1 & 4.78 & 0.44 & 4.67 & 0.71 \\
\hline Q2 & 4.78 & 0.44 & 4.44 & 0.53 \\
\hline Q3 & 4.56 & 0.53 & 4.78 & 0.44 \\
\hline Q4 & 4.78 & 0.44 & 4.00 & 1.00 \\
\hline Q5 & 4.56 & 0.73 & 4.89 & 0.33 \\
\hline Q6 & 4.89 & 0.33 & 4.56 & 0.73 \\
\hline Q7 & 4.67 & 0.50 & 4.33 & 0.50 \\
\hline Q8 & 3.89 & 1.05 & 4.00 & 1.00 \\
\hline Q9 & 4.00 & 0.71 & 3.78 & 0.67 \\
\hline Q10 & 4.56 & 1.01 & 4.78 & 0.67 \\
\hline Q11 & 4.33 & 0.71 & 4.22 & 0.67 \\
\hline Q12 & 4.78 & 0.44 & 4.67 & 0.50 \\
\hline Q13 & 4.33 & 0.71 & 4.22 & 0.67 \\
\hline Q14 & 4.33 & 1.12 & 3.67 & 1.22 \\
\hline Q15 & 4.11 & 0.78 & 4.22 & 0.83 \\
\hline Q16 & 4.56 & 0.73 & 4.11 & 0.78 \\
\hline Q17 & 4.56 & 0.53 & 4.33 & 0.71 \\
\hline Q18 & 4.33 & 1.00 & 4.56 & 0.73 \\
\hline Q19 & 4.44 & 0.73 & 4.22 & 0.67 \\
\hline Q20 & 4.33 & 0.71 & 4.22 & 0.67 \\
\hline Q21 & 4.44 & 0.73 & 4.22 & 0.83 \\
\hline Q22 & 4.56 & 0.53 & 4.44 & 0.53 \\
\hline Q23 & 4.78 & 0.44 & 4.33 & 0.71 \\
\hline Q24 & 4.67 & 0.50 & 4.44 & 0.53 \\
\hline Q25 & 4.56 & 0.53 & 4.56 & 0.53 \\
\hline Q26 & 4.33 & 0.71 & 4.22 & 0.44 \\
\hline Q27 & 4.33 & 0.71 & 4.56 & 0.73 \\
\hline Q28 & 4.56 & 0.88 & 4.33 & 0.87 \\
\hline Q29 & 4.78 & 0.44 & 4.33 & 0.71 \\
\hline Q30 & 4.44 & 0.73 & 4.33 & 0.71 \\
\hline Q31 & 4.44 & 0.73 & 4.44 & 0.73 \\
\hline Q32 & 4.44 & 0.73 & 4.33 & 0.71 \\
\hline Q13 & 4.33 & 0.71 & 4.33 & 0.71 \\
\hline & 4.67 & 0.50 & 4.78 & 0.44 \\
\hline & 4.50 & & 4.36 & \\
\hline
\end{tabular}


An example of the feedback by one of the experts:

This question is asking participants about the price of Smartphone devices and price of smartphone services. The question is asking about two things and it should be broken into two questions.

Table 23: Experts participated in the first expert panel

\begin{tabular}{|l|l|l|l|}
\hline \multicolumn{2}{|c|}{ Title } & Credential & \multicolumn{1}{c|}{ Affiliation } \\
\hline EXP1 & $\begin{array}{l}\text { Adjunct Assistant } \\
\text { Professor }\end{array}$ & PhD & Portland State University \\
\hline EXP2 & Store Manager & BS & $\begin{array}{l}\text { T Mobile Corporation } \\
\text { smartphones providers }\end{array}$ \\
\hline EXP3 & $\begin{array}{l}\text { Adjunct Faculty } \\
\text { Member }\end{array}$ & PhD & $\begin{array}{l}\text { Engineering Management } \\
\text { Department } \\
\text { CASE (Center for Advanced Studies } \\
\text { in Engineering) }\end{array}$ \\
\hline EXP4 & $\begin{array}{l}\text { Electrical } \\
\text { engineer, } \\
\text { Software } \\
\text { designer. Taught } \\
\text { classes in PSU }\end{array}$ & PhD & $\begin{array}{l}\text { Tyfone Corporate } \\
\text { Developing hardware and } \\
\text { software related to security of } \\
\text { mobile devices including } \\
\text { Smartphones }\end{array}$ \\
\hline EXP5 & $\begin{array}{l}\text { Retail Sales } \\
\text { Consultant }\end{array}$ & BS & $\begin{array}{l}\text { T Mobile Corporation } \\
\text { Smartphones providers }\end{array}$ \\
\hline EXP6 & $\begin{array}{l}\text { Electrical } \\
\text { engineering, } \\
\text { worked as a } \\
\text { professor in } \\
\text { KFPMU }\end{array}$ & PhD & $\begin{array}{l}\text { Digimarc Company. } \\
\text { Developing a technology that help } \\
\text { to identify and track digital files in } \\
\text { smartphones }\end{array}$ \\
\hline EXP7 & $\begin{array}{l}\text { Retail Store } \\
\text { Associate }\end{array}$ & BS & $\begin{array}{l}\text { Sprint Corporation } \\
\text { Smartphones providers }\end{array}$ \\
\hline EXP8 & Marketing Analyst & BS & Intel Corporation \\
\hline EXP9 & $\begin{array}{l}\text { Senior Engineer } \\
\text { PhD }\end{array}$ & $\begin{array}{l}\text { IT corporation; developing } \\
\text { software to protect and identify } \\
\text { digital media }\end{array}$ \\
\hline & & &
\end{tabular}




\section{Step Five}

The Pilot Test approach has been used in a number of previous related research studies to develop, modify and validate survey instruments. Version four of the survey questionnaire has been incorporated into a web-based survey and a link has been emailed to a number of students at Portland State University who are Smartphone-users. Seventeen students have participated in the web-based pilot test and provided their feedback. Please see the screenshot of the web-based pilot test in Figure 8 below. 
The survey starts with a brief introduction. A number of Participants suggested removing it since it's mentioned in the emailed invitation

\section{Dear Participanat,}

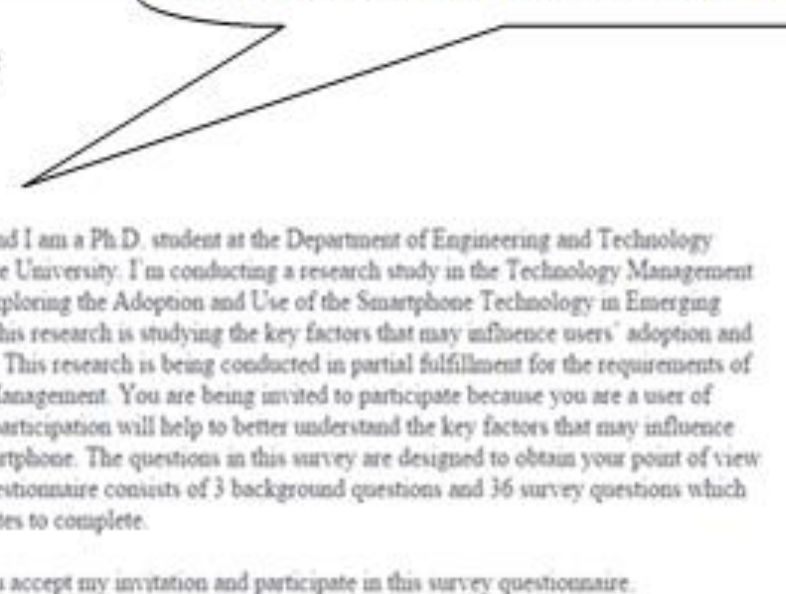

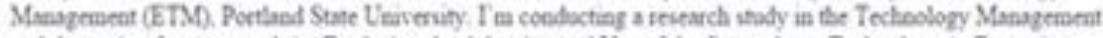

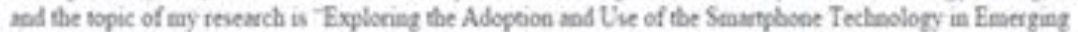

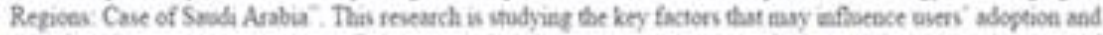

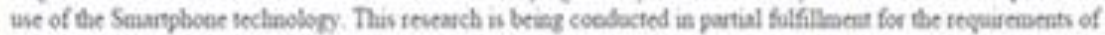
a doctoral depree in Techoology Management You are being invited to participase because you ane a user of

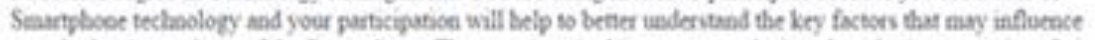

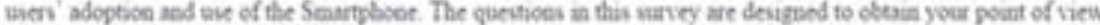

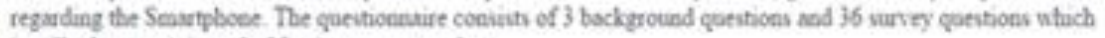
it will take approximately 15 mimutes to conplete

I wall greally wprecute it if you accepe my imvation and participate in this survey questionsase
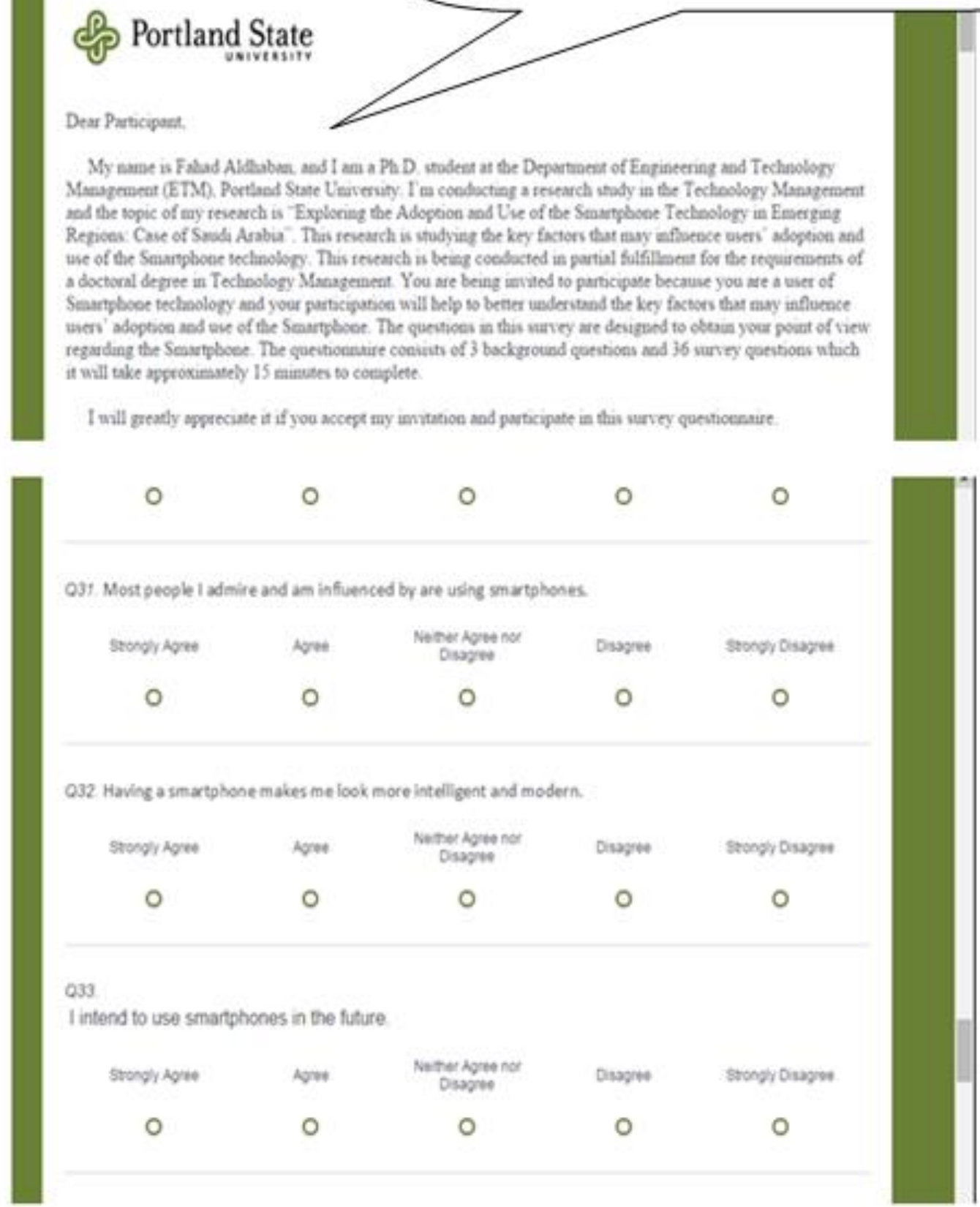

Figure 8: A Screen-shot of the Pilot Test of the survey questionnaire - English version. 
An example of the feedback by participants in the pilot test:

I think the survey questions are good. Since your email invitation includes all information that you provide in the heading of the Web-based survey, I think it is better to remove the introduction from the web page and start with the questions. It is repetitive and it does not provide new information other than that mentioned in the email invitation.

The researcher discussed this thought with other participants and they also recommended removing the introduction header from the webbased survey since it is provided in the email invitation. The researcher removed the introduction from the survey, thus starting the survey with questions. Feedback from each participant was reviewed and applied to the survey questionnaire as applicable. The survey questionnaire was modified accordingly and Version 5 of the survey was established.

\section{Phase Two:}

\section{Step One:}

This survey instrument is intended to collect data from Smartphone users in Saudi Arabia, therefore, the final version (5) has been translated from English into Arabic. The researcher used a number of translation applications and software, including Google translation, to ensure more accurate 
translation. The final modifications were made and Version Six of the survey questionnaire (in Arabic) was established.

\section{Step Two:}

A group of students from Portland State University who speak fluent Arabic were invited to participate in a read-aloud session to assess the translation of the survey from English into Arabic. A total of seven students participated. A hard copy of the translated survey, Version Six, was provided to each participant. Participants were asked to read each question aloud, discuss it with the rest of the group and provide their comments accordingly. The session took around 35 minutes to be completed. Feedback and comments from each participant were reviewed and applied to the survey questionnaire as applicable. The survey questionnaire was modified accordingly and Version 7 of the survey was established.

\section{Step Three:}

To ensure the quality of the survey translation from English into Arabic and validate it another expert panel was formed. The researcher contacted seventeen experts, who speak both English and Arabic fluently and have sufficient academic background, and invited them to participate in this panel. Thirteen experts accepted, but only seven were able to participate (See table 24 below). Version 7 of the survey questionnaire was used to develop a tool provided to experts to review, modify and validate the survey instrument (See 
Appendix F). The feedback from each expert was reviewed and applied to the survey questionnaire. The survey questionnaire was modified accordingly and Version 8 of the survey was established.

Table 24: Experts participated in the second expert panel - validating survey translation

\begin{tabular}{|l|l|l|l|}
\hline \multicolumn{2}{|c|}{ Title } & Credential & \multicolumn{1}{c|}{ Affiliation } \\
\hline EXP1 & PhD student & MS & Portland State University \\
\hline EXP2 & $\begin{array}{l}\text { Computer } \\
\text { Engineering }\end{array}$ & PhD & Intel Corporation \\
\hline EXP3 & $\begin{array}{l}\text { Graduate } \\
\text { Student }\end{array}$ & BS & Portland State University \\
\hline EXP4 & $\begin{array}{l}\text { Electrical } \\
\text { engineering, } \\
\text { Professor }\end{array}$ & PhD & $\begin{array}{l}\text { Digimarc Company. } \\
\text { Worked as a professor in King } \\
\text { Fahd University of Petroleum and } \\
\text { Minerals (KFUPM) }\end{array}$ \\
\hline EXP5 & PhD student & MS, MBA & Portland State University \\
\hline EXP6 & PhD student & MS & Portland State University \\
\hline EXP7 & Senior Engineer & PhD & $\begin{array}{l}\text { IT corporation; developing } \\
\text { software to protect and identify } \\
\text { digital media }\end{array}$ \\
\hline
\end{tabular}

IV. Step four: Version 7 of the survey has been translated again from Arabic into English.

\section{Step Five:}

Version eight was translated back into English and used in developing a tool to review, modify and validate the translations of the survey questionnaire back into English. Since the experts participating in the previous expert panel speak both English and Arabic fluently, the researcher asked them to participate in validating the survey translation of Arabic back into English. All of 
the seven experts initially agreed to participate; however, only five actually participated along with one newly recruited expert (see Table 25 of experts below). The feedback from each expert was reviewed and applied as applicable. The survey questionnaire was modified accordingly and Version 9 of the survey was established.

Table 25: Experts panel 3 - validating survey translation back to English

\begin{tabular}{|l|l|l|l|}
\hline \multicolumn{2}{|c|}{ Title } & Credential & \multicolumn{1}{c|}{ Affiliation } \\
\hline EXP1 & $\begin{array}{l}\text { Graduate } \\
\text { Student }\end{array}$ & MS & Oregon State University \\
\hline EXP2 & $\begin{array}{l}\text { Computer } \\
\text { Engineering }\end{array}$ & PhD & Intel Corporation \\
\hline EXP3 & $\begin{array}{l}\text { Electrical } \\
\text { engineering, } \\
\text { Professor }\end{array}$ & PhD & $\begin{array}{l}\text { Digimarc Company. } \\
\text { Worked as a professor in King } \\
\text { Fahd University of Petroleum and } \\
\text { Minerals (KFUPM) }\end{array}$ \\
\hline EXP4 & PhD student & MS, MBA & Portland State University \\
\hline EXP5 & PhD student & MS & Portland State University \\
\hline EXP6 & Senior Engineer & PhD & IT corporation; developing \\
software to protect and identify \\
digital media
\end{tabular}

\section{Pilot Test}

Version 9 of the survey questionnaire was incorporated into a webbased survey and a link was emailed to a number of students at Portland State University who are Smartphone users plus other smartphones users all of 
whom speak Arabic fluently. Seventeen participants participated in the webbased pilot test and provided their feedback. Please see the screenshot of the web-based pilot test.

An example of the feedback by participants in the pilot test:

"the survey questions are all listed in one long page which makes it look like a long survey. I think it is better to break it into a number of pages where participants can go to the next page and not feel it is a very long survey."

The researcher discussed this thought with the other participants and they also recommended breaking it into several pages. The researcher therefore broke the survey into more pages. Feedback from each participant was reviewed and applied to the survey questionnaire, which was modified accordingly so that the final version of the survey questionnaire could be established and activated. (A screenshot of the final survey is presented in figure 9 below) 


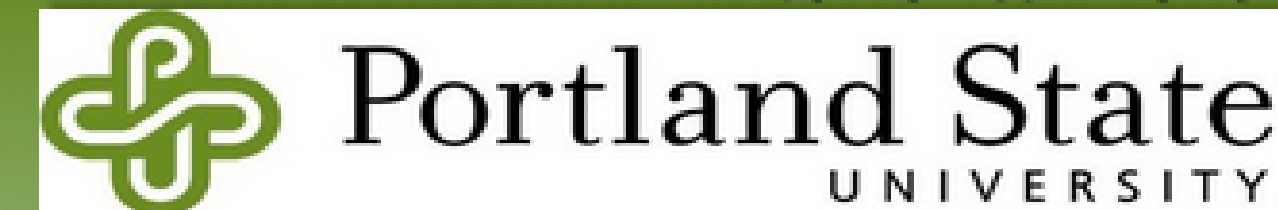
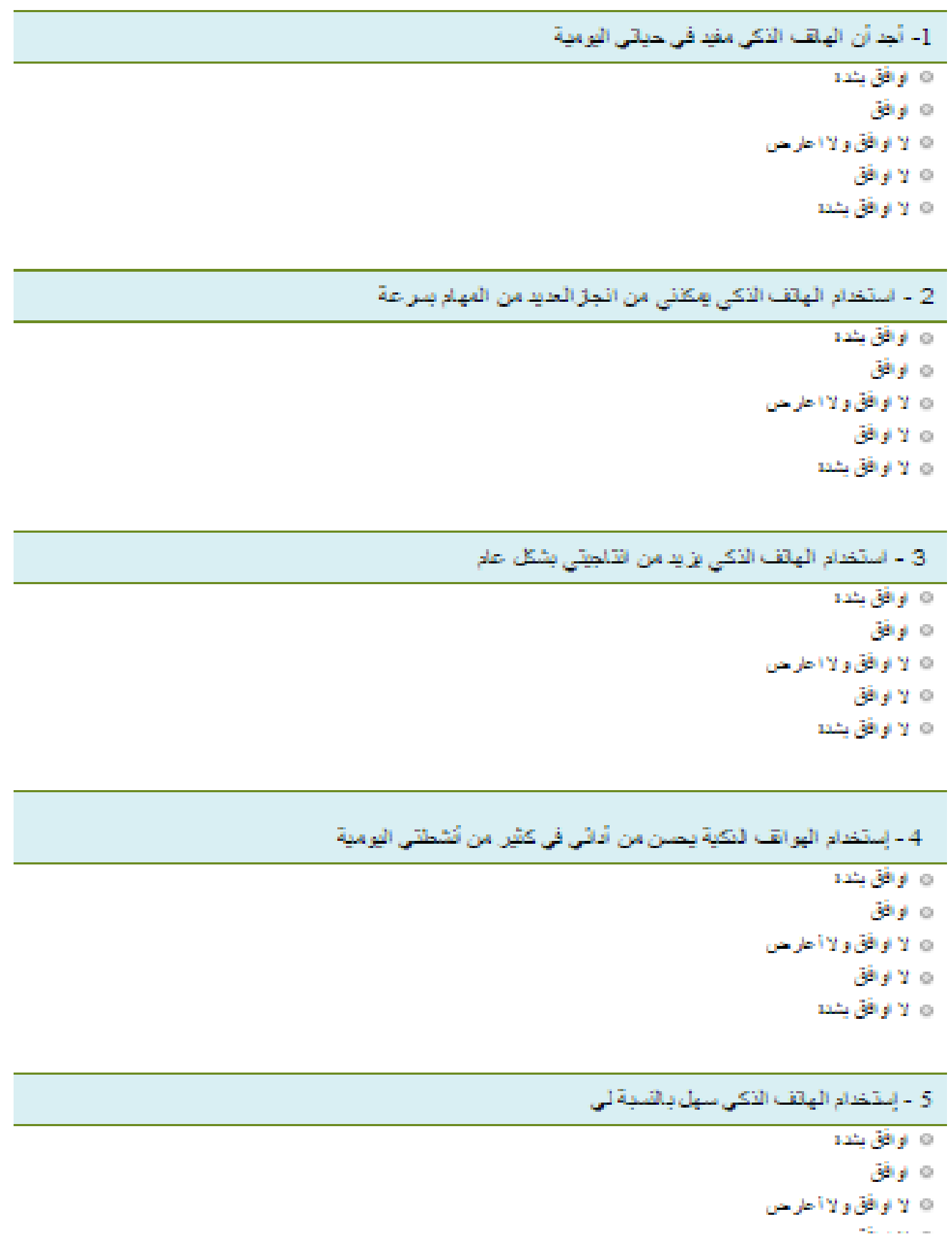

Figure 9: A Screen-shot of the web based survey questioner the Arabic version 


\subsection{Instrument Administration}

There are two main approaches to administration of a survey: structured interviews and self-completion questionnaires [225]. When using self-completion questionnaires, there are three types that can be utilized: supervised, postal, and internet [225]. The internet web-based survey is growing in popularity and commonly utilized among researchers for many reasons including the following [226, 225, 227229]:

- More economical than other methods

- Time effective: it can reach a larger group of participants instantly and get their responses as soon as it is completed

- Enables researcher to reach large numbers of participants

- Eliminates the distance problem

- More manageable

- Enables researcher to add audio or video if needed

- More flexible

For this dissertation an internet web-based survey was developed and administered since it has many advantages and it seems to be the most appropriate approach. A number of principles have been suggested when designing a web-based survey to improve the quality of the survey and reduce errors [230]:

- Design a nice welcoming screen and smooth instruction

- Start the survey with the most interesting question 
- Questions should be presented in a form that is similar to a paper-based survey

- Use care with color so the clarity of the survey questions is not effected

- Provide the needed instruction for various participants

- Keep survey appearance consistent

- Open ended questions should be avoided

The above suggestions have been applied when designing the survey instrument for this dissertation to improve quality and reduce errors wherever possible. A number of major steps have been conducted in designing and conducting data through a webbased survey including:

- A web-based survey has been designed with Arabic characters using survey design software available through and provided by Portland State University which can be seen in (portlandstate.qualtrics.com)

- The targeted respondents have been contacted by email that included a link to the web-based survey. The email included an invitation for Smartphone users to participate in the survey by answering the questions. Also the email included a brief introduction to the research, encouraged participation and insured them that participation is total voluntarily.

- Reminder emails or follow ups sent to the participant of the web survey is recommended and has a positive impact on increasing the response rate 
[231]. Therefore, follow up emails that target participants were sent to remind participants about the survey and encourage them to participate.

\subsubsection{Sampling}

The idea of sampling was described as: "by selecting some elements of a population, we can draw a conclusion about the [overall] population" [203]. The subject of interest for a research study, from which a sample will be selected, is called population, which should always be identified in the research [213]. A population is defined as "the set of all the individuals of interest in a particular study" [213]. A population can be as large as all the children on the planet earth or it can be more specific as a set of children in a specific school who have certain type of talent. A population can be a set of people, animal, plants, products, services or anything that a researcher wants to study and examine.

Even though the researcher's interest is about the whole population under consideration, it is generally impossible to investigate each individual case of the whole population. Therefore, a smaller group that intended to represent the targeted population can be selected from the population so that the researcher can manage to test the majority of individuals in this selected group. The group of individuals that is selected from a specific population set is called a sample. A sample in a research study can be defined as a set of selected individuals from a specific population, intended to 
represent the population of interest $[203,213]$. There are a number of issues that usually associated with sampling process, including:

\section{Sampling error:}

Sampling error is identified as "the discrepancy, or amount of error, that exists between a sample statistic and the corresponding population parameter" [213]. The sample statistic refers to a value, usually numerical, that describes or represents a sample. Population parameter is a value that describes a population [213]. In a specific population there are a number of possible samples that can be selected to represent the specific population and each of these samples contain different individuals with different values. Therefore the difference between any two possible samples from the same population is called a sampling error. This difference, or sampling error, can be accounted for as a percentage of error that can happen only as a chance of sampling error. Therefore, the researcher usually defines the percentage of sampling error that can be acceptable in their particular research.

\section{Reasons for sampling:}

There are a number of important reasons for sampling [203, 232, 233]:

- Cost is one of the most compelling reasons to use sampling instead of testing the whole population. It would be very costly to get every individual in a population to participate in a given research study. Therefore sampling can save the researcher(s) a considerable amount of cost and still enable them to draw a valid conclusion about the targeted population. 
- Time effectiveness: sampling can save the researcher a great amount of time and effort since its less time consuming to test a sample then to test a whole targeted population.

- Availability of population elements: sampling can enable the researcher to test and study a targeted population especially when the population is large, hard to reach and infinite.

- Better accuracy of results: sampling often has better supervision, processing, and testing for missing data, which can increase the quality and accuracy of the results.

When sampling there are recommended steps that researchers usually follow including: $[202,203,234]$ :

- Determining the target population

- Determining a sampling frame

- Choosing a sampling method

- Determining the sample size needed

- Drawing the sample

Based on the steps above, the sampling for this research has followed a number of steps and it is as following:

- The targeted population: in this dissertation the researcher is aiming to study the general users of the Smartphone from one of the four main 
telecommunication companies in Saudi Arabia. The population of Saudi Arabia is around 21 million Saudi citizens and around 10 million foreigners [56]. According to the Saudi Communication and Information Technology Commission, the number of mobile subscribers increased significantly in Saudi Arabia, primarily the prepaid subscriber type. This indicates that there are around $42 \%$ mobile broadband subscribers in the total population, which includes Smartphone subscribers [235]. The penetration of smartphones technology in Saudi Arabia is estimated to be around $51.3 \%$ for the year 2014 [236]. Therefore, the targeted population in this research is Saudi citizens aged 18 years and older who are smartphones users.

- Sampling frame: There are four main telecommunications companies in Saudi Arabia, which provide mobile services, including Smartphone services. The four companies are Saudi Telecom Company (STC), Mobily, Zain Telecom and Bravo Telecom. Each company has an equal chance of providing mobile services, including Smartphone technology, to all type of customers [237]. Each company has its own main branches and sub-branches in all major regions of Saudi Arabia. Due to the time, cost and effort needed to collect data, the author intends to limit the research sampling frame to 5,000 smartphones users who have been randomly selected from one of these four Saudi telecommunications companies. 
- Sampling Method: Simple random sampling is that in which every element of the population has an equal chance to be selected. In this dissertation simple random sampling has been used when select the targeted sample subjects.

\section{- Sample size needed:}

When using the Structural Equation Modeling (SEM) method, it is recommended to obtain at least 10 observations for each indicator (item) to set the lower boundary for an appropriate sample size [238-242]. Another suggestion indicated that the minimum sample size can be indicated by the use of the ratio $(r)$ of indicators to the latent variables where $r=P / K$; $P$ is the indicator variables and the $\mathrm{K}$ is the latent variables $[243,244]$. Based on this ratio suggestion, if $r=$ 3 , it would require a sample size of at least 200 cases, and if $r=2$ it would require a sample size of at least 400 cases [245-247]. For setting the lower boundary of sample size in a medium complexity SEM model, it was suggested to obtain at least 200 cases $[248,249]$. Hair suggested that, when using SEM to analyze, for a model with seven or less, construction of a minimum sample size of 300 cases is required and for a model with a larger number of factors and with fewer than three measured items, a minimum sample size of 500 cases are required [214]. 


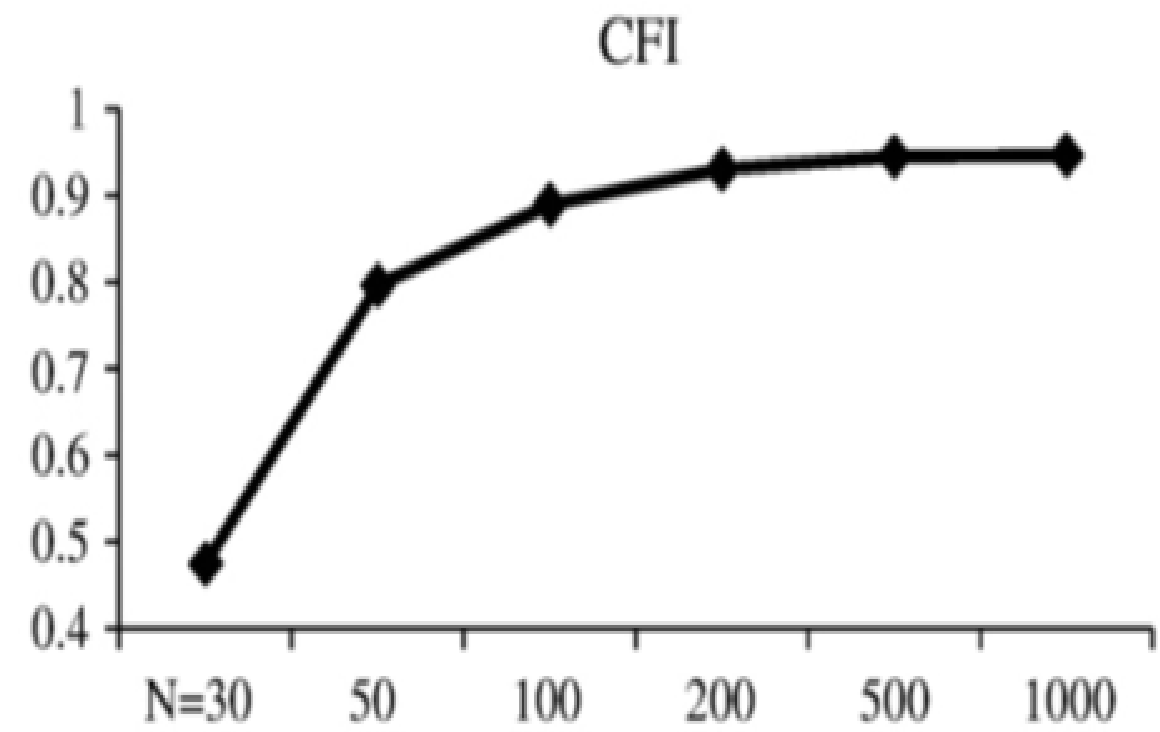

Figure 10: Effect of sample size on fit indices CFI [235]

lacobucci studied the effect of increasing the sample size on fit indices such as comparative fit index (CFI) using sample sizes as small as $\mathbf{3 0}$ cases and as large as $\mathbf{5 0 0}$ and 1000 cases [250]. The results, as shown in Figure 10 above, indicated that the effect is nonlinear, which suggests that increasing the sample size will have minimal effects on CFI [250]. When using SEM to analyze data, sample size can be associated with a number of critical aspects that should be considered to gain more robust results, such as obtaining reliable factors that each have three or more indicators to gain sufficient convergence and a proper solution even with a smaller sample size such as 150 cases [251]. When using SEM, its factors and indicators will be measured and validated and it 
should obtain an acceptable model fit to continue to the next step of testing the path relationships in the structural model.

The plan for setting the minimum effective sample size for this dissertation based on the above suggestions when using SEM will be as follows: The initial research model for this research consists of eight factors or variables. The researcher intends to have at least three to four indicators for each factor which could total around 27 items or indicators. Following the suggestion to have at least 10 observations for each indicator makes the minimum sample size equal 270 cases. When using the ratio method that was suggested above, 27 indicators divided by 8 variables will generate 3.3 that is in the category of a ratio $r=3$ which indicates a minimum size of at least 200 cases. Response rate estimated in some previous studies and dissertations was indicated to be between $8 \%$ to $20 \%$ [252]. Since the SEM minimum sample size is based on the number of variables and predictors in the model, based on the response rate for web-based surveys, the minimum or lower bound of the sample size will follow the scenarios below in Table 26: 
Table 26: Example of scenarios to Estimate the minimum sample size required for this dissertation

\begin{tabular}{|l|l|l|l|l|}
\hline $\begin{array}{l}\text { Number of } \\
\text { possible }\end{array}$ & $\begin{array}{l}\text { Expected } \\
\text { Variables in the } \\
\text { model }\end{array}$ & $\begin{array}{l}\text { Minimum } \\
\text { indicators }(\mathrm{P})\end{array}$ & $\begin{array}{l}\text { Expected } \\
(\text { lower bound) } \\
(\mathrm{P} \times 10)\end{array}$ & $\begin{array}{l}\mathrm{N} \\
\text { response rate }\end{array}$ \\
\hline 8 & 27 & 216 & $8 \%$ & 2700 \\
\hline 8 & 30 & 240 & $8 \%$ & 3000 \\
\hline 8 & 27 & 216 & $20 \%$ & 1080 \\
\hline 8 & 30 & 240 & $20 \%$ & 1200 \\
\hline
\end{tabular}

\subsubsection{Survey Administration}

After the design for the web-based survey has been finalized and activated, an invitation email with an electronic link to the web survey has been set to a randomly selected 5,000 possible participants. As mentioned earlier the 5,000 possible participants are Saudi citizens age 18 years and older who are smartphones users. There emails have been randomly selected from one of the four telecommunication companies in Saudi Arabia.

A number of suggestions were provided that can be useful and help to improve the quality of the survey and encourage more response from participants including the following $[230,253]$ :

- Appeal to respondents, indicating that by responding they would be helping complete a Ph.D. dissertation.

- Emphasize that the survey is short and will not be time-consuming. 
- Highlight that the request is from an academic institution, rather than from a marketing business firm.

- Have the survey web address jump out when viewing the email.

- Highlight the prize drawing to entice respondents.

- Provide clear instructions for how to access the survey.

- Provide contact information in case there is a need for recipients to contact researcher.

The suggested tips have been applied as much as possible in this survey as shown in the screenshot of the invitation email as shown in figure 11 below. 


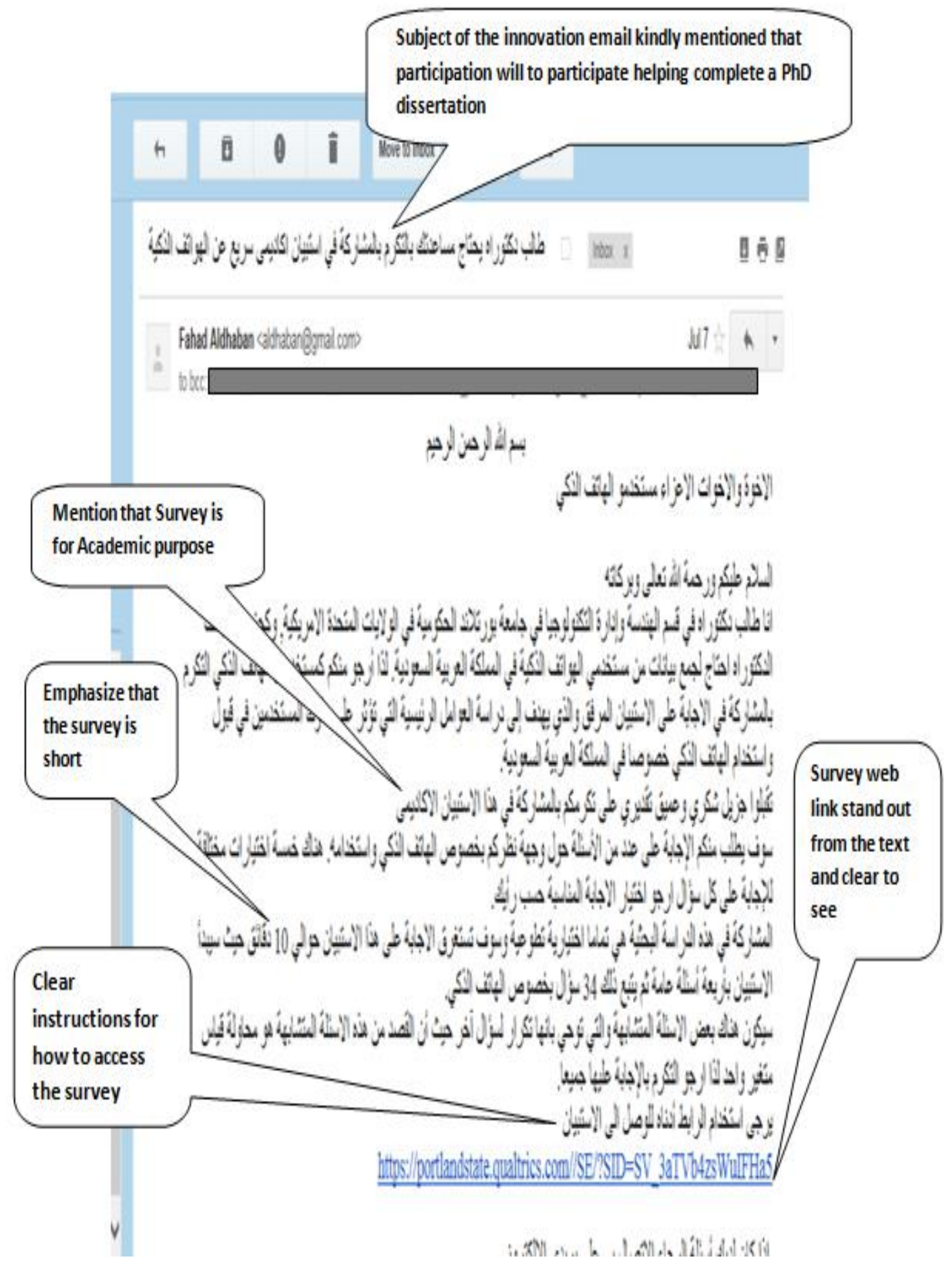

Figure 11: A screenshot of the invitation email 
The survey invitation was emailed out in three rounds, including follow ups. On June $29^{\text {th }}$, we started emailing-out the initial round of surveys. On July $12^{\text {th }}$, we started to email-out the second round as a first reminder to participants. On July $25^{\text {th }}$, we started to email-out the third round, a second survey reminder. 408 responses were received from the initial survey which is an $8.16 \%$ return. The second round (first reminder) increased the response total to 553 with 145 responses in this round which accounts for an additional $2.9 \%$ response. The third round (second reminder) increased the total of responses to 657 with 104 responses in this third round, which accounts for 2.08\% additional responses as shown in Figure 11 below.

In the invitation emailed to participants, it was indicated that the time expected to complete the survey was 10 minutes. After analysis, it was revealed that the average compilation time was 9 minutes.

\subsubsection{Response Rate}

Cobanoglu et al. [254] indicated, in their study comparing mail, fax and webbased surveys, that the response rate in web-based sampling methods is expected to be much higher in the first seven days following the start of the survey. In this research the pattern of response rate has been much higher in the initial survey, especially in the earlier days, which is consistent with the findings of Cobangolue et al. [254]. Baruch and Holtom stated that "researchers who observe a low initial response rate to a survey may redouble their efforts to increase it and one of the most likely tactics to use as 
reminders" [255]. Even though they encourage research to use reminders to increase response rate it was found that using reminders may not result in a higher response rate. In this survey, three waves of e-mail invitations were sent to participants: the initial survey invitation and two reminders. The response flow was higher for the initial survey followed by a first reminder and a second reminder as shown in the figure 12 below:

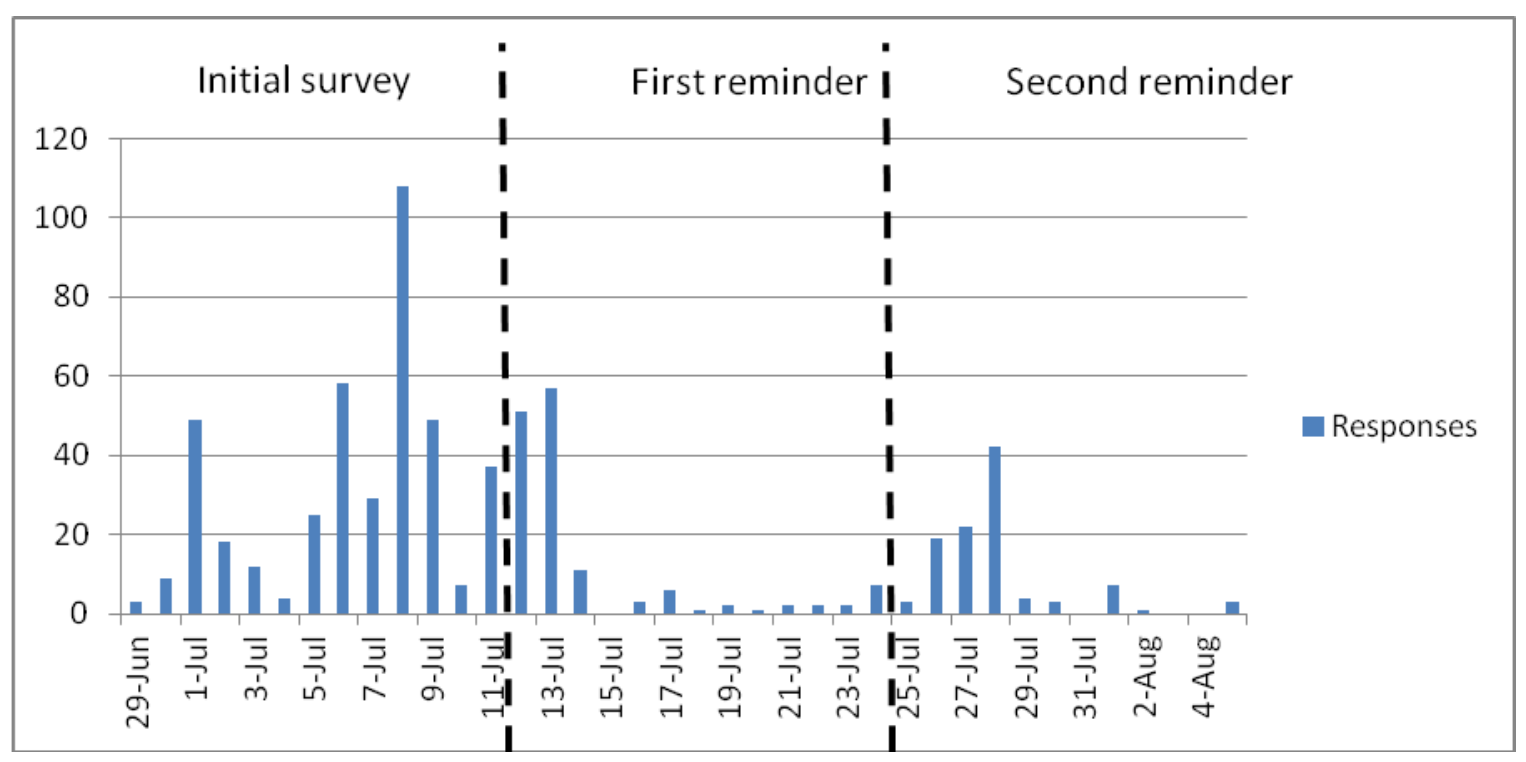

Figure 12 Response rate over time

Out of the 5,000 requests sent out, a total of 657 responses were returned, giving an overall response rate of $13.14 \%$ (657/5000). After data screening and elimination of invalid responses, 641 responses were analyzed (12.8\%). Responses were received in the following spread pattern:

Initial survey $\quad R R=\frac{408}{5000}=8.16 \%$

First Reminder $\quad R R=\frac{145}{5000}=2.9 \%$ 
Second Reminder $\mathrm{RR}=\frac{104}{5000}=2.08 \%$

Combined $\quad \mathrm{RR}=\frac{657}{5000}=13.14 \%$

When using SEM, it is recommended to obtain at least ten data points for each item. The survey questionnaire for this research was designed based on the developed research model and it included a total of 34 items. The minimum suggested sample size for this model would be 340 data points and the total final responses usable in this research were 641 (12.8\%). It has been indicated that a typical research survey often obtains no more than a 5 to 10 percent response rate [256] so $12.8 \%$ is satisfactory. Additionally, this response rate is consistent with the response rate of a typical PhD dissertation survey in the field of engineering and technology management, which typically obtains a response rate range from $6.1 \%$ to $11.4 \%[252,257,224]$. Therefore, the response rate in this dissertation of 12.8 percent is well within the expected and acceptable range.

\subsubsection{Respondent Profile}

The completed surveys indicated that a typical respondent could be described as an individual who owns and uses a smartphone in Saudi Arabia. The subject could be from any city or part of Saudi Arabia. Subjects were not filtered for age, knowledge, or academic background. Participants' age ranged from 18 to 56 years or more. A total of $254(40 \%)$ respondents identified themselves as between the ages of 36 to 45 as shown in Table 28 below. The respondent level of education ranged from less than high school 
to a PhD. degree. Of the total respondents, 320 (50\%) have a bachelor's degree, as shown in table 27 below.

Table 27: Respondent age

\begin{tabular}{|c|l|c|c|}
\hline group & Answer & Respondent & percentage \\
\hline 1 & Less than High School & 12 & $2 \%$ \\
\hline 2 & high school & 86 & $13 \%$ \\
\hline 3 & Associate degree & 130 & $20 \%$ \\
\hline 4 & bachelor degree & 320 & $50 \%$ \\
\hline 5 & Master's degree & 68 & $11 \%$ \\
\hline 6 & PhD degree & 25 & $4 \%$ \\
\hline Total & & 641 & $100 \%$ \\
\hline
\end{tabular}

Table 28: Respondent level of education

\begin{tabular}{|c|l|l|c|}
\hline group & \multicolumn{1}{|c|}{ Age } & Respondent & percentage \\
\hline 1 & $18-25$ & 30 & $5 \%$ \\
\hline 2 & $26-35$ & 178 & $28 \%$ \\
\hline 3 & $36-45$ & 254 & $40 \%$ \\
\hline 4 & $46-55$ & 142 & $22 \%$ \\
\hline 5 & $56-$ and up & 37 & $6 \%$ \\
\hline Total & & 641 & $100 \%$ \\
\hline
\end{tabular}

\subsubsection{Non-Response Error: Wave Analysis}

ANOVA was used as the preferred statistical analysis method to investigate the possibility of non-response bias occurrence. Based on the ANOVA analysis, there was no statistically significant difference between respondents among the three waves of data collection (initial survey and the two follow-ups). The mean of measurement items from respondents in the initial survey and the two follow ups have been compared at $(p<0.05)$ for five important variables measured in this survey: Performance Expectancy 
(PE) item (PE1), Expected Effort (EE) item (EE1), Social Influence (SI) item (SI1), Brand Influence (BIF) item (BIF1) and Economic Factors (EF) item (EF1) as shown tables 29 to 33 below:

Table 29: Performance Expectancy (PE) item (PE1)

ANOVA

PE1

\begin{tabular}{|c|c|c|c|c|c|}
\hline & $\begin{array}{l}\text { Sum of } \\
\text { Squares }\end{array}$ & df & Mean Square & $\mathrm{F}$ & Sig. \\
\hline Between Groups & .635 & 2 & .317 & .867 & .421 \\
\hline Within Groups & 233.596 & 638 & .366 & & \\
\hline Total & 234.231 & 640 & & & \\
\hline
\end{tabular}

Table 30: Expected Effort (EE) item (EE1)

ANOVA

EE1

\begin{tabular}{|l|r|r|r|r|r|}
\hline & Sum of Squares & df & Mean Square & F & \multicolumn{1}{c|}{ Sig. } \\
\hline Between Groups & .738 & 2 & .369 & 1.105 & .332 \\
Within Groups & 213.022 & 638 & .334 & & \\
Total & 213.760 & 640 & & & \\
\hline
\end{tabular}

Table 31: Social Influence (SI) item (SI1)

ANOVA

SI1

\begin{tabular}{|l|r|r|r|r|r|}
\hline & \multicolumn{1}{|c|}{$\begin{array}{c}\text { Sum of } \\
\text { Squares }\end{array}$} & \multicolumn{1}{c|}{$\mathrm{df}$} & \multicolumn{1}{c|}{$\begin{array}{c}\text { Sean } \\
\text { Square }\end{array}$} & \multicolumn{1}{c|}{$\mathrm{F}$} & \multicolumn{1}{c|}{ Sig. } \\
\hline Between Groups & .577 & 2 & .288 & .688 & .503 \\
Within Groups & 267.380 & 638 & .419 & & \\
Total & 267.956 & 640 & & & \\
\hline
\end{tabular}


Table 32: Brand Influence (BIF) item (BIF1)

ANOVA

BIF1

\begin{tabular}{|l|r|r|r|r|r|}
\hline & \multicolumn{1}{|c|}{$\begin{array}{c}\text { Sum of } \\
\text { Squares }\end{array}$} & df & Mean Square & F & \multicolumn{1}{c|}{ Sig. } \\
\hline Between Groups & .151 & 2 & .075 & .126 & .882 \\
Within Groups & 380.654 & 638 & .597 & & \\
Total & 380.805 & 640 & & & \\
\hline
\end{tabular}

Table 33: Economic Factors (EF) item (EF1)

ANOVA

EF1

\begin{tabular}{|l|r|r|r|r|r|}
\hline & \multicolumn{1}{|c|}{$\begin{array}{c}\text { Sum of } \\
\text { Squares }\end{array}$} & df & Mean Square & F & \multicolumn{1}{c|}{ Sig. } \\
\hline Between Groups & 1.275 & 2 & .637 & .672 & .511 \\
Within Groups & 604.884 & 638 & .948 & & \\
Total & 606.159 & 640 & & & \\
\hline
\end{tabular}

\subsubsection{Nonresponse Error: Item Nonresponse}

Qualtrics software reported 691 responses, out of which, 34 responses were incomplete. The incomplete surveys were identified and deleted. The survey questions were designed to be mandatory for participants to answer each question before they can move into the next question (the force-to-answer feature of Qualtrics software has been applied). Therefore there were no incomplete or missing data in the surveys that 
were used in the analysis for this research. After data screening and removing non usable responses, 641 responses were used.

\subsubsection{Post-Survey Adjustments}

In this survey, there was no missing data relevant to the research hypothesis; therefore, no post-survey adjustments were needed.

\subsubsection{Data Screening}

Outliers: This survey used a Likert scale, which limited the possible answers in a range from 1 to 5 for each question. Therefore, there will be no outliers because the possible answer has to be within the range of 1 to 5 .

unengaged respondent [258]: when a participant is selecting only one answer for all questions in the survey. It indicates that this particular participant is not paying attention to the survey's questions, which indicates a lack of engagement in the survey. To improve data quality it is recommended to identify unengaged respondents and delete them from the data set. There are a number of techniques that can be implemented to identify unengaged respondent such as calculating the standard deviations (SD) for each respondent. The SD for each participant has been calculated using Microsoft excel. In this research, any response that has a SD equal to zero is identified as a situation of unengaged respondent. Sixteen participants were identified as unengaged respondents and have been removed from the survey. 


\subsubsection{Reliability}

All factors in the research model are specified as reflective since their indicators are highly correlated and largely interchangeable as shown in Table 33 below [259]. To assess the reliability of the survey instrument used, Cronbach's alpha measurement was conducted to test the internal consistency for each factor. Scholars indicated that increasing the value of Cronbach's alpha is partially based upon the number of items; the more items the higher the value [252]. Cronbach's alpha of .7 is considered to be a good and an acceptable level of reliability[260]. However, the recommended minimum Cronbach's alpha is .6 [253]. The results of Cronbach's alpha showed that all factors in this research have achieved Cronbach's alpha values above the recommended value of .6 as shown in table 34 below.

Table 34: Reliability of factors and its specification

\begin{tabular}{|l|l|l|l|l|}
\hline Factor Name & Factor Code & \multicolumn{1}{|c|}{$\begin{array}{c}\text { Number of } \\
\text { Items }\end{array}$} & \multicolumn{1}{c|}{$\begin{array}{c}\text { Cronbach's } \\
\text { Alpha }\end{array}$} & Specification \\
\hline $\begin{array}{l}\text { Performance } \\
\text { Expectancy }\end{array}$ & PE & 4 & .803 & Reflective \\
\hline $\begin{array}{l}\text { Expectancy } \\
\text { Brand }\end{array}$ & EE & 3 & .870 & Reflective \\
\hline $\begin{array}{l}\text { Influence } \\
\text { Factors }\end{array}$ & BIF & 3 & .803 & Reflective \\
\hline $\begin{array}{l}\text { Perceived } \\
\text { Enjoyment }\end{array}$ & PJ & 4 & .734 & Reflective \\
\hline
\end{tabular}




\begin{tabular}{|l|l|l|l|l|}
\hline Design & DS & 3 & .727 & Reflective \\
\hline $\begin{array}{l}\text { Facilitating } \\
\text { Conditions }\end{array}$ & FC & 4 & .748 & Reflective \\
\hline $\begin{array}{l}\text { Social } \\
\text { Influence }\end{array}$ & SI & 3 & .601 & Reflective \\
\hline $\begin{array}{l}\text { Behavioral } \\
\text { Intentions }\end{array}$ & BI & 3 & .862 & Reflective \\
\hline Use Behavior & UB & 3 & .646 & Reflective \\
\hline
\end{tabular}

\section{Chapter Five: Research Methodology}

\subsection{Structural Educational Modeling (SEM)}

In order to statistically analyze data collected in this research and obtain better results, it was important to use a suitable and adequate method. In this study, SEM was utilized since it is a suitable multivariate or statistical technique to analyze the data collected. The aim of using a multivariate or a statistical technique is to examine the hypothesized relationship among variables in the research model, to know what types of relationships exist among them, and to find out how significant each relationship is based on the data that have been collected. Selecting the appropriate statistical technique depends on a number of factors, including the type and the basis of the relationships to be analyzed and the desired outcome of the research. The hypothesized relationships in this research model are multiple interrelated dependence relationships that were developed based on modification of existing theoretical IT adoption model, 
UTAUT. Therefore, Structural Equation Modeling (SEM) as a suitable multivariate technique was used to analyze the data in this dissertation.

The SEM is a suitable multivariate technique to be used in this research for a number of reasons including [261-263, 203, 264]:

- First: SEM is a powerful multivariate technique, especially when it is utilized to examine or analyze theoretical-based hypotheses with multiple interrelated dependence relationships [214]. Moreover, SEM was described as a powerful statistical technique that takes a confirmatory approach, such as hypothesis testing, rather than an exploratory approach to the analysis of a structural theory and its effects on a specific phenomenon [262]. When using SEM, the research foundations of the relationships under study should be based on a strong theoretical basis [214].

- Errors can negatively and critically affect the results and the process of statistical analysis [265, 264]. Errors are common problems that researchers work hard to avoid and eliminate as much as possible. Errors can accrue at any point of the research phase starting from preparing the research instrument to collecting data and through all the statistical analysis phases. Unlike other statistical techniques, SEM can provide unique solutions for this problem. SEM can explicitly estimate errors and the errors' variance parameters.

SEM analysis starts from the measurements model, which accounts for and accommodates all indicators (items), independent and dependent variables, 
continuously through a measurement structural model, while accommodating for errors in the whole process. SEM establishes a direct correction for measuring errors to allow for more accurate estimates of the relationships under consideration. One of the most important and known features of SEM is its approach to the explicitness of the covariance and errors structure for better testing of the data and its fit to the model. SEM explicitly specifies observations and the error variable(s), which greatly enhance the result of the analyses [263].

- Unlike alternative multivariate techniques, SEM is a comprehensive technique that can be used to examine sequences of theoretical dependence relationships simultaneously [261]. SEM is the only multivariate technique that enables complete and simultaneous testing of all relationships in a given model, which gives a more comprehensive explanation for the phenomena under study.

- Unlike other multivariate techniques that mostly analyze the variable directly, SEM distinguishes between variables and factors. SEM utilizes both a measurement model and a structural model to gain more accurate and comprehensive results. In SEM, variables or indicators (items) that are collected and measured using instruments such as surveys, are considered observable and SEM obtains direct measures of them along the whole process. With regards to factors, they can be exogenous or endogenous. Exogenous factors are the independent or latent variables that have a number of indicators, from outside 
the model, to determine them. The endogenous factors are the dependent variable in the model.

- SEM was explicitly indicated to be the most distinguished multivariate technique to test behavioral theory. The research model in this research is based on IT adoption theories and it is a behavioral-based theory. It is intended to understand and explain factors that influence the behavioral intention of users to adopt and use the Smartphone. Therefore, SEM is the most appropriate multivariate technique to be used in this research.

- In SEM the structural model is built and analyzed, showing the result in both tables and structural or path visual diagrams that make it easier to visualize, follow and understand the paths and effects of all relationship in a given analyses.

- SEM was described as "the dominant multivariate technique" [266]. SEM is very widely used in research in the IT adoption domain and related to the adoption and use mobile.

\subsection{Reflective Measurement}

For the SEM approach, the items or indicators used to measure the latent variables (LV) can be a reflective or formative measurement. Reflective measurement is the most widely used method and one of the key features that differentiates it from formative measurement is that a change in any LV will be 
reflected in all the items or indicators [267]. Reflective measures are known to be consistent with confirmatory factor analysis (CFA) and it accounts for errors [267], while formative measures can be achieved by using the partial least square (PLS) method [267]. In reflective measures, indicators should have similar contents, same antecedent and account for errors in the level of indicators (items) [259]. Reflective measurement models are mostly used in fit well with factors such as attitude, personality and behavioral intention [214]. Hair et al. [214] provided an example to explain reflective measurement in study of medical "symptoms such as shortness of breath, tiring easily, wheezing, and reduced lung functioning would be considered indicators that would reflect the latent factor of emphysema". Unlike formative measurement, reflective measurement dictates that all indicator items are caused by the same latent construct therefore, items within the same factor should have a high correlation with each other [214]. Moreover, in reflective measurement individual items should be interchangeable so that moving out a single item will not change the factor [214]. The factors in the research model for this dissertation related to attitude and behavioral intentions which fit the reflective measurements. Moreover, the indicators measurement in this dissertation is reflective and the CFA has been utilized to analyze the data. the measurement for all factors in the research model are specified as reflective since their indicators are highly correlated and largely interchangeable as shown previously in Table 33 [259]. 


\subsection{Use of SEM in IT adoption Research}

The SEM method has been used widely in empirical research related to the use and adoption of IT. Kim used SEM to study and analyze the effects of job relevance and experience on the adoption of Smartphone technology by individuals. His model was based on the technology acceptance model (TAM) [91]. Lewis et al. used the SEM method to study the potential of young consumers to use mobile banking services [155]. Their research model was based on TAM. Kijsanayotin et al. used SEM to examine the factors that influence health information adoption [26]. Their research model and hypotheses were based on UTAUT. Based on TAM, Kim investigated mobile wireless technology adoption using the SEM method [105]. Kang et al. used the SEM method in their research studying the adoption of Smartphones in Korea [49]. Their research model was based on a modification of TAM [49]. Verkasalo et al. utilized the SEM method in their research to analyze users' use of Smartphone' applications[90]. Their research was based on TAM theory [90]. The popularity of SEM and the frequent use of it in the domain of IT adoption increases the credibility of SEM and makes it more appealing, applicable and reliable for use in the IT adoption area.

\subsection{SEM Process, Assumptions and Limitations}

Structural Equation Modeling (SEM) is defined as "multivariate technique combining aspects of factor analysis and multiple regression that enables the researcher to simultaneously examine a series of interrelated dependence relationships among the 
measured variables and latent construct (variants) as well as between several latent constructs" [214]. Since 1980, SEM has become increasingly popular among researchers as one of the preferred alternatives among other multivariate techniques $[203,268]$. SEM is described as a statistical method that can be utilized to draw conclusions of dependency relationships from a combination of observed data and theoretical assumptions [269, 262, 270]. SEM enables researchers to simultaneously examine a series of effects and relationships while accounting for measurement errors within the same process [214].

The term structural equation modeling carries two critical aspects of the procedure:[271]

- First: the interrelated relationships in the research under consideration are being represented by a sequence of structural equations.

- Second: the mentioned structural relationships can be modeled to reflect better conceptualization of the theory under consideration.

SEM is a very powerful multivariate technique, particularly when used to test theories that have multiple equations with dependence relationships. [214, 242]. When using SEM, the researchers should base their research on prior experiences and theoretical foundations that provide some explanations of which independent variables predict or influence each dependent variable in a given research framework or model. In SEM, dependent variables in a set of given relationships can become independent variables in subsequent relationships in the same model or structure. After that, all of 
these mentioned relationships are translated into a sequence of structural equations for each dependent variable in which every relationship is simultaneously accommodated with differing effects $[262,214]$. Unlike other alternative multivariate techniques, SEM is characterized as a confirmatory approach which means a statistical approach to test or confirm a set of relationships that was already specified [214]. There are a number of stages or steps that SEM processes usually go through including: [214]

- Defining the individual factors: In this stage the researcher defines what items measure each variable.

- Developing and specifying the measurement model: In this stage, each factor or variable that is going to be in the model are going to be identified and the indicators (items) are going to be assigned into their respondent variable. Each latent variable that is going to be used in the model must be identified.

- Designing a study to produce empirical results: In this stage, the researcher has to assess the adequacy of the data and look at its appropriateness for the model under consideration to obtain more accurate empirical results.

- Assessing the measurement model validity: This is very critical stage and it is the most fundamental event of the SEM testing process. The analysis will not go to the next stage until there is an acceptable model fit. Measuring the model validity depends on obtaining an acceptable level of goodness of fit for the model under consideration and obtaining specific evidence that shows factor validity. There are a number of goodness-of-fit indices that can be used to assess 
the fit between the hypothesized model and the data collected such as: Chisquare/degrees of freedom (df), Goodness-of-fit Index (GFI), Adjusted Goodnessof-fit Index (AGFI), Comparative Fit Index (CFI), or Root Mean Square of Approximation (RMSEA).

In the measurement model, the researcher specifies a number of indicators for each single dependent or independent variable. Confirmatory factor analysis (CFA) can be used to perform convergent validity to determine if each factor can be reflected by its indicators (items). CFA is also used to assess and test if each factor is statistically valid. As shown in Figure 13 below, all the variables are treated as latent or dependent variables and all are correlated. Each factor is linked into its indicators (items) and there are no structural relationships among variables in this stage (see Figure 13). In this stage, the researcher is going to form and run the measurement model without linking or showing the hypothesized relationships in which all variables are correlated and each variable is linked to its indicators. 


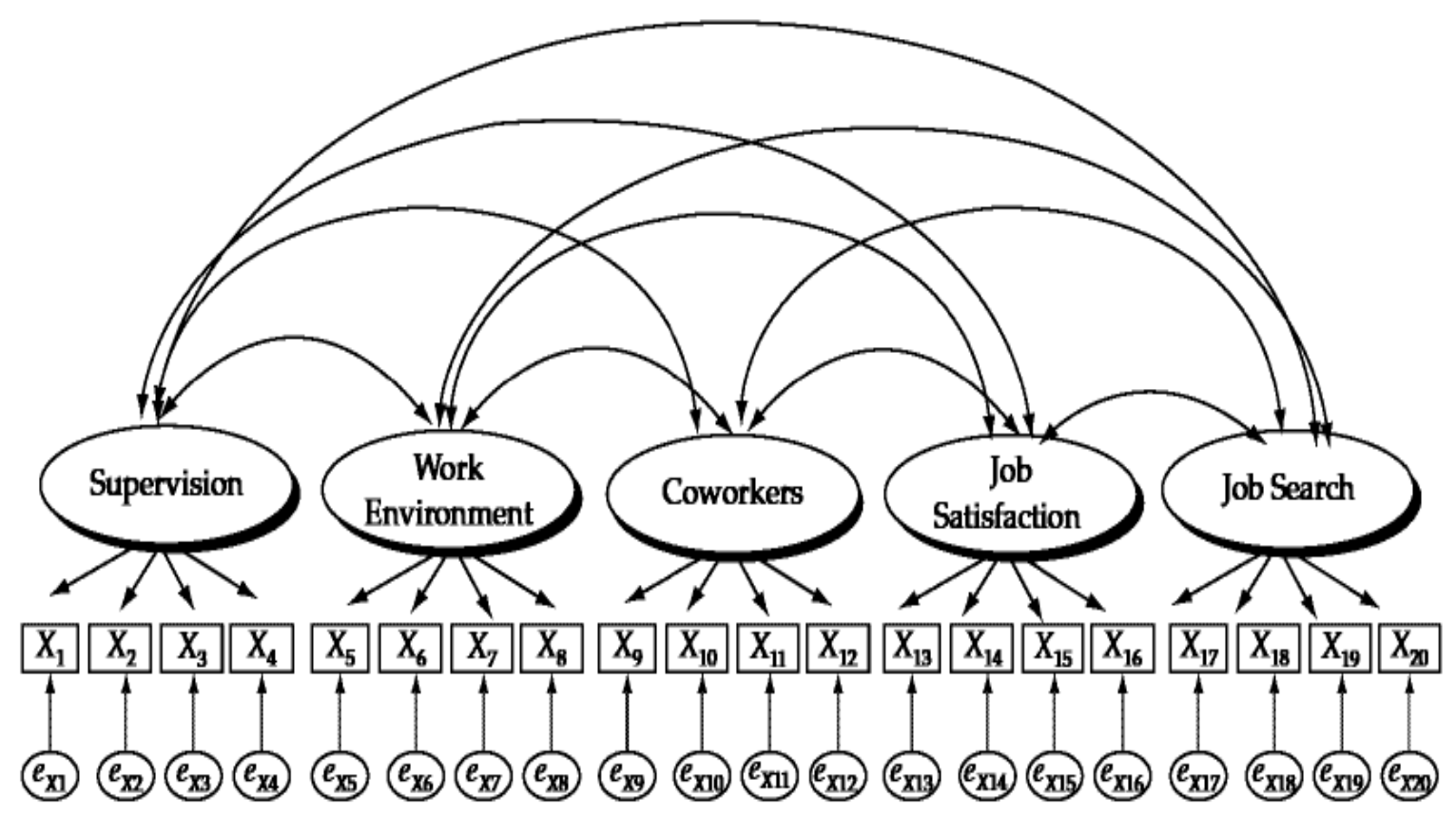

Figure 13: An example of measurement model (CFA) model [214].

- Specifying the structural model: This is an important step in the process of developing a SEM model, in which the structural model is going to be specified. Based on the research model, this step is going to assess the relationships from one variable to another within the model. This stage will indicate all types of hypothesized dependence relationships which exist among all factors and its magnitude or significant will be calculated. In this stage the model is going to show the structural relationships among all factors based on the hypothesized relationships and the theory behind them. It indicates the overall test of the theory and the hypothesized relationships among all factors in the theoretical model including the indicators (items) and errors. 
By using CFA to run and test the structural model, the type of relationships among all model factors and their significance is going to be presented. The hypothesized relationships are going to be set and the exogenous or independent as well as the endogenous or dependent variables are identified in this stage.

After obtaining a good model fit, SEM then will test the nature and significance of the relationships among all variables in the model that was hypothesized. In this stage, the measurement model is going to be changed into a structural model based on the hypothesized research model. In the structural model, the co-relational relationships are going to be changed into dependence relationships with unidirectional arrows that show the direction of each relationship that was hypothesized for each path diagram. Applying SEM will show the nature of each hypothesis and if each hypothesized path is significant or not in its assigned direction. After obtaining an acceptable model fit, the researcher should modify the model by connecting or linking the independent variables and the dependent variables based on the hypotheses. After all links and connections have been established, the researcher can run the structural model to obtain the final results for each hypothesized relationship. 


\section{Assumptions for SEM}

To obtain a more accurate and robust result, there are number of assumptions that a researcher should consider when using the SEM method to analyze data including the following [214]:

- Having a theoretical basis or prior experience to set or indicate an initial relationship among variables in the model under consideration,

- Having a normal distribution of data,

- Having well measured variables with at least three indicators,

- Having at least ten cases for each indicator as a minimum sample size.

When the researcher meets the above-mentioned assumptions, it will greatly contribute to the quality of the outcome that SEM is trying to achieve.

\section{Limitations to SEM}

There are number of limitations associated with SEM that a researcher should be aware of when selecting a multivariate technique in a given research including the following $[238,214,250,242]$ :

- SEM needs a theoretical or prior experience hypothesis that can set the initial base of logic for the relationships among variables in the model under consideration. SEM will test and analyze these hypotheses based on the theory or the logic behind it. 
- SEM may not work well with a small sample size. It requires a minimum sample size based on the number of variables and indicators in the model under consideration.

- SEM requires at least three indicators for each variable, two indicators per variable is problematic, and one indicator may not allow the measurement model to run or it may indicate a poor model fit and require modifications of the model. In some situations it is difficult to provide the required number of indicators per variable in SEM. 


\section{Chapter Six: Analysis}

This chapter describes the statistical analysis that has been conducted to analyze the data collected and test the research hypotheses.

Data collected for this research have been screened and organized as detailed in the previous chapter using a number of methods and software applications such as SPSS and Microsoft Excel. Structural Equation Modeling (SEM) has been utilized in this research which included two main steps: 1) Conducting Confirmatory Factor Analysis (CFA) to verify the measurement of the research model and obtain an acceptable and adequate model fit; and, 2) Transferring the acceptable model into a full structural model to analyze the hypothesized relationships among factors in the research model.

Structural Equation Modeling (SEM) is a multivariate technique that combines aspects of factor analysis and multiple regression, allowing researchers to simultaneously examine a series of interrelated dependence relationships [214]. As mentioned in the previous chapter, SEM has become an increasingly popular statistical approach among researchers and a preferred alternative among other multivariate techniques [203, 268]. It is a statistical method that can be used to test and explain dependency relationships by combining observed data and theoretical assumptions [269, 262, 270]. Using SEM, a researcher can simultaneously examine a series relationships while accounting for measurement errors at the same process [214]. In this dissertation there are two main components in SEM: first is the measurement model and second is the structural model. 


\subsection{Measurement Model}

In the Measurement Model, CFA enabled the researcher to examine if the hypothesized relationships between the observed and latent variables do indeed exist.

The main task in the measurement mode phase is to test the model and verify the goodness-of-fit between the data collected and the hypothesized model. There are a number of indices that have been developed and recommended as goodness of model fit indicators as shown in Table 35 below.

Table 35: Recommended indices to obtain a goodness of model fit indicators

\begin{tabular}{|l|l|l|c|}
\hline \multicolumn{1}{|c|}{$\begin{array}{c}\text { Indicators } \\
\text { name }\end{array}$} & $\begin{array}{l}\text { Indicators } \\
\text { code }\end{array}$ & \multicolumn{1}{|c|}{ Explanation } & $\begin{array}{c}\text { Recommended } \\
\text { level }\end{array}$ \\
\hline $\begin{array}{l}\text { Chi- } \\
\text { square/degrees } \\
\text { of freedom (df), }\end{array}$ & $\chi 2$ /d.f & $\begin{array}{l}\text { It is based on ratio between chi } \\
\text { square and the degrees of freedom. } \\
\text { Compensates for sample size impact } \\
\text { on X2 statistic. }\end{array}$ & $<3$ \\
\hline $\begin{array}{l}\text { Goodness-of-fit } \\
\text { Index }\end{array}$ & GFI & $\begin{array}{l}\text { Goodness-of-fit Index is Less sensitive } \\
\text { to sample size than X2. }\end{array}$ & $>.9$ \\
\hline $\begin{array}{l}\text { Adjusted } \\
\text { Goodness-of-fit } \\
\text { Index }\end{array}$ & (AGFI) & $\begin{array}{l}\text { (AGFI) corrects the GFI, which is } \\
\text { affected by the number of indicators } \\
\text { of each latent variable. }\end{array}$ & $>.8$ \\
\hline $\begin{array}{l}\text { Comparative Fit } \\
\text { Index }\end{array}$ & (CFI) & $\begin{array}{l}\text { It is one of the indices that assess in } \\
\text { to what extent or how well a specified } \\
\text { model fits relative to some alternative } \\
\text { baseline model (referred to as null } \\
\text { model), which assumes that all } \\
\text { observed variables are uncorrelated. } \\
\text { It represents the improvement in the } \\
\text { in model fit by the specification of } \\
\text { related multi-item factors. }\end{array}$ & $>.9$ \\
\hline $\begin{array}{l}\text { Root Mean } \\
\text { Square of } \\
\text { Approximation }\end{array}$ & (RMSEA) & $\begin{array}{l}\text { It takes into account the error of } \\
\text { approximation in the population. } \\
\text { It explicitly tries to correct for the } \\
\text { model complexity and the sample size } \\
\text { by including each in its computation. }\end{array}$ & \\
\hline
\end{tabular}


CFA examined the relationship between latent variables and their observed measures as shown in Figure 14 below. A theoretical basis and a number of qualitative methods have been utilized to develop the research model to be tested using CFA. It has been used to validate the measurement model to obtain an acceptable and adequate model fit necessary to proceed to next step the structural model.

Figure 14 below shows the measurement model using CFA with SPSS package and AMOS software. Based on recommended indices, the first model measurement has shown an acceptable fit in a number of recommended indices. However, a number of indices showed a lower score than recommended.

To improve model measurement and obtain an acceptable model fit actions had to be taken. A number of error terms that showed a high covariance within their own factor namely e33 and e31 were correlated and e18 and e17 were correlated [272]. Moreover a number of items that showed a low loading namely SI3 and EF1 were removed [272]. After making the recommended changes, the model was run again and it showed a better model fit with better indices scores as shown in Table 36 below. 
Table 36: Model fit indices - Results of the model measurement fit

\begin{tabular}{|l|l|l|l|l|l|l|}
\hline Model Fit Indices & \multicolumn{1}{|c|}{ GFI } & AGFI & NFI & CFI & RMSEA & X2 /d.f \\
\hline $\begin{array}{l}\text { Recommended } \\
\text { Value }\end{array}$ & $>.9$ & $>.8$ & $>.9$ & $>.9$ & $<.05$ & $<3$ \\
\hline $\begin{array}{l}\text { Obtained Value } \\
\text { (first Model fit) }\end{array}$ & .896 & .871 & .885 & .927 & .049 & 2.5 \\
\hline $\begin{array}{l}\text { Obtained Value } \\
\text { (Final Model fit) }\end{array}$ & .913 & .892 & .907 & .946 & .044 & 2.2 \\
\hline
\end{tabular}




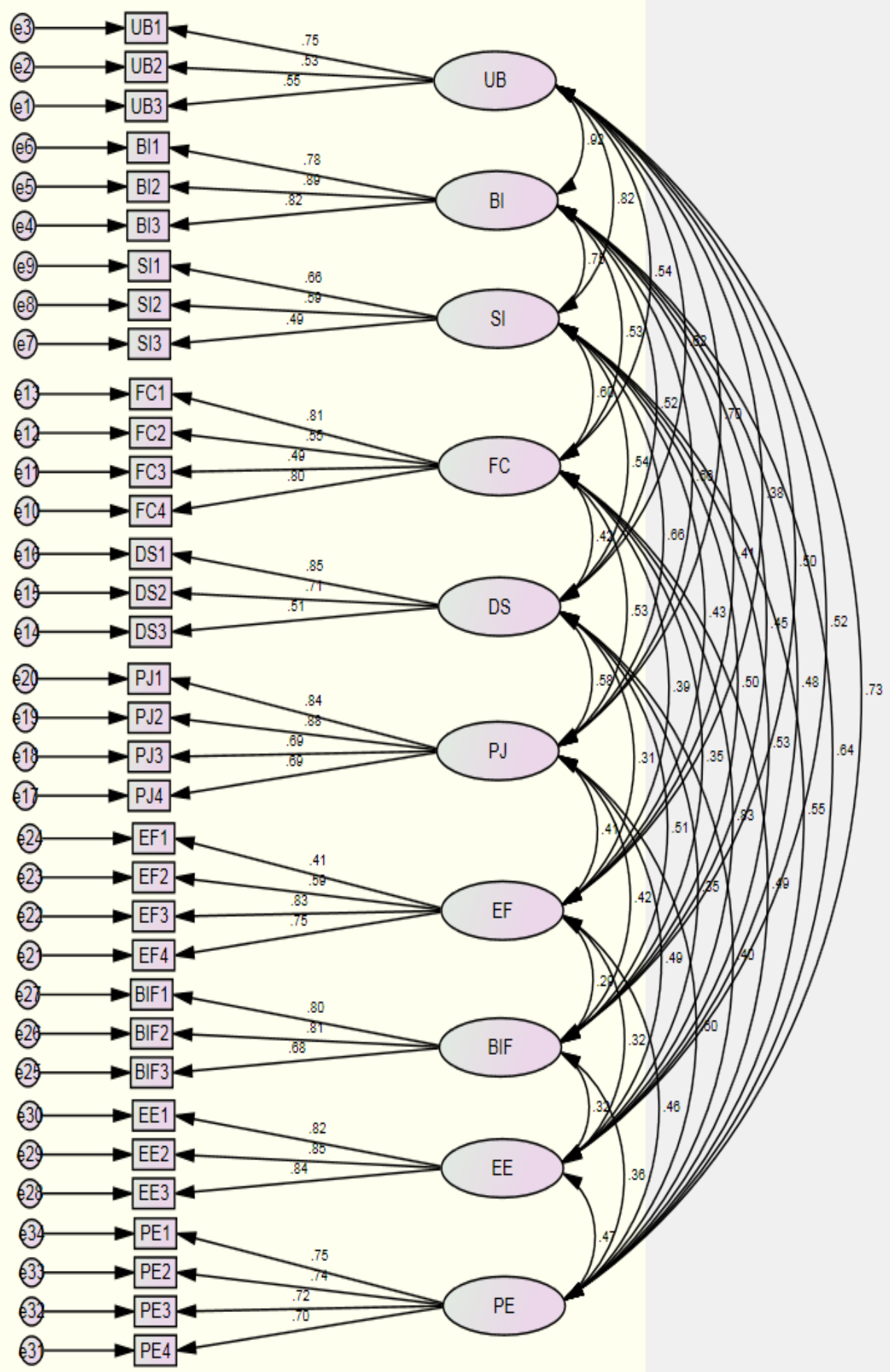

Figure 14: Measurement Model 


\subsection{Structural Model}

After obtaining an adequate and acceptable model fit during the measurement model phase, the next phase is the full structural model. In this phase the research model is assessed and all hypothesized relationships among model factors are examined and identified. In this phase, the research model shows the structural relationships among all factors, type of relationships and the level of significance for each relationship.

In Figure 15, the structural model shows the nature and magnitude of the relationships between factors in the research model. Based on the developed research model, the structural model tested the hypothesized relationships between the behavioral intention factor and six factors: performance expectancy factor, effort expectancy factor, economic factors factor, received enjoyment factor, brand influence contract and design factor. Also, the structural model examined the hypothesized relationships between the use behavior factor and three specific factors: behavioral intentions factor, social factors factor, and facilitating conditions factor. Figure 15, below, shows a screenshot of the full structural model from SPSS-AMOS software. The final results of the SEM - structural model is shown in Figure 15 \& 16 below. 


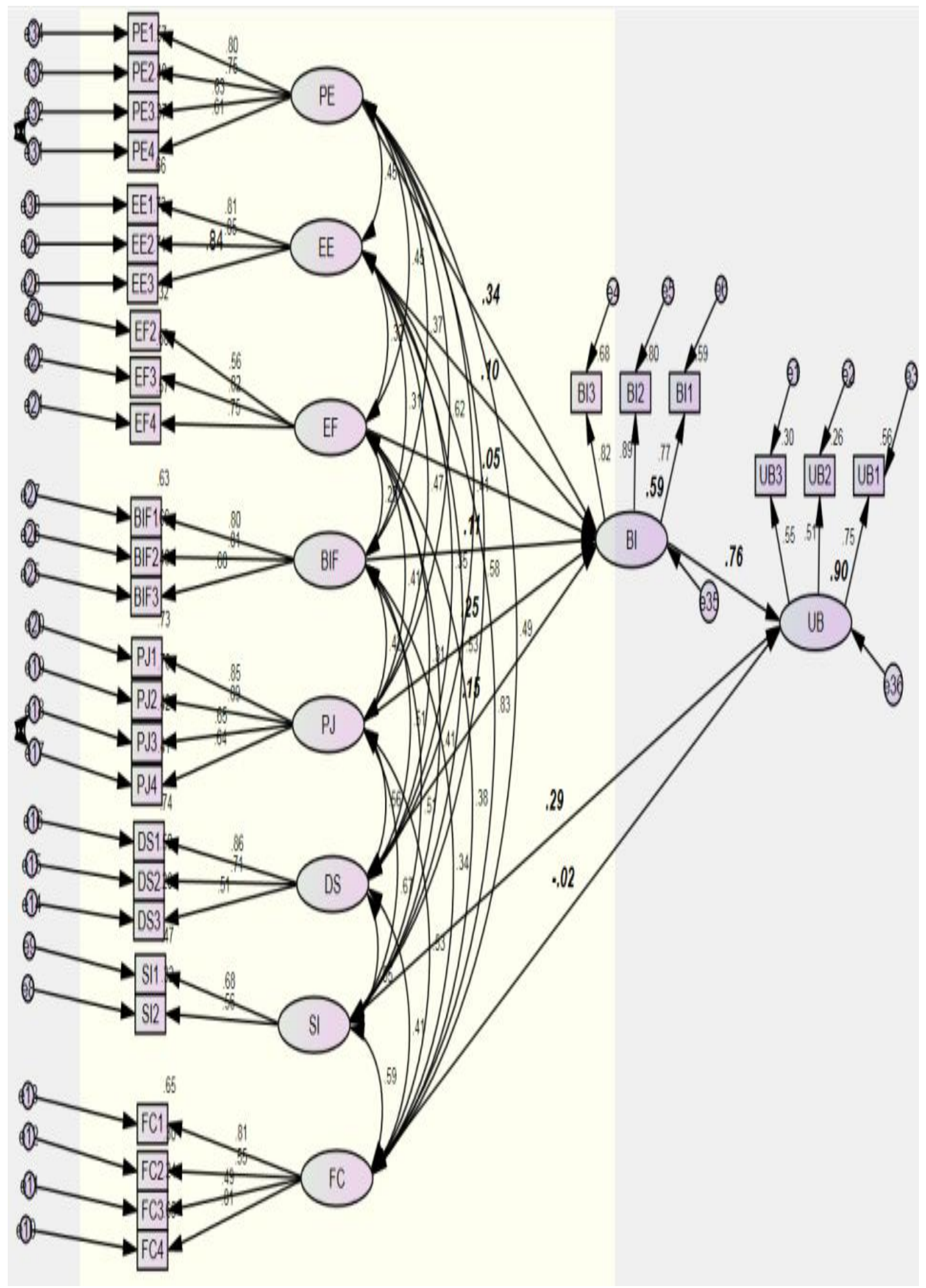

Figure 15: Structural model 


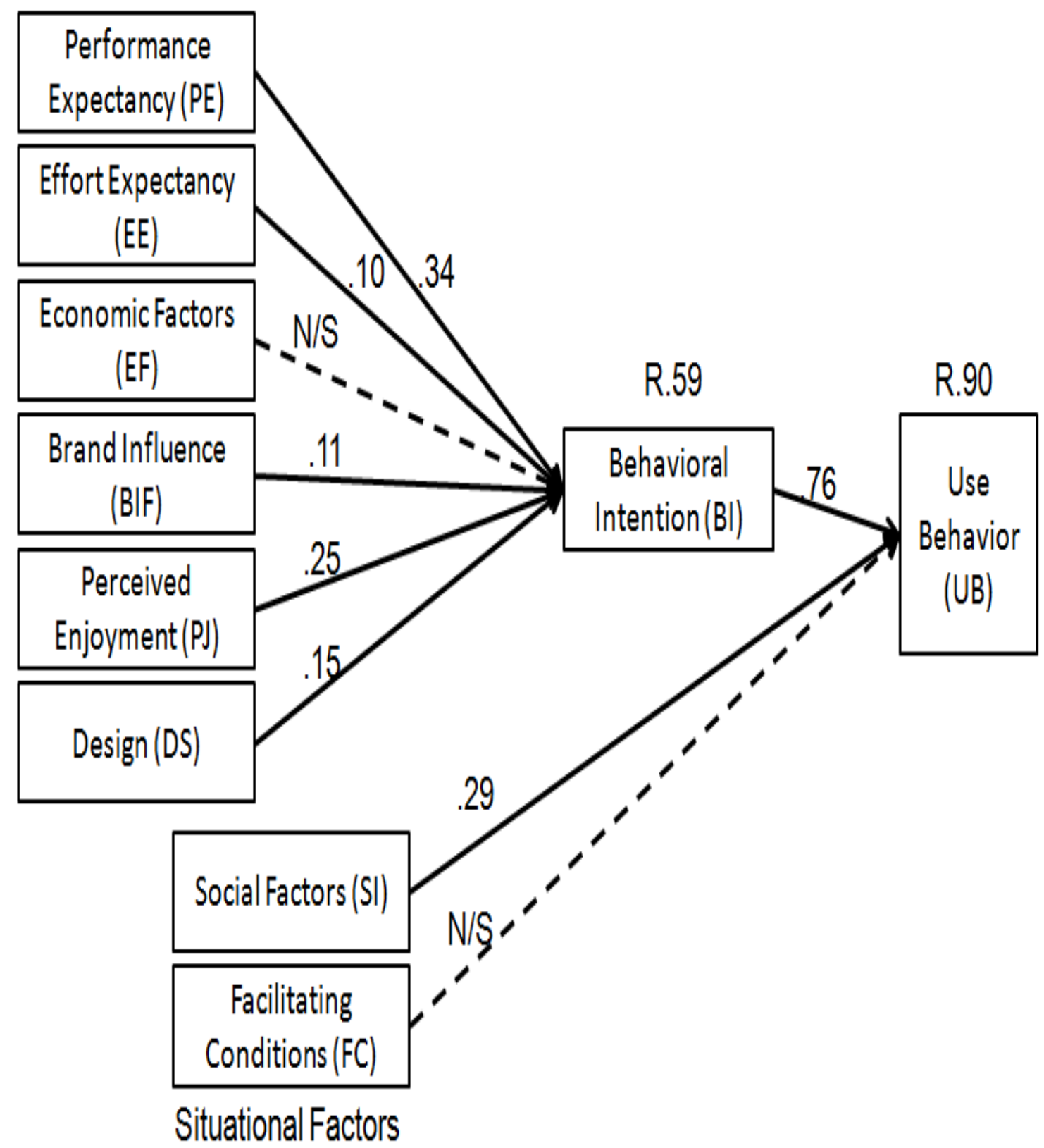

Figure 16: The research model with the results 


\section{Chapter Seven: Results}

In this chapter, the results of the data analysis are discussed, starting with descriptive statistics, the full structural model evaluation and finally testing the hypotheses.

\subsection{Performance Expectancy Factor}

Performance expectancy factor measures the degree to which an individual feels or believes that adopting and using smartphone technologies will help him/her achieve gains in performing their daily tasks. Items PE1, PE2, PE3, and PE4 in the survey questionnaire measure this factor using a five-point Likert scale arranged as: (1) "strongly disagree," (2) "disagree," (3) "neither disagree nor agree," (4) "agree," and (5) "strongly agree".

Table 37 and Table 38 show the respondent statistics for item PE1; one of four items designed to measure performance expectancy factor. Of the total respondents, 351 (55\%) have selected the answer "strongly agree" and $258(40 \%)$ have selected the answer "agree." Responses for more items and its statistics are attached in the Appendix G.

Table 37: Proportion of respondent for item PE1

\begin{tabular}{|c|c|c|}
\hline Answer & Respondent & Percentage \\
\hline 5 & 351 & $55 \%$ \\
\hline 4 & 258 & $40 \%$ \\
\hline 3 & 29 & $5 \%$ \\
\hline 2 & 3 & $0 \%$ \\
\hline
\end{tabular}




\begin{tabular}{|c|c|c|}
\hline 1 & 0 & $0 \%$ \\
\hline Total & 641 & $100 \%$ \\
\hline
\end{tabular}

Table 38: PE1 statistics

\begin{tabular}{|l|c|}
\hline \multicolumn{1}{|c|}{ Statistic } & Value \\
\hline Min Value & 1 \\
\hline Max Value & 4 \\
\hline Mean & 4.49 \\
\hline Variance & 0.37 \\
\hline Standard & 0.60 \\
\hline Total Responses & 641 \\
\hline
\end{tabular}

\subsection{Effort Expectancy Factor}

This factor measures the degree of effort or ease associated with the use of smartphones. Items EE1, EE2, and EE3 in the survey questionnaire measure effort expectancy factor using a five-point Likert scale arranged as: (1) "strongly disagree", (2) "disagree", (3) "neither disagree nor agree", (4) "agree", (5) "strongly agree".

Table 39 and Table 40 show the respondents' responses by proportion and statistics for item EE1; one of three items designed to measure the effort expectancy factor. Of the total respondents, 283 (44\%) selected answer "strongly agree" and 330 (51\%) selected answer "agree." A breakdown of responses for more items and its statistics are attached in Appendix G.

Table 39: Proportion of respondent for item EE1

\begin{tabular}{|c|c|c|}
\hline Answer & Respondent & Percentage \\
\hline 5 & 283 & $44 \%$ \\
\hline 4 & 330 & $51 \%$ \\
\hline
\end{tabular}




\begin{tabular}{|c|c|c|}
\hline 3 & 25 & $4 \%$ \\
\hline 2 & 2 & $0 \%$ \\
\hline 1 & 1 & $0 \%$ \\
\hline Total & 641 & $100 \%$ \\
\hline
\end{tabular}

Table 40: EE1 statistics

\begin{tabular}{|l|c|}
\hline \multicolumn{1}{|c|}{ Statistic } & Value \\
\hline Min Value & 1 \\
\hline Max Value & 5 \\
\hline Mean & 4.40 \\
\hline Variance & 0.34 \\
\hline Standard Deviation & 0.58 \\
\hline Total Responses & 641 \\
\hline
\end{tabular}

\subsection{Economic Factors Factor}

This factor measures the degree to which an individual believes that she/he perceived value from the tradeoff between the perceived benefits of smartphones and the cost for acquiring and using it. Items EF1, EF2, EF3 and EF4 in the survey questionnaire measure economic factors using a five-point Likert scale arranged as: (1) "strongly disagree", (2) "disagree", (3) "neither disagree nor agree", (4) "agree", (5) "strongly agree".

Table 41 and Table 42 show the respondents' responses by proportion and statistics for item EF1; one of four items designed to measure effort the expectancy factor. Of the total respondents, 198 (31\%) selected answer "neither disagree nor 
agree" and 189 (29\%) selected answer "agree". Responses for more items and its statistics are attached in the Appendix G.

Table 41: Proportion of respondent for item EF1

\begin{tabular}{|c|c|c|}
\hline Answer & Respondent & Percentage \\
\hline 5 & 21 & $3 \%$ \\
\hline 4 & 189 & $29 \%$ \\
\hline 3 & 198 & $31 \%$ \\
\hline 2 & 192 & $30 \%$ \\
\hline 1 & 41 & $6 \%$ \\
\hline Total & 641 & $100 \%$ \\
\hline
\end{tabular}

Table 42: EF1 statistics

\begin{tabular}{|l|c|}
\hline Statistic & Value \\
\hline Min Value & 1 \\
\hline Max Value & 5 \\
\hline Mean & 3.19 \\
\hline Variance & 0.95 \\
\hline Standard Deviation & 0.97 \\
\hline Total Responses & 641 \\
\hline
\end{tabular}

\subsection{Brand Influence Factor}

This factor measures the degree of importance associated with brand names of smartphones for an individual when adopting and using a smartphone. Items BIF1, BIF2, and BIF3 in the survey questionnaire measure brand influence factor using a five-point Likert scale arranged as: (1) "strongly disagree", (2) "disagree", (3) "neither disagree nor agree", (4) "agree", (5) "strongly agree".

Table 43 and Table 44 below show the respondents' answers by proportion and statistics for item BIF1; one of three items designed to measure the brand influence 
factor. Of the total respondents, $308(48 \%)$ selected answer "strongly disagree", and $256(40 \%)$ selected the answer "agree". Responses for more items and its statistics are attached in the Appendix G.

Table 43: Proportion of respondent for item BIF1

\begin{tabular}{|c|c|c|}
\hline Answer & Respondent & Percentage \\
\hline 5 & 308 & $48 \%$ \\
\hline 4 & 256 & $40 \%$ \\
\hline 3 & 47 & $7 \%$ \\
\hline 2 & 24 & $4 \%$ \\
\hline 1 & 6 & $1 \%$ \\
\hline Total & 641 & $100 \%$ \\
\hline
\end{tabular}

Table 44: BIF1 statistics

\begin{tabular}{|l|c|}
\hline \multicolumn{1}{|c|}{ Statistic } & Value \\
\hline Min Value & 1 \\
\hline Max Value & 5 \\
\hline Mean & 4.34 \\
\hline Variance & 0.59 \\
\hline Standard Deviation & 0.77 \\
\hline Total Responses & 641 \\
\hline
\end{tabular}

\subsection{Perceived Enjoyment Factor}

Perceived enjoyment factor measures the degree to which an individual feels or believes that adopting and using smartphones is enjoyable in its own right, aside from any performance consequences resulting from its usage. Items PJ1, PJ2, PJ3 and PJ4 in the survey questionnaire measure perceived enjoyment factor using a five-point Likert scale arranged as: (1) "strongly disagree", (2) "disagree", (3) "neither disagree nor agree", (4) "agree", (5) "strongly agree". 
Table 45 and Table 46 below show the respondents' answers by proportion and statistics for item PJ1; one of four items designed to measure the brand influence factor. Of the total respondents, 253 (39\%) selected answer "strongly disagree", and 326 (51\%) selected the answer "agree". Responses for more items and its statistics are attached in the Appendix G.

Table 45: Proportion of respondent for item PJ1

\begin{tabular}{|c|c|c|}
\hline Answer & Respondent & Percentage \\
\hline 5 & 253 & $39 \%$ \\
\hline 4 & 326 & $51 \%$ \\
\hline 3 & 55 & $9 \%$ \\
\hline 2 & 6 & $1 \%$ \\
\hline 1 & 1 & $0 \%$ \\
\hline Total & 641 & $100 \%$ \\
\hline
\end{tabular}

Table 46: PJ1 statistics

\begin{tabular}{|l|c|}
\hline \multicolumn{1}{|c|}{ Statistic } & Value \\
\hline Min Value & 1 \\
\hline Max Value & 5 \\
\hline Mean & 4.29 \\
\hline Variance & 0.44 \\
\hline Standard Deviation & 0.66 \\
\hline Total Responses & 641 \\
\hline
\end{tabular}

\subsection{Design Factor}

This factor measures the degree to which an individual feels or believes that the design of smartphones is important and valuable. Items DS1, DS2, and DS3 in the survey questionnaire measures perceived design factor using a five-point Likert scale arranged 
as: (1) "strongly disagree", (2) "disagree", (3) "neither disagree nor agree", (4) "agree", (5) "strongly agree".

Table 47 and Table 48 below show the respondents' answers by proportion and statistics for item DS1; one of three items designed to measure the design factor. Of the total respondents, 204 (32\%) selected the answer "strongly disagree", and 327 (51\%) selected the answer "agree". Responses for more items and its statistics are attached in the Appendix G.

Table 47: Proportion of respondent for item DS1

\begin{tabular}{|c|c|c|}
\hline Answer & Respondent & Percentage \\
\hline 5 & 204 & $32 \%$ \\
\hline 4 & 327 & $51 \%$ \\
\hline 3 & 80 & $12 \%$ \\
\hline 2 & 27 & $4 \%$ \\
\hline 1 & 3 & $0 \%$ \\
\hline Total & 641 & $100 \%$ \\
\hline
\end{tabular}

Table 48: DS1 statistics

\begin{tabular}{|l|c|}
\hline \multicolumn{1}{|c|}{ Statistic } & Value \\
\hline Min Value & 1 \\
\hline Max Value & 5 \\
\hline Mean & 4.12 \\
\hline Variance & 0.60 \\
\hline Standard Deviation & 0.78 \\
\hline Total Responses & 641 \\
\hline
\end{tabular}

\subsection{Facilitating Conditions Factor}

This factor measures the degree to which an individual believes that experience, technical and infrastructure supports are available to support the use of Smartphones. 
Items FC1, FC2, FC3 and FC4 in the survey questionnaire measure the facilitating conditions factor using a five-point Likert scale arranged as: (1) "strongly disagree", (2) “disagree", (3) "neither disagree nor agree", (4) "agree", (5) “strongly agree".

Table 49 and Table 50 below show the respondents' answers by proportion and statistics for item FC1; one of four items designed to measure the Facilitating Conditions factor. Of the total respondents, 202 (32\%) selected answer "strongly disagree", and 394 (61\%) selected the answer "agree". Responses for more items and its statistics are attached in the Appendix G.

Table 49: Proportion of respondent for item FC1

\begin{tabular}{|c|c|c|}
\hline Answer & Respondent & Percentage \\
\hline 5 & 202 & $32 \%$ \\
\hline 4 & 394 & $61 \%$ \\
\hline 3 & 36 & $6 \%$ \\
\hline 2 & 9 & $1 \%$ \\
\hline 1 & 0 & $0 \%$ \\
\hline Total & 641 & $100 \%$ \\
\hline
\end{tabular}

Table 50: FC1 statistics

\begin{tabular}{|l|c|}
\hline \multicolumn{1}{|c|}{ Statistic } & Value \\
\hline Min Value & 1 \\
\hline Max Value & 4 \\
\hline Mean & 4.23 \\
\hline Variance & 0.37 \\
\hline Standard Deviation & 0.61 \\
\hline Total Responses & 641 \\
\hline
\end{tabular}




\subsection{Social Influence Factor}

This factor measures the level or extent that social influence, or the opinions of others as to whether he or she should use a Smartphone, was important. Items SI1, SI2 and $\mathrm{SI} 3$ in the survey questionnaire measure the facilitating conditions factor using a five-point Likert scale arranged as: (1) "strongly disagree", (2) "disagree", (3) "neither disagree nor agree", (4) "agree", (5) "strongly agree".

Table 51 and Table 52 below show the respondents' answers by proportion and statistics for item SI1; one of three items designed to measure the Social Influence factor. Of the total respondents, 222 (35\%) selected answer "strongly disagree", and $348(54 \%)$ selected the answer "agree". Responses for more items and its statistics are attached in the Appendix G.

Table 51: Proportion of respondent for item SI1

\begin{tabular}{|c|c|c|}
\hline Answer & Respondent & Percentage \\
\hline 5 & 222 & $35 \%$ \\
\hline 4 & 348 & $54 \%$ \\
\hline 3 & 65 & $10 \%$ \\
\hline 2 & 4 & $1 \%$ \\
\hline 1 & 2 & $0 \%$ \\
\hline Total & 641 & $100 \%$ \\
\hline
\end{tabular}

Table 52: SI1 statistics

\begin{tabular}{|l|c|}
\hline \multicolumn{1}{|c|}{ Statistic } & Value \\
\hline Min Value & 1 \\
\hline Max Value & 5 \\
\hline Mean & 4.24 \\
\hline Variance & 0.42 \\
\hline Standard Deviation & 0.65 \\
\hline Total Responses & 641 \\
\hline
\end{tabular}




\subsection{Behavioral Intentions Factor}

This factor measures the extent and level of an individual's intention to adopt and use the smartphone. Items $\mathrm{BI} 1, \mathrm{BI} 2$ and $\mathrm{BI} 3$ in the survey questionnaire measure behavioral intentions factor using a five-point Likert scale arranged as: (1) "strongly disagree", (2) "disagree", (3) "neither disagree nor agree", (4) "agree", (5) "strongly agree".

Table 53 and Table 54 below show the respondents' answers by proportion and statistics for item $\mathrm{BI} 1$; one of three items designed to measure the behavioral intentions factor. Of the total respondents, 272 (42\%) selected answer "strongly disagree", and $302(47 \%)$ selected the answer "agree". Responses for more items and its statistics are attached in the Appendix G.

Table 53: Proportion of respondent for item BI1

\begin{tabular}{|c|c|c|}
\hline Answer & Respondent & Percentage \\
\hline 5 & 272 & $42 \%$ \\
\hline 4 & 302 & $47 \%$ \\
\hline 3 & 58 & $9 \%$ \\
\hline 2 & 8 & $1 \%$ \\
\hline 1 & 1 & $0 \%$ \\
\hline Total & 641 & $100 \%$ \\
\hline
\end{tabular}

Table 54: BI1 statistics

\begin{tabular}{|l|c|}
\hline \multicolumn{1}{|c|}{ Statistic } & Value \\
\hline Min Value & 1 \\
\hline Max Value & 5 \\
\hline Mean & 4.31 \\
\hline Variance & 0.47 \\
\hline Standard Deviation & 0.68 \\
\hline Total Responses & 641 \\
\hline
\end{tabular}




\section{Chapter Eight: Hypotheses Testing and Discussion}

\subsection{Performance expectancy factor}

Smartphone technology can help users to attain benefits not only in their job environment but also in their daily life and the surrounding environments. Therefore, in this research, the original definition of performance expectancy has been modified to be "the degree to which an individual believes that using Smartphone technology will help him or her to attain benefits in their overall performance." In a number of previous research studies, the performance expectancy factor was found to have a strong relationship with users' intentions and a key predictor of the users' intention to adopt and use new technologies [82]. The Smartphone technology provides users with many features and benefits that contribute to improving their overall performance in many aspects of their daily lives. Therefore, the following hypothesis has been developed to test the relationship between the performance expectation factor and the users' intention to adopt and use the Smartphone technology.

H1: The performance expectancy factor will have a positive relationship with the users' behavioral intention to use the Smartphone technology.

The analysis results show a significant and positive relationship between performance expectancy factor and users' behavioral intentions to adopt and use the smartphones in Saudi Arabia. Based on the findings in this research, performance 
expectancy has the strongest positive relationship with users' behavioral intention to adopt and use the smartphones in Saudi Arabia. The findings suggest that facilitating and improving users' adoption and use of smartphones is positively associated with the improvement of expected performance of Smartphone technology. The results imply that smartphones services providers, device providers, manufacturers and other stakeholders may increase potential consumers' intention to adopt and use smartphones by focusing on aspects that contribute to enhancing and improving performance of smartphones. The results indicated smartphone users in Saudi Arabia think that the performance of a Smartphone is significantly important to them and performance attributes can increase their adoption and use of smartphones. This finding is consistent with results in a number of related previous studies [98, 273]. Based on the analysis results and consistent with previous finding in related literature, a conclusion can be drawn that performance of smartphones can be an important, positive and significant determinant of users' intention to adopt and use smartphones in Saudi Arabia.

\subsection{Effort expectancy Factor}

Effort expectancy factor can be explained as the level of ease that is associated with use of the smartphone technology [82]. Scholars have identified a number of factors that are associated with level of effort expectancy when using smartphones including simplicity [101], design [49], and complexity [156] versus ease of use factor $[167,49,155,27,126]$. In a number of previous studies, the effort expectancy factor 
was found to have a significant positive relationship with users' intention to adopt and use Smartphone technology [164, 98]. Therefore, the following hypothesis has been developed to test the relationship between the effort expectancy factor and users' intention to adopt and use the Smartphone technology.

H2: The effort expectancy factor will have a positive relationship with the users' behavioral intention to adopt and use the Smartphone technology.

The analysis results show a significant and positive relationship between effort expectancy factor and users' behavioral intentions to adopt and use the Smartphone technology in Saudi Arabia. The findings suggest that enhancing and improving users' intention to adopt and use the smartphones is positively associated with the improvement of effort expectancy of Smartphone technology and that, smartphones services providers, device providers and manufacturers as well as other stakeholders may increase potential consumers' intention to adopt and use smartphones by focusing on aspects that contribute to effort expectancy factor such as improving simplicity and ease of using smartphones. This result indicates that improving the level of effort expectancy is positively associated with improving the users' intention to adopt and use the smartphone. This finding is consistent with results in a number of related previous studies [98]. Based on the analysis results and consistent with previous findings in related literature, a conclusion can be drawn that efforts associated with improving use of smartphones can be important, positive and significant determinants of users' intention to adopt and use smartphones in Saudi Arabia. 


\subsection{Economic factors Factor}

The economic factors factor can be defined as the perceived value of the tradeoff between the apparent benefits of the technologies and the cost of acquiring and using it [190, 191]. Economic factors have been identified as a predictor of users' behavioral intention to adopt and use new information technologies [191]. It has been indicated that there is a relationship between economic factors and users' intention to adopt and use a technology. Many individuals balance the benefits of obtaining a technology compared to the cost of acquiring that technology [191]. In previous studies, the perceived cost saving factor was found to have a positive relationship with users' intention to use mobile wireless technology via Smartphone [91]. In previous research that investigated the adoption of smartphones in a number of emerging countries, scholars found that economic factor such as price found to be one of the main factors that influence the adoption of smartphones [274]. Scholars found that the cost of mobile internet has a significant and positive relationship with users' behavioral intention to adopt mobile technology [170]. A number of factors related to economic factors, namely perceived cost [155], perceived cost saving [91] and company willingness to fund [91] have been identified in previous research as important factors that are associated with users' adoption and use of the Smartphone. Therefore, the following hypothesis is created to test the relationship between the economic factors factor and users' intention to adopt and use the Smartphone technology. 
H3: The economic factors factor will have a positive relationship with the users' behavioral intention to adopt and use the Smartphone technology.

The analysis conducted did not show a significant relationship between the economic factor and the behavioral intention factor. In contrast to previous research, this factor has no significant relationship with users' intention to adopt and use Smartphone technology in Saudi Arabia. These results imply, to some extent, the general feeling by users of smartphones in Saudi Arabia that the price of smartphone devices and services are reasonable compared to the economic value they offer. Contrary to popular belief in mobile and smartphones literature, economic factors such as cost and pricing seem to have no association with users' intention to adopt and use smartphones in Saudi Arabia. That may be attributed to the high competition among smartphones device manufacturers and providers to provide better and cheaper smartphones devices and services. Moreover, it may be attributed generally to the strong and growing economy in Saudi Arabia at the time of conducting this research which contributes to improving users' ability to consider Smartphone devices and services as reasonable and very affordable technology for them. Based on analysis and results a conclusion can be drawn that economic factors related to smartphones are not a significant determinant of users' intention to adopt and use smartphones in Saudi Arabia. 


\subsection{Brand Influence Factor}

Brand influence on the adoption and use of a technology is a phenomenon that has been considered [106, 107]. With regard to Smartphone technology, brand name has been the focus of scholars in a number of studies, such as exploring the influence of learning effects on the rate of adoption in the market to better explain the impact of learning effects on the adoption rate of the iPhone [107]. Brand influence factor was found to have a positive relationship with users' adoption of Smartphone technology [188]. A number of scholars investigated individual attitudes toward the adoption of a specific Smartphone, namely Blueberry [106]. Brand names of smartphone technology has been the subject of a number of studies, and many researchers have dedicated their efforts to study different aspects of one brand, the iPhone [108-111, 7]. Therefore, the following hypothesis has been developed to test the relationship between the brand influence factor and users' intention to adopt and use the Smartphone technology.

H4: The brand influence factor will have a positive relationship with the users' behavioral intention to adopt and use the Smartphone technology.

The analysis shows a significant and positive relationship between brand influence factor and the users' behavioral intention factor. The results indicate that the users' intention to adopt and use Smartphone technology in Saudi Arabia is significantly and positively associated with the users' perception of smartphones' brand. The findings suggest that enhancing and improving users' perception of a Smartphone's brand could positively attribute to their intention to adopt and use smartphones. Moreover, the 
results imply that smartphones' service providers, device manufacture and other stakeholders may increase potential consumers' intention to adopt and use smartphones by focusing on aspects that contribute to brand influence.

The Apple iPhone could be an example of how brand influence is positively associated with users' intention to adopt and use smartphones. Loyal iPhone users have adopted the Apple iPhone because they have a positive perception of Apple; they are more excited to see the next generation of the iPhone; and, they are willing to wait in line and pay more money to get it because it's the Apple brand. Hard work to improve the brand image of a Smartphone such Apple can positively attribute to users' intention to adopt and use smartphones, especially in Saudi Arabia. Based on the analysis results and consistent with previous finding in related literature, a conclusion can be reached that the brand of a Smartphone can be a positive and significant predictor of users' intentions to adopt and use smartphones in Saudi Arabia.

\subsection{Perceived Enjoyment Factor}

Scholars in a number of previous studies have found perceived enjoyment to be a significant predictor of users' intention to adopt and use new information technology $[193,194,25]$ and their behavioral intention to adopt and use technology related to smartphones $[98,166,90]$. Therefore, the following hypothesis is created to test the relationship between the perceived enjoyment factor and users' intention to adopt and use the Smartphone technology. 
H5: The perceived enjoyment factor will have a positive relationship with users' behavioral intention to adopt and use the Smartphone technology.

The analysis results show a significant and positive relationship between perceived enjoyment factor and users' behavioral intention factor. The results indicate that, users' intention to adopt and use Smartphone technology in Saudi Arabia is significantly and positively associated with the users' perceived enjoyment of the smartphones. The finding suggests that, enhancing and improving users' perceived enjoyment of a Smartphone could positively attribute to their intention to adopt and use smartphones. Moreover, the results imply that smartphones services providers, device manufactures and other stakeholders may increase potential consumers' intention to adopt and use smartphones by focusing on improving aspects that contribute to users' enjoyment of Smartphones. The finding of this analysis is aligned with the results in a number of previous studies [98]. Based on findings, and consistent with previous findings in related literature, a conclusion can be reached that perceived enjoyment of smartphones can be an important, positive and significant determinant of users' intention to adopt and use smartphones in Saudi Arabia.

\subsection{Design Factor}

Design is an important aspect that has been used by many manufacturers to distinguish and differentiate their products to make them more appealing to consumers. In previous research, scholars found design factor to have an important and positive relationship with users' behavioral intention to adopt Smartphone technology [49] 
Therefore, the following hypothesis is created to test the relationship between the design factor and users' intention to adopt and use the Smartphone technology.

H6: The design factor will have a positive relationship with the users' behavioral intention to adopt and use the Smartphone technology.

The analysis results show a significant and positive relationship between design factor and users' behavioral intention factor. The findings indicate that users' intention to adopt and use Smartphone technology in Saudi Arabia is significantly and positively associated with the design of the Smartphone and that enhancing and improving the design of a Smartphone could positively attribute to users' intention to adopt and use Smartphones, especially in Saudi Arabia. Moreover, the results imply that Smartphone device providers and manufacturers may increase potential consumers' intention to adopt and use smartphones by focusing on aspects that contribute to the design of the smartphones. This finding, to some extent, is consistent with the results in a number of previous studies, which indicated that design can positively and significantly contribute to users' adoption and use of smartphones. Based on findings and consistent with previous results in related literature, a conclusion can be drawn that the design of a Smartphone can be an important, positive and significant determinant of users' intention to adopt and use smartphones in Saudi Arabia.

\subsection{Social Influence Factor}

As explained earlier the social influence factor can vary in some emerging regions. Scholars indicated that the social influence factor has a relationship with users' 
adoption and use of technology [82]. A number of factors, namely self-efficacy [27], social norms [90], and social pressure [126] have been indicated in previous research as important factors that are related to social influence on users' adoption of and use of the Smartphone and its related technology. Moreover, the social influence factor has been found to have a significant and positive influence on users' adoption of the Smartphone $[275,42]$. Subjective norms were found to have a significant and positive relationship with users' adoption and use of the Smartphone [43]. Scholars pointed out the important role of cultural factors and its influence on the adoption use of new information technologies [32-36]. Saudi society has different cultural contexts in that it is characterized as a society that is more collectivist in nature and in which individuals have closer personal ties with each other and influential effects among these contacts [32]. A number of scholars empirically studied the adoption of technology related to the Smartphone. They found that social influence is a key factor that directly influences the use behavior factor [276]. Therefore, the following hypothesis is created to test the relationship between the social influence factor and usage behavior.

H7: The Social Influence factor will have a positive relationship with the usage behavior factor.

The analysis results show a significant and positive relationship between the social influence factor and the use behavior factor. The results indicate that users' use behavior regarding Smartphone technology in Saudi Arabia is significantly and positively associated with the social influence factor. The findings further suggest that the 
surrounding social influence could positively attribute to users' use behavior of smartphones. Moreover, the results imply that smartphones service providers and manufacturers may increase potential consumers' use behavior in using smartphones by paying more attention to the social influences in a region and focusing on aspects that contribute to social influence in that region. This finding is aligned with the results in a number of previous studies in which social influence showed a positive and significant relationship with use of smartphones and its related technologies as mentioned above. Based on that, and consistent with previous findings in related literature, a conclusion can be drawn that social influence can be an important, positive and significant determinant of users' actual use of smartphones in Saudi Arabia.

\subsection{Facilitating conditions factor}

With regard to Smartphone technology, facilitating conditions can include connectivity and internet service availability, services support, usage information, system compatibility, individual financial resources, and other factors that facilitate better use of this technology. A number of factors have been identified that are related to facilitating conditions. Scholars, in previous research, indicated that the facilitating conditions factor has a significant relationship with users' adoption and use of smartphones in e-health services [164]. Moreover, researchers found that the facilitating conditions factor has a significant influence on adoption and use of Smartphone technology among older adults [98]. Therefore, the following hypothesis is 
created to test the relationship between the facilitating conditions factor and the use behavior.

H8: The Facilitating conditions factor will have a positive relationship with the use behavior.

The analysis conducted did not show a significant relationship between the facilitating conditions factor and the use behavior factor. In contrast to related previous research, the facilitating conditions factor has no significant relationship with actual use of smartphones in Saudi Arabia. This result could imply, to some extent, a general feeling among users of smartphones in Saudi Arabia that service support, usage information, system compatibility, individual financial resources, and experience are widely available and satisfied. This is contrary to multiple findings in research related to mobile and smartphones, facilitating conditions related factors such as services support, usage information, system compatibility, individual financial resources, and experience seems not to induce significant association with users' actual use of smartphones in Saudi Arabia. That can be attributed to the wide availability of technical supports, reliable infrastructure and users' knowledge and experiences of the actual use of Smartphone technology in Saudi Arabia. Moreover, that could be attributed to the hard work by smartphones services providers and device manufacturers to provide smartphones users with the needed technical supports, reliable infrastructure and better knowledge and experiences driven by high competition telecommunications companies in Saudi Arabia and the smartphones devise manufacturers worldwide. 


\subsection{Behavioral Intention Factor}

A number of researchers examined the relationship between the behavioral intention factor and the use behavior factor or actual use of technology. Their findings indicated that the behavioral intention factor is a key and important predictor of use behavior (actual use) of smartphones and its related technologies [199, 82, 159]. Use behavior or actual use of technology has been found to be associated with users' behavioral intention in many previous studies. Therefore, behavioral intention is expected to have a positive relationship with the use behavior factor or actual use of smartphones. Thus, the following hypothesis is created.

H9: The behavioral intentions factor will have a positive relationship with the Use behavior factor.

The analysis results show a significant and positive relationship between perceived behavioral intentions and the use behavior factor. The results indicate that use behavior or actual usage of Smartphone technology in Saudi Arabia is significantly and positively associated with the users' behavioral intentions to adopt and use the Smartphone. The findings suggest that enhancing and improving users' use behavior or actual usage of smartphones could positively attribute to improving and enhancing their behavioral intention to adopt and use smartphones. Moreover, the results imply that smartphones services providers, device manufactures and other stakeholders may increase potential actual usage of smartphones by focusing on aspects that contribute to users' behavioral intentions to adopt and use Smartphone. Moreover, a number of 
factors such as performance expectancy, effort expectancy, brand influence, perceived enjoyment, and design have a positive indirect relationship with users' actual use of smartphones through users' behavioral intention factor. This finding corresponds with the results of a number of previous studies which indicated that users' behavioral intention is an important determinant of actual use. Based on analysis results and consistent with previous findings in related literature, a conclusion can be drawn that users' behavioral intentions can be an important, positive and significant determinant of users' actual use of smartphones in Saudi Arabia. 
Table 55 through 57 below presents a summary of the hypotheses testing and the regression weights.

Table 55: hypotheses testing results

\begin{tabular}{|c|c|c|c|c|}
\hline Hypotheses & IV & DV & Type of relationships & Results \\
\hline $\mathrm{H} 1$ & $(\mathrm{PE})$ & $\mathrm{BI}$ & $\begin{array}{l}\text { Positive: as performance } \\
\text { expectancy factor increases the } \\
\text { Behavioral intention factor will } \\
\text { increase }\end{array}$ & Supported \\
\hline $\mathrm{H} 2$ & (EE) & $\mathrm{BI}$ & $\begin{array}{l}\text { Positive: as effort expectancy } \\
\text { factor increases the behavioral } \\
\text { intention factor will increase }\end{array}$ & Supported \\
\hline H3 & (EF) & $\mathrm{BI}$ & $\begin{array}{l}\text { Positive: as economic factors } \\
\text { increases the behavioral intention } \\
\text { factor will increase }\end{array}$ & $\begin{array}{l}\text { Not } \\
\text { supported }\end{array}$ \\
\hline $\mathrm{H} 4$ & (BIF) & $\mathrm{BI}$ & $\begin{array}{l}\text { Positive: as brand influence factor } \\
\text { increases the behavioral intention } \\
\text { factor will increase }\end{array}$ & Supported \\
\hline H5 & (PJ) & $\mathrm{BI}$ & $\begin{array}{l}\text { Positive: as perceived enjoyment } \\
\text { factor increases the behavioral } \\
\text { intention factor will increase }\end{array}$ & Supported \\
\hline H6 & (DS) & $\mathrm{BI}$ & $\begin{array}{l}\text { Positive: as design factor increases } \\
\text { the facilitating conditions factor } \\
\text { will increase }\end{array}$ & Supported \\
\hline $\mathrm{H7}$ & (SI) & UB & $\begin{array}{l}\text { Positive: as social influence factor } \\
\text { increases the use behavior factor } \\
\text { will increase }\end{array}$ & Supported \\
\hline H8 & $(\mathrm{FC})$ & UB & $\begin{array}{l}\text { Positive: as facilitating conditions } \\
\text { factor increases the use behavior } \\
\text { factor will increase }\end{array}$ & $\begin{array}{l}\text { Not } \\
\text { supported }\end{array}$ \\
\hline
\end{tabular}




\begin{tabular}{|l|l|l|l|l|}
\hline H9 & (BI) & UB & $\begin{array}{l}\text { Positive: as behavioral intention } \\
\text { factor increases the use behavior } \\
\text { factor will increase }\end{array}$ & Supported \\
\hline
\end{tabular}

Table 56: Hypotheses testing results - Standardized Regression Weights

\begin{tabular}{|c|c|c|c|c|c|}
\hline Factor & Relationship & Factor & Estimate & $p$-value & Label \\
\hline $\mathrm{BI}$ & $\leftarrow$ & PE & .339 & .000 & Supported \\
\hline $\mathrm{BI}$ & $\leftarrow$ & EE & .102 & .009 & Supported \\
\hline $\mathrm{BI}$ & $\leftarrow$ & $\mathrm{EF}$ & .051 & .302 & $\begin{array}{c}\text { Not } \\
\text { supported }\end{array}$ \\
\hline $\mathrm{BI}$ & $\leftarrow$ & BIF & .106 & .014 & Supported \\
\hline $\mathrm{BI}$ & $\leftarrow$ & PJ & .249 & .000 & Supported \\
\hline $\mathrm{BI}$ & $\leftarrow$ & DS & .153 & .002 & Supported \\
\hline UB & $\leftarrow$ & $\mathrm{BI}$ & .762 & .000 & Supported \\
\hline UB & $\leftarrow$ & SI & .291 & .000 & Supported \\
\hline UB & $\leftarrow$ & FC & -.018 & .429 & $\begin{array}{c}\text { Not } \\
\text { supported }\end{array}$ \\
\hline
\end{tabular}


Table 57: Full structural model

\begin{tabular}{|c|c|c|c|}
\hline Relationship & Estimate & $\begin{array}{c}p- \\
\text { value }\end{array}$ & Label \\
\hline $\begin{array}{l}\text { Behavioral Intention }(B \mathrm{I}) \leftarrow \text { Performance } \\
\text { Expectancy }(\mathrm{PE})\end{array}$ & .339 & .000 & $\begin{array}{l}\text { When PE } \\
\text { goes } \\
\text { up by } 1, \text { BI } \\
\text { goes } \\
\text { up by } 0.339\end{array}$ \\
\hline $\begin{array}{l}\text { Behavioral Intention }(\mathrm{BI}) \leftarrow \text { Effort Expectancy } \\
\text { (EE) }\end{array}$ & .102 & .009 & $\begin{array}{l}\text { When EE } \\
\text { goes } \\
\text { up by } 1, \text { BI } \\
\text { goes } \\
\text { up by } 0.102\end{array}$ \\
\hline $\begin{array}{l}\text { Behavioral Intention (BI) } \leftarrow \text { Brand Influence } \\
\text { (BIF) }\end{array}$ & .106 & .014 & $\begin{array}{l}\text { When BIF } \\
\text { goes } \\
\text { up by } 1, \mathbf{B I} \\
\text { goes } \\
\text { up by } 0.106\end{array}$ \\
\hline $\begin{array}{l}\text { Behavioral Intention }(\mathrm{BI}) \leftarrow \text { Perceived } \\
\text { Enjoyment }(\mathrm{PJ})\end{array}$ & .249 & .000 & $\begin{array}{l}\text { When PJ } \\
\text { goes } \\
\text { up by } 1, \mathbf{B I} \\
\text { goes } \\
\text { up by } 0.249\end{array}$ \\
\hline Behavioral Intention (BI) $\leftarrow$ Design (DS) & .153 & .002 & $\begin{array}{l}\text { When DS } \\
\text { goes } \\
\text { up by } 1, \text { BI } \\
\text { goes } \\
\text { up by } 0.153\end{array}$ \\
\hline $\begin{array}{l}\text { Use Behavior (UB) } \leftarrow \text { Behavioral Intention } \\
\text { (BI) }\end{array}$ & .762 & .000 & $\begin{array}{l}\text { When BI } \\
\text { goes } \\
\text { up by } 1, \text { UB } \\
\text { goes } \\
\text { up by } 0.762\end{array}$ \\
\hline Use Behavior (UB) $\leftarrow$ Social Influence (SI) & .291 & .000 & $\begin{array}{l}\text { When SI goes } \\
\text { up by } 1 \text {, UB } \\
\text { goes } \\
\text { up by } 0.291\end{array}$ \\
\hline
\end{tabular}




\section{Chapter nine: Conclusion, Research Contribution, Limitation and Future Research}

\subsection{Conclusion}

This dissertation developed a research model based on literature review, existing related theoretical models and the use of a number of qualitative methods to obtain experts' opinions. The developed research model has been utilized, using the data collected to explore the key factors that are associated with users' adoption and use of smartphones in emerging regions, specifically in the case of Saudi Arabia. This dissertation has been conducted starting with an extensive literature review to gain better understanding of research conducted related to the adoption of Smartphone technology and to understand the IT adoption models related to the adoption and use of Smartphone technology.

An extensive literature review has been conducted to obtain more insight into the existing research related to the adoption and use of smartphones and the theoretical models that have been utilized in previous related research. Taxonomy of factors related to the adoption and use of smartphones have been developed based on the literature review. More than forty factors related to the adoption and use of smartphones in previous research were reviewed and identified. A research model has been developed for this research based on the UTAUT model. A number of qualitative methods have been conducted to review, elevate, validate, and select the factors that 
are most related and can be included in the research model to explore and study users' adoption and use of smartphones.

Based on the literature review and the results of the qualitative methods conducted, the research model has been developed, modified and finalized. Moreover, hypotheses have been developed to explain and test the relationships among factors in the research model. A survey instrument has been developed, translated into Arabic language and a web-based survey questionnaire was designed. The web-based survey was administered to users of smartphones in Saudi Arabia to collect data. Data was screened, organized and statistically analyzed using SEM, SPSS and AMOS software. Research hypotheses were tested based on the data collected. The results indicated that performance expectancy, effort expectancy, brand influence, perceived enjoyment, and design factors have a positive and significant relationship with users' behavioral intention to adopt and use smartphones in Saudi Arabia. Also, the results indicate that the social influence factor has a significant and positive relationship with use behavior or actual use of Smartphones in Saudi Arabia.

The results of this dissertation indicate both similarities and differences between prior studies and this study:

- In consistent with previous research, the results imply that:

- Many smartphones users in Saudi Arabia are influenced mostly by the expected performance of their smartphones, benefits and gains that they may attain in their daily life from adopting and using smartphones. 
- Many smartphones users in Saudi Arabia are influenced by their peers, close friends and other figures in their society in their use behavior of smartphones and they are more likely to follow the social norm in their society.

- More smartphones users in Saudi Arabia are looking for more hedonic features and entertainment options in their smartphones.

- More smartphones users in Saudi Arabia believe that the appearance, color, the overall look and feel of smartphones are important to them and they pay attention to the brand names of smartphones.

- In contrary with previous research, the results imply that:

- Many smartphones users in Saudi Arabia believe that the cost and pricing of smartphones are reasonable and acceptable for them.

- Many smartphones users in Saudi Arabia may have more experiences and knowledge with use of smartphones and its related technologies.

\section{Implications of Findings and Recommendations:}

- The findings in this dissertation showed that smartphones users in Saudi Arabia rely mainly on their perceptions of performance expected of the smartphones to make decisions to adopt and use smartphones. Therefore, the implications for related practitioners are to improve the expected performance and the expected benefits or 
gains of adopting and use smartphones to encourage and increase more favorable intentions among potential users to adopt and use smartphones. Moreover, the results imply that more people will adopt and use smartphones in Saudi Arabia if smartphones became more useful to them in their daily lives, enabling them to accomplish tasks more quickly, and increasing their overall productivity.

- Brand name influence was found to be a one of the factors that could encourage and increase users' intention to adopt and use smartphones; therefore, it is recommended to enhance brand name and increase users' loyalty to their brand name.

- Perceived enjoyments were found to be one of the key factors that could increase users' intention to adopt and use smartphones; therefore, it is recommended that smartphones be made more enjoyable to users.

- Design of the smartphones was found to be one of the factors that could increase users' intention to adopt and use smartphones; therefore, it is recommended that the design of smartphones be enhanced to appeal to more users.

\subsection{Research Contributions}

This empirical research provides a number of useful contributions to the body of knowledge on the information technology adoption, related research and to practitioners in the IT domain including: 
- In this dissertation a research model have been developed and modified based on existing IT adoption theoretical model, literature review, and the use of qualitative methods.

- "The Communication and Information Technology Commission (CITC) has adopted a cooperative strategy between the related parties (government agencies, media players, telecom operators, and educational bodies in the country) to leverage the broadband based economy, mainly the e-commerce" $[277,278]$. The results of this dissertation can contribute to CITC and support strategy. CITC may implement their strategy partially based on the following implication: The finding showed that the social influence factor showed a positive and significant relationship with the actual use of Smartphones in Saudi Arabia. Therefore, providing incentives and encouragement to groups' leaders, celebrities, society leaders and other figures could facilitate, drive and encourage the use of smartphones to obtain services and products by government agencies.

- This research has comprehensively studied the general users of Smartphone technology to provide more insight into the key factors that are associated with users' intention to adopt and use the Smartphone in Saudi Arabia. The empirical results of this dissertation provide beneficial information to both researchers 
and practitioners in the IT domain. Furthermore, the outcome of this research provides stakeholders with valuable insight and precise information that is based on data obtained from general smartphones users in Saudi Arabia. Those insights and information can greatly assist in improving the adoption and use of Smartphone technology, enhancing users' experiences, improving products, services and their related markets, especially in Saudi Arabia.

- This empirical research is expected to show the importance and benefits of utilizing and modifying theoretical model to better understand users' intention to adopt and use the Smartphone. Furthermore, this research has empirically demonstrated the use of the literature review, a number of qualitative methods, and the modification of the IT theoretical model UTAUT to study, test and analyze users' adoption and use of new IT such as the Smartphone technology in emerging regions such as Saudi Arabia.

- A number of market researchers indicated that the capabilities of smartphones provide marketers with a substantial possibility to reach and better serve their consumers [279]. Also, they indicated that the more the price of the smartphone and its services decrease the more users will most likely increase their online usage [279]. This provides a huge opportunity to expand their marketing strategy with mobile marketing strategy. The finding showed that the price of smartphones and their service seems to be reasonable and acceptable to many 
users in Saudi Arabia and this can be used by marketers to align and expand their strategies accordingly.

- Telecommunication companies in Saudi Arabia are facing a sharp decline in their revenues for the year 2015 [280]. An expert in Communications and Information Technology Dr. Ahmed Sindi, linked that decline in revenue to several causes, including the lack of effective actions to reach their customers and understand their needs and preferences in time [280]. The results of this dissertation provide useful insights and information that can be used by telecommunication companies in Saudi Arabia to better understand their customers and develop their strategies accordingly.

- A trend noticed is that many smartphones users are starting to shift to the use of smartphones for computing more than using laptops [118]. Also, it was indicated that there is a lack of more innovative soft keyboard options in smartphones [118]. The results in this dissertation show that performance expectancy is a key factor that has a positive and significant relationship with users' intention to adopt and use smartphones in Saudi Arabia. The results imply that more people will adopt and use smartphones if the phone could help them to attain more benefits in their daily life, enable them to accomplish tasks more quickly, and to improve their performance in many of their daily activities. Based on those results, practitioners could modify and align their strategy and policy to focus 
more on developing and building smartphones that could satisfy users' preferences and needs.

- As mentioned in the introduction of this dissertation, $[8,6,7]$ smartphones manufacturers and providers change their strategies and policies in order to obtain a better market share. For example; Apple had a policy that made its iphone available exclusively through AT\&T. The company decided to change its strategies and sell their product to more companies to increase its market share. The results of this dissertation provide a useful insight that can be used by practitioners in building and developing a better strategies and policies based on users' points of view.

\subsection{Limitation and Future Research}

- The research model that has been developed in this dissertation was developed to explore and study key factors that may have relationships with users' adoption and use of Smartphone technology in Saudi Arabia using a comprehensive and holistic approach. This research did not look at other mediating factors that may modify the relationships between the factors in the research model. The researcher is considering future research that reviews, evaluates and includes possible mediating factors and explores the influence of these mediating factors.

- This research has collected data from Smartphone users in Saudi Arabia at one point in time. The economy of Saudi Arabia at that time was very strong and 
people were eager to spend and explore newer and better technology. The results of this study showed that economic factors did not show a significant relationship with users' behavioral intention to adopt and use Smartphones in Saudi Arabia. The economic factors could change dramatically from any change in the Saudi Arabian economy, which could change the significance of the results found in this research.

- This dissertation explored the key factors that may have relationships with users' adoption and use of smartphones in a comprehensive and holistic way. Based on the results of this research, future research can focus more on the specific factors that have significant relationships. Each of these key factors has a number of sub-factors which may have different contributes. Based on the results of this research, further research can be conducted that can focus on the sub-factors and investigate their relationships and influence.

- This research has collected data from general smartphones users in Saudi Arabia and did not focus on early adaptors of smartphones. Early adopters may have a different view of smartphones that could be targeted and investigated in future research.

- The results can not be generalizable on all of the Saudi users of smartphones since the data have been collected from one of the four main 
telecommunications companies in Saudi Arabia. A future research may extend the scope of the simple and collect data from all four companies. 


\section{References:}

[1] M. Rohan. (2015, 6/2015). Worldwide Smartphones Market Worth US\$258.9 Billion By 2015 Available:

http://www.marketsandmarkets.com/PressReleases/worldwide-smartphonesmarket.

[2] A. M. Kaplan, "If you love something, let it go mobile: Mobile marketing and mobile social media 4x4," Business Horizons, vol. 55, pp. 129-139, 2012.

[3] S. Santhipriya, B. Sastry, and K. Akshitha, "Securing Smartphone Apps In Online Environment," International Journal of Mathematical Archive (IJMA) ISSN 22295046, vol. 2, 2011.

[4] G. Gueguen, "Coopetition and business ecosystems in the information technology sector: the example of Intelligent Mobile Terminals," International journal of entrepreneurship and small business, vol. 8, pp. 135-153, 2009.

[5] R. M. Müller, B. Kijl, and J. K. Martens, "A comparison of inter-organizational business models of mobile app stores: There is more than open vs. closed," Journal of theoretical and applied electronic commerce research, vol. 6, pp. 6376, 2011.

[6] S. P. Hall and E. Anderson, "Operating systems for mobile computing," Journal of Computing Sciences in Colleges, vol. 25, pp. 64-71, 2009.

[7] J. West and M. Mace, "Browsing as the killer app: Explaining the rapid success of Apple's iPhone," Telecommunications Policy, vol. 34, pp. 270-286, 2010.

[8] M. Butler, "Android: Changing the mobile landscape," Pervasive Computing, IEEE, vol. 10, pp. 4-7, 2011.

[9] S. Alwahaishi and V. Snášel, "Factors Influencing The Consumer' Adoption Of Mobile Internet," in The Third International Conference on Digital Information and Communication Technology and its Applications (DICTAP2013), 2013, pp. 3139.

[10] E. G. Carayannis and S. C. Clark, "Do smartphones make for smarter business? The smartphone CEO study," Journal of the Knowledge Economy, vol. 2, pp. 201233, 2011.

[11] A. J. Rohm, T. T. Gao, F. Sultan, and M. Pagani, "Brand in the hand: A crossmarket investigation of consumer acceptance of mobile marketing," Business Horizons, vol. 55, pp. 485-493, 2012.

[12] H. Chun, H. Lee, and D. Kim, "The integrated model of smartphone adoption: Hedonic and utilitarian value perceptions of smartphones among Korean college students," Cyberpsychology, Behavior, and Social Networking, vol. 15, pp. 473479, 2012.

[13] S. M. Goldman, "Transformers," Journal of Consumer Marketing, vol. 27, pp. 469473, 2010.

[14] B. Saddik, D. Barakah, and B. Aldosari, "A study of PDA and Smartphone adoption rates at King Saud Medical City Hospitals," in Medical Information and 
Communication Technology (ISMICT), 2012 6th International Symposium on, 2012, pp. 1-3.

[15] (3/30/2014). Global market share held by the leading smartphone operating systems in sales to end users from 1st quarter 2009 to 4th quarter 2013.

Available: http://www.statista.com/statistics/266136/global-market-share-heldby-smartphone-operating-systems/

[16] M. Kenney and B. Pon, "Structuring the smartphone industry: is the mobile internet OS platform the key?," Journal of Industry, Competition and Trade, vol. 11, pp. 239-261, 2011.

[17] T. S. Portal. (2015, 8/15/2015). Worldwide market share forecast of smartphone operating systems from 2010 to 2015 . Available:

http://www.statista.com/statistics/216420/global-market-share-forecast-ofsmartphone-operating-systems/

[18] V. Venkatesh, "Determinants of perceived ease of use: Integrating control, intrinsic motivation, and emotion into the technology acceptance model," Information systems research, vol. 11, pp. 342-365, 2000.

[19] A. Dillon and M. G. Morris, "User acceptance of information technology: theories and models," in Annual review of information science and technology. Vol.31, ed Medford, NJ, USA: Information Today, 1996, pp. 3-32.

[20] A. L. Gilbert and H. Han, "Understanding mobile data services adoption: demography, attitudes or needs?," Technological Forecasting and Social Change, vol. 72, pp. 327-337, 2005.

[21] H. Dai and P. C. Palvi, "Mobile commerce adoption in China and the United States: a cross-cultural study," ACM SIGMIS Database, vol. 40, pp. 43-61, 2009.

[22] F.-M. Tseng, Y.-L. Liu, and H.-H. Wu, "Market penetration among competitive innovation products: The case of the Smartphone Operating System," Journal of Engineering and Technology Management.

[23] S. A. Vannoy and P. Palvia, "The social influence model of technology adoption," Communications of the ACM, vol. 53, pp. 149-153, 2010.

[24] M. S. Chtourou and N. Souiden, "Rethinking the TAM model: time to consider fun," Journal of Consumer Marketing, vol. 27, pp. 336-344, 2010.

[25] Y. Song and J. Han, "Is Enjoyment Important? An Empirical Research on the Impact of Perceive Enjoyment on Adoption of New Technology," in International Conference on Information Management, Innovation Management and Industrial Engineering, 2009, pp. 511-514.

[26] B. Kijsanayotin, S. Pannarunothai, and S. M. Speedie, "Factors influencing health information technology adoption in Thailand's community health centers: Applying the UTAUT model," International Journal of Medical Informatics, vol. 78, pp. 404-416, 2009.

[27] Y. Park and J. V. Chen, "Acceptance and adoption of the innovative use of smartphone," Industrial Management \& Data Systems, vol. 107, pp. 1349-1365, 2007. 
[28] G. J. Putzer and Y. Park, "The effects of innovation factors on smartphone adoption among nurses in community hospitals," Perspectives in health information management/AHIMA, American Health Information Management Association, vol. 7, 2010.

[29] J. V. Chen, D. C. Yen, and K. Chen, "The acceptance and diffusion of the innovative smart phone use: A case study of a delivery service company in logistics," Information \& Management, vol. 46, pp. 241-248, 2009.

[30] S. Y. Lee, "Examining the factors that influence early adopters' smartphone adoption: The case of college students," Telematics and Informatics, vol. 31, pp. 308-318, 2014.

[31] L. G. Tornatzky and K. J. Klein, "Innovation characteristics and innovation adoption-implementation: A meta-analysis of findings," IEEE Transactions on Engineering Management, vol. EM-29, pp. 28-45, 1982.

[32] S. S. Al-Gahtani, G. S. Hubona, and J. Wang, "Information technology (IT) in Saudi Arabia: Culture and the acceptance and use of IT," Information \& Management, vol. 44, pp. 681-691, 2007.

[33] P. A. Herbig and F. Palumbo, "The effect of culture on the adoption process: A comparison of Japanese and American behavior," Technological Forecasting and Social Change, vol. 46, pp. 71-101, 1994.

[34] D. Straub, M. Keil, and W. Brenner, "Testing the technology acceptance model across cultures: A three country study," Information \& Management, vol. 33, pp. 1-11, 1997.

[35] D. W. Straub, "The Effect of Culture on IT Diffusion: E-Mail and FAX in Japan and the US," Information Systems Research, vol. 5, pp. 23-47, 1994.

[36] Y. M. Van Everdingen and E. Waarts, "The effect of national culture on the adoption of innovations," Marketing Letters, vol. 14, pp. 217-232, 2003.

[37] W. A. Al-Ghaith, L. Sanzogni, and K. Sandhu, "Factors influencing the adoption and usage of online services in Saudi Arabia," The Electronic Journal of Information Systems in Developing Countries, vol. 40, 2010.

[38] E. Alwagait, "Popularity Analysis for Saudi Telecom Companies Based on Twitter Data," 2013.

[39] J. Que and V. Hurtado. 10/30/2013). The rise of Saudi Arabian telecoms: Unrivalled promise and opportunity in a vibrant market. Available: http://www.deltapartnersgroup.com/our_insights/whitepapers/the-rise-ofsaudi-telecoms-unrivalled-promise-and-opportunity-in-a-vibrant-market

[40] I. Arpaci, Y. C. Yardimci, and O. Turetken, "The impact of cultural differences on smartphone adoption by organizations," in Innovative Computing Technology (INTECH), 2013 Third International Conference on, 2013, pp. 421-423.

[41] G. Alnajjar, M. Mahmuddin, and T. Ramayah, "Adoption Factors of m-Commerce in Jordan: From Personal and Societal Norms Perspectives," International Journal of Computer Theory and Engineering, vol. 5, p. 155, 2013. 
[42] D. Pan, N. Chen, and P.-L. P. Rau, "The Acceptance and Adoption of Smartphone Use among Chinese College Students," in Cross-Cultural Design. Methods, Practice, and Case Studies, ed: Springer, 2013, pp. 450-458.

[43] M. Ling and P. Yuan, "An empirical research: Consumer intention to use smartphone based on consumer innovativeness," in Consumer Electronics, Communications and Networks (CECNet), 2012 2nd International Conference on, 2012, pp. 2368-2371.

[44] I. K. Lai and D. C. Lai, "User acceptance of mobile commerce: an empirical study in Macau," International Journal of Systems Science, pp. 1-11, 2013.

[45] J. Park, S. Yang, and X. Lehto, "ADOPTION OF MOBILE TECHNOLOGIES FOR CHINESE CONSUMERS," Journal of Electronic Commerce Research, vol. 8, 2007.

[46] S. Pan and M. Jordan-Marsh, "Internet use intention and adoption among Chinese older adults: From the expanded technology acceptance model perspective," Computers in human behavior, vol. 26, pp. 1111-1119, 2010.

[47] J. Lu, C. Liu, C.-S. Yu, and J. E. Yao, "Exploring factors associated with wireless internet via mobile technology acceptance in Mainland China," Communications of the International Information Management Association, vol. 3, pp. 101-120, 2003.

[48] C. E. Hill, K. D. Loch, D. Straub, and K. El-Sheshai, "A qualitative assessment of Arab culture and information technology transfer," Journal of Global Information Management (JGIM), vol. 6, pp. 29-38, 1998.

[49] Y. M. Kang, C. Cho, and S. Lee, "Analysis of factors affecting the adoption of smartphones," in 1st International Technology Management Conference (ITMC), San Jose, CA, United states, 2011, pp. 919-925.

[50] R. F. Perozzo and C. E. Pereira, "Management of services in intelligent environments for mobile devices," in 4th International Conference on Intelligent Environments, Seattle, WA, United states, 2008.

[51] H. Verkasalo, "Analysis of smartphone user behavior," in Ninth International Conference on Mobile Business and Global Mobility Roundtable (ICMB-GMR), 2010, pp. 258-263.

[52] S. A. Al-Meshal and M. A. Almotairi, "Consumer Acceptance of Mobile Marketing: An Empirical Study on the Saudi Female," International Journal of Marketing Studies, vol. 5, 2013.

[53] A. Alsenaidy and A. Tauseef, "A Review of Current State M Government in Saudi Arabia," Global Engineers \& Technologists Review, vol. 2, pp. 5-8, 2012.

[54] M. E. Seliaman and M. Al-Turki, "Mobile Learning Adoption in Saudi Arabia," in Proceedings of World Academy of Science, Engineering and Technology, 2012.

[55] O. M. Alakloby, "Dermatology Research in Saudi Arabia: Challenges and Hopes," Journal of the Saudi Society of Dermatology \& Dermatologic Surgery, 2012.

[56] c. d. o. s. a. information. (2015, september 10). Estimate of population by sex and nationality. Available:

http://www.cdsi.gov.sa/english/index.php?option=com_docman\&ltemid=160 
[57] K. A. Alkhathlan, "Contribution of oil in economic growth of Saudi Arabia," Applied Economics Letters, vol. 20, pp. 343-348, 2013.

[58] A. M. Khatib, "Oil and Infrastructure Expenditures in Saudi Arabia," Journal of Business Studies Quarterly, vol. 4, pp. 72-76, 2012.

[59] M. Qobo and M. Soko. (2010, Saudi Arabia as an Emerging Market: Commercial Opportunities and Challenges for South Africa. Available: http://dspace.cigilibrary.org/jspui/handle/123456789/30038

[60] I. A. Al-Darrab, W. A. Gulzar, and K. S. Ali, "Status of implementation of safety, quality and environmental management systems in Saudi Arabian industries," Total Quality Management \& Business Excellence, vol. 24, pp. 336-354, 2013.

[61] N. Y. Mansouri, R. J. Crookes, and T. Korakianitis, "A projection of energy consumption and carbon dioxide emissions in the electricity sector for Saudi Arabia: The case for carbon capture and storage and solar photovoltaics," Energy Policy, vol. 63, pp. 681-695, 2013.

[62] M. T. Simsim, "Internet usage and user preferences in Saudi Arabia," Journal of King Saud University-Engineering Sciences, vol. 23, pp. 101-107, 2011.

[63] R. AlGhamdi, S. Drew, and S. Alkhalaf, "Government initiatives: The missing key for e-commerce growth in KSA," arXiv preprint arXiv:1211.2398, 2012.

[64] C. a. I. T. Commission. (2010, On the Internet Ecosystem in Saudi Arabia. Available: http://www.citc.gov.sa/English/Reportsandstudies/Reports/Documents/IT\%200 06\%20E\%20-\%20IT\%20Report\%202010.pdf

[65] B. Kargin, N. Basoglu, and T. Daim, "Factors affecting the adoption of mobile services," International Journal of Services Sciences, vol. 2, pp. 29-52, 2009.

[66] K. Phan and T. Daim, "Exploring technology acceptance for mobile services," Journal of Industrial Engineering and Management, vol. 4, pp. 339-360, 2011.

[67] Alawi et. al. (2012, Saudi Telecom Sector. Available: http://www.aljaziracapital.com.sa/report_file/ess/SEC-32.pdf

[68] M. O. Al-Fakhri, R. A. Cropf, P. Kelly, and G. Higgs, "E-government in Saudi Arabia: Between promise and reality," International Journal of Electronic Government Research (IJEGR), vol. 4, pp. 59-85, 2008.

[69] I. Monitor. (2014, July 21). Opportunity knocks in Saudi Arabia. Available: http://monitor.icef.com/2012/01/opportunity-knocks-in-saudi-arabia/

[70] C. D. o. S. Information. (2014, November 3). Population (15 years and over) by age groups and educational status. Available: http://www.cdsi.gov.sa/english/index.php?option=com_docman\&ltemid=161

[71] J. C. Stephens, M. E. Hernandez, M. Román, A. C. Graham, and R. W. Scholz, "Higher education as a change agent for sustainability in different cultures and contexts," International Journal of Sustainability in Higher Education, vol. 9, pp. 317-338, 2008.

[72] Z. Krieger, "Saudi Arabia puts its billions behind Western-style higher education," The Chronicle of Higher Education, vol. 54, p. A1, 2007. 
[73] M. Alamri, "Higher Education in Saudi Arabia," Journal of Higher Education Theory \& Practice, vol. 11, 2011.

[74] A. A. News. (2015, november 6). All Saudi students in U.S. included in King's scholarship program. Available:

http://english.alarabiya.net/en/perspective/features/2015/09/06/All-Saudistudents-in-U-S-included-in-kingdom-s-scholarship-program.html

[75] F. Luqman. 12/21/2013). KAUST will become one of the best in the world. Available: http://www.arabnews.com/news/461379

[76] J. Adams, C. King, D. Pendlebury, D. Hook, J. Wilsdon, and A. Zewail, "Global Research Report, the Middle East," Exploring the Changing Landscape of Arabian, Persian and Turkish Research: Thomson Reuters, pp. 25-27, 2011.

[77] A. Dillon and M. G. Morris, "User acceptance of new information technology: theories and models," Annual Review of Information Science and Technology, vol. 14, pp. 3-32, 1996.

[78] G. C. Moore and I. Benbasat, "Development of an instrument to measure the perceptions of adopting an information technology innovation," Information systems research, vol. 2, pp. 192-222, 1991.

[79] E. M. Rogers, Diffusion of innovations, 5th Edition ed.: Free press, 2003.

[80] M. Alavi and E. A. Joachimsthaler, "Revisiting DSS implementation research: A meta-analysis of the literature and suggestions for researchers," Mis Quarterly, pp. 95-116, 1992.

[81] S. Taylor and P. A. Todd, "Understanding information technology usage: A test of competing models," Information systems research, vol. 6, pp. 144-176, 1995.

[82] V. Venkatesh, M. G. Morris, G. B. Davis, and F. D. Davis, "User acceptance of information technology: Toward a unified view," Management Information Systems (MIS), vol. 27, pp. 425-478, 2003.

[83] I. Ajzen, "The theory of planned behavior.," Organizational Behavior and Human Decision Processes, vol. 50, pp. 179-211, 1991.

[84] F. D. Davis, "Perceived usefulness, perceived ease of use, and user acceptance of information technology," MIS Q., vol. 13, pp. 319-340, 1989.

[85] S. Heshan and Z. Ping, "A methodological analysis of user technology acceptance," in Proceedings of the 37th Annual Hawaii International Conference on System Sciences, 5-8 Jan. 2004, Los Alamitos, CA, USA, 2004, p. 10 pp.

[86] Y. Lee, K. A. Kozar, and K. R. Larsen, "The technology acceptance model: past, present, and future," The Communications of the Association for Information Systems, vol. 12, pp. 752-780., 2003.

[87] F. D. Davis, R. P. Bagozzi, and P. R. Warshaw, "User acceptance of computer technology: a comparison of two theoretical models," Management Science, vol. 35, pp. 982-1003, 1989.

[88] H. Rui and L. Lu, "The diffusion and adoption research of mobile commerce-A Review," in Management and Service Science, 2009. MASS'09. International Conference on, 2009, pp. 1-5. 
[89] Y. W. Sawng and H. S. Han, "Market analysis for the next-generation mobile communications (DMB) service from the perspective of innovation adoption and diffusion," International Journal of Satellite Communications and Networking, vol. 25, pp. 323-348, 2007.

[90] H. Verkasalo, C. López-Nicolás, F. J. Molina-Castillo, and H. Bouwman, "Analysis of users and non-users of smartphone applications," Telematics and Informatics, vol. 27, pp. 242-255, 2010.

[91] K. Sang Hyun, "Moderating effects of job relevance and experience on mobile wireless technology acceptance: adoption of a smart phone by individuals," Information and Management, vol. 45, pp. 387-93, 2008.

[92] P. Legris, J. Ingham, and P. Collerette, "Why do people use information technology? A critical review of the technology acceptance model," Information and Management, vol. 40, pp. 191-204, 2003.

[93] Z. Liu, Q. Min, and S. Ji, "A comprehensive review of research in IT adoption," in Wireless Communications, Networking and Mobile Computing, 2008. WiCOM'08. 4th International Conference on, 2008, pp. 1-5.

[94] M. Conner and C. J. Armitage, "Extending the theory of planned behavior: A review and avenues for further research," Journal of applied social psychology, vol. 28, pp. 1429-1464, 1998.

[95] D. L. Goodhue and R. L. Thompson, "Task-technology fit and individual performance," MIS Q., vol. 19, pp. 213-236, 1995.

[96] M. Fishbein, and I Ajzen, Belief, Attitude, Intention and Behaviour: An Introduction to Theory and Research: Addison-Wesley, 1975.

[97] F. Aldhaban, "Exploring the adoption of Smartphone technology: Literature review," in Technology Management for Emerging Technologies (PICMET), 2012 Proceedings of PICMET'12:, 2012, pp. 2758-2770.

[98] J. Choudrie, S. Pheeraphuttharangkoon, E. Zamani, and G. Giaglis, "Investigating the adoption and use of smartphones in the UK: a silver-surfers perspective," 2014.

[99] S.-C. Ho, W.-Y. Sun, and Y.-M. Wang, "Investigation of factors influencing the adoption of mobile data services," in Proceedings of the 13th International Conference on Electronic Commerce, 2011, p. 11.

[100] A. Aarnio, A. Enkenberg, J. Heikkila, and S. Hirvola, "Adoption and use of mobile services. Empirical evidence from a Finnish survey," in System Sciences, 2002. HICSS. Proceedings of the 35th Annual Hawaii International Conference on, 2002, pp. 1454-1463.

[101] B. Kargin, N. Basoglu, and T. Daim, "Exploring mobile service adoption: A conjoint model," in Portland International Conference on Management of Engineering and Technology (PICMET), 2008, pp. 2623-2633.

[102] B. Swar, J. Kim, D. H. Lee, and J. Moon, "Impact of culture on mobile phone service adoption and diffusion: a cross-country analysis," in Computer Sciences 
and Convergence Information Technology, 2009. ICCIT'09. Fourth International Conference on, 2009, pp. 1442-1444.

[103] M. Cherubini, R. de Oliveira, A. Hiltunen, and N. Oliver, "Barriers and bridges in the adoption of today's mobile phone contextual services," in Proceedings of the 13th International Conference on Human Computer Interaction with Mobile Devices and Services, 2011, pp. 167-176.

[104] J. Huang, Q. Xu, B. Tiwana, Z. M. Mao, M. Zhang, and P. Bahl, "Anatomizing application performance differences on smartphones," in Proceedings of the 8th international conference on Mobile systems, applications, and services, 2010, pp. 165-178.

[105] S. Kim and G. Garrison, "Investigating mobile wireless technology adoption: An extension of the technology acceptance model," Information Systems Frontiers, vol. 11, pp. 323-333, 2009.

[106] S. Kim and Y. Song, "Determinants Influencing Individuals' Likelihood of Adopting and Actual use of Blueberry," Journal of Applied Sciences, vol. 9, pp. 3662-3671, 2009.

[107] C. Maloney. (2009). the Newton ball multi-National diffusion acceleration effect: an apple iPhone case study. . Available:

http://chrismaloney.files.wordpress.com/2009/06/newton-ball-multi-nationaldiffusion-acceleration-effect-an-apple-iphone-case-study1.pdf

[108] E. J. Arruda-Filho, J. A. Cabusas, and N. Dholakia, "Social behavior and brand devotion among iPhone innovators," International journal of information management, vol. 30, pp. 475-480, 2010.

[109] A. Haywood and G. Boguslawski, "I Love My iPhone... But There Are Certain Things That 'Niggle'Me," in Human-Computer Interaction. New Trends, ed: Springer, 2009, pp. 421-430.

[110] M. M. Rana and U. Rana, "Accessibility evaluation of iPhone's user interface for visually impaired," The proceedings of internet and multimedia systems and applications, pp. 164-167, 2009.

[111] H. Tscherning and L. Mathiassen, The Role of Social Networks in Early Adoption of Mobile Devices: Springer, 2010.

[112] J. Yoo, Y. Yoon, and M. Choi, "Importance of positive reputation for Smartphone adoption," in Information and Communication Technology Convergence (ICTC), 2010 International Conference on, 2010, pp. 314-318.

[113] P. Nanda, J. Bos, K.-L. Kramer, C. Hay, and J. Ignacz, "Effect of smartphone aesthetic design on users' emotional reaction: An empirical study," The TQM Journal, vol. 20, pp. 348-355, 2008.

[114] H. Bouwman, M. de Reuver, and S. Stalman, "Mobile TV: The Search for a Holy Grail that Isn't," in Proceddings of the 9th international interactive conference on Interactive television, 2011, pp. 185-194. 
[115] H. Verkasalo, "Empirical observations on the emergence of mobile multimedia services and applications in the US and Europe," in Proceedings of the 5th international conference on Mobile and ubiquitous multimedia, 2006, p. 3.

[116] D. Schuurman, C. Courtois, and L. De Marez, "New media adoption and usage among Flemish youngsters," Telematics and Informatics, vol. 28, pp. 77-85, 2011.

[117] Y. Liu, H. Li, and C. Carlsson, "Factors driving the adoption of m-learning: An empirical study," Computers \& Education, vol. 55, pp. 1211-1219, 2010.

[118] T. Page, "Usability of text input interfaces in smartphones," Journal of Design Research, vol. 11, pp. 39-56, 2013.

[119] D.-H. Shin, Y.-J. Shin, H. Choo, and K. Beom, "Smartphones as smart pedagogical tools: Implications for smartphones as u-learning devices," Computers in Human Behavior, vol. 27, pp. 2207-2214, 2011.

[120] M. N. Boulos, S. Wheeler, C. Tavares, and R. Jones, "How smartphones are changing the face of mobile and participatory healthcare: an overview, with example from eCAALYX," Biomedical engineering online, vol. 10, p. 24, 2011.

[121] L. Wolfenden, L. Brennan, and B. I. Britton, "Intelligent obesity interventions using Smartphones," Preventive medicine, vol. 51, pp. 519-520, 2010.

[122] A. M. Khan, Y.-K. Lee, S. Lee, and T.-S. Kim, "Human activity recognition via an accelerometer-enabled-smartphone using kernel discriminant analysis," in Future Information Technology (FutureTech), 2010 5th International Conference on, 2010, pp. 1-6.

[123] J. J. Oresko, Z. Jin, J. Cheng, S. Huang, Y. Sun, H. Duschl, and A. C. Cheng, "A wearable smartphone-based platform for real-time cardiovascular disease detection via electrocardiogram processing," Information Technology in Biomedicine, IEEE Transactions on, vol. 14, pp. 734-740, 2010.

[124] P. Yu, M. X. Wu, H. Yu, and G. Q. Xiao, "The challenges for the adoption of Mhealth," in Service Operations and Logistics, and Informatics, 2006. SOLI'06. IEEE International Conference on, 2006, pp. 181-186.

[125] I. Carreras and D. Tacconi, "U-hopper: User-centric heteogeneous opportunistic middleware," in Bio-Inspired Models of Network, Information and Computing Systems, 2007. Bionetics 2007. 2nd, 2007, pp. 302-305.

[126] D.-H. Shin, "User acceptance of mobile Internet: Implication for convergence technologies," Interacting with Computers, vol. 19, pp. 472-483, 2007.

[127] Y. Yoon, S. Patino, N. Jarpa, and H. Alanazi, "WiMAX: Forecasting by integrating scenario planning and Bass model methodologies," in Management of Engineering \& Technology, 2009. PICMET 2009. Portland International Conference on, 2009, pp. 2375-2390.

[128] M. Edo, M. Garcia, C. Turro, and J. Lloret, "IP Telephony Development and Performance over IEEE 802.11 g WLAN," in Networking and Services, 2009. ICNS'09. Fifth International Conference on, 2009, pp. 186-191. 
[129] C. Caini, P. Cornice, R. Firrincieli, M. Livini, and D. Lacamera, "DTN meets smartphones: Future prospects and tests," in Wireless Pervasive Computing (ISWPC), 2010 5th IEEE International Symposium on, 2010, pp. 355-360.

[130] T. Evens, D. Schuurman, L. De Marez, and G. Verleye, "Forecasting broadband Internet adoption on trains in Belgium," Telematics and Informatics, vol. 27, pp. 10-20, 2010.

[131] S. M. Habib, C. Jacob, and T. Olovsson, "A practical analysis of the robustness and stability of the network stack in smartphones," in Computer and Information Technology, 2008. ICCIT 2008. 11th International Conference on, 2008, pp. 393398.

[132] M.-K. Kim, J.-H. Park, and J.-H. Paik, "Factors influencing adoption of Korean $3 G$ mobile services: The role of relative advantages, facilitating condition and adoption barriers," in Advanced Communication Technology, 2009. ICACT 2009. 11th International Conference on, 2009, pp. 1392-1395.

[133] Q. Wang and R. Deters, "SOA's Last Mile-Connecting Smartphones to the Service Cloud," in Cloud Computing, 2009. CLOUD'09. IEEE International Conference on, 2009, pp. 80-87.

[134] Y. Agarwal, R. Chandra, A. Wolman, P. Bahl, K. Chin, and R. Gupta, "Wireless wakeups revisited: energy management for voip over wi-fi smartphones," in Proceedings of the 5th international conference on Mobile systems, applications and services, 2007, pp. 179-191.

[135] P. Briggs, R. Chundury, and J. Olsson, "Carrier ethernet for mobile backhaul," Communications Magazine, IEEE, vol. 48, pp. 94-100, 2010.

[136] J. Harno, "Impact of $3 G$ and beyond technology development and pricing on mobile data service provisioning, usage and diffusion," Telematics and informatics, vol. 27, pp. 269-282, 2010.

[137] R. F. Perozzo and C. E. Pereira, "Management of services in intelligent environments for mobile devices," in Intelligent Environments, 2008 IET 4th International Conference on, 2008, pp. 1-6.

[138] B. Dixon and S. Mishra, "On rootkit and malware detection in smartphones," in Dependable Systems and Networks Workshops (DSN-W), 2010 International Conference on, 2010, pp. 162-163.

[139] B. Steinke, "Reconfigurable object based multimedia display communication system for Smartphones," in Information and Telecommunication Technologies, 2008. APSITT. 7th Asia-Pacific Symposium on, 2008, pp. 253-257.

[140] X. Ni, Z. Yang, X. Bai, A. C. Champion, and D. Xuan, "DiffUser: Differentiated user access control on smartphones," in Mobile Adhoc and Sensor Systems, 2009. MASS'09. IEEE 6th International Conference on, 2009, pp. 1012-1017.

[141] C. Tseng, M. Ali, and R. Vibhandik, "Common Visual Representation for websites and smartphones," in Granular Computing (GrC), 2010 IEEE International Conference on, 2010, pp. 477-482. 
[142] D.-H. Kim, M.-H. Yun, S.-J. Kim, and C.-H. Lee, "Design and Implementation of Smartphone Edition based on Embedded Linux," in Advanced Communication Technology, 2008. ICACT 2008. 10th International Conference on, 2008, pp. 328331.

[143] V. L. Thing, K.-Y. Ng, and E.-C. Chang, "Live memory forensics of mobile phones," digital investigation, vol. 7, pp. S74-S82, 2010.

[144] P. Gasti and Y. Chen, "Breaking and Fixing the Self Encryption Scheme for Data Security in Mobile Devices," in Parallel, Distributed and Network-Based Processing (PDP), 2010 18th Euromicro International Conference on, 2010, pp. 624-630.

[145] N. B. Mabrouk, N. Georgantas, and V. Issarny, "A semantic end-to-end QoS model for dynamic service oriented environments," in Proceedings of the 2009 ICSE Workshop on Principles of Engineering Service Oriented Systems, 2009, pp. 34-41.

[146] T. J. Gerpott, "Impacts of mobile Internet use intensity on the demand for SMS and voice services of mobile network operators," Attitudes and Behaviors of Mobile Network Operator Customers: Contributions toward empirically founded marketing strategies for mobile navigation and Internet services, p. 129, 2010.

[147] N.-Y. Jeong and Y. Yoo, "A study of adopting Warshaw's purchase intention model in mobile-RFID services and on moderating effect of personal innovativeness," in Management of Engineering and Technology, Portland International Center for, 2007, pp. 2932-2939.

[148] A. Denoo, "The ORANGE Telematic services for mass market," in Telecommunications, 2007. ITST'07. 7th International Conference on ITS, 2007, pp. 1-6.

[149] L. Bauer, L. F. Cranor, M. K. Reiter, and K. Vaniea, "Lessons learned from the deployment of a smartphone-based access-control system," in Proceedings of the 3rd Symposium on Usable Privacy and Security, 2007, pp. 64-75.

[150] S.-Y. Tsai, C.-Y. Wang, and R.-H. Hwang, "Ubiquitous Phone System," in Ubiquitous Intelligence and Computing, ed: Springer, 2008, pp. 201-215.

[151] P. Zhuang, D. Wang, and Y. Shang, "SMART: Simultaneous indoor localization and map construction using smartphones," in Neural Networks (IJCNN), The 2010 International Joint Conference on, 2010, pp. 1-8.

[152] M. Boari, A. Corradi, E. Lodolo, S. Monti, and S. Pasini, "Coordination for the internet of services: A user-centric approach," in Communication Systems Software and Middleware and Workshops, 2008. COMSWARE 2008. 3rd International Conference on, 2008, pp. 434-441.

[153] E. Miluzzo, C. T. Cornelius, A. Ramaswamy, T. Choudhury, Z. Liu, and A. T. Campbell, "Darwin phones: the evolution of sensing and inference on mobile phones," in Proceedings of the 8th international conference on Mobile systems, applications, and services, 2010, pp. 5-20. 
[154] T. Zhou, Y. Lu, and B. Wang, "Integrating TTF and UTAUT to explain mobile banking user adoption," Computers in Human Behavior, vol. 26, pp. 760-767, 2010.

[155] N. Koenig-Lewis, A. Palmer, and A. Moll, "Predicting young consumers' take up of mobile banking services," International Journal of Bank Marketing, vol. 28, pp. 410-432, 2010.

[156] N. Mallat, "Exploring consumer adoption of mobile payments - A qualitative study," Journal of Strategic Information Systems, vol. 16, pp. 413-432, 2007.

[157] H. H. Bauer, S. J. Barnes, T. Reichardt, and M. M. Neumann, "Driving consumer acceptance of mobile marketing: A theoretical framework and empirical study," Journal of electronic commerce research, vol. 6, pp. 181-192, 2005.

[158] T. Zhou, "Exploring mobile user acceptance based on UTAUT and contextual offering," in Electronic Commerce and Security, 2008 International Symposium on, 2008, pp. 241-245.

[159] J.-H. Wu and S.-C. Wang, "What drives mobile commerce?: An empirical evaluation of the revised technology acceptance model," Information \& management, vol. 42, pp. 719-729, 2005.

[160] R. Xia, M. Rost, and L. E. Holmquist, "Business models in the mobile ecosystem," in Mobile Business and 2010 Ninth Global Mobility Roundtable (ICMB-GMR), 2010 Ninth International Conference on, 2010, pp. 1-8.

[161] F. Lin and W. Ye, "Operating system battle in the ecosystem of smartphone industry," in Information Engineering and Electronic Commerce, 2009. IEEC'09. International Symposium on, 2009, pp. 617-621.

[162] R. Balocco, R. Mogre, and G. Toletti, "Mobile internet and SMEs: a focus on the adoption," Industrial Management \& Data Systems, vol. 109, pp. 245-261, 2009.

[163] B. Beurer-Zuellig and M. Meckel, "Smartphones enabling mobile collaboration," in Hawaii International Conference on System Sciences, Proceedings of the 41st Annual, 2008, pp. 49-49.

[164] W. Boontarig, W. Chutimaskul, V. Chongsuphajaisiddhi, and B. Papasratorn, "Factors influencing the Thai elderly intention to use smartphone for e-Health services," in Humanities, Science and Engineering Research (SHUSER), 2012 IEEE Symposium on, 2012, pp. 479-483.

[165] U. Sekaran, Research methods for business: A skill building approach, 4th ed.: John Wiley \& Sons, 2003.

[166] F. D. Davis, R. P. Bagozzi, and P. R. Warshaw, "Extrinsic and Intrinsic Motivation to Use Computers in the Workplace," Journal of Applied Social Psychology, vol. 22, pp. 1111-1132, 1992.

[167] S.-C. Ho, W.-Y. Sun, and Y.-M. Wang, "Investigation of Factors Influencing the Adoption of Mobile Data Services," in Proceedings of the 13th International Conference on Electronic Commerce, Liverpool, United Kingdom, 2011, pp. 1-8. 
[168] D. H. Haejung Yun, and Choong Lee, , "Extending UTAUT to Predict the Use of Location-Based Services," International Conference on Information Systems (ICIS), 2011.

[169] G. J. Putzer and Y. Park, "The effects of innovation factors on smartphone adoption among nurses in community hospitals," Perspectives in health information management / AHIMA, American Health Information Management Association, vol. 7, p. 1b, 2010.

[170] H.-W. Kim, H. C. Chan, and S. Gupta, "Value-based adoption of mobile internet: an empirical investigation," Decision Support Systems, vol. 43, pp. 111-126, 2007.

[171] H. Sun and P. Zhang, "An exploration of affect factors and their role in user technology acceptance: Mediation and causality," Journal of the American society for information science and technology, vol. 59, pp. 1252-1263, 2008.

[172] J. F. Finch and S. G. West, "The investigation of personality structure: Statistical models," Journal of Research in Personality, vol. 31, pp. 439-485, 1997.

[173] A. E. Hurley, T. A. Scandura, C. A. Schriesheim, M. T. Brannick, A. Seers, R. J. Vandenberg, and L. J. Williams, "Exploratory and confirmatory factor analysis: Guidelines, issues, and alternatives," Journal of organizational behavior, vol. 18, pp. 667-683, 1997.

[174] B. Williams, T. Brown, and A. Onsman, "Exploratory factor analysis: A five-step guide for novices," Australasian Journal of Paramedicine, vol. 8, p. 1, 2012.

[175] J. Ritchie, J. Lewis, C. M. Nicholls, and R. Ormston, Qualitative research practice: A guide for social science students and researchers: Sage, 2013.

[176] C. O. Seneler, N. Basoglu, and T. U. Daim, "A taxonomy for technology adoption: A human computer interaction perspective," in Management of Engineering \& Technology, 2008. PICMET 2008. Portland International Conference on, 2008, pp. 2208-2219.

[177] N. K. Gale, G. Heath, E. Cameron, S. Rashid, and S. Redwood, "Using the framework method for the analysis of qualitative data in multi-disciplinary health research," BMC medical research methodology, vol. 13, p. 117, 2013.

[178] A. McKenna, F. McMartin, Y. Terada, V. Sirivedhin, and A. Agogino, "A Framework for Interpreting Students' Perceptions of an Integrated Curriculum," in Proceedings, 2001 ASEE Annual Conference and Exposition, 2001.

[179] M. A. Meyer and J. M. Booker, Eliciting and analyzing expert judgment: a practical guide vol. 7: SIAM, 2001.

[180] P. B. Paulus and V. R. Brown, "Toward More Creative and Innovative Group Idea Generation: A Cognitive-Social-Motivational Perspective of Brainstorming," Social and Personality Psychology Compass, vol. 1, pp. 248-265, 2007.

[181] R. P. McGlynn, D. McGurk, V. S. Effland, N. L. Johll, and D. J. Harding, "Brainstorming and task performance in groups constrained by evidence," Organizational behavior and human decision processes, vol. 93, pp. 75-87, 2004.

[182] H.-C. Wang, D. Cosley, and S. R. Fussell, "Idea Expander: Supporting group brainstorming with conversationally triggered visual thinking stimuli," in 
Proceedings of the 2010 ACM conference on Computer supported cooperative work, 2010, pp. 103-106.

[183] P. C. Shih, G. Venolia, and G. M. Olson, "Brainstorming under constraints: why software developers brainstorm in groups," in Proceedings of the 25th BCS Conference on Human-Computer Interaction, 2011, pp. 74-83.

[184] D. L. Morgan, Focus groups as qualitative research vol. 16: Sage, 1997.

[185] L. Chase and J. Alvarez, "Internet research: The role of the focus group," Library \& Information Science Research, vol. 22, pp. 357-369, 2000.

[186] D. W. Stewart and P. N. Shamdasani, Focus groups vol. 20: Sage, 2014.

[187] K. Phan, "Innovation Measurement: A Decision Framework to Determine Innovativeness of a Company," Dissertation, PORTLAND STATE UNIVERSITY, 2013.

[188] N. Mohd Suki, "Students' demand for smartphones: Structural relationships of product features, brand name, product price and social influence," Campus-Wide Information Systems, vol. 30, pp. 236-248, 2013.

[189] L. Oshlyansky, P. Cairns, and H. Thimbleby, "Validating the unified theory of acceptance and use of technology (UTAUT) tool cross-culturally," presented at the Proceedings of the 21st British $\mathrm{HCl}$ Group Annual Conference on People and Computers: $\mathrm{HCl}$...but not as we know it - Volume 2, University of Lancaster, United Kingdom, 2007.

[190] W. B. Dodds, K. B. Monroe, and D. Grewal, "Effects of price, brand, and store information on buyers' product evaluations," Journal of Marketing Research (JMR), vol. 28, 1991.

[191] V. Venkatesh, J. Thong, and X. Xu, "Consumer acceptance and use of information technology: extending the unified theory of acceptance and use of technology," MIS quarterly, vol. 36, pp. 157-178, 2012.

[192] M. A. Osman, A. Z. Talib, Z. A. Sanusi, T. Shiang-Yen, and A. S. Alwi, "A Study of the Trend of Smartphone and its Usage Behavior in Malaysia," International Journal of New Computer Architectures and their Applications (IJNCAA), vol. 2, pp. 274-285, 2012.

[193] S.-J. Hong, K. Y. Tam, and J. Kim, "Mobile data service fuels the desire for uniqueness," Journal of Communications of the ACM, vol. 49, pp. 89-94, 2006.

[194] C. Je Ho and P. Myeong-Cheol, "Mobile internet acceptance in Korea," Internet Research: Electronic Networking Applications and Policy, vol. 15, pp. 125-40, 2005.

[195] R. W. Belk, "An exploratory assessment of situational effects in buyer behavior," Journal of Marketing Research, pp. 156-163, 1974.

[196] R. W. Belk, "Situational variables and consumer behavior," Journal of Consumer research, pp. 157-164, 1975.

[197] S. Ward and T. S. Robertson, "Consumer behavior research: Promise and prospects," Scott Ward and Thomas S. Robertson, Consumer Behavior: Theoretical Sources. Englewood Cliffs: Prentice-Hall, pp. 3-42, 1973. 
[198] R. R. Harmon and G. Laird, "Linking marketing strategy to customer value: implications for technology marketers," in Innovation in Technology Management-The Key to Global Leadership. PICMET'97: Portland International Conference on Management and Technology, 1997, pp. 896-900.

[199] S. H. Kim, "Moderating effects of job relevance and experience on mobile wireless technology acceptance: Adoption of a smartphone by individuals," Information \& Management, vol. 45, pp. 387-393, 2008.

[200] G. G. Gable, "Integrating case study and survey research methods: an example in information systems," European Journal of Information Systems, vol. 3, pp. 112126, 1994.

[201] A. Pinsonneault and K. L. Kraemer, "Survey research methodology in management information systems: an assessment," Journal of management information systems, pp. 75-105, 1993.

[202] T. R. Anderson, Research Methods for Technology Management and other Fields. Portland, OR: print-on-demand system, 2012.

[203] D. R. Cooper, P. S. Schindler, and J. Sun, Business research methods, ninth ed. New York, NY: McGraw-Hill/Irwin, 2006.

[204] J. R. Fraenkel and N. E. Wallen, "How to design and evaluate research in education," third ed: McGraw-Hill (New York), 1996.

[205] D. Andrews, B. Nonnecke, and J. Preece, "Electronic survey methodology: A case study in reaching hard-to-involve Internet users," International Journal of Human-Computer Interaction, vol. 16, pp. 185-210, 2003.

[206] E. R. Babbie, Survey research methods, second ed.: Wadsworth Publishing Company Belmont, CA, 1990.

[207] A. Rindfleisch, A. J. Malter, S. Ganesan, and C. Moorman, "Cross-sectional versus longitudinal survey research: concepts, findings, and guidelines," Journal of Marketing Research, vol. 45, pp. 261-279, 2008.

[208] C. Carlsson, J. Carlsson, K. Hyvonen, J. Puhakainen, and P. Walden, "Adoption of Mobile Devices/Services - Searching for Answers with the UTAUT," in System Sciences, 2006. HICSS '06. Proceedings of the 39th Annual Hawaii International Conference on, 2006, pp. 132a-132a.

[209] J. W. Creswell, Research design: Qualitative, quantitative, and mixed methods approaches, second ed.: SAGE Publications, Incorporated, 2004.

[210] J. G. Geer, "What do open-ended questions measure?," Public Opinion Quarterly, vol. 52, pp. 365-367, 1988.

[211] R. Likert, "A technique for the measurement of attitudes," Archives of psychology, vol. 22, 1932.

[212] D. L. Clason and T. J. Dormody, "Analyzing data measured by individual Likerttype items," Journal of Agricultural Education, vol. 35, p. 4, 1994.

[213] F. J. Gravetter and L. B. Wallnau, Essentials of statistics for the behavioral sciences, sixth ed.: Wadsworth Publishing Company, 2008. 
[214] J. F. Hair, W. Black, B. J. Babin, and R. E. Anderson, Multivariate data analysis, Seventh ed.: Pearson, 2010.

[215] P. Slottje, J. van der Sluijs, and A. B. Knol, "Expert Elicitation: Methodological suggestions for its use in environmental health impact assessments," National Institute for Public Health and the Environment, RIVM Letter report 2008.

[216] G. Rowe and G. Wright, "The Delphi technique as a forecasting tool: issues and analysis," International journal of forecasting, vol. 15, pp. 353-375, 1999.

[217] R. Cooke and L. Goossens, "Procedures guide for structural expert judgement in accident consequence modelling," Radiation Protection Dosimetry, vol. 90, pp. 303-309, 2000.

[218] G. Rowe, G. Wright, and F. Bolger, "Delphi: a reevaluation of research and theory," Technological Forecasting and Social Change, vol. 39, pp. 235-251, 1991.

[219] N. A. Behkami, "Examining Health Information Technology Implementations: Case of the Patient-centered Medical Home," PhD Dissertation in Engineering Management, , Portland State University, 2012.

[220] K. L. Manfreda and V. Vehovar, "Internet surveys," International handbook of survey methodology, pp. 264-284, 2008.

[221] L. J. Cronbach, "Coefficient alpha and the internal structure of tests," Psychometrika, vol. 16, pp. 297-334, 1951.

[222] J. R. A. Santos, "Cronbach's alpha: A tool for assessing the reliability of scales," Journal of extension, vol. 37, pp. 1-5, 1999.

[223] J. Pallant, SPSS survival manual: A step by step guide to data analysis using SPSS, fourth ed.: Open University Press, 2010.

[224] R. H. Salman, "Exploring Capability Maturity Models and Relevant Practices as Solutions Addressing IT Service Offshoring Project Issues," Doctor of Philosophy, Portland State University, 2014.

[225] A. Bryman, Social research methods, Second Edition ed.: OUP Oxford, 2004.

[226] K. K. Boyer, J. R. Olson, and E. C. Jackson, "Electronic surveys: advantages and disadvantages over traditional print surveys," Decision Line, vol. 32, pp. 4-7, 2001.

[227] R. D. Fricker and M. Schonlau, "Advantages and disadvantages of Internet research surveys: Evidence from the literature," Field Methods, vol. 14, pp. 347367, 2002.

[228] D. H. Granello and J. E. Wheaton, "Online data collection: Strategies for research," Journal of Counseling \& Development, vol. 82, pp. 387-393, 2004.

[229] K. B. Wright, "Researching Internet based populations: Advantages and disadvantages of online survey research, online questionnaire authoring software packages, and web survey services," Journal of Computer Mediated Communication, vol. 10, 2005.

[230] D. A. Dillman, Mail and internet surveys: The tailored design method vol. 2: Wiley New York, 2000. 
[231] M. D. Kaplowitz, T. D. Hadlock, and R. Levine, "A comparison of web and mail survey response rates," Public opinion quarterly, vol. 68, pp. 94-101, 2004.

[232] F. J. Fowler Jr, Survey research methods vol. 1: SAGE Publications, Incorporated, 2008.

[233] R. Sapsford, Survey research: SAGE Publications Limited, 2006.

[234] K. Kelley, B. Clark, V. Brown, and J. Sitzia, "Good practice in the conduct and reporting of survey research," International Journal for Quality in Health Care, vol. 15, pp. 261-266, 2003.

[235] c. a. i. t. commission, "Annual Report 2012," Saudi Arabia2012.

[236] emarketer. (2015, september 9). United-Arab-Emirates-Leads-Middle-EastAfrica-Mobile-Phone-Penetration. Available:

http://www.emarketer.com/Article/United-Arab-Emirates-Leads-Middle-EastAfrica-Mobile-Phone-Penetration/1011971

[237] C. a. I. T. Commission, "Market Definition, Designation and Dominance Report " 2010.

[238] D. Barclay, C. Higgins, and R. Thompson, "The partial least squares (PLS) approach to causal modeling: personal computer adoption and use as an illustration," Technology studies, vol. 2, pp. 285-309, 1995.

[239] W. W. Chin, "The partial least squares approach for structural equation modeling," Modern Methods for business research, pp. 295-336, 1998.

[240] W. W. Chin and P. R. Newsted, "Structural equation modeling analysis with small samples using partial least squares," Statistical strategies for small sample research, vol. 1, pp. 307-341, 1999.

[241] S. S. Kahai and R. B. Cooper, "Exploring the core concepts of media richness theory: The impact of cue multiplicity and feedback immediacy on decision quality," Journal of Management Information Systems, vol. 20, pp. 263-300, 2003.

[242] B. G. Tabachnick and L. S. Fidell, Using multivariate statistics. Needham Heights, MA USA: A Pearson Education Company, 2001.

[243] A. Boomsma, "The robustness of LISREL against small sample sizes in factor analysis models," Systems under indirect observation: Causality, structure, prediction, vol. 1, pp. 148-173, 1982.

[244] H. W. Marsh and M. Bailey, "Confirmatory factor analyses of multitraitmultimethod data: A comparison of alternative models," Applied psychological measurement, vol. 15, pp. 47-70, 1991.

[245] L. Ding, W. F. Velicer, and L. L. Harlow, "Effects of estimation methods, number of indicators per factor, and improper solutions on structural equation modeling fit indices," Structural Equation Modeling: A Multidisciplinary Journal, vol. 2, pp. 119-143, 1995.

[246] H. W. Marsh, J. R. Balla, and R. P. McDonald, "Goodness-of-fit indexes in confirmatory factor analysis," Psychological bulletin, vol. 103, pp. 391-410, 1988. 
[247] H. W. Marsh, K.-T. Hau, J. R. Balla, and D. Grayson, "Is more ever too much? The number of indicators per factor in confirmatory factor analysis," Multivariate Behavioral Research, vol. 33, pp. 181-220, 1998.

[248] S. A. Mulaik, L. R. James, J. Van Alstine, N. Bennett, S. Lind, and C. D. Stilwell, "Quantitative methods in psychology," Psychological Bulletin, vol. 105, pp. 430445, 1989.

[249] L. Pui-Wa and S. B. Dunbar, "Effects of score discreteness and estimating alternative model parameters on power estimation methods in structural equation modeling," Structural Equation Modeling, vol. 11, pp. 20-44, 2004.

[250] D. lacobucci, "Structural equations modeling: Fit indices, sample size, and advanced topics," Journal of Consumer Psychology, vol. 20, p. 90, 2010.

[251] J. C. Anderson and D. W. Gerbing, "The effect of sampling error on convergence, improper solutions, and goodness-of-fit indices for maximum likelihood confirmatory factor analysis," Psychometrika, vol. 49, pp. 155-173, 1984.

[252] N. A. Behkami, "Examining Health Information Technology Implementations: Case of the Patient-centered Medical Home," Portland State University, 2012.

[253] D. A. Dillman and D. K. Bowker, "The web questionnaire challenge to survey methodologists," Bemad Batinic, Ulf-Dietrich Reips, Michael Bosnjak \& Andreas Werner: Online Social Sciences. Seattle: Hogrefe \& Huber, pp. 53-71, 2001.

[254] C. Cobanoglu, B. Warde, and P. J. Moreo, "A comparison of mail, fax and webbased survey methods," International journal of market research, vol. 43, pp. 441-452, 2001.

[255] Y. Baruch and B. C. Holtom, "Survey response rate levels and trends in organizational research," Human Relations, vol. 61, pp. 1139-1160, 2008.

[256] P. L. Alreck and R. B. Settle, The survey research handbook: McGraw-Hill, 1994.

[257] T. Daim, "Technology Evaluation and Acquision Strategies and their Implications in the U.S. Electronics Manufacturing Industry.," Doctor of Philosophy, , Portland State University., 1998.

[258] T. Downes-Le Guin, R. Baker, J. Mechling, and E. Ruylea, "Myths and realities of respondent engagement in online surveys," International Journal of Market Research, vol. 54, pp. 1-21, 2012.

[259] C. B. Jarvis, S. B. MacKenzie, and P. M. Podsakoff, "A critical review of construct indicators and measurement model misspecification in marketing and consumer research," Journal of consumer research, vol. 30, pp. 199-218, 2003.

[260] R. A. Hassad, "Development and validation of a teaching practice scale (TISS) for instructors of introductory statistics at the college level," arXiv preprint arXiv:1007.3654, 2010.

[261] J. C. Anderson and D. W. Gerbing, "Structural equation modeling in practice: A review and recommended two-step approach," Psychological bulletin, vol. 103, pp. 411-423, 1988. 
[262] B. M. Byrne, Structural Equation Modeling With Eqs: Basic Concepts, Applications, And Programming, 2nd ed. Routledge, New York.: Psychology Press, 2006.

[263] J. Cohen, Applied Multiple Regression/Correlation Analysis for the Behavioral Sciences. Mahwah, New Jersey: Lawrence Erlbaum Associates, 2003.

[264] L. K. Muthén and B. O. Muthén, "Statistical analysis with latent variables," Los Angeles: Muthén \& Muthén, 2001.

[265] J. E. Hunter and F. L. Schmidt, Methods of meta-analysis: Correcting error and bias in research findings: SAGE Publications, Incorporated, 2004.

[266] S. L. Hershberger, "The growth of structural equation modeling: 1994-2001," Structural Equation Modeling, vol. 10, pp. 35-46, 2003.

[267] A. Diamantopoulos, "Viewpoint-export performance measurement: reflective versus formative indicators," International Marketing Review, vol. 16, pp. 444457, 1999.

[268] K.-H. Yuan and Z. Zhang, "Structural Equation Modeling Diagnostics Using R Package semdiag and EQS," Structural Equation Modeling, vol. 19, pp. 683-702, 2012.

[269] H. M. Blalock, Causal inferences in nonexperimental research. Chapel Hill: University of North Carolina Press, 1964.

[270] O. D. Duncan, Introduction to structural equation models. New York, USA: Academic Press, 1975.

[271] B. M. Byrne, Structural equation modeling with AMOS: Basic concepts, applications, and programming: Psychology Press, 2010.

[272] D. Hooper, J. Coughlan, and M. Mullen, "Structural equation modelling: guidelines for determining model fit," Electronic Journal of Business Research Methods, vol. 6, pp. 53-60, 2008.

[273] S. Gao, Y. Yang, and J. Krogstie, "The Adoption of Smartphones Among Older Adults in China," in Information and Knowledge Management in Complex Systems, ed: Springer, 2015, pp. 112-122.

[274] S. Lee and S. Lee, "Early diffusion of smartphones in OECD and BRICS countries: An examination of the effects of platform competition and indirect network effects," Telematics and Informatics, vol. 31, pp. 345-355, 2014.

[275] M. S. Kocour, "An Investigation of the Key Factors that Affect the Adoption of Smartphones in Global Midmarket Professional Service Firms," 2014.

[276] W. Yu-Lung, T. Yu-Hui, and J. Pei-Chi Yang, "Using UTAUT to explore the behavior of $3 \mathrm{G}$ mobile communication users," in IEEE International Conference on Industrial Engineering and Engineering Management 2007, pp. 199-203.

[277] T. C. a. I. T. C. (CITC). (2014, december, 8). Establishment Report. Available: http://www.citc.gov.sa/English/AboutUs/AreasOfwork/Pages/default.aspx

[278] S. A. Al-Hudhaif and A. Alkubeyyer, "E-commerce adoption factors in Saudi Arabia," International Journal of Business and Management, vol. 6, p. p122, 2011. 
[279] A. Persaud and I. Azhar, "Innovative mobile marketing via smartphones: are consumers ready?," Marketing Intelligence \& Planning, vol. 30, pp. 418-443, 2012.

[280] A. Alfaifi. (2015, November 1). Ghost pressures prosecuted telecommunications companies. Available:

http://www.alwatan.com.sa/Economy/News_Detail.aspx?ArticleID=240656\&Cat egorylD=2 


\section{Appendix A: Brainstorming Session}

\section{invitation for targeted participants in brainstorming session}

Dear Mrs. /Mr.

I am a PhD student in the Department of Engineering and Technology Management (ETM) at Portland State University. The topic of my PhD research is "Exploring the Adoption and Use of the Smartphone Technology in Emerging Regions: Case of Saudi Arabia". As a part of my research, I develop a preliminary research model Unified Theory of Acceptance and Use of Technology (UTAUT) to study and identify the key factors that are associated with users' intention to adopt and use the Smartphone. Through a literature review conducted for this research a number of factors have been identified that are related to the adoption and use of Smartphone and its related technologies. As a part of my research I need to conduct a brainstorming session to help in introducing new factors and selecting the most important factors that can be included in the research preliminary research model.

You have been identified as an experienced user of the Smartphone and your expertise and knowledge will be very helpful in my research. The brainstorming session is expected to take around one hour to be completed and will be conducted in the most convenient time and place for the participants. People who agree to participate will receive more details about the research including the research model, main factors and the factors derived from literature review. I will really appreciate it if you accept my invitation and participate in this brainstorming session.

\section{Details provided to participants in brainstorming session}




\section{More details provided to participants}

Dear Dr. X,

Thank you for accepting my invitation to participate in the brainstorming session

for my PhD research. The author developed a preliminary research model, shown in figure 2 below, to study and identify the key factors that influence users' adoption and use of the Smartphone. The preliminary research model is developed based on Unified Theory of Acceptance and Use of Technology (UTAUT) model which include five main factors adopted from UTAUT model. UTAUT model claims that each of these five main factors, namely performance expectancy, effort expectancy, social influence, facilitating conditions and economic factors can have an influence on users' intention to adopt and use a new technology. Through a literature review conducted for this research more than factors have been identified which may have relationships with users' adoption and use of Smartphone and its related technologies (see table1 below). Taxonomy of factors related to the adoption and use of the Smartphone has been developed based on the factors that have been identified in literature (see figure 1 below). The aim of conducting a brainstorming session is to obtain creative ideas and thought of experienced users of the Smartphone in evaluating the identified factors and adding any missing factors that may have relationship with adoption and use of the Smartphone. Below is the preliminary research model that is developed for this research (see figure 2), table of the external factors identified in literature, definitions of the main factors in the preliminary research model, and definitions of the external factors identified in 
literature (see table 1, table 2, and table 3). Please read them and let me know if you need more details.

Table1: factors identified in literature that may have relationships with users' adoption and use of the Smartphone

\begin{tabular}{|l|l|}
\hline Factors derived for literature \\
\hline$>$ Performance expectancy \\
\hline$>$ Task Technology Fit \\
\hline$>$ Perceived ubiquity \\
\hline$>$ Perceived reachability \\
\hline$>$ Mobility \\
\hline$>$ Accuracy \\
\hline$>$ Controllability \\
\hline$>$ Security \\
\hline$>$ Perceived availability \\
\hline$>$ Perceived quality \\
\hline$>$ Content \\
\hline$>$ Screen size \\
\hline$>$ Service speeds \\
\hline$>$ Design \\
\hline$>$ Multimedia \\
\hline$>$ Applications \\
\hline$>$ Wireless Internet \\
\hline$>$ Effort expectancy \\
\hline$>$ Simplicity \\
\hline$>$ Social influence \\
\hline$>$ Complexity \\
\hline$>$ Self-efficacy \\
\hline$>$ Social norm \\
\hline$>$ Social pressure \\
\hline$>$ Facilitating conditions \\
\hline$>$ Environments \\
\hline$>$ Organizational \\
\hline$>$ Compatibility \\
\hline$>$ Behavior control \\
\hline$>$ Price value \\
\hline$>$ Perceived cost \\
\hline$>$ Cost \\
\hline$>$ Perceived cost saving \\
\hline$>$ Company willingness to fund \\
\hline & Enjoyment \\
\hline
\end{tabular}




\begin{tabular}{|l|l|}
\hline$>$ Perceived enjoyment \\
\hline$>$ Computer playfulness \\
\hline$>$ Fun \\
\hline$>$ Entertainment utility \\
\hline$>$ After service \\
\hline
\end{tabular}

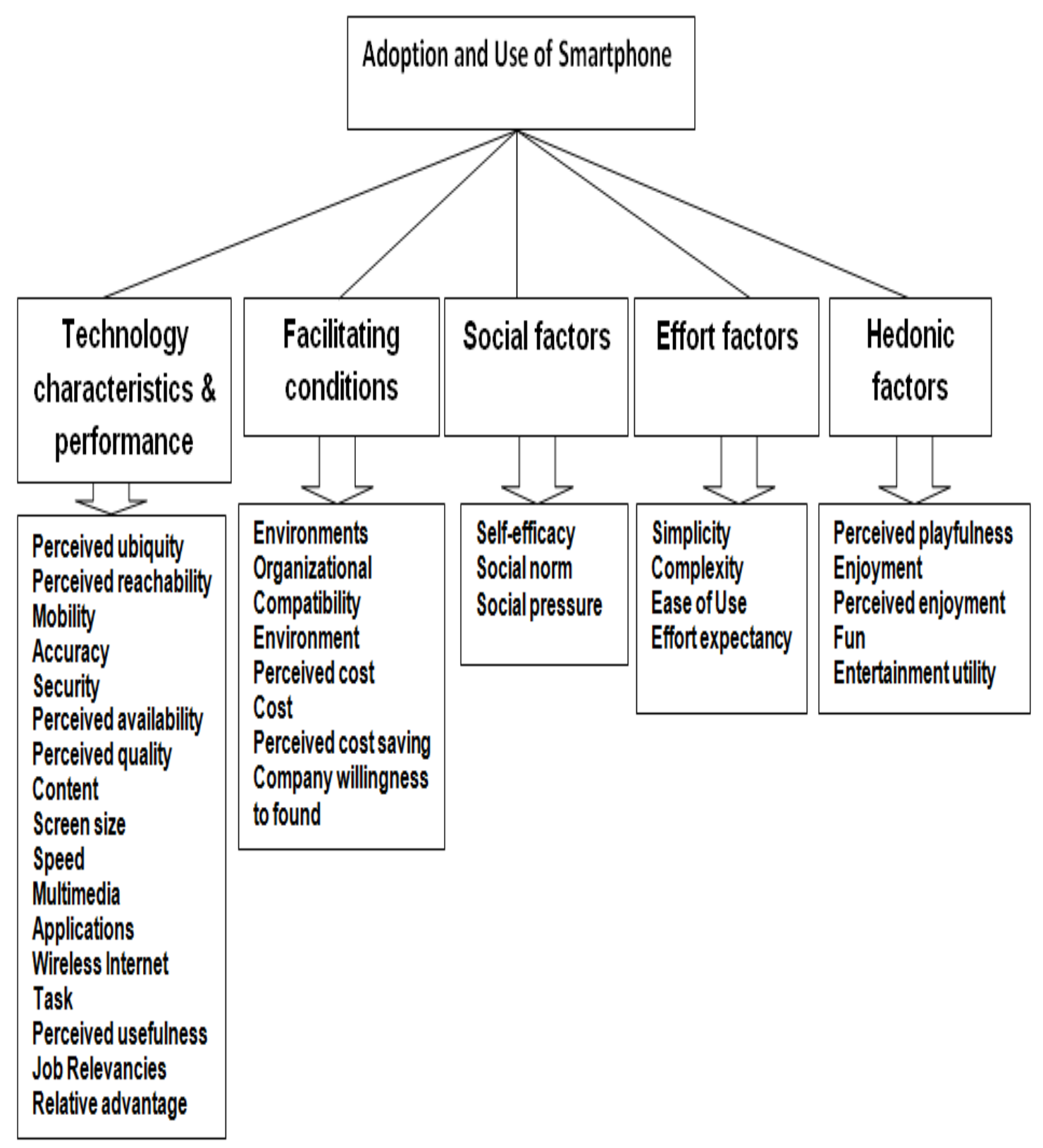


Figure 1: Taxonomy of factors identified in literate that are related to the adoption and use of Smartphone technology

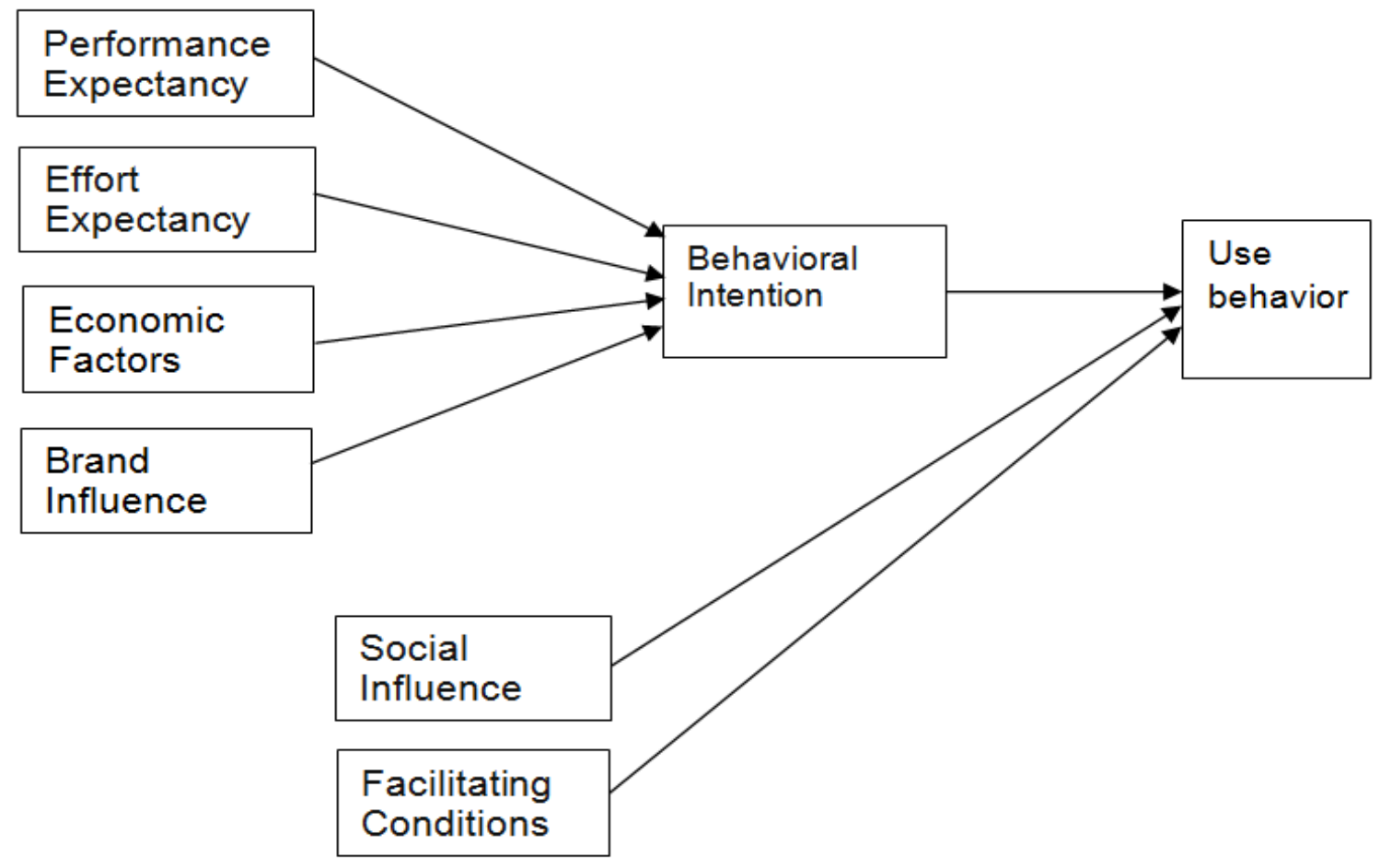

Situational factors

Figure2: The preliminary research model based on UTAUT

Table 2: Definition of the main factors of the preliminary research model

\begin{tabular}{|c|c|}
\hline Factors & Definition \\
\hline $\begin{array}{l}\text { Performance } \\
\text { Expectancy }\end{array}$ & $\begin{array}{l}\text { Performance expectancy is defined as the degree to which } \\
\text { an individual believes that using a Smartphone will help him } \\
\text { or her to attain benefits in their overall performance. }\end{array}$ \\
\hline Effort Expectancy & $\begin{array}{l}\text { Effort expectancy was defined as the degree of ease } \\
\text { associated with the use of the Smartphone. }\end{array}$ \\
\hline Social Influence & $\begin{array}{l}\text { Social influence is defined as the extent to which an } \\
\text { individual perceives that important others to believe he or } \\
\text { she should use a Smartphone. }\end{array}$ \\
\hline Facilitating Conditions & $\begin{array}{l}\text { defined facilitating conditions as "the degree to which an } \\
\text { individual believes that technical and infrastructure } \\
\text { supports are available to support the use of Smartphone }\end{array}$ \\
\hline Economic factors & $\begin{array}{l}\text { Economic factors can be defined as the perceived value of } \\
\text { the tradeoff between the perceived benefits of the } \\
\text { technologies and the cost for acquiring and using it }\end{array}$ \\
\hline
\end{tabular}


Table 3: definitions of the external factors identified in literature

\begin{tabular}{|c|c|}
\hline External Factors & Definition \\
\hline Mobility & $\begin{array}{l}\text { To have access in real time for information and } \\
\text { communications. Mobility provides users more freedom, } \\
\text { as they can access information and services without } \\
\text { having to find a physical place. }\end{array}$ \\
\hline $\begin{array}{l}\text { Perceived ubiquity or } \\
\text { availability }\end{array}$ & $\begin{array}{l}\text { Perceived service availability is defined as "the consumers' } \\
\text { perception of whether mobile services are able to provide } \\
\text { widely accessible services and timely connections" }\end{array}$ \\
\hline Perceived quality & $\begin{array}{l}\text { Perceived quality has been defined "as one of the } \\
\text { consumer satisfaction over content or services provided } \\
\text { by technologies" }\end{array}$ \\
\hline Content & $\begin{array}{l}\text { "Content correctness, content delivery time, content } \\
\text { quality, content quantity, and content provider are the } \\
\text { ingredients of content" }\end{array}$ \\
\hline Screen size & The size of screen small, big \\
\hline Design & $\begin{array}{l}\text { The design has two aspects: ( } 1 \text { ) inherent design and colors } \\
\text { of mobile phones, and ( } 2 \text { ) detailed elements of design } \\
\text { regarding the entire appearance, color, harmony of } \\
\text { appearance, shape of keypads, etc. }\end{array}$ \\
\hline Multimedia & $\begin{array}{l}\text { "The multimedia refers to the various media functions, } \\
\text { such as camera, mp3, and games." }\end{array}$ \\
\hline Applications & $\begin{array}{l}\text { "The application refers to contents that are executed in } \\
\text { the mobile equipment, and we can determine the supply } \\
\text { of diverse applications that meet users' BI." }\end{array}$ \\
\hline Wireless Internet & $\begin{array}{l}\text { "The wireless Internet can be defined as the services that } \\
\text { provide digitized information or contents to users, which } \\
\text { can eliminate time constraints or spatial constraints." }\end{array}$ \\
\hline Simplicity & the simplicity of understanding and using the system \\
\hline Complexity & $\begin{array}{l}\text { "degree to which an innovation is perceived as difficult to } \\
\text { understand and use" }\end{array}$ \\
\hline $\begin{array}{l}\text { Switching cost or } \\
\text { benefits }\end{array}$ & $\begin{array}{l}\text { "Switching benefits mean that the perceived utility that a } \\
\text { user gains in switching from the status quo to the new } \\
\text { situation" }\end{array}$ \\
\hline Self-efficacy & $\begin{array}{l}\text { "An individual's perception of his or her ability to use a } \\
\text { computer in the accomplishment of a job task". }\end{array}$ \\
\hline Social norm & $\begin{array}{l}\text { "Social norms, also referred to as subjective norms or } \\
\text { social influence, represent a factor that is assumed to } \\
\text { have a direct impact on perceived utility" }\end{array}$ \\
\hline
\end{tabular}




\begin{tabular}{|c|c|}
\hline Social pressure & $\begin{array}{l}\text { Normative pressure as "the person's perception that most } \\
\text { people } \\
\text { who are important to him think he should or should not } \\
\text { perform the behavior in question" }\end{array}$ \\
\hline Perceived security & $\begin{array}{l}\text { Feeling the risk of unauthorized use of mobile devices and } \\
\text { the concerns of the following: } \\
\text { Transaction errors, lack of transaction record and } \\
\text { documentation, privacy and device and network reliability }\end{array}$ \\
\hline Environments & $\begin{array}{l}\text { "Environmental factors are: competitor pressure, } \\
\text { customer satisfaction, and marketing approach" }\end{array}$ \\
\hline Organizational & $\begin{array}{l}\text { "Organizational factors include top management support, } \\
\text { size, user involvement, and product champion" }\end{array}$ \\
\hline Compatibility & $\begin{array}{l}\text { "Compatibility captures the consistency between an } \\
\text { innovation and the values, experiences, and needs of } \\
\text { potential adopters" } \\
\text { "The more an innovation is recognized as compatible with } \\
\text { the system, the more it would be adopted" }\end{array}$ \\
\hline Perceived cost & Premium pricing, services and transaction costs \\
\hline Costs & Premium pricing, services and transaction costs \\
\hline Perceived cost saving & $\begin{array}{l}\text { "Referred to an individual's perception about the way that } \\
\text { mobile wireless technology (MWT) provided cost-effective } \\
\text { communication and information exchange. Costs include } \\
\text { more than monetary factors, e.g., time and emotional } \\
\text { effort" }\end{array}$ \\
\hline $\begin{array}{l}\text { Company willingness to } \\
\text { found }\end{array}$ & $\begin{array}{l}\text { "defined here as the degree to which a company believes } \\
\text { that funding would enhance an individual's adoption of } \\
\text { MWT" }\end{array}$ \\
\hline Task & $\begin{array}{l}\text { Task was defined broadly as "the action carried out by } \\
\text { individuals in turning inputs into outputs" }\end{array}$ \\
\hline Task-technology fit & $\begin{array}{l}\text { Task-technology fit TTF is defined as the degree to which a } \\
\text { technology assists an individual in performing his or her } \\
\text { portfolio of tasks. }\end{array}$ \\
\hline Enjoyment & \multirow{2}{*}{$\begin{array}{l}\text { perceived enjoyment is defined as the extent to which the } \\
\text { activity of using a specific system is perceived to be } \\
\text { enjoyable in its own right, aside from any performance } \\
\text { consequences resulting from system usage [166]. }\end{array}$} \\
\hline Perceived enjoyment & \\
\hline
\end{tabular}




\section{Main question for the brainstorming session}

Q1 Please take five to 10 minutes to think about new factors that can be introduced which you believe are associated with users' adoption and use of the Smartphone.

Please introduce only new factors that are not mentioned in list of factors provided to you.

Q2. Please take five to 10 minutes to think and evaluate all factors; the newly introduced in this brainstorming session and the factors that are in the list provided to you, and narrow them down into only the most important factors.

Q3. Please take five to 10 minutes to re-evaluate all factors including the main factors showing in the preliminary research model and explain how can the most important factors selected can be logically linked into the main factors and the behavioral intention in the preliminary research model. 


\section{Conference room reservation confirmation email}

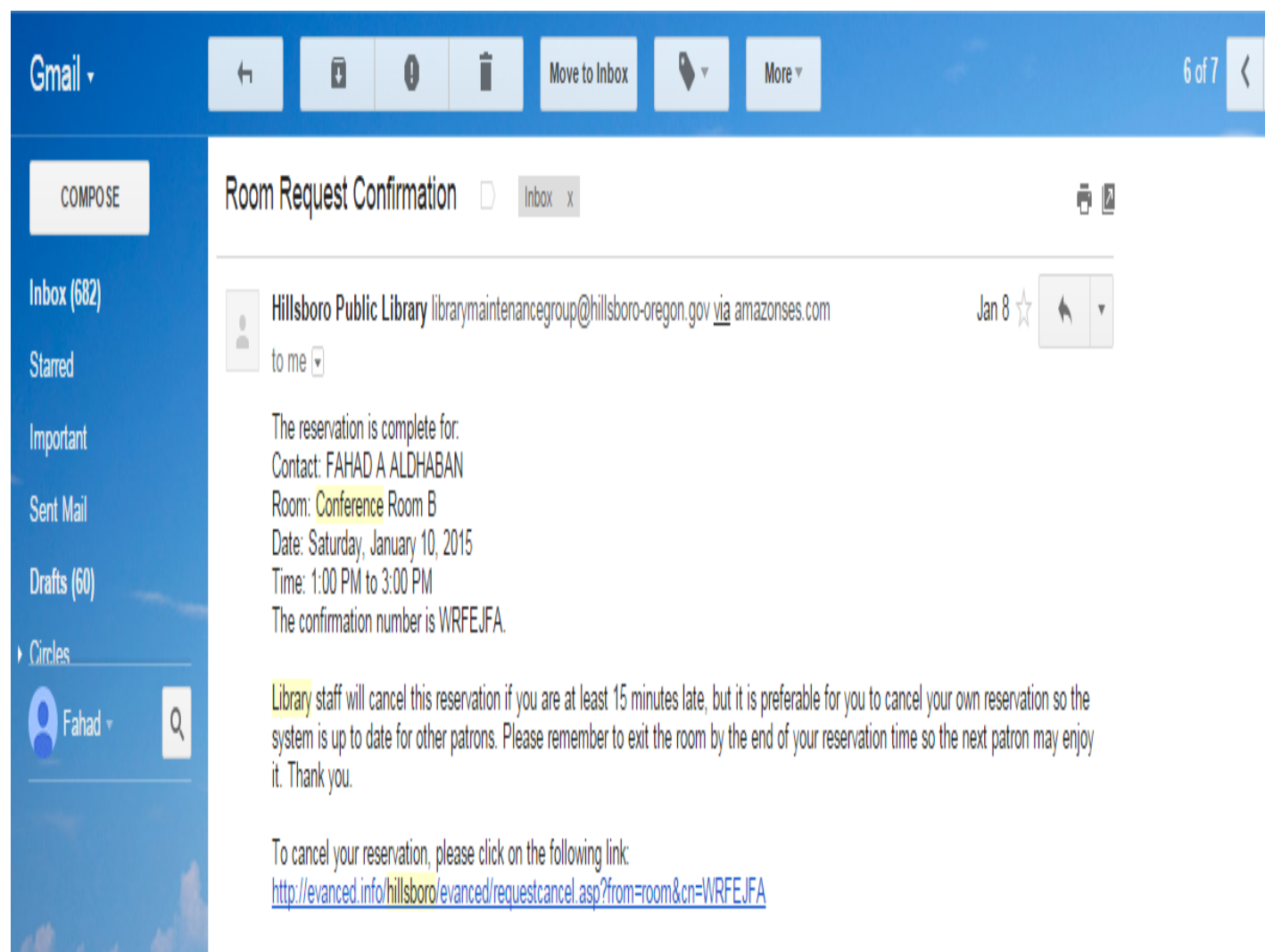


sample slides of the presentation in the brainstorming session

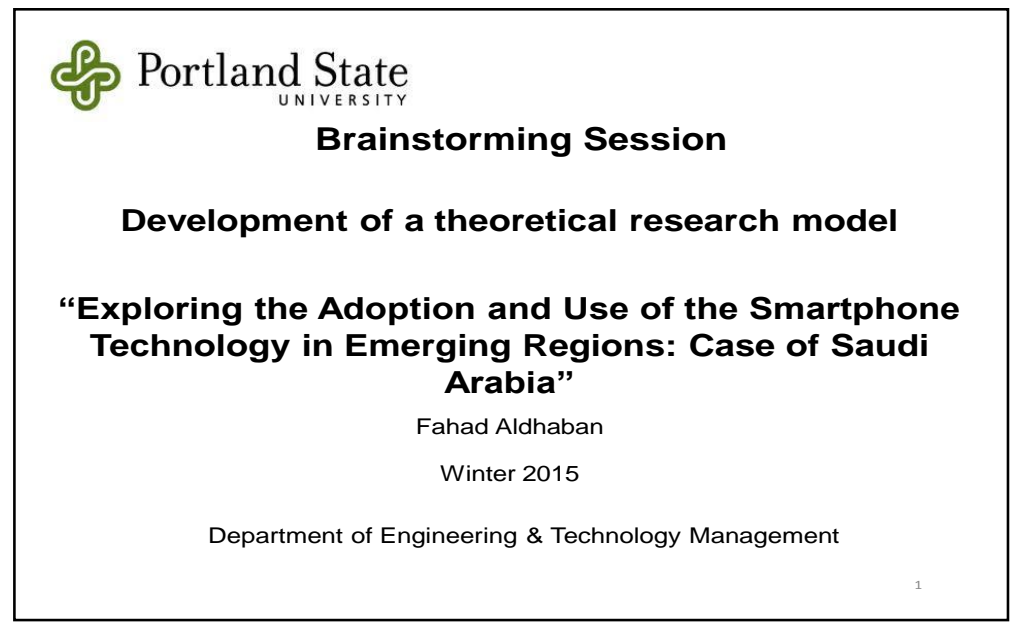

\section{Agenda}

- Introduction

- Research Background

- Brainstorming Session

- Aim of this brainstorming session

- Focus of this brainstorming session

- Main questions and expectations

\section{Introduction}

- This research aims to explore the key factors that may influence users' adoption and use of Smartphone technology

- Through a literature review a number of factors related to the adoption and use of Smartphone were identified and classified in a taxonomy

- A preliminary research model were developed based on Unified Theory of Acceptance and Use of Technology (UTAUT). 


\section{Appendix B: Focus Group Session}

(An invitation email that was sent to targeted participates in the focus group session)

Dear Mrs. /Mr.

I am a PhD student in the Department of Engineering and Technology Management (ETM) at Portland State University. The topic of my PhD research is "Exploring the Adoption and Use of the Smartphone Technology in Emerging Regions: Case of Saudi Arabia". As a part of my research, I develop a preliminary research model Unified Theory of Acceptance and Use of Technology (UTAUT) to study and identify the key factors that are associated with users' intention to adopt and use the Smartphone. Through a literature review conducted for this research a number of factors have been identified that are related to the adoption and use of Smartphone and its related technologies. As a part of my research I need to conduct a Focus group session to help in introducing new factors and selecting the most important factors that can be included in the research preliminary research model.

You have been identified as an experienced user of the Smartphone and your expertise and knowledge will be very helpful in my research. The focus group session is expected to take around one hour to be completed and it will be conducted in the most convenient time and place for the participants. People who agree to participate will receive more details about the research including the research model, main factors and the factors derived from literature review. I will really appreciate it if you accept my invitation and participate in this focus group session. 


\section{Details provided to participants in the focus group session}

Dear Dr. X,

Thank you for accepting my invitation to participate in the focus group session for my PhD research. The author developed a preliminary research model, shown in figure 2 below, to study and identify the key factors that influence users' adoption and use of the Smartphone. The preliminary research model is developed based on Unified Theory of Acceptance and Use of Technology (UTAUT) model which include four main factors adopted from UTAUT model. UTAUT model claims that each of these five main factors, namely performance expectancy, effort expectancy, social influence, and facilitating conditions, can have an influence on users' intention to adopt and use a new technology. Through a literature review conducted for this research forty factors have been identified which may have relationships with users' adoption and use of Smartphone and its related technologies (see table1 below). Taxonomy of factors related to the adoption and use of the Smartphone has been developed based on the factors that have been identified in literature (see figure 1 below). The aim of conducting this focus group session is to obtain participants' opinions and perspective in evaluating the identified and selecting factors and adding any missing factors that may have relationship with adoption and use of the Smartphone. Below is the preliminary research model that is developed for this research (see figure 2), table of factors identified in literature, definitions of the main factors in the preliminary research model, and definitions of the external factors identified in literature (see table 1, table 2, and table 3). Please read them and let me know if you need more details. 
Table1: factors identified in literature that may have relationships with users' adoption and use of the Smartphone

\begin{tabular}{|c|}
\hline Factors derived for literature \\
\hline$>$ Performance expectancy \\
\hline$>$ Task Technology Fit \\
\hline$>$ Perceived ubiquity \\
\hline$>$ Perceived reachability \\
\hline$>$ Mobility \\
\hline$>$ Accuracy \\
\hline$>$ Controllability \\
\hline$>$ Security \\
\hline$>$ Perceived availability \\
\hline$>$ Perceived quality \\
\hline$>$ Content \\
\hline$>$ Screen size \\
\hline$>$ Service speeds \\
\hline$>$ Design \\
\hline$>$ Multimedia \\
\hline$>$ Applications \\
\hline$>$ Wireless Internet \\
\hline$>$ Effort expectancy \\
\hline$>$ Simplicity \\
\hline$>$ Social influence \\
\hline$>$ Complexity \\
\hline$>$ Self-efficacy \\
\hline$>$ Social norm \\
\hline$>$ Social pressure \\
\hline$>$ Facilitating conditions \\
\hline$>$ Environments \\
\hline$>$ Organizational \\
\hline$>$ Compatibility \\
\hline$>$ Behavior control \\
\hline$>$ Price value \\
\hline$>$ Perceived cost \\
\hline$>$ Cost \\
\hline$>$ Perceived cost saving \\
\hline$>$ Company willingness to fund \\
\hline$>$ Enjoyment \\
\hline$>$ Perceived enjoyment \\
\hline$>$ Computer playfulness \\
\hline$>$ Fun \\
\hline$>$ Entertainment utility \\
\hline
\end{tabular}




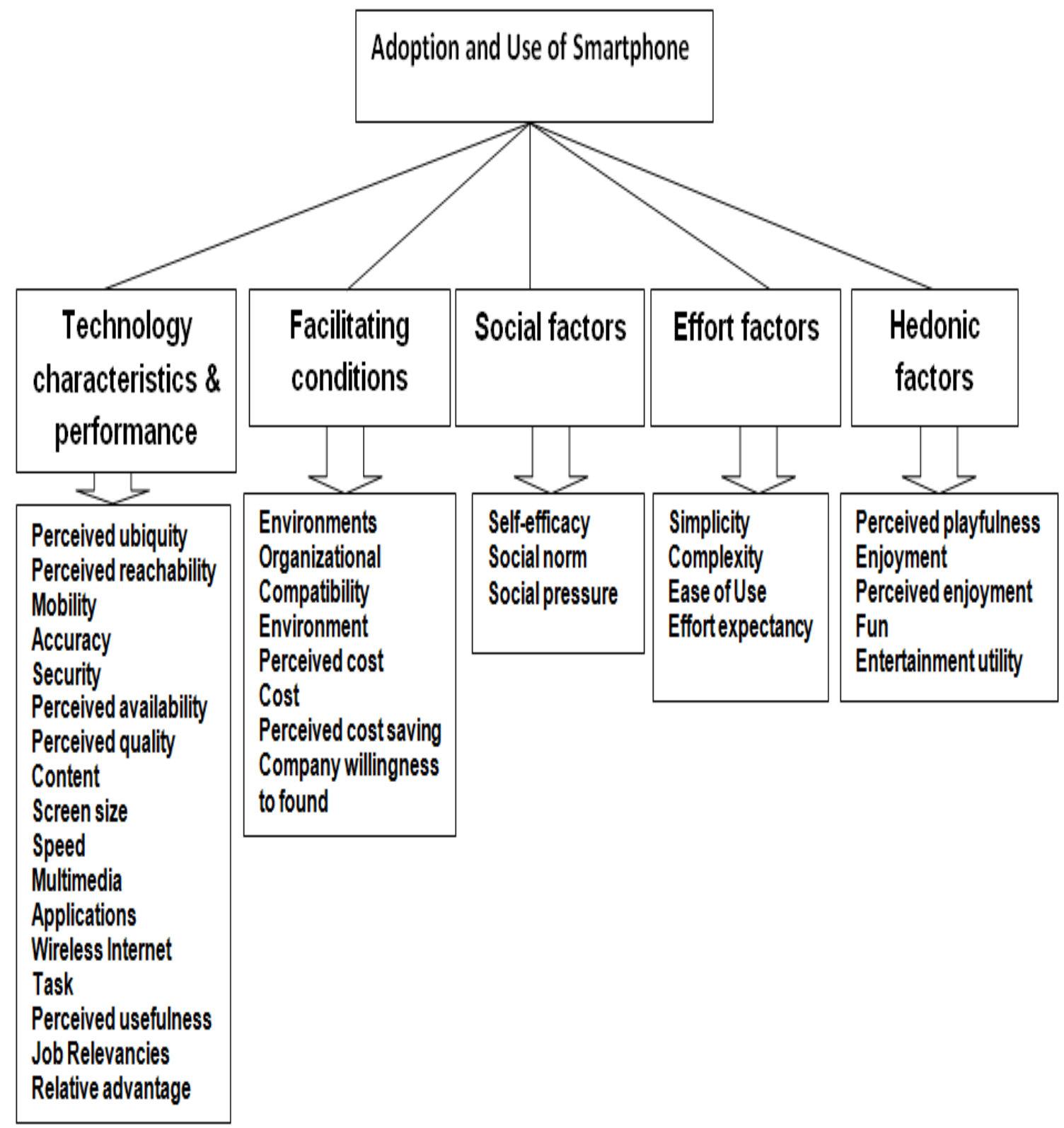

Figure 1: Taxonomy of factors identified in literature that are related to the adoption and use of Smartphone technology 
Figure 2: The preliminary research model based on UTAUT

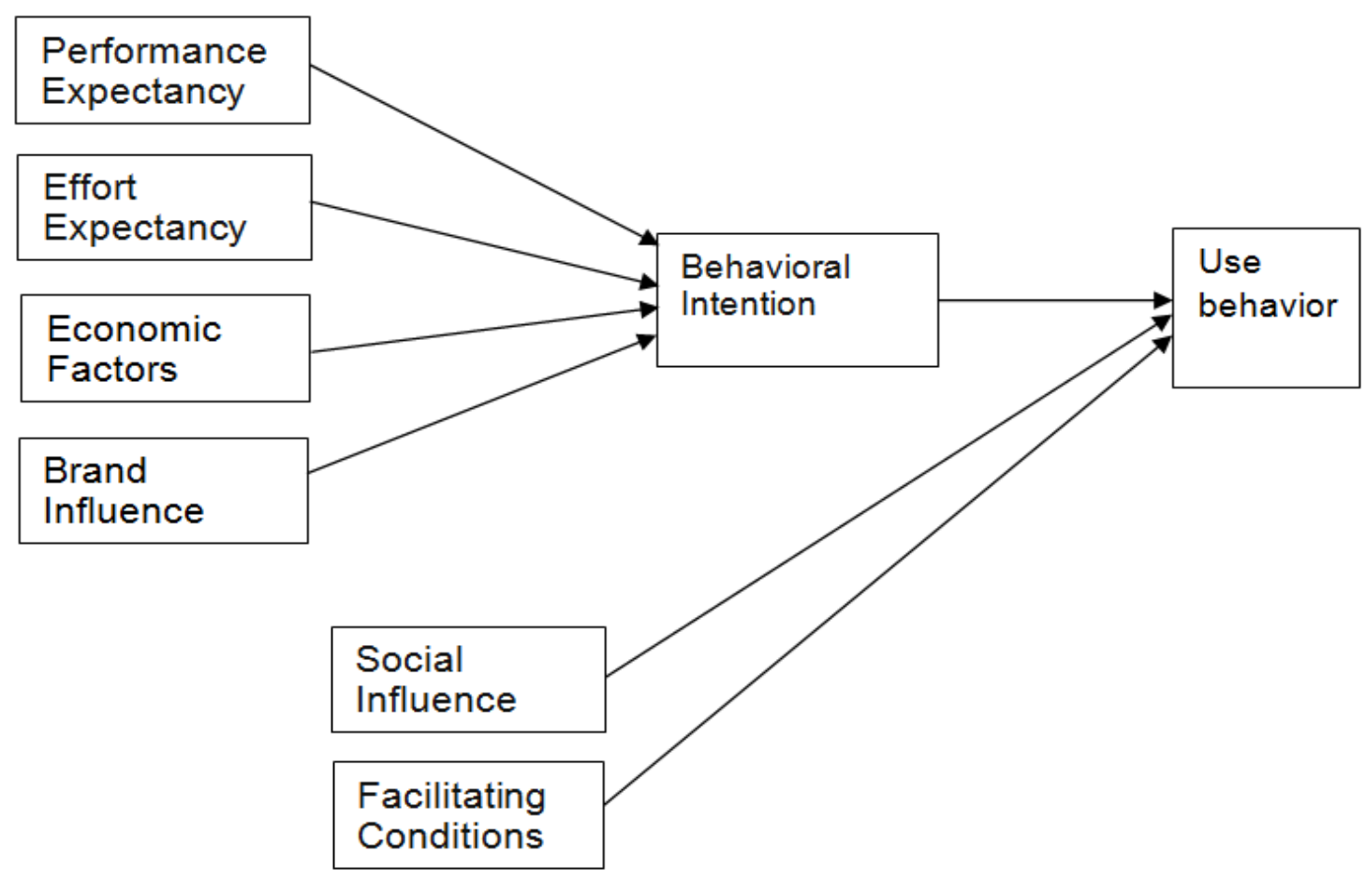

Situational factors

Table 2: Definition of the main factors of the preliminary research model

\begin{tabular}{|l|l|}
\hline Factors & Definition \\
\hline Performance & $\begin{array}{l}\text { Performance expectancy is defined as the degree to which } \\
\text { an individual believes that using a Smartphone will help } \\
\text { him or her to attain benefits in their overall performance. }\end{array}$ \\
\hline Effort Expectancy & $\begin{array}{l}\text { Effort expectancy was defined as the degree of ease } \\
\text { associated with the use of the Smartphone. }\end{array}$ \\
\hline Social Influence & $\begin{array}{l}\text { Social influence is defined as the extent to which an } \\
\text { individual perceives that important others to believe he or } \\
\text { she should use a Smartphone. }\end{array}$ \\
\hline Facilitating Conditions & $\begin{array}{l}\text { defined facilitating conditions as "the degree to which an } \\
\text { individual believes that technical and infrastructure } \\
\text { supports are available to support the use of Smartphone }\end{array}$ \\
\hline Economic factors & $\begin{array}{l}\text { Economic factors can be defined as the perceived value of } \\
\text { the tradeoff between the perceived benefits of the } \\
\text { technologies and the cost for acquiring and using it }\end{array}$ \\
\hline
\end{tabular}


Table 3: definitions of the external factors identified in literature

\begin{tabular}{|c|c|}
\hline External Factors & Definition \\
\hline Mobility & $\begin{array}{l}\text { To have access in real time for information and } \\
\text { communications. Mobility provides users more freedom, } \\
\text { as they can access information and services without } \\
\text { having to find a physical place. }\end{array}$ \\
\hline $\begin{array}{l}\text { Perceived ubiquity or } \\
\text { availability }\end{array}$ & $\begin{array}{l}\text { Perceived service availability is defined as "the } \\
\text { consumers" perception of whether mobile services are } \\
\text { able to provide widely accessible services and timely } \\
\text { connections" }\end{array}$ \\
\hline Perceived quality & $\begin{array}{l}\text { Perceived quality has been defined "as one of the } \\
\text { consumer satisfaction over content or services provided } \\
\text { by technologies" }\end{array}$ \\
\hline Content & $\begin{array}{l}\text { "Content correctness, content delivery time, content } \\
\text { quality, content quantity, and content provider are the } \\
\text { ingredients of content" }\end{array}$ \\
\hline Screen size & The size of screen small, big \\
\hline Design & $\begin{array}{l}\text { The design has two aspects: ( } 1 \text { ) inherent design and colors } \\
\text { of mobile phones, and (2) detailed elements of design } \\
\text { regarding the entire appearance, color, harmony of } \\
\text { appearance, shape of keypads, etc. }\end{array}$ \\
\hline Multimedia & $\begin{array}{l}\text { "The multimedia refers to the various media functions, } \\
\text { such as camera, mp3, and games." }\end{array}$ \\
\hline Applications & $\begin{array}{l}\text { "The application refers to contents that are executed in } \\
\text { the mobile equipment, and we can determine the supply } \\
\text { of diverse applications that meet users' BI." }\end{array}$ \\
\hline Wireless Internet & $\begin{array}{l}\text { "The wireless Internet can be defined as the services that } \\
\text { provide digitized information or contents to users, which } \\
\text { can eliminate time constraints or spatial constraints." }\end{array}$ \\
\hline Simplicity & the simplicity of understanding and using the system \\
\hline Complexity & $\begin{array}{l}\text { "degree to which an innovation is perceived as difficult to } \\
\text { understand and use" }\end{array}$ \\
\hline $\begin{array}{l}\text { Switching cost or } \\
\text { benefits }\end{array}$ & $\begin{array}{l}\text { "Switching benefits mean that the perceived utility that a } \\
\text { user gains in switching from the status quo to the new } \\
\text { situation" }\end{array}$ \\
\hline Self-efficacy & $\begin{array}{l}\text { "An individual's perception of his or her ability to use a } \\
\text { computer in the accomplishment of a job task". }\end{array}$ \\
\hline Social norm & $\begin{array}{l}\text { "Social norms, also referred to as subjective norms or } \\
\text { social influence, represent a factor that is assumed to } \\
\text { have a direct impact on perceived utility" }\end{array}$ \\
\hline
\end{tabular}




\begin{tabular}{|c|c|}
\hline Social pressure & $\begin{array}{l}\text { Normative pressure as "the person's perception that most } \\
\text { people } \\
\text { who are important to him think he should or should not } \\
\text { perform the behavior in question" }\end{array}$ \\
\hline Perceived security & $\begin{array}{l}\text { Feeling the risk of unauthorized use of mobile devices and } \\
\text { the concerns of the following: } \\
\text { Transaction errors, lack of transaction record and } \\
\text { documentation, privacy and device and network reliability }\end{array}$ \\
\hline Environments & $\begin{array}{l}\text { "Environmental factors are: competitor pressure, } \\
\text { customer satisfaction, and marketing approach" }\end{array}$ \\
\hline Organizational & $\begin{array}{l}\text { "Organizational factors include top management support, } \\
\text { size, user involvement, and product champion" }\end{array}$ \\
\hline Compatibility & $\begin{array}{l}\text { "Compatibility captures the consistency between an } \\
\text { innovation and the values, experiences, and needs of } \\
\text { potential adopters" } \\
\text { "The more an innovation is recognized as compatible with } \\
\text { the system, the more it would be adopted" }\end{array}$ \\
\hline Perceived cost & Premium pricing, services and transaction costs \\
\hline Costs & Premium pricing, services and transaction costs \\
\hline Perceived cost saving & $\begin{array}{l}\text { "Referred to an individual's perception about the way that } \\
\text { mobile wireless technology (MWT) provided cost-effective } \\
\text { communication and information exchange. Costs include } \\
\text { more than monetary factors, e.g., time and emotional } \\
\text { effort" }\end{array}$ \\
\hline $\begin{array}{l}\text { Company willingness } \\
\text { to found }\end{array}$ & $\begin{array}{l}\text { "defined here as the degree to which a company believes } \\
\text { that funding would enhance an individual's adoption of } \\
\text { MWT" }\end{array}$ \\
\hline Task & $\begin{array}{l}\text { Task was defined broadly as "the action carried out by } \\
\text { individuals in turning inputs into outputs" }\end{array}$ \\
\hline Task-technology fit & $\begin{array}{l}\text { Task-technology fit TTF is defined as the degree to which a } \\
\text { technology assists an individual in performing his or her } \\
\text { portfolio of tasks. }\end{array}$ \\
\hline Enjoyment & \multirow{2}{*}{$\begin{array}{l}\text { perceived enjoyment is defined as the extent to which the } \\
\text { activity of using a specific system is perceived to be } \\
\text { enjoyable in its own right, aside from any performance } \\
\text { consequences resulting from system usage [166]. }\end{array}$} \\
\hline Perceived enjoyment & \\
\hline
\end{tabular}




\section{Questions for the participants in the focus group}

Q1. Please review the list of factors provided to you and introduce any new relevant factors that you believe is associated with users' intention to adopt and use the Smartphone that are not listed in the list provided to you.

Q2. Please review and evaluate all factors in the list provided to you including the main factors in preliminary research model and mark the factors that you agree with, remove any factors that you think is not important, similar or duplicate factors.

Q3. Based on your opinions please narrow down the list of factors generated from question one and two into only the most important factors.

Q4. Based on your opinions, please select the most important factors that you believe is very important and logically connect them into main factors or the behavioral intention factor in the preliminary research model. 
Example of the slides of the presentation presented in the focus group session

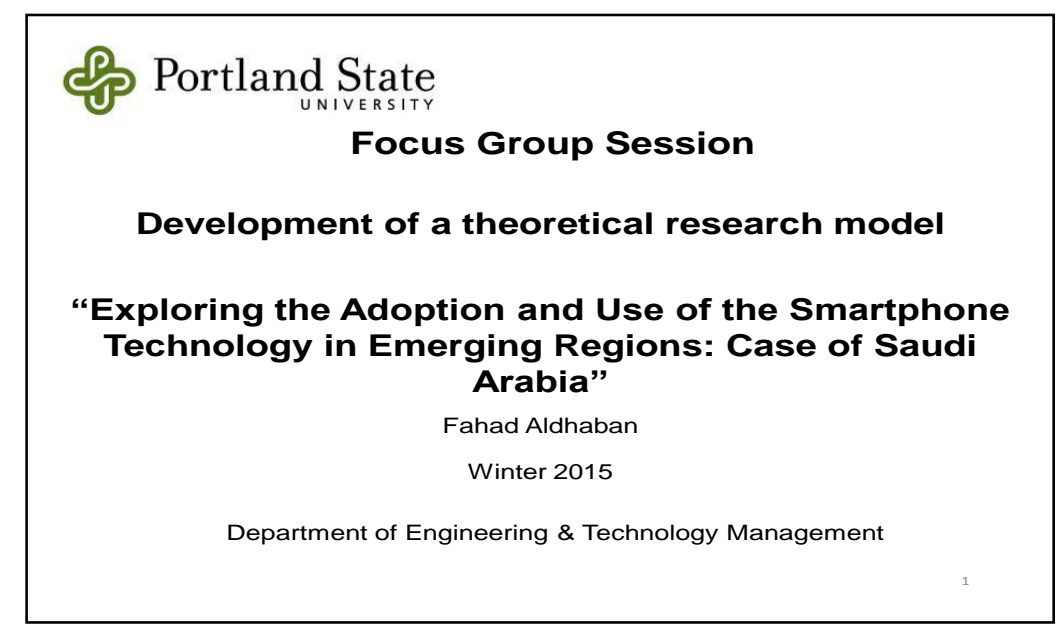

\section{Agenda}

- Introduction

- Research background

- Focus group session

- Aim of conducting focus group

- Main questions focus group session

- Expectations

\section{Focus group session}

- This researcher aims to conduct a number of qualitative methods namely brainstorming session, focus group and individual interviews.

- The aim of conducting the mention methods is to obtain opinions of experienced users of Smartphone and individuals who work in related sectors about new factors related to adoption and use of the Smartphone.

- The focus group session is topically conducted to obtain participants' impressions, point view and opinions as the participants are invited to discuss and talk about a specific issue 


\section{Appendix C: Individual Interviews}

(An invitation email that was sent or submitted to targeted participates in the interviews)

Dear Mrs. /Mr.

I am a PhD student in the Department of Engineering and Technology Management (ETM) at Portland State University. The topic of my PhD research is "Exploring the Adoption and Use of the Smartphone Technology in Emerging Regions: Case of Saudi Arabia". As a part of my research, I develop a preliminary research model Unified Theory of Acceptance and Use of Technology (UTAUT) to study and identify the key factors that are associated with users' intention to adopt and use the Smartphone. Through a literature review conducted for this research a number of factors have been identified that are related to the adoption and use of Smartphone and its related technologies. As a part of my research I need to conduct individual interviews to help in introducing new factors and selecting the most important factors that can be included in the research preliminary research model.

You have been identified as an experienced user of the Smartphone and your expertise and knowledge will be very helpful in my research. The individual interview is expected to take 20 to 40 minutes to be completed and it will be conducted in the most convenient time and place for each individual. Individual who agree to participate will receive more details about the research including the research model, main factors and the factors derived from the literature review. I will really appreciate it if you accept my invitation and participate in this individual interview. 


\section{Details provided to participants who agreed to participate in the interviews}

Dear Dr. X,

Thank you for accepting my invitation to participate in the individual interview for my PhD research. The author developed a preliminary research model, shown in figure 2 below, to study and identify the key factors that influence users' adoption and use of the Smartphone. The preliminary research model is developed based on Unified Theory of Acceptance and Use of Technology (UTAUT) model which include four main factors adopted from UTAUT model. UTAUT model claims that each of these five main factors, namely performance expectancy, effort expectancy, social influence, and facilitating conditions, can have an influence on users' intention to adopt and use a new technology. Through a literature review conducted for this research thirty five external factors have been identified which may have relationships with users' adoption and use of Smartphone and its related technologies (see table1 below). Taxonomy of factors related to the adoption and use of the Smartphone has been developed based on the factors that have been identified in literature (see figure 1 below). The aim of conducting this individual interview is to obtain participants' opinions and perspective in evaluating the identified and selecting factors and adding any missing factors that may have relationship with adoption and use of the Smartphone. Below is the preliminary research model that is developed for this research (see figure 2), table of the external factors identified in literature, definitions of the main factors in the preliminary research 
model, and definitions of the external factors identified in literature (see table 1, table 2, and table 3). Please read them and let me know if you need more details.

Table1: factors identified in literature that may have relationships with users' adoption and use of the Smartphone

\begin{tabular}{|l|l|}
\hline Factors derived for literature \\
\hline$>$ Performance expectancy \\
\hline$>$ Task Technology Fit \\
\hline$>$ Perceived ubiquity \\
\hline$>$ Perceived reachability \\
\hline$>$ Mobility \\
\hline$>$ Accuracy \\
\hline$>$ Controllability \\
\hline$>$ Security \\
\hline$>$ Perceived availability \\
\hline$>$ Perceived quality \\
\hline$>$ Content \\
\hline$>$ Screen size \\
\hline$>$ Service speeds \\
\hline$>$ Design \\
\hline$>$ Multimedia \\
\hline$>$ Applications \\
\hline$>$ Wireless Internet \\
\hline$>$ Effort expectancy \\
\hline$>$ Simplicity \\
\hline$>$ Social influence \\
\hline$>$ Complexity \\
\hline$>$ Self-efficacy \\
\hline$>$ Social norm \\
\hline$>$ Social pressure \\
\hline$>$ Facilitating conditions \\
\hline$>$ Environments \\
\hline$>$ Organizational \\
\hline$>$ Compatibility \\
\hline$>$ Behavior control \\
\hline$>$ Price value \\
\hline$>$ Perceived cost \\
\hline$>$ Cost \\
\hline$>$ Perceived cost saving \\
\hline$>$ Company willingness to fund \\
\hline$>$ Enjoyment \\
\hline
\end{tabular}




\begin{tabular}{|l|}
\hline$>$ Perceived enjoyment \\
\hline$>$ Computer playfulness \\
\hline$>$ Fun \\
\hline$>$ Entertainment utility \\
\hline$>$ After service \\
\hline
\end{tabular}

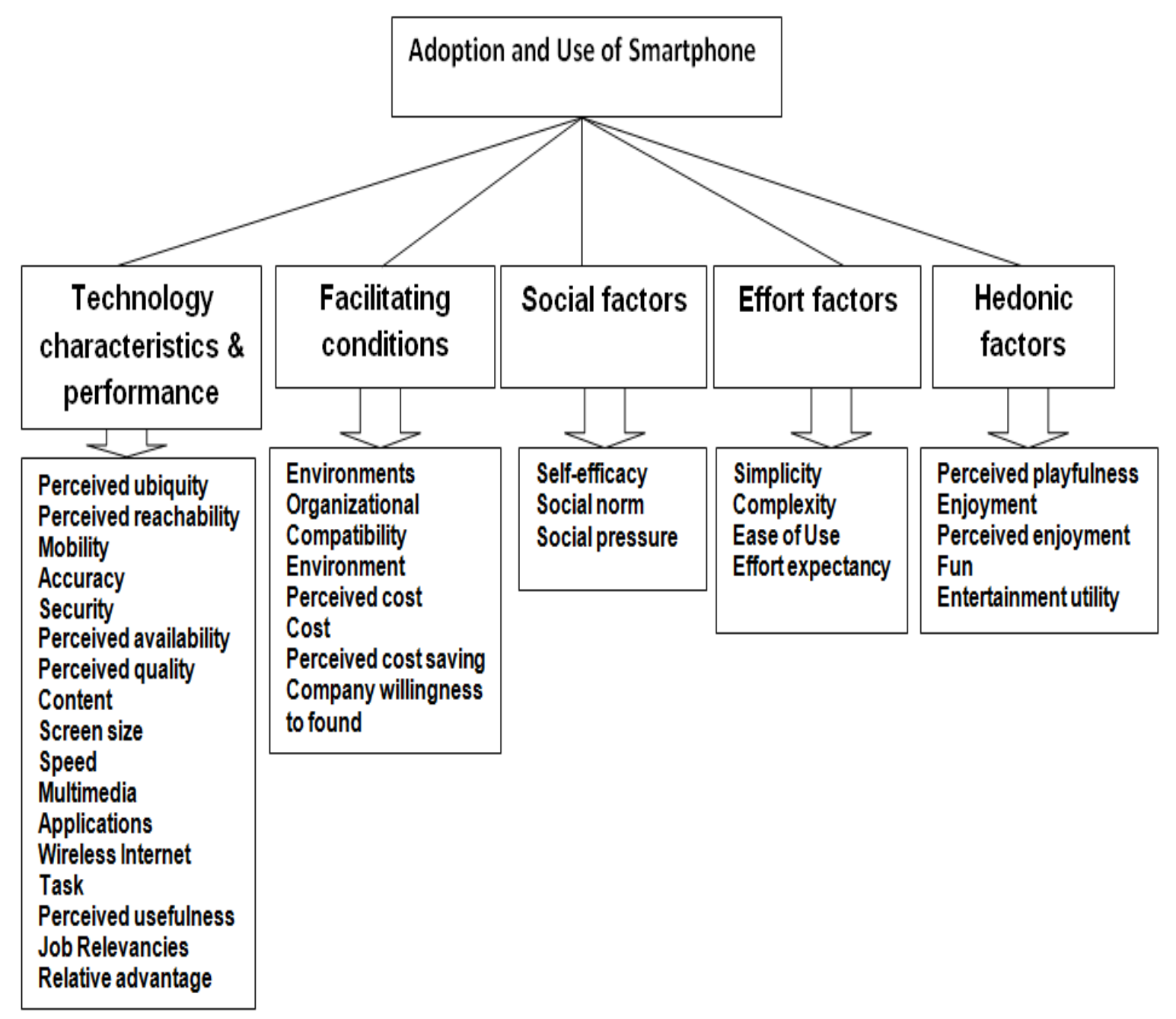

Figure 1: Taxonomy of factors identified in literature that are related to the adoption and use of Smartphone technology 


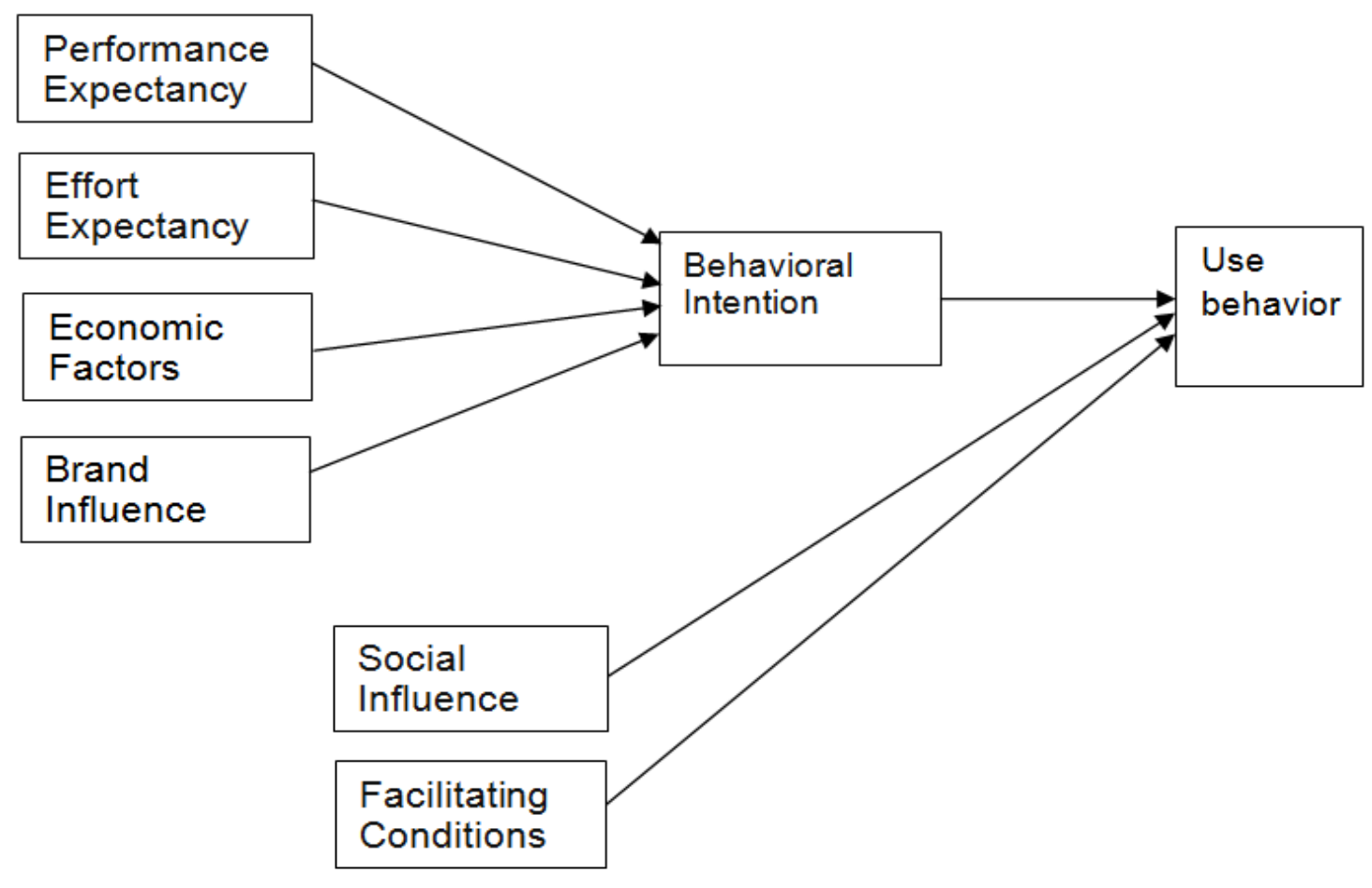

Situational factors

Figure 2: The preliminary research model based on UTAUT

Table 2: Definition of the main factors of the preliminary research model

\begin{tabular}{|l|l|}
\hline Factors & Definition \\
\hline Performance & $\begin{array}{l}\text { Performance expectancy is defined as the degree to which an } \\
\text { individual believes that using a Smartphone will help him or } \\
\text { her to attain benefits in their overall performance. }\end{array}$ \\
\hline Effort Expectancy & $\begin{array}{l}\text { Effort expectancy was defined as the degree of ease } \\
\text { associated with the use of the Smartphone. }\end{array}$ \\
\hline Social Influence & $\begin{array}{l}\text { Social influence is defined as the extent to which an } \\
\text { individual perceives that important others to believe he or } \\
\text { she should use a Smartphone. }\end{array}$ \\
\hline Facilitating Conditions & $\begin{array}{l}\text { defined facilitating conditions as "the degree to which an } \\
\text { individual believes that technical and infrastructure supports } \\
\text { are available to support the use of Smartphone }\end{array}$ \\
\hline Economic factors & $\begin{array}{l}\text { Economic factors can be defined as the perceived value of } \\
\text { the tradeoff between the perceived benefits of the } \\
\text { technologies and the cost for acquiring and using it }\end{array}$ \\
\hline
\end{tabular}


Table 3: definitions of the external factors identified in literature

\begin{tabular}{|c|c|}
\hline External Factors & Definition \\
\hline Mobility & $\begin{array}{l}\text { To have access in real time for information and } \\
\text { communications. Mobility provides users more freedom, as } \\
\text { they can access information and services without having to } \\
\text { find a physical place. }\end{array}$ \\
\hline $\begin{array}{l}\text { Perceived ubiquity or } \\
\text { availability }\end{array}$ & $\begin{array}{l}\text { Perceived service availability is defined as "the consumers' } \\
\text { perception of whether mobile services are able to provide } \\
\text { widely accessible services and timely connections" }\end{array}$ \\
\hline Perceived quality & $\begin{array}{l}\text { Perceived quality has been defined "as one of the consumer } \\
\text { satisfaction over content or services provided by } \\
\text { technologies" }\end{array}$ \\
\hline Content & $\begin{array}{l}\text { "Content correctness, content delivery time, content quality, } \\
\text { content quantity, and content provider are the ingredients of } \\
\text { content" }\end{array}$ \\
\hline Screen size & The size of screen small, big \\
\hline Design & $\begin{array}{l}\text { The design has two aspects: (1) inherent design and colors of } \\
\text { mobile phones, and (2) detailed elements of design regarding } \\
\text { the entire appearance, color, harmony of appearance, shape } \\
\text { of keypads, etc. }\end{array}$ \\
\hline Multimedia & $\begin{array}{l}\text { "The multimedia refers to the various media functions, such } \\
\text { as camera, mp3, and games." }\end{array}$ \\
\hline Applications & $\begin{array}{l}\text { "The application refers to contents that are executed in the } \\
\text { mobile equipment, and we can determine the supply of } \\
\text { diverse applications that meet users' Bl." }\end{array}$ \\
\hline Wireless Internet & $\begin{array}{l}\text { "The wireless Internet can be defined as the services that } \\
\text { provide digitized information or contents to users, which can } \\
\text { eliminate time constraints or spatial constraints." }\end{array}$ \\
\hline Simplicity & the simplicity of understanding and using the system \\
\hline Complexity & $\begin{array}{l}\text { "degree to which an innovation is perceived as difficult to } \\
\text { understand and use" }\end{array}$ \\
\hline $\begin{array}{l}\text { Switching cost or } \\
\text { benefits }\end{array}$ & $\begin{array}{l}\text { "Switching benefits mean that the perceived utility that a } \\
\text { user gains in switching from the status quo to the new } \\
\text { situation" }\end{array}$ \\
\hline Self-efficacy & $\begin{array}{l}\text { "An individual's perception of his or her ability to use a } \\
\text { computer in the accomplishment of a job task". }\end{array}$ \\
\hline Social norm & $\begin{array}{l}\text { "Social norms, also referred to as subjective norms or social } \\
\text { influence, represent a factor that is assumed to have a direct }\end{array}$ \\
\hline
\end{tabular}




\begin{tabular}{|c|c|}
\hline & impact on perceived utility" \\
\hline Social pressure & $\begin{array}{l}\text { Normative pressure as "the person's perception that most } \\
\text { people } \\
\text { who are important to him think he should or should not } \\
\text { perform the behavior in question" }\end{array}$ \\
\hline Perceived security & $\begin{array}{l}\text { Feeling the risk of unauthorized use of mobile devices and } \\
\text { the concerns of the following: } \\
\text { Transaction errors, lack of transaction record and } \\
\text { documentation, privacy and device and network reliability }\end{array}$ \\
\hline Environments & $\begin{array}{l}\text { "Environmental factors are: competitor pressure, customer } \\
\text { satisfaction, and marketing approach" }\end{array}$ \\
\hline Organizational & $\begin{array}{l}\text { "Organizational factors include top management support, } \\
\text { size, user involvement, and product champion" }\end{array}$ \\
\hline Compatibility & $\begin{array}{l}\text { "Compatibility captures the consistency between an } \\
\text { innovation and the values, experiences, and needs of } \\
\text { potential adopters" } \\
\text { "The more an innovation is recognized as compatible with } \\
\text { the system, the more it would be adopted" }\end{array}$ \\
\hline Perceived cost & Premium pricing, services and transaction costs \\
\hline Costs & Premium pricing, services and transaction costs \\
\hline Perceived cost saving & $\begin{array}{l}\text { "Referred to an individual's perception about the way that } \\
\text { mobile wireless technology (MWT) provided cost-effective } \\
\text { communication and information exchange. Costs include } \\
\text { more than monetary factors, e.g., time and emotional effort" }\end{array}$ \\
\hline $\begin{array}{l}\text { Company willingness to } \\
\text { found }\end{array}$ & $\begin{array}{l}\text { "defined here as the degree to which a company believes } \\
\text { that funding would enhance an individual's adoption of } \\
\text { MWT" }\end{array}$ \\
\hline Task & $\begin{array}{l}\text { Task was defined broadly as "the action carried out by } \\
\text { individuals in turning inputs into outputs" }\end{array}$ \\
\hline Task-technology fit & $\begin{array}{l}\text { Task-technology fit TTF is defined as the degree to which a } \\
\text { technology assists an individual in performing his or her } \\
\text { portfolio of tasks. }\end{array}$ \\
\hline Enjoyment & perceived enjoyment is defined as "the extent to which the \\
\hline Perceived enjoyment & $\begin{array}{l}\text { activity of using a specific system is perceived to be } \\
\text { enjoyable in its own right, aside from any performance } \\
\text { consequences resulting from system usage" }\end{array}$ \\
\hline
\end{tabular}




\section{Main Interview Questions}

Q1. Please review the list of factors provided to you and introduce any new relevant factors that you believe is associated with users' intention to adopt and use the Smartphone that are not listed in the list provided to you.

Q2. Please review and evaluate all factors in the list provided to you including the main factors in preliminary research model and mark the factors that you agree with, remove any factors that you think is not important, similar or duplicate factors.

Q3. Based on your opinions please narrow down the list of factors generated from question one and two into only the most important factors.

Q4. Based on your opinions, please select the most important factors that you believe is very important and logically connect them into main factors or the behavioral intention factor in the preliminary research model. 


\title{
Appendix D: Consent Form
}

\section{Consent form for participants in the Qualitative methods}

\author{
The Portland State University \\ Consent to Participate in Research \\ "Exploring the Adoption and Use of the Smartphone Technology in Emerging Regions: \\ Case of Saudi Arabia"
}

You are being asked to participate in a research study that is being done by Tugrul U. Daim, who is the principal investigator and the associate researcher Fahad Aldhaban, from the department of Engineering and Technology Management at Portland State University in Portland, Oregon. This research is studying the key factors that may influence users' adoption and use of the Smartphone technology. This research is being conducted in partial fulfillment for the requirements for a doctoral degree in Technology Management. You are being asked to participate in this research because are an experienced user of the Smartphone or you have a work experience in industries related to Smartphones technology. Your feedback will help the researcher to study and better understand key factors that may influence users' adoption and use of the Smartphone.

If you agree to participate, you will be given a list of adoption factors that were derived from literature, which may have relationships with users' adoption of the Smartphone. You will be asked to participate in either an interview, brainstorming session, or focus group session. You will be asked to review, evaluate, and select only the factors that may be more important and can be added to the research model. Participation in this research will take approximately 30 minutes of your time to complete. You will participate in only one session.

Risks are minimal for participating in this research study. Data that contain identifiers linked to the participants will be kept confidential at all times and will be accessible to only the principal investigator and the co-principal investigator. All the data obtained from participants will be kept confidential and will only be reported in the aggregate format (reporting only combined results and never reporting individual results). Before any presentation, sharing data outside of the research team or publication the names and identifiers linked to the participants will be removed to insure anonymity. Within three years after completing this research the investigator and the co-principal Investigator will destroy or delete the collected information. Participants in the focus group should know that, the investigator can only be responsible for the confidentiality of the data collected by the researcher. Confidentiality may be breached by other participants in the focus group. As a participant in the focus group, you are encouraged not to speak of what is discussed during the group once the group has ended. 
There is no direct benefit from participating in this research, but the research may help to increase knowledge, which may help in improving service and production of Smartphones. Your participation in this study is completely voluntary. You have the right to choose not to participate or to withdraw your participation at any point in this study without penalty or loss of benefits to which you are otherwise entitled.

If you have questions, concerns or complaints at any time about this research study, you may contact the researcher Fahad Aldhaban, at 503-935-XXXX, aldhaban@pdx.edu. If you have questions regarding your rights as a research participant, you may call the PSU Office for Research Integrity at (503) 725-2227 or 1(877) 4804400. The ORI is the office that supports the PSU Institutional Review Board (IRB). The IRB is a group of people from PSU and the community who provide independent oversight of safety and ethical issues related to research involving human participants. For more information, you may also access the IRB website at https://sites.google.com/a/pdx.edu/research/integrity.

You are making a decision whether to participate in this study. Your signature below indicates that you have read the information provided. By signing this consent form, you are not waiving any of your legal rights as a research participant. You have had an opportunity to ask questions and all questions have been answered to your satisfaction. By signing this consent form, you agree to participate in this study. A copy of this consent form will be provided to you.

Name of Adult Subject (print) Signature of Adult Subject Date

\section{INVESTIGATOR SIGNATURE}

This research study has been explained to the participant and all of his/her questions have been answered. The participant understands the information described in this consent form and freely consents to participate.

Fahad Aldhaban

(Name) (Signature) Date 


\section{Appendix E: An Example of the Validation Tool Developed to be Used by Experts.}

\section{Validation Tool}

This research aims to explore the key factors that influence users to adopt and use Smartphone technology: Case of Saudi Arabia. A research model and hypotheses have been developed based on a literature review conducted on related previous research and theoretical models. The research model is based on Unified Theory of Acceptance and Use of Technology (UTAUT) model and it has been modified and validated using a number of qualitative methods, namely a brainstorming session, a focus group session, and individual face-to-face interviews. In order to test the hypothesized relationship among factors/variables in the research model shown in figure 1, a survey questionnaire has been developed to collect data. For each factor/variable in this research model a number of items/questions have been developed to measure the relationships among each factor/variable as shown in figure 1 and 2. In order to collect data from smartphone users, a research instrument has been developed using a survey questionnaire. The questions in the survey have been adopted from survey instruments that have been developed and validated in previous related research. Also, the survey questions have been modified using read aloud method and tested in a pilot test administrated to a group of PhD. students at the department of ETM. This tool is developed to obtain your judgment on the degree of relevance of each item or question to the factor/variable that it is intended to measure, as well as to obtain your judgment on how easy is it for smartphone users to answer each question/item. Please provide your judgments and comments in table 1 below.

For more information about the research factors/variables please see their definitions in table 2 below. If you have any questions or need more information, please contact me

Please provide your judgments in the table below using the following two questions and their possible answers:

- Question 1 (Relevance): In your judgment, how closely dose each item/question's text represent the intention of that item/question?

- Answer range from 1 to 5: 1- Not Very Closely, 2- Somewhat Not Closely, 3Neutral, 4- Somewhat Closely, 5- Very Closely.

- Question 2 (Ease of answering the question): In your judgment, how easy is it for a smartphone user to answer the each question? 
- Answer range from 1 to 5: 1- Not Very Easy, 2- Somewhat Not Easy, 3Neutral, 4- Somewhat Easy, 5- Very Easy.

- Please provide your comments to modify each item/question as needed in table 1 below.

Table 1: Survey testing and validation tool

\begin{tabular}{|c|c|c|c|c|}
\hline $\begin{array}{l}\text { Question } \\
\text { (Item) }\end{array}$ & Intention of the question & $\begin{array}{c}\text { Q1: } \\
\text { Relevance } \\
(1)(2)(3)(4)(5)\end{array}$ & $\begin{array}{l}\text { Q2:Ease of } \\
\text { answering } \\
\text { the question } \\
(1)(2)(3)(4)(5)\end{array}$ & Comments \\
\hline $\begin{array}{l}\text { Example: } \\
\text { 1. PE1: I would } \\
\text { find the } \\
\text { smartphone to be } \\
\text { useful in my daily } \\
\text { life. }\end{array}$ & $\begin{array}{l}\text { To obtain information to } \\
\text { measure the influence of } \\
\text { Performance Expectancy } \\
\text { variable. }\end{array}$ & 5 & 4 & $\begin{array}{l}\frac{\text { It can be }}{\text { changed to: }} \\
\text { Ifind the ..... }\end{array}$ \\
\hline $\begin{array}{l}\text { 1. PE1: I find } \\
\text { smartphones to } \\
\text { be useful in my } \\
\text { daily life. }\end{array}$ & $\begin{array}{l}\text { To obtain information to } \\
\text { measure the relationship } \\
\text { between the performance } \\
\text { expectancy factor and the } \\
\text { behavioral intention factor }\end{array}$ & 5 & 5 & \\
\hline $\begin{array}{l}\text { 2. PE2: Using a } \\
\text { smartphone } \\
\text { enables me to } \\
\text { accomplish more } \\
\text { tasks quickly. }\end{array}$ & $\begin{array}{l}\text { To obtain information to } \\
\text { measure the relationship } \\
\text { between the performance } \\
\text { expectancy factor and the } \\
\text { behavioral intention factor }\end{array}$ & 5 & 4 & \\
\hline $\begin{array}{l}\text { 3. PE3: Using a } \\
\text { smartphone } \\
\text { increases my } \\
\text { overall } \\
\text { productivity. }\end{array}$ & $\begin{array}{l}\text { To obtain information to } \\
\text { measure the relationship } \\
\text { between the performance } \\
\text { expectancy factor and the } \\
\text { behavioral intention factor }\end{array}$ & 5 & 5 & \\
\hline $\begin{array}{l}\text { 4. PE4: Using a } \\
\text { smartphone } \\
\text { increases the } \\
\text { chances of } \\
\text { improving my } \\
\text { overall } \\
\text { performance. }\end{array}$ & $\begin{array}{l}\text { To obtain information to } \\
\text { measure the relationship } \\
\text { between the performance } \\
\text { expectancy factor and the } \\
\text { behavioral intention factor }\end{array}$ & 5 & 3 & $\begin{array}{l}\text { How do } \\
\text { differentiate } \\
\text { between } \\
\text { increasing } \\
\text { overall } \\
\text { productivity } \\
\text { and } \\
\text { performance }\end{array}$ \\
\hline $\begin{array}{l}\text { 5. EE1: Using a } \\
\text { smartphone is } \\
\text { easy for me. }\end{array}$ & $\begin{array}{l}\text { To obtain information to } \\
\text { measure the relationship } \\
\text { between the effort } \\
\text { expectancy factor and the }\end{array}$ & 5 & 5 & \\
\hline
\end{tabular}




\begin{tabular}{|c|c|c|c|c|}
\hline & behavioral intention factor & & & \\
\hline $\begin{array}{l}\text { 6. EE2: I think it is } \\
\text { easy to learn how } \\
\text { to use a } \\
\text { smartphone. }\end{array}$ & $\begin{array}{l}\text { To obtain information to } \\
\text { measure the relationship } \\
\text { between the effort } \\
\text { expectancy factor and the } \\
\text { behavioral intention factor }\end{array}$ & 5 & 5 & \\
\hline $\begin{array}{l}\text { 7. EE3: Operating } \\
\text { and navigating } \\
\text { through } \\
\text { smartphones' } \\
\text { features and } \\
\text { functions is easy. }\end{array}$ & $\begin{array}{l}\text { To obtain information to } \\
\text { measure the relationship } \\
\text { between the effort } \\
\text { expectancy factor and the } \\
\text { behavioral intention factor }\end{array}$ & 5 & 4 & $\begin{array}{l}\text { It can vary } \\
\text { from smart } \\
\text { phone to } \\
\text { smart phone }\end{array}$ \\
\hline $\begin{array}{l}\text { 8. BIF1: The brand } \\
\text { of a smartphone } \\
\text { is not important } \\
\text { to me }\end{array}$ & $\begin{array}{l}\text { To obtain information to } \\
\text { measure the relationship } \\
\text { between the brand influence } \\
\text { factor and the behavioral } \\
\text { intention factor }\end{array}$ & 5 & 5 & \\
\hline $\begin{array}{l}\text { 9. BIF2: } \\
\text { Smartphone } \\
\text { brands are closely } \\
\text { similar in quality }\end{array}$ & $\begin{array}{l}\text { To obtain information to } \\
\text { measure the relationship } \\
\text { between the brand influence } \\
\text { factor and the behavioral } \\
\text { intention factor }\end{array}$ & 5 & 5 & \\
\hline $\begin{array}{l}\text { 10. BIF3: I would } \\
\text { most likely buy } \\
\text { only a specific } \\
\text { brand of } \\
\text { smartphones } \\
\text { whose quality I } \\
\text { trust. }\end{array}$ & $\begin{array}{l}\text { To obtain information to } \\
\text { measure the relationship } \\
\text { between the brand influence } \\
\text { factor and the behavioral } \\
\text { intention factor }\end{array}$ & 5 & 5 & \\
\hline $\begin{array}{l}\text { 11. EF1: } \\
\text { Smartphone } \\
\text { devices and } \\
\text { services are } \\
\text { reasonably } \\
\text { priced. }\end{array}$ & $\begin{array}{l}\text { To obtain information to } \\
\text { measure the relationship } \\
\text { between the economic factors } \\
\text { factor and the behavioral } \\
\text { intention factor }\end{array}$ & 5 & 5 & \\
\hline $\begin{array}{l}\text { 12. EF2: } \\
\text { Smartphones } \\
\text { have good } \\
\text { benefits for its } \\
\text { cost. }\end{array}$ & $\begin{array}{l}\text { To obtain information to } \\
\text { measure the relationship } \\
\text { between the economic factors } \\
\text { factor and the behavioral } \\
\text { intention factor }\end{array}$ & 5 & 5 & \\
\hline $\begin{array}{l}\text { 13. EF3: At the } \\
\text { current price, a } \\
\text { smartphone } \\
\text { provides a good } \\
\text { value. }\end{array}$ & $\begin{array}{l}\text { To obtain information to } \\
\text { measure the relationship } \\
\text { between the economic factors } \\
\text { factor and the behavioral } \\
\text { intention factor }\end{array}$ & 4 & 4 & \\
\hline
\end{tabular}




\begin{tabular}{|c|c|c|c|c|}
\hline $\begin{array}{l}\text { 14. EF4: A } \\
\text { smartphone is } \\
\text { very cost effective } \\
\text { to me. }\end{array}$ & $\begin{array}{l}\text { To obtain information to } \\
\text { measure the relationship } \\
\text { between the economic factors } \\
\text { factor and the behavioral } \\
\text { intention factor }\end{array}$ & 5 & 5 & \\
\hline $\begin{array}{l}\text { 15. PJ1: I believe } \\
\text { that it is fun to } \\
\text { have and use } \\
\text { smartphones. }\end{array}$ & $\begin{array}{l}\text { To obtain information to } \\
\text { measure the relationship } \\
\text { between the perceived } \\
\text { enjoyment factor and the } \\
\text { behavioral intention factor }\end{array}$ & 5 & 4 & \\
\hline $\begin{array}{l}\text { 16. PJ2: Using my } \\
\text { smartphone } \\
\text { brings me joy. }\end{array}$ & $\begin{array}{l}\text { To obtain information to } \\
\text { measure the relationship } \\
\text { between the perceived } \\
\text { enjoyment factor and the } \\
\text { behavioral intention factor }\end{array}$ & 3 & 3 & $\begin{array}{l}15 \text { and } 16 \\
\text { looks the } \\
\text { same what is } \\
\text { the } \\
\text { difference } \\
\text { between fun } \\
\text { and joy }\end{array}$ \\
\hline $\begin{array}{l}\text { 17. PJ3: Using } \\
\text { smartphones is } \\
\text { very entertaining } \\
\text { to me. }\end{array}$ & $\begin{array}{l}\text { To obtain information to } \\
\text { measure the relationship } \\
\text { between the perceived } \\
\text { enjoyment factor and the } \\
\text { behavioral intention factor }\end{array}$ & 4 & 3 & $\begin{array}{l}\text { Same } \\
\text { comment as } \\
\text { above }\end{array}$ \\
\hline $\begin{array}{l}\text { 18. PJ4: I use the } \\
\text { smartphones to } \\
\text { make my leisure } \\
\text { time more } \\
\text { enjoyable. }\end{array}$ & $\begin{array}{l}\text { To obtain information to } \\
\text { measure the relationship } \\
\text { between the perceived } \\
\text { enjoyment factor and the } \\
\text { behavioral intention factor }\end{array}$ & 5 & 5 & \\
\hline $\begin{array}{l}\text { 19. DS1: The } \\
\text { overall look and } \\
\text { feel } \\
\text { smartphones is } \\
\text { appealing to me. }\end{array}$ & $\begin{array}{l}\text { To obtain information to } \\
\text { measure the relationship } \\
\text { between the design attribute } \\
\text { factor and the behavioral } \\
\text { intention factor }\end{array}$ & 5 & 5 & \\
\hline $\begin{array}{l}\text { 20. DS2: I pay } \\
\text { more attention to } \\
\text { the design, } \\
\text { harmonious } \\
\text { appearance, } \\
\text { colors and shape } \\
\text { when choosing a } \\
\text { smartphone }\end{array}$ & $\begin{array}{l}\text { To obtain information to } \\
\text { measure the relationship } \\
\text { between the design attribute } \\
\text { factor and the behavioral } \\
\text { intention factor }\end{array}$ & 5 & 5 & \\
\hline $\begin{array}{l}\text { 21. DS3: The } \\
\text { design, } \\
\text { harmonious } \\
\text { appearance, color } \\
\text { and shape of a } \\
\text { smartphone } \\
\text { reflect its quality } \\
\text { and value. }\end{array}$ & $\begin{array}{l}\text { To obtain information to } \\
\text { measure the relationship } \\
\text { between the design attribute } \\
\text { factor and the behavioral } \\
\text { intention factor }\end{array}$ & 3 & 3 & $\begin{array}{l}\text { These look } \\
\text { the same as } \\
20\end{array}$ \\
\hline
\end{tabular}




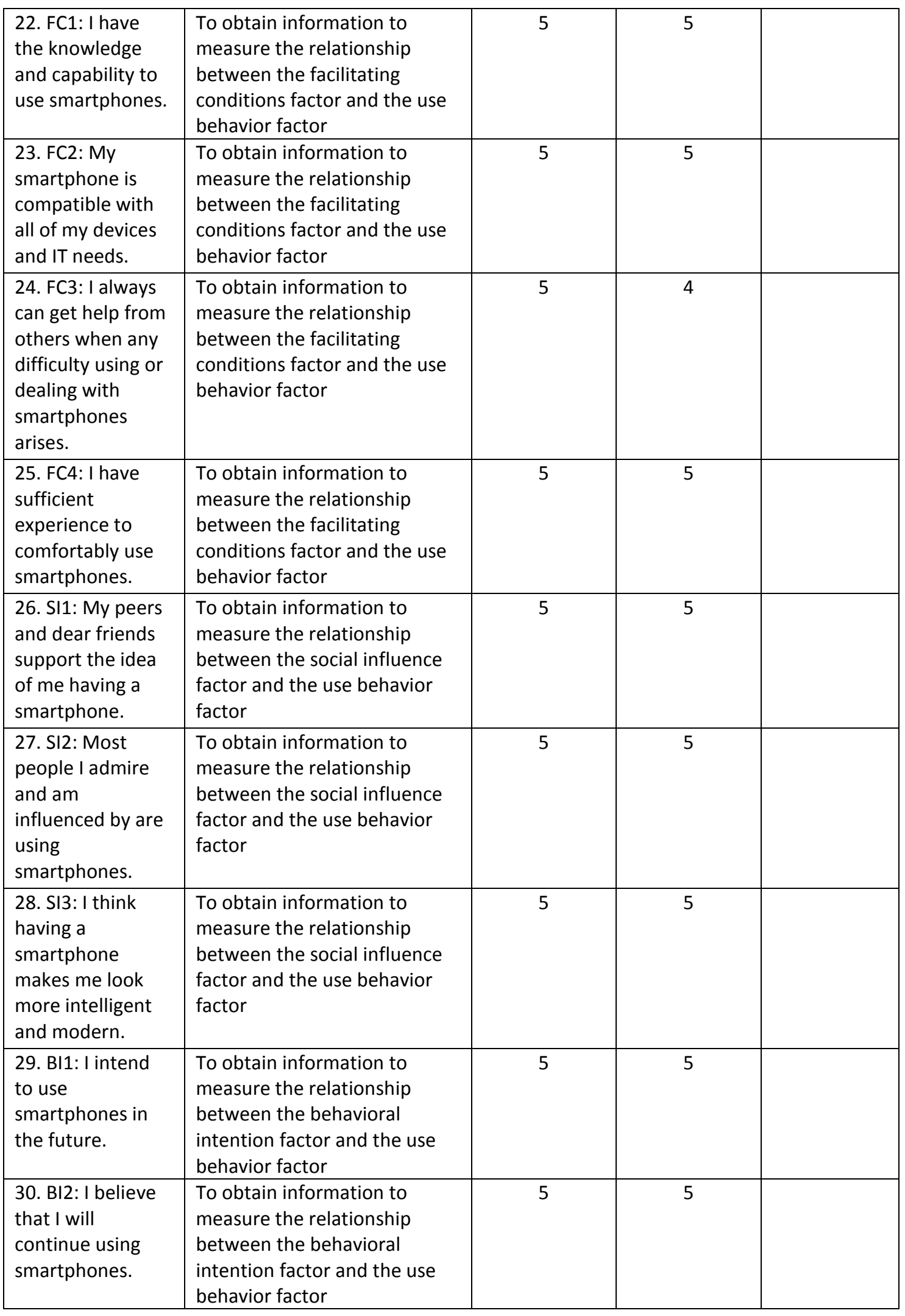




\begin{tabular}{|l|l|c|c|c|}
\hline $\begin{array}{l}\text { 31. BI3: I will } \\
\text { always choose to } \\
\text { use a smartphone } \\
\text { in my daily life. }\end{array}$ & $\begin{array}{l}\text { To obtain information to } \\
\text { measure the relationship } \\
\text { between the behavioral } \\
\text { intention factor and the use } \\
\text { behavior factor }\end{array}$ & 5 & 5 & 5 \\
\hline $\begin{array}{l}\text { 32. UB1: My use } \\
\text { of smartphones } \\
\text { will continue to } \\
\text { increase. }\end{array}$ & $\begin{array}{l}\text { To obtain information to } \\
\text { measure the use behavior } \\
\text { factor }\end{array}$ & 5 & 3 & $\begin{array}{l}\text { It looks same } \\
\text { as in } 32\end{array}$ \\
\hline $\begin{array}{l}\text { 33. UB2: I believe } \\
\text { that I will be using } \\
\text { smartphones } \\
\text { more frequently. }\end{array}$ & $\begin{array}{l}\text { To obtain information to } \\
\text { measure the use behavior } \\
\text { factor }\end{array}$ & 5 & 5 & \\
\hline $\begin{array}{l}\text { 34. UB3: I use my } \\
\text { smartphone more } \\
\text { than my other } \\
\text { computing } \\
\text { devices. }\end{array}$ & $\begin{array}{l}\text { To obtain information to } \\
\text { measure the use behavior } \\
\text { factor }\end{array}$ & 5 & 5 & \\
\hline
\end{tabular}




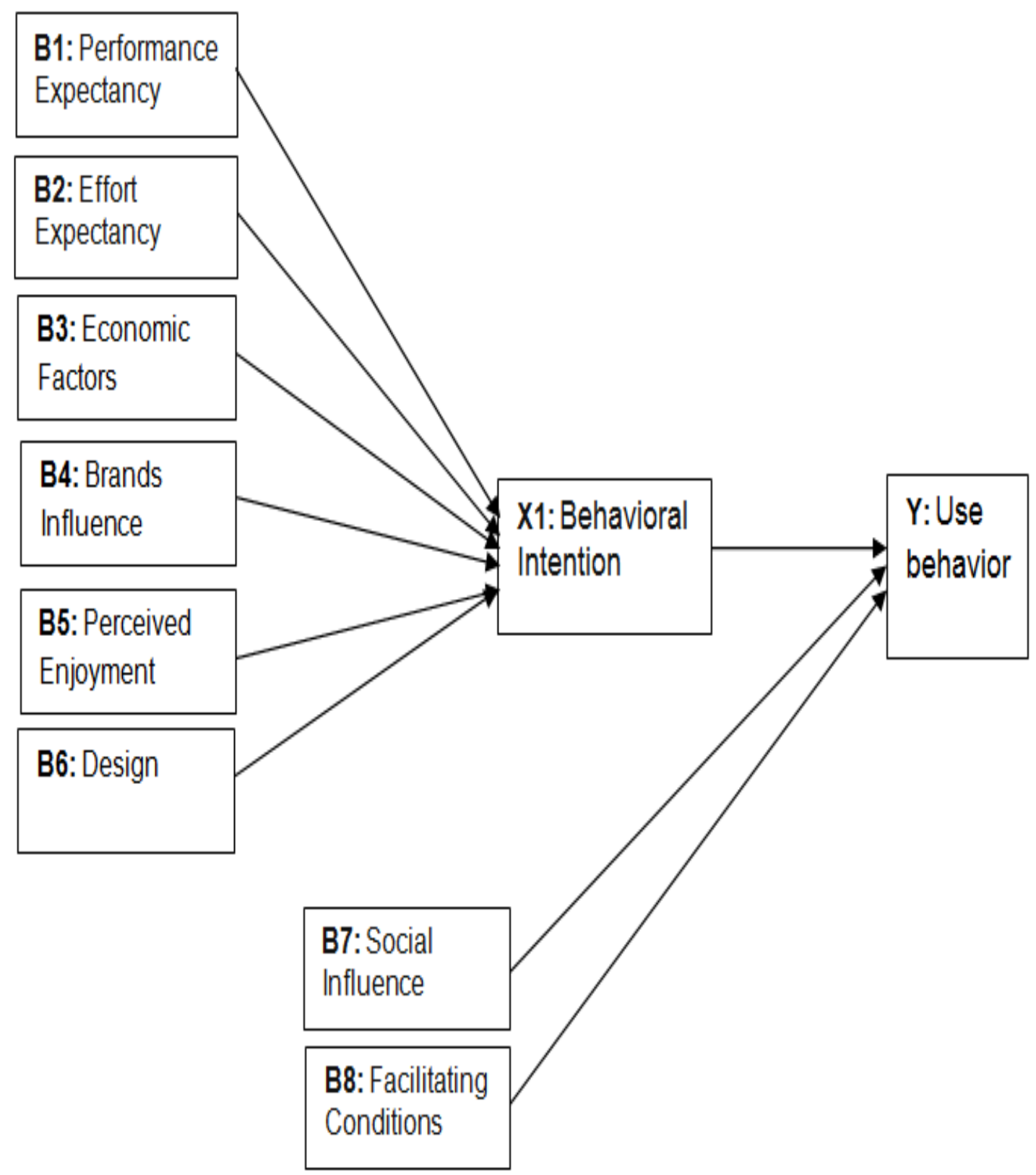

Situational factors

Figure 1: research model and hypothesized relationships. 


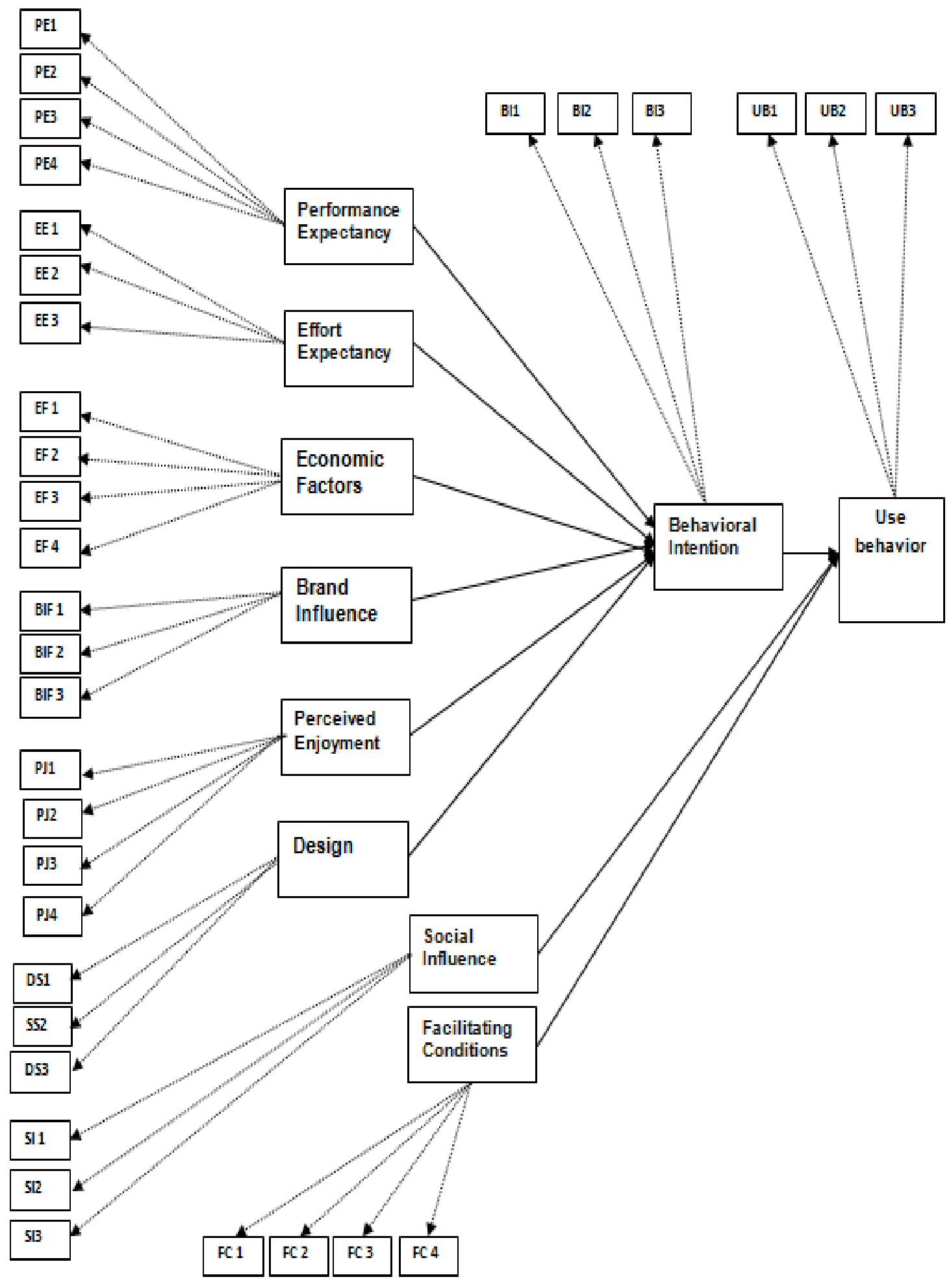

Figure 2: Items developed to measure each factor/variable 


\begin{tabular}{|c|c|}
\hline Factors & Definition \\
\hline $\begin{array}{l}\text { Performance } \\
\text { Expectancy }\end{array}$ & $\begin{array}{l}\text { Performance expectancy is defined as the degree to which } \\
\text { an individual believes that using a Smartphone will help } \\
\text { him or her to attain benefits in their overall performance. } \\
\text { The factors below have been integrated under } \\
\text { performance expectancy factor by the authors of UTAUT } \\
\text { model since they are considered to be related to it and the } \\
\text { root for this factors: } \\
\text { Perceived Usefulness } \\
\text { Relative Advantage } \\
\text { Job Relevancies } \\
\text { Extrinsic Motivation } \\
\text { Outcome Expectations } \\
\text { Job-fit }\end{array}$ \\
\hline Effort Expectancy & $\begin{array}{l}\text { Effort expectancy was defined as the degree of ease } \\
\text { associated with the use of the Smartphone. } \\
\text { The factors below have been integrated under effort } \\
\text { expectancy factor by the authors of UTAUT model since } \\
\text { they are considered to be related to it and the root for this } \\
\text { factors: } \\
\text { Perceived Ease of Use } \\
\text { Complexity }\end{array}$ \\
\hline Social Influence & $\begin{array}{l}\text { Social influence is defined as the extent to which a person } \\
\text { perceives that important others believe he or she should } \\
\text { use the Smartphone. } \\
\text { The factors below have been integrated under social } \\
\text { influence factor by the authors of UTAUT model since they } \\
\text { are considered to be related to it and the root for this } \\
\text { factors: } \\
\text { Subjective Norm } \\
\text { Social Factors } \\
\text { Image }\end{array}$ \\
\hline Facilitating Conditions & $\begin{array}{l}\text { defined facilitating conditions as the degree to which an } \\
\text { individual believes that technical and infrastructure } \\
\text { supports are available to support the use of Smartphone } \\
\text { The factors below have been integrated under defined } \\
\text { facilitating factor by the authors of UTAUT model since } \\
\text { they are considered to be related to it and the root for this } \\
\text { factors: } \\
\text { Perceived Behavioral Control } \\
\text { Compatibility }\end{array}$ \\
\hline Economic factors & Economic factors can be defined as the perceived value of \\
\hline
\end{tabular}




\begin{tabular}{|l|l|}
\hline & $\begin{array}{l}\text { the tradeoff between the perceived benefits of the } \\
\text { technologies and the cost for acquiring and using it }\end{array}$ \\
\hline Design & $\begin{array}{l}\text { The design has two aspects: (1) inherent design and colors } \\
\text { of mobile phones, and (2) detailed elements of design } \\
\text { regarding the entire appearance, color, harmony of } \\
\text { appearance, shape of keypads, etc. }\end{array}$ \\
\hline Perceived enjoyment & $\begin{array}{l}\text { perceived enjoyment is defined as "the extent to which the } \\
\text { activity of using a specific system is perceived to be } \\
\text { enjoyable in its own right, aside from any performance } \\
\text { consequences resulting from system usage" }\end{array}$ \\
\hline Brand Influence & $\begin{array}{l}\text { "Brand perceptions are values a consumer believes a brand } \\
\text { has on the perceptual attributes of the given products } \\
\text { category" }\end{array}$ \\
\hline
\end{tabular}

Table 2: Definitions of the research model's factor/variables 


\section{Appendix F: Example of the Translation Validation Tool}

\section{Translation Validation Tool}

\section{Introduction}

This research aims to study the key factors that may have relationships with users' adoption and use Smartphone technology. To collect data from Smartphones' users, a research a survey instrument have been developed consists of 34 questions. The data will be collected to test the hypothesized relationships among variables in the research model as shown in figure 1 . The questions in the survey have been adopted from a number of survey instruments that have been developed and validated in previous related research. The survey questionnaire will be used to collect data from Smartphone' users in Saud Arabia, therefore it has been translated from English language into Arabic language. It is very critical to make sure that the translation is accurate, clear, and capture and present the original meaning of the questions. You are invited as an expert who fluently speaks English and Arabic languages to edit, validate, and provide your comments on the following survey questionnaire.

Please carefully read and review each question in English and in Arabic in the survey below. Please edit as needed and validate the accuracy of each question to assess its translation.

\begin{tabular}{|c|c|c|c|}
\hline $\begin{array}{l}\text { Variables to } \\
\text { be measured }\end{array}$ & Arabic & $\begin{array}{l}\text { Accuracy } \\
\text { From 1-5 }\end{array}$ & Comments \\
\hline & $\begin{array}{l}\text { Example: } \\
\text { 1. I find the smartphone to be useful in } \\
\text { my daily life. } \\
\text { أجد ان الهواتف الذكية مفيلة في حياتس البيوبة }\end{array}$ & $\underline{5}$ & \\
\hline & \multicolumn{2}{|c|}{ أجد ان الههواتف الذكيه نافعة فحى حياتحى البيومية } & \\
\hline \multirow{2}{*}{ 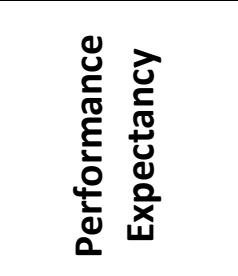 } & $\begin{array}{l}\text { 1. I find the smartphone to be useful in my } \\
\text { daily life. } \\
\qquad \begin{array}{l}\text { أجد أن الهاتف الذكي مفيد في حياتي اليومية }\end{array}\end{array}$ & & \\
\hline & & & \\
\hline
\end{tabular}




\begin{tabular}{|c|c|}
\hline & $\begin{array}{l}\text { 2. Using a smartphone enables me to } \\
\text { accomplish more tasks quickly. } \\
\text { وبستخد عة الهاتف الذكي يمكني من إنجاز العديد من المهام }\end{array}$ \\
\hline & Edit as needed: \\
\hline & $\begin{array}{l}\text { 3. Using a smartphone increases my } \\
\text { overall productivity. } \\
\text { إستخدام الهاتف الذكي يزيد من إنتاجيتي بشكل عام }\end{array}$ \\
\hline & Edit as needed: \\
\hline & 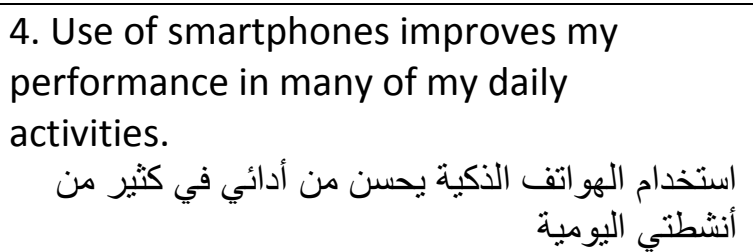 \\
\hline & Edit as needed: \\
\hline \multirow{6}{*}{ 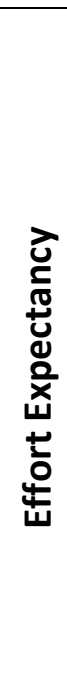 } & $\begin{array}{l}\text { 5. Using a smartphone is easy for me. } \\
\qquad \begin{array}{l}\text { استخدام الهاتف الذكي سهل بالنسبة لي }\end{array}\end{array}$ \\
\hline & Edit as needed: \\
\hline & $\begin{array}{l}\text { 6. It is easy for me to learn how to use a } \\
\text { smartphone. } \\
\text { sm السهل بالنسبة لي تعلم كيفية استخدام الهاتف الذكي }\end{array}$ \\
\hline & Edit as needed: \\
\hline & $\begin{array}{l}\text { 7. Using a smartphone and operating its } \\
\text { functions is easy for me. } \\
\text { استخدام الهاتف الذكي وتشغيل وظائفة سهله بالنسبة لي }\end{array}$ \\
\hline & Edit as needed: \\
\hline \multirow{3}{*}{ 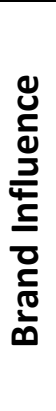 } & $\begin{array}{l}\text { 8. The brand name of a smartphone is } \\
\text { important to me when choosing one. } \\
\text { بالنسبة اختيار هاتف ذكي فان اسم العلامة التجارية مهر }\end{array}$ \\
\hline & Edit as needed: \\
\hline & $\begin{array}{l}\text { 9. I am very attracted to one particular } \\
\text { smartphone brand more than other. }\end{array}$ \\
\hline
\end{tabular}




\begin{tabular}{|c|c|}
\hline & جاذبية العلامات التجارية لهاتف ذكي، بالنسبة لي أكثر، \\
\hline & Edit as needed: \\
\hline & 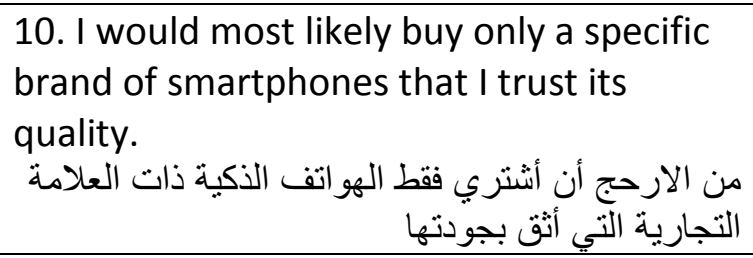 \\
\hline & Edit as needed: \\
\hline \multirow{8}{*}{ 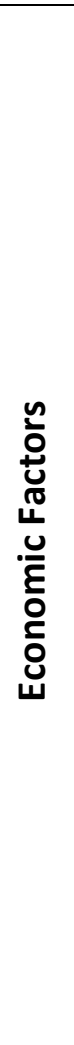 } & $\begin{array}{l}\text { 11. Smartphone devices are reasonably } \\
\text { priced to me. } \\
\text { أجهزة الهو اتف الذكية أسعار ها معقولة بالنسبة لي }\end{array}$ \\
\hline & Edit as needed: \\
\hline & $\begin{array}{l}\text { 12. The cost of smartphones services is } \\
\text { reasonable to me. } \\
\text { تكلفة خدمات الهو اتف الذكية معقولة بالنسبة لي }\end{array}$ \\
\hline & \\
\hline & $\begin{array}{l}\text { 13. At the current price, smartphones } \\
\text { provide a good value. } \\
\text { بالتكلفة الحالية الهو اتف الذكية توفر فو ائد جيدة بالنسبة }\end{array}$ \\
\hline & Edit as needed: \\
\hline & $\begin{array}{l}\text { 14. Smartphones are very beneficial to me } \\
\text { compared to their cost } \\
\text { أعتبر الهو اتف الذكية مفيد جدا بالنسبة لي مقابل تكلفتها }\end{array}$ \\
\hline & Edit as needed: \\
\hline \multirow{4}{*}{ 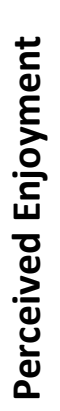 } & 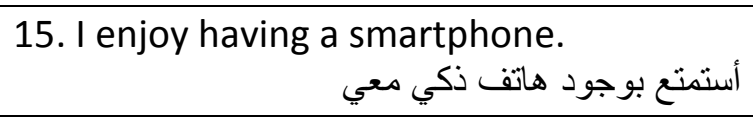 \\
\hline & Edit as needed: \\
\hline & 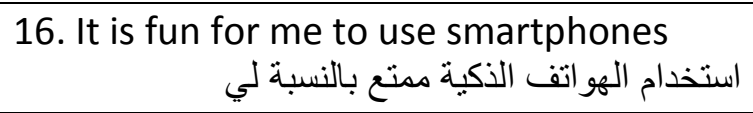 \\
\hline & Edit as needed: \\
\hline
\end{tabular}




\begin{tabular}{|c|c|}
\hline & $\begin{array}{l}\text { 17. I use smartphones to make my free } \\
\text { time more enjoyable. } \\
\text { أستخدم الهو اتف الذكية لجعل وقت فر اغي أكثر متعة }\end{array}$ \\
\hline & Edit as needed: \\
\hline & $\begin{array}{l}\text { 18. Smartphones provide me with many } \\
\text { entertainment options } \\
\text { الهو اتف الذكية توفر لي العديد من خيار الترفيه }\end{array}$ \\
\hline & Edit as needed: \\
\hline \multirow{6}{*}{$\frac{c}{\frac{c}{n}}$} & $\begin{array}{l}\text { 19. The overall look and feel of } \\
\text { smartphones is important to me. } \\
\text { الثكل العام للهو اتف الذكية وملمسها يعتبر مهم بالنسبة }\end{array}$ \\
\hline & Edit as needed: \\
\hline & 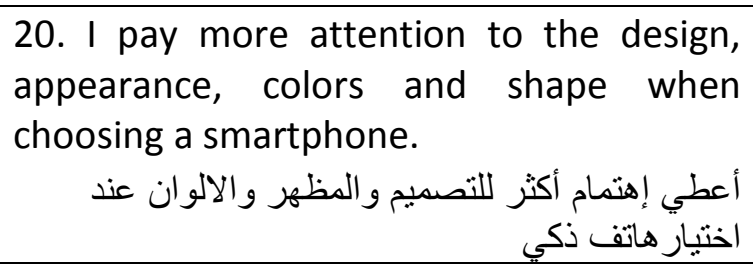 \\
\hline & Edit as needed: \\
\hline & 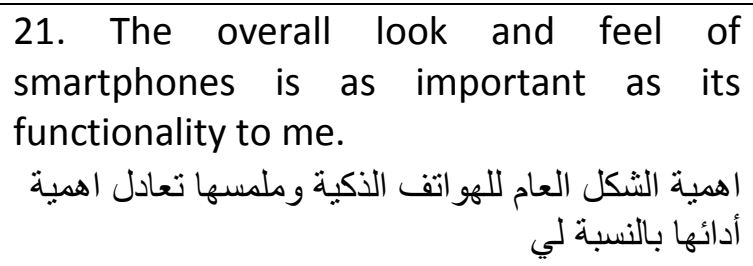 \\
\hline & Edit as needed: \\
\hline \multirow{3}{*}{ 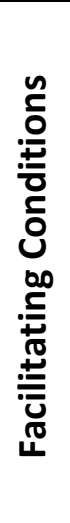 } & 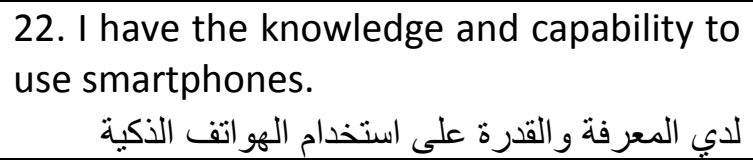 \\
\hline & Edit as needed: \\
\hline & 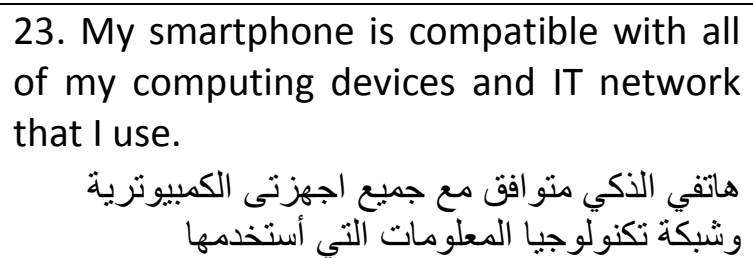 \\
\hline
\end{tabular}




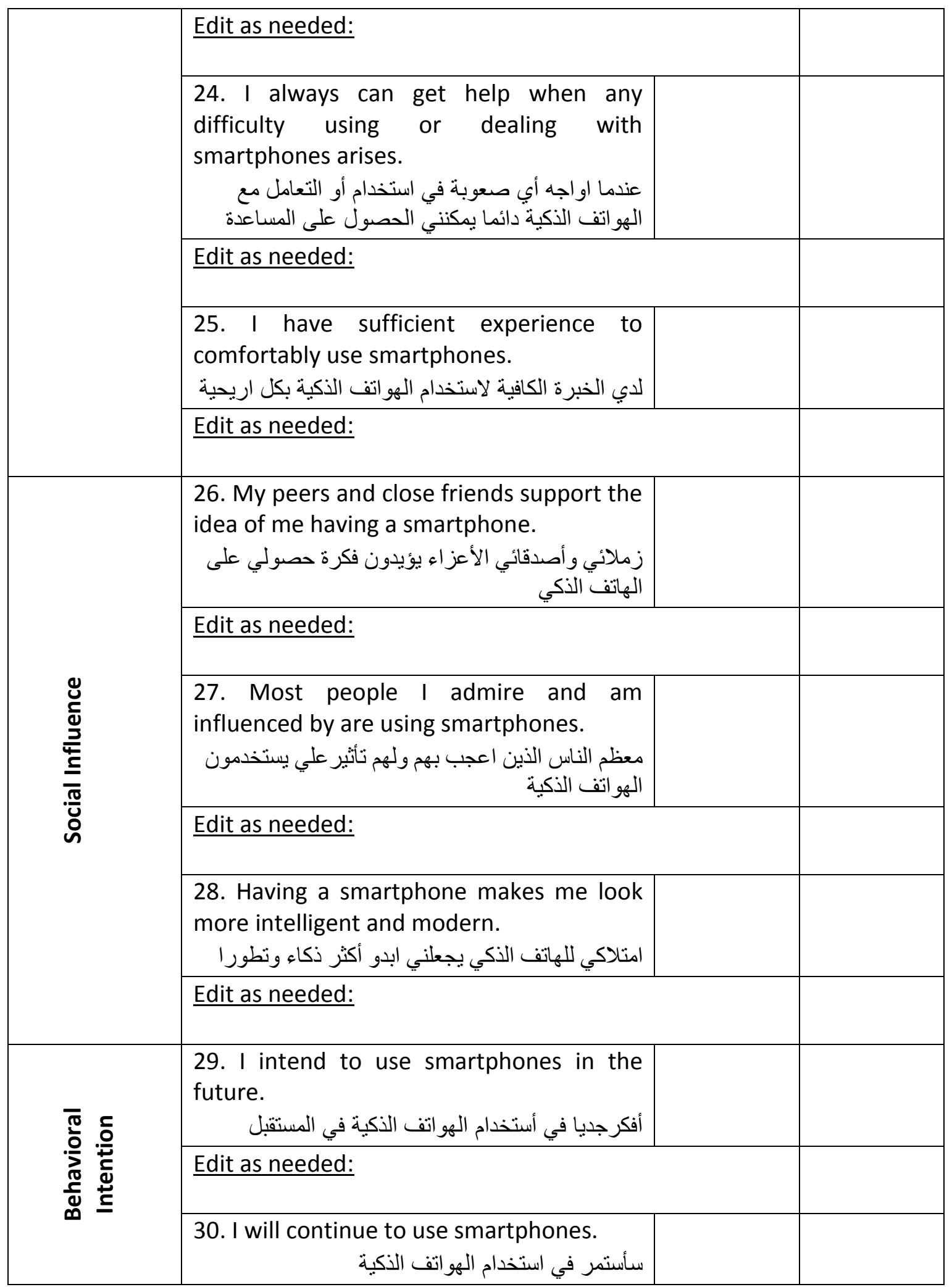




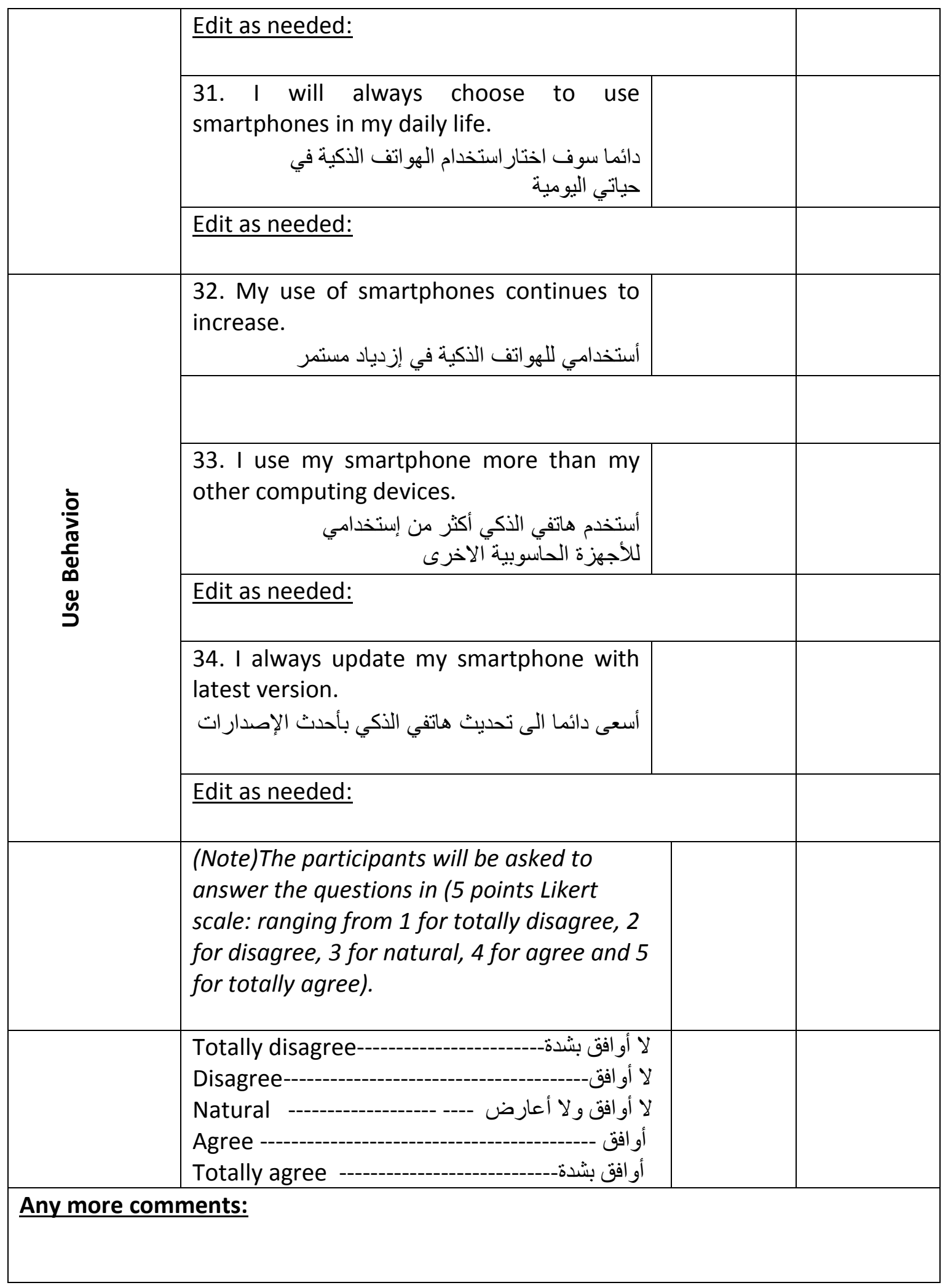




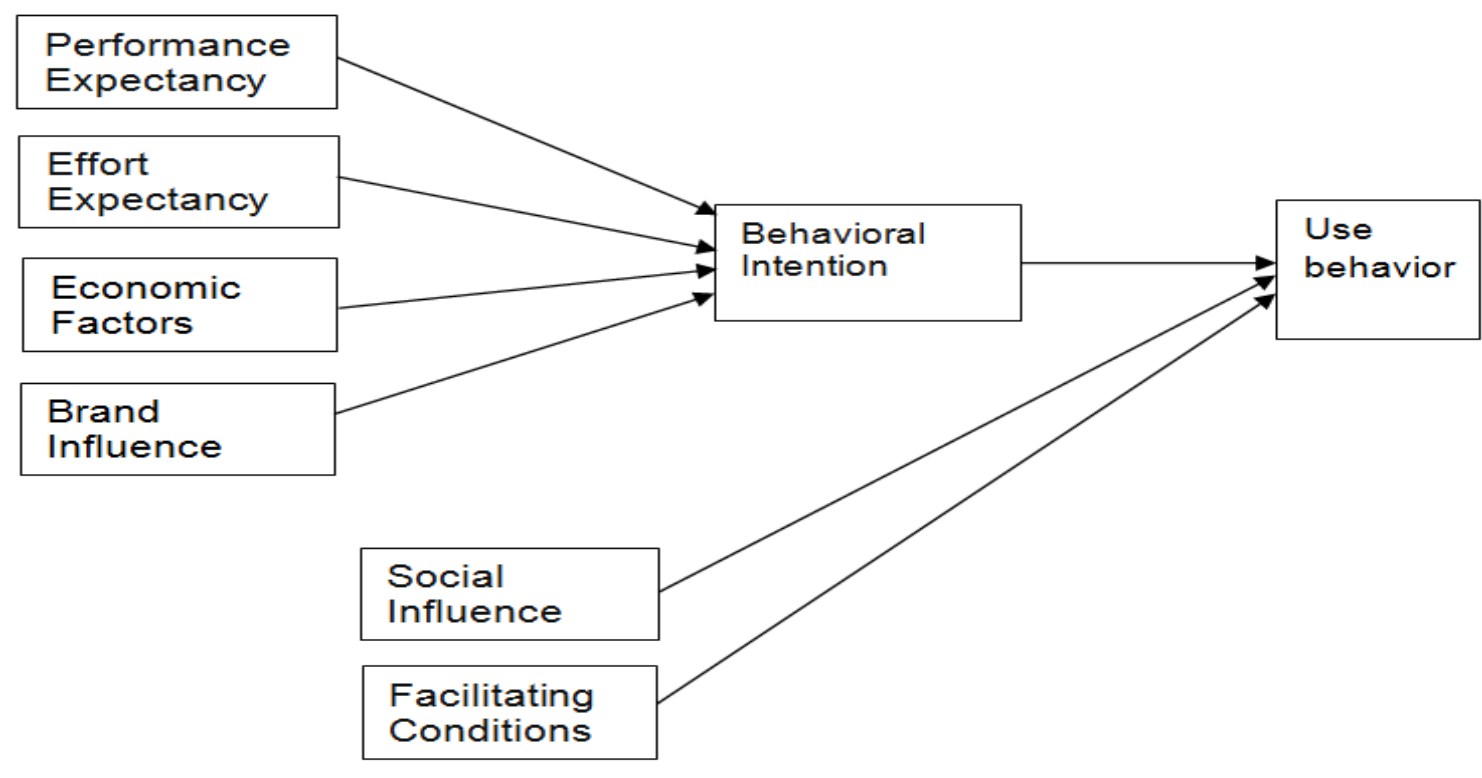

Situational factors

Figure 1: Research model 


\section{Appendix G: Email Invitation Sent to Invite Participants to Participate in the Survey}

طالب دكتور اه يحتاج مساعدتك بالتكرم بالمشاركة في استبيان اكاديمى سريع عن الهو اتف الذكية

$$
\text { بسم الله الرحمن الرحيم }
$$

الاخوة والاخوات الاعزاء مستخدمو الهاتف الذكي السلام عليكم ورحمة الله تعالى وبركاته

انا طالب دكتور اه في قسم الهندسة و إدارة التكنولوجيا في جامعة بورتلاند الحكومية في الو لايات

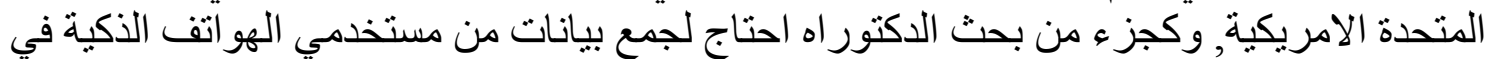

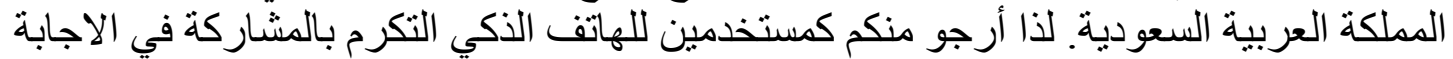

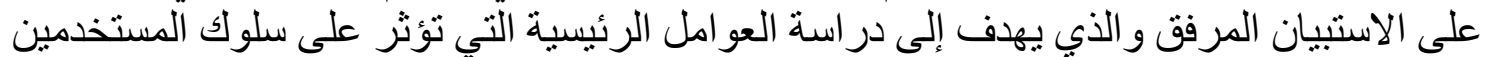

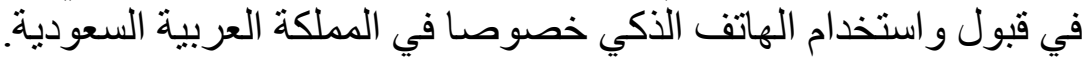

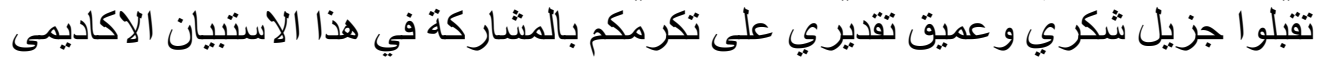

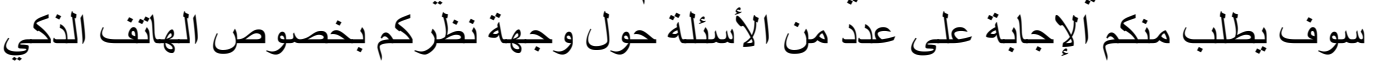

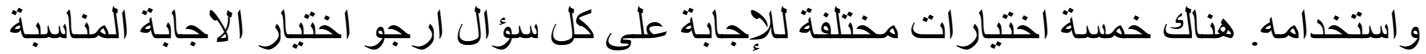
حسب رأيك.

المشاركة في هذه الدر اسة البحثبة هي تماما اختيارية تطو عية وسوف تستغرق الاجابة على هذا

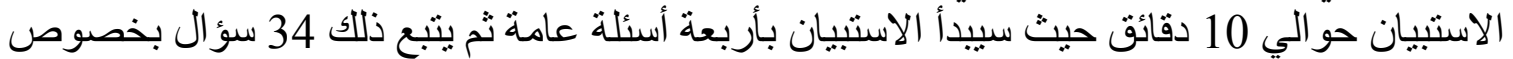

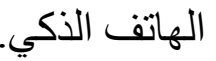
سيكون هناك بعض الاسئلة المتشابهة والتي توحي بانها تكر ار لسؤ ال آخر حيث أن القيأ القصد من هذه

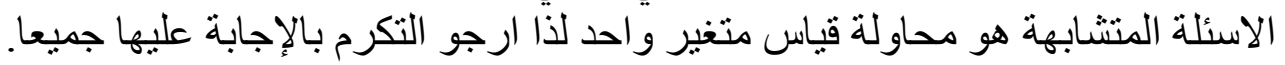

يرجى استخدام الر ابط أدناه للوصل الى الاستبيان https://portlandstate.qualtrics.com//SE/?SID=SV_3aTVb4zsWuIFHa5

$$
\begin{aligned}
& \text { اذا كان لديك أسئلة الرجاء الاتصال بي على بريدي الالكتروني } \\
& \text { اشكر للك مشاركتكم في هذا الاستبيان }
\end{aligned}
$$

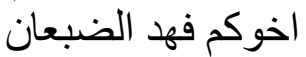

$$
\begin{aligned}
& \text { aldhaban@gmail.com }
\end{aligned}
$$


Appendix H: Examples of Proportion of Respondent to Items and Items Statistics

Proportion of respondent for item PE2

\begin{tabular}{|c|c|c|}
\hline Answer & Response & Percentage \\
\hline 5 & 379 & $59 \%$ \\
\hline 4 & 230 & $36 \%$ \\
\hline 3 & 25 & $4 \%$ \\
\hline 2 & 7 & $1 \%$ \\
\hline 1 & 0 & $0 \%$ \\
\hline Total & 641 & $100 \%$ \\
\hline
\end{tabular}

PE2 Statistics

\begin{tabular}{|l|c|}
\hline \multicolumn{1}{|c|}{ Statistic } & Value \\
\hline Min Value & 1 \\
\hline Max Value & 4 \\
\hline Mean & 4.53 \\
\hline Variance & 0.39 \\
\hline Standard Deviation & 0.62 \\
\hline Total Responses & 641 \\
\hline
\end{tabular}

Proportion of respondent for item EE2

\begin{tabular}{|c|c|c|}
\hline Answer & Response & Percentage \\
\hline 5 & 270 & $42 \%$ \\
\hline 4 & 335 & $52 \%$ \\
\hline 3 & 28 & $4 \%$ \\
\hline 2 & 7 & $1 \%$ \\
\hline 1 & 1 & $0 \%$ \\
\hline Total & 641 & $100 \%$ \\
\hline
\end{tabular}




\section{EE2 Statistics}

\begin{tabular}{|l|c|}
\hline Statistic & Value \\
\hline Min Value & 1 \\
\hline Max Value & 5 \\
\hline Mean & 4.36 \\
\hline Variance & 0.38 \\
\hline Standard Deviation & 0.62 \\
\hline Total Responses & 641 \\
\hline
\end{tabular}

Proportion of respondent for item EF2

\begin{tabular}{|c|c|c|}
\hline Answer & Response & Percentage \\
\hline 5 & 23 & $4 \%$ \\
\hline 4 & 259 & $40 \%$ \\
\hline 3 & 172 & $27 \%$ \\
\hline 2 & 159 & $25 \%$ \\
\hline 1 & 28 & $4 \%$ \\
\hline Total & 641 & $100 \%$ \\
\hline
\end{tabular}

\section{EF2 Statistics}

\begin{tabular}{|l|c|}
\hline Statistic & Value \\
\hline Min Value & 1 \\
\hline Max Value & 5 \\
\hline Mean & 3.32 \\
\hline Variance & 0.87 \\
\hline Standard Deviation & 0.93 \\
\hline Total Responses & 641 \\
\hline
\end{tabular}

Proportion of respondent for item BIF2

\begin{tabular}{|c|c|c|}
\hline Answer & Response & Percentage \\
\hline 5 & 274 & $43 \%$ \\
\hline 4 & 275 & $43 \%$ \\
\hline 3 & 56 & $9 \%$ \\
\hline 2 & 30 & $5 \%$ \\
\hline 1 & 6 & $1 \%$ \\
\hline Total & 641 & $100 \%$ \\
\hline
\end{tabular}




\section{BIF2 Statistics}

\begin{tabular}{|l|c|}
\hline Statistic & Value \\
\hline Min Value & 1 \\
\hline Max Value & 5 \\
\hline Mean & 4.26 \\
\hline Variance & 0.64 \\
\hline Standard Deviation & 0.80 \\
\hline Total Responses & 641 \\
\hline
\end{tabular}

Proportion of respondent for item PJ2

\begin{tabular}{|c|c|c|}
\hline Answer & Response & Percentage \\
\hline 5 & 232 & $36 \%$ \\
\hline 4 & 325 & $51 \%$ \\
\hline 3 & 68 & $11 \%$ \\
\hline 2 & 15 & $2 \%$ \\
\hline 1 & 1 & $0 \%$ \\
\hline Total & 641 & $100 \%$ \\
\hline
\end{tabular}

\section{PJ2 Statistics}

\begin{tabular}{|l|c|}
\hline \multicolumn{1}{|c|}{ Statistic } & Value \\
\hline Min Value & 1 \\
\hline Max Value & 5 \\
\hline Mean & 4.20 \\
\hline Variance & 0.52 \\
\hline Standard Deviation & 0.72 \\
\hline Total Responses & 641 \\
\hline
\end{tabular}

Proportion of respondent for item DS2

\begin{tabular}{|c|c|c|}
\hline Answer & Response & Percentage \\
\hline 5 & 162 & $25 \%$ \\
\hline 4 & 316 & $49 \%$ \\
\hline 3 & 104 & $16 \%$ \\
\hline 2 & 54 & $8 \%$ \\
\hline 1 & 5 & $1 \%$ \\
\hline Total & 641 & $100 \%$ \\
\hline
\end{tabular}


DS2 Statistics

\begin{tabular}{|l|c|}
\hline \multicolumn{1}{|c|}{ Statistic } & Value \\
\hline Min Value & 1 \\
\hline Max Value & 5 \\
\hline Mean & 3.93 \\
\hline Variance & 0.76 \\
\hline Standard Deviation & 0.87 \\
\hline Total Responses & 641 \\
\hline
\end{tabular}

Proportion of respondent for item FC2

\begin{tabular}{|c|c|c|}
\hline Answer & Response & Percentage \\
\hline 5 & 125 & $20 \%$ \\
\hline 4 & 350 & $55 \%$ \\
\hline 3 & 103 & $16 \%$ \\
\hline 2 & 59 & $9 \%$ \\
\hline 1 & 4 & $1 \%$ \\
\hline Total & 641 & $100 \%$ \\
\hline
\end{tabular}

\section{FC2 Statistics}

\begin{tabular}{|l|c|}
\hline \multicolumn{1}{|c|}{ Statistic } & Value \\
\hline Min Value & 1 \\
\hline Max Value & 5 \\
\hline Mean & 3.86 \\
\hline Variance & 0.71 \\
\hline Standard Deviation & 0.84 \\
\hline Total Responses & 641 \\
\hline
\end{tabular}

Proportion of respondent for item SI2

\begin{tabular}{|c|c|c|}
\hline Answer & Response & Percentage \\
\hline 5 & 189 & $29 \%$ \\
\hline 4 & 304 & $47 \%$ \\
\hline 3 & 106 & $17 \%$ \\
\hline 2 & 33 & $5 \%$ \\
\hline 1 & 9 & $1 \%$ \\
\hline Total & 641 & $100 \%$ \\
\hline
\end{tabular}




\section{SI2 Statistics}

\begin{tabular}{|l|c|}
\hline Statistic & Value \\
\hline Min Value & 1 \\
\hline Max Value & 5 \\
\hline Mean & 4.04 \\
\hline Variance & 0.70 \\
\hline Standard Deviation & 0.83 \\
\hline Total Responses & 641 \\
\hline
\end{tabular}

Proportion of respondent for item BI2

\begin{tabular}{|c|c|c|}
\hline Answer & Response & Percentage \\
\hline 5 & 310 & $48 \%$ \\
\hline 4 & 287 & $45 \%$ \\
\hline 3 & 41 & $6 \%$ \\
\hline 2 & 3 & $0 \%$ \\
\hline 1 & 0 & $0 \%$ \\
\hline Total & 641 & $100 \%$ \\
\hline
\end{tabular}

\section{BI2 Statistics}

\begin{tabular}{|l|c|}
\hline \multicolumn{1}{|c|}{ Statistic } & Value \\
\hline Min Value & 1 \\
\hline Max Value & 4 \\
\hline Mean & 4.41 \\
\hline Variance & 0.40 \\
\hline Standard Deviation & 0.63 \\
\hline Total Responses & 641 \\
\hline
\end{tabular}

Proportion of respondent for item UB2

\begin{tabular}{|c|c|c|}
\hline Answer & Response & Percentage \\
\hline 5 & 302 & $47 \%$ \\
\hline 4 & 257 & $40 \%$ \\
\hline 3 & 55 & $9 \%$ \\
\hline 2 & 27 & $4 \%$ \\
\hline 1 & 0 & $0 \%$ \\
\hline Total & 641 & $100 \%$ \\
\hline
\end{tabular}


UB2 Statistics

\begin{tabular}{|l|c|}
\hline \multicolumn{1}{|c|}{ Statistic } & Value \\
\hline Min Value & 1 \\
\hline Max Value & 4 \\
\hline Mean & 4.30 \\
\hline Variance & 0.64 \\
\hline Standard Deviation & 0.80 \\
\hline Total Responses & 641 \\
\hline
\end{tabular}


Appendix I: Screen Captures of The Web-based Survey

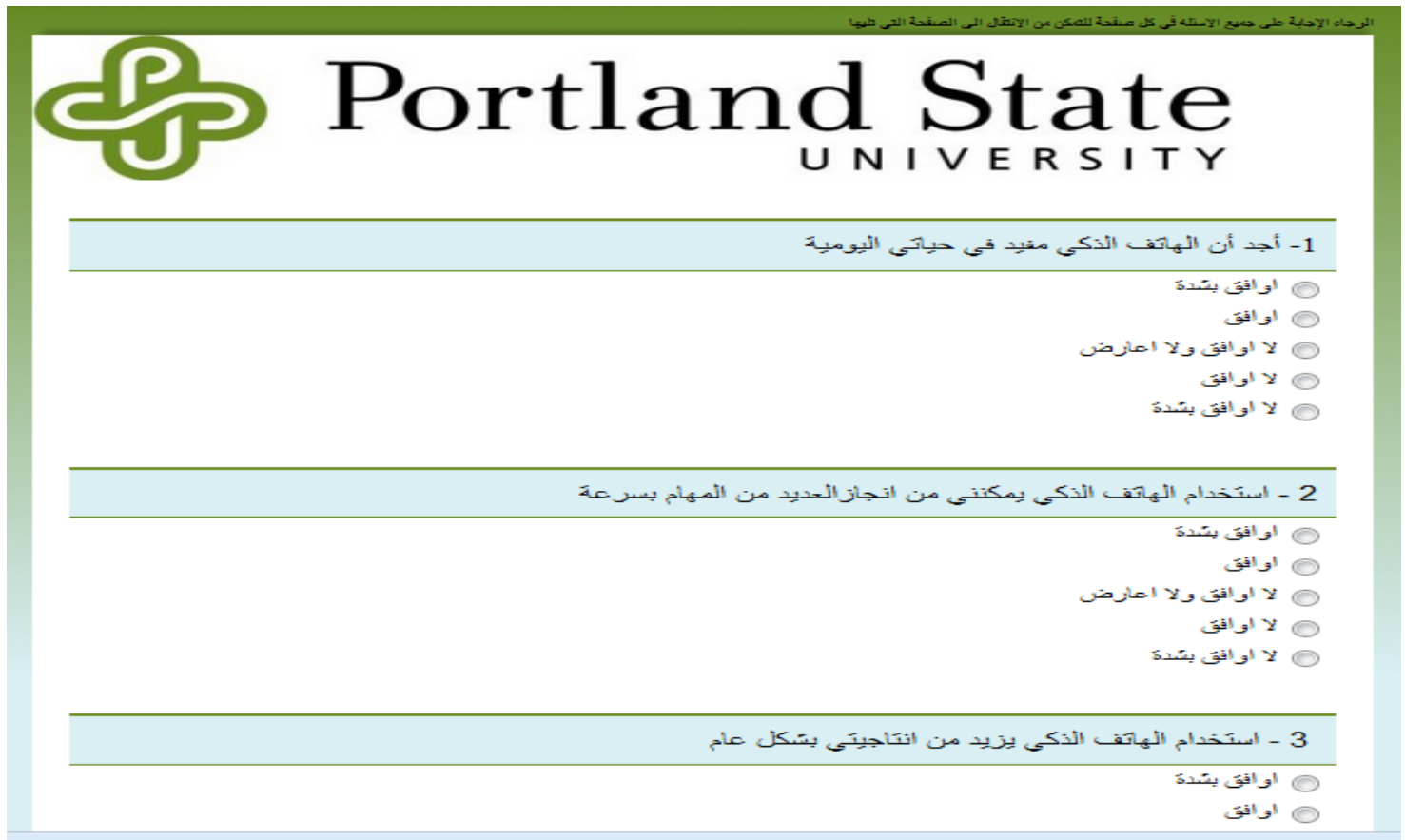




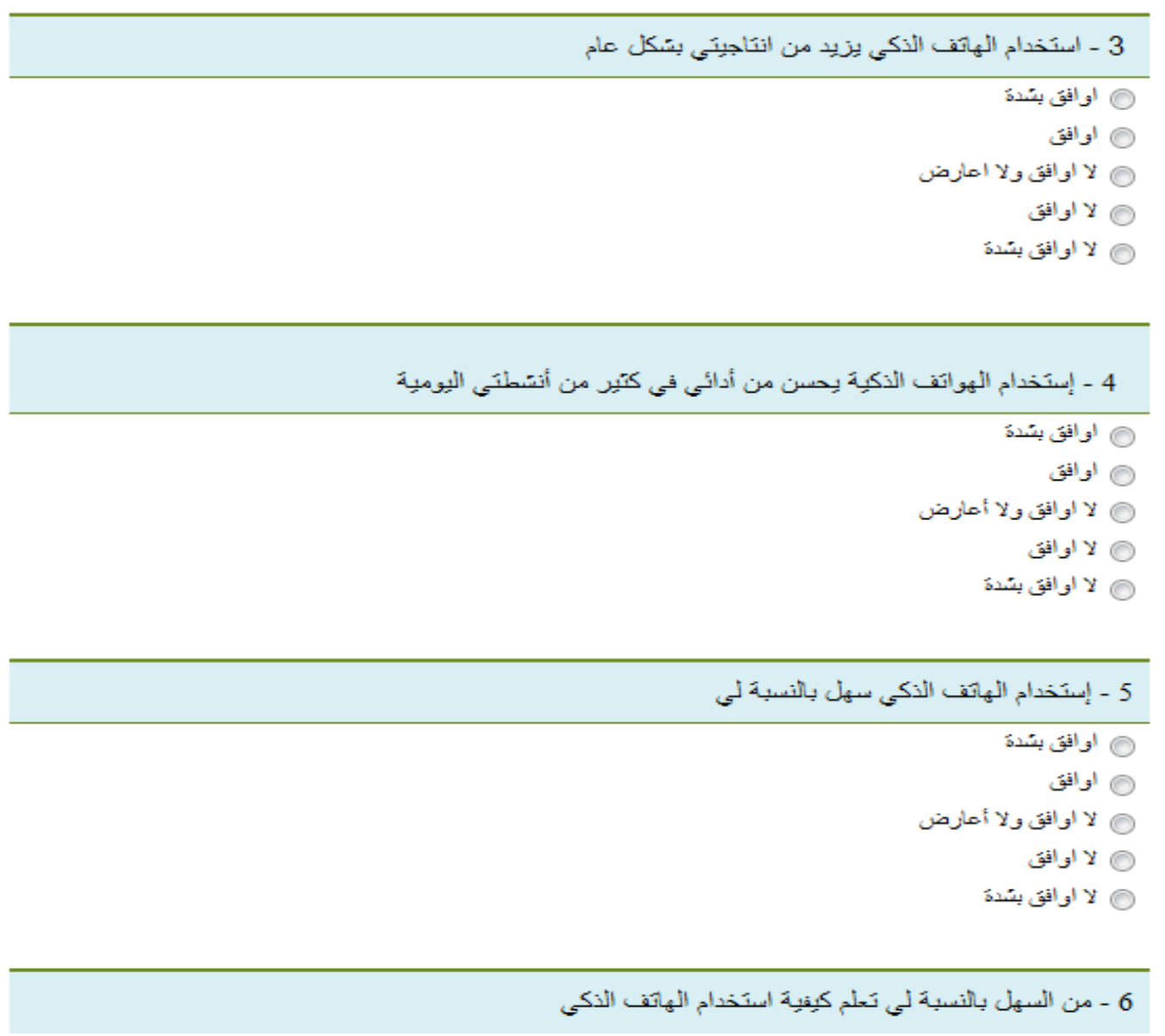




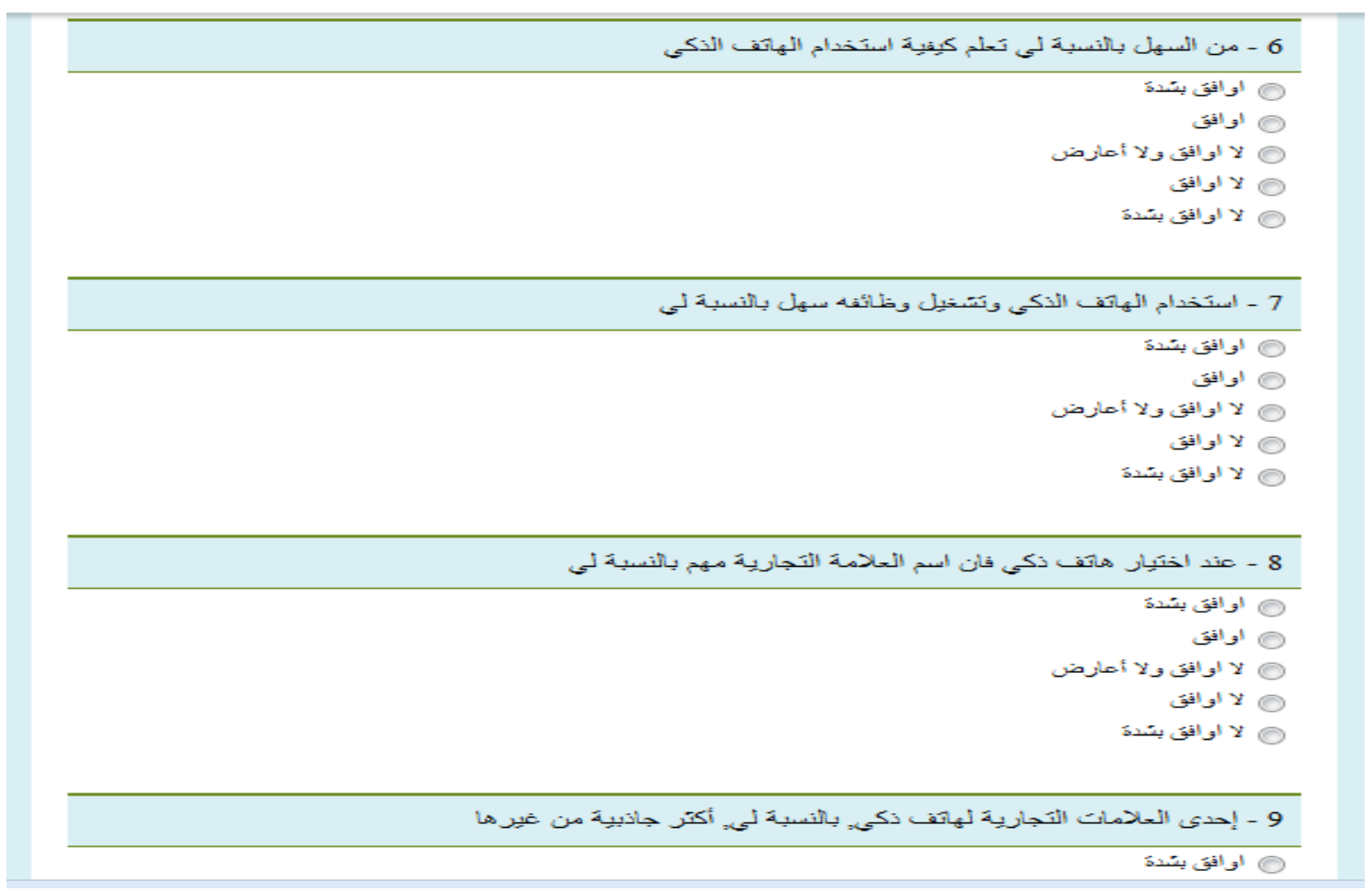




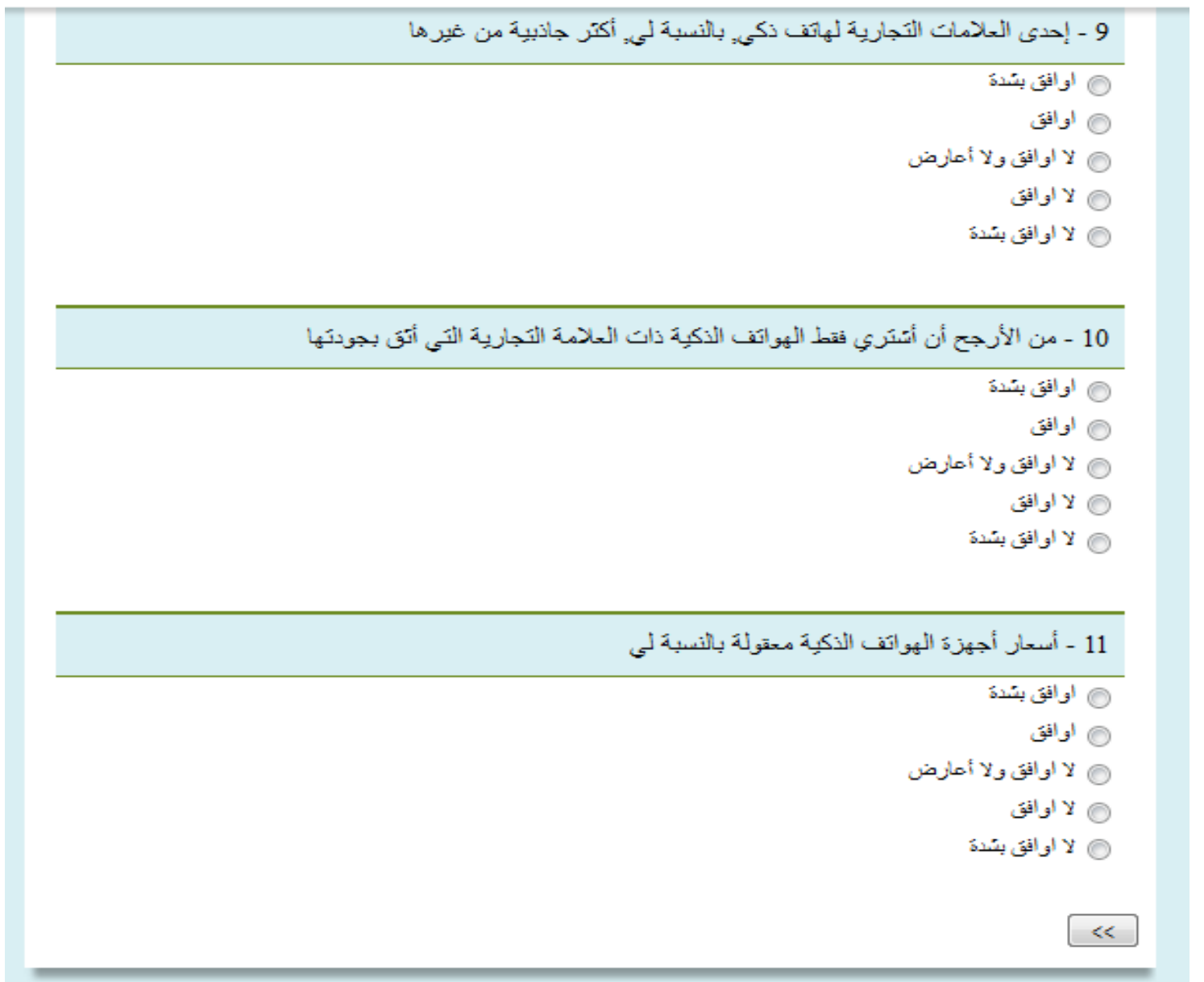




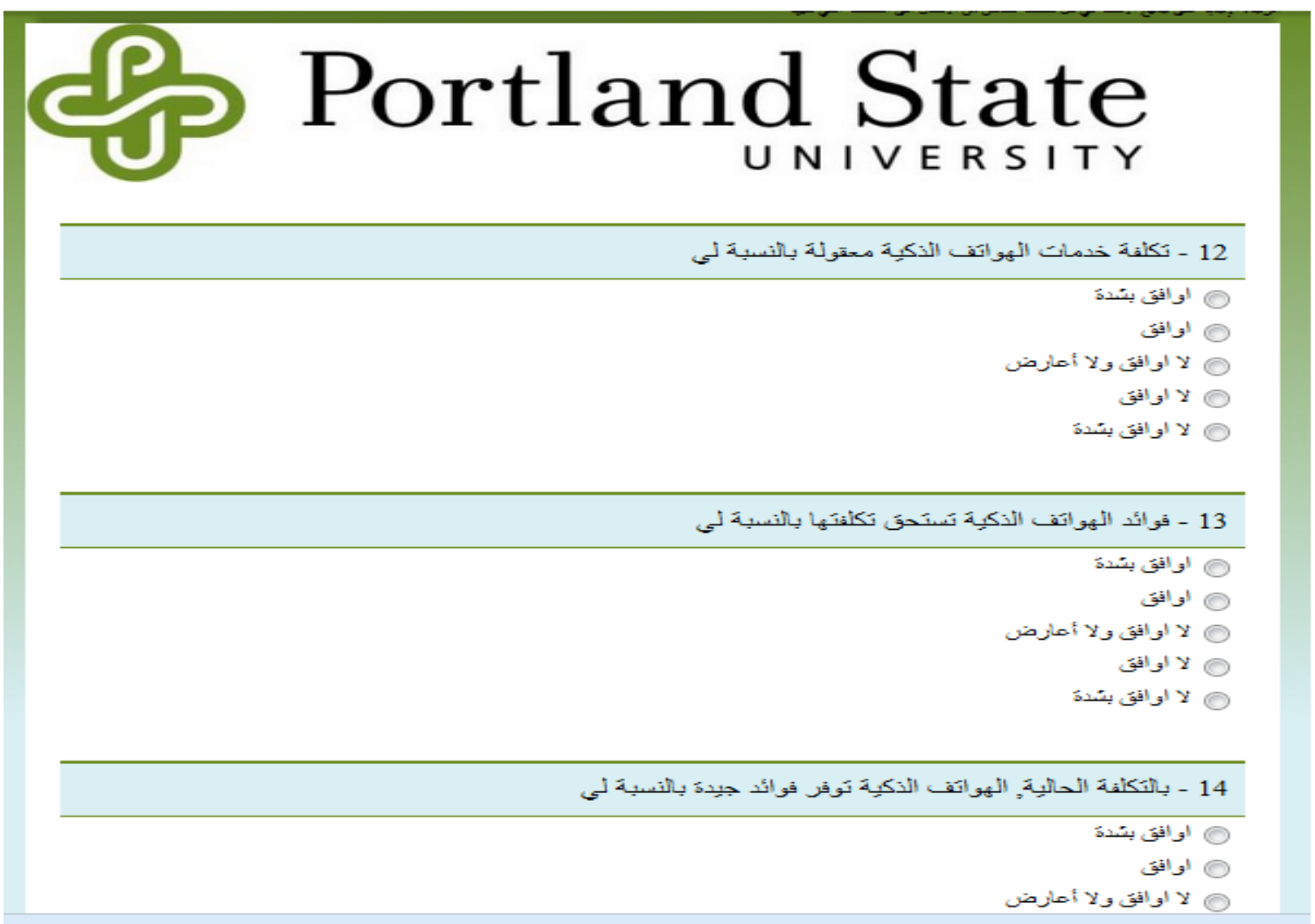




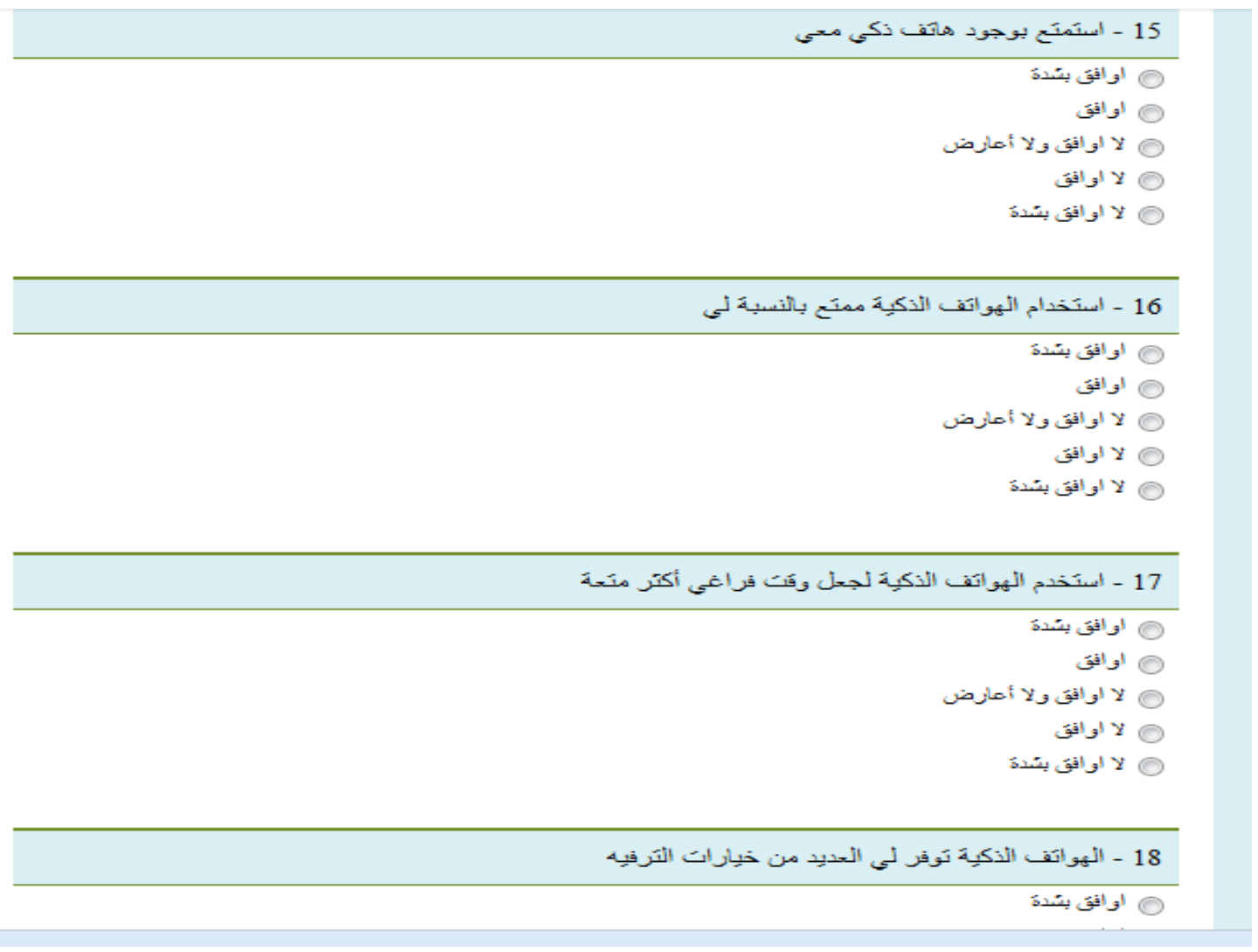

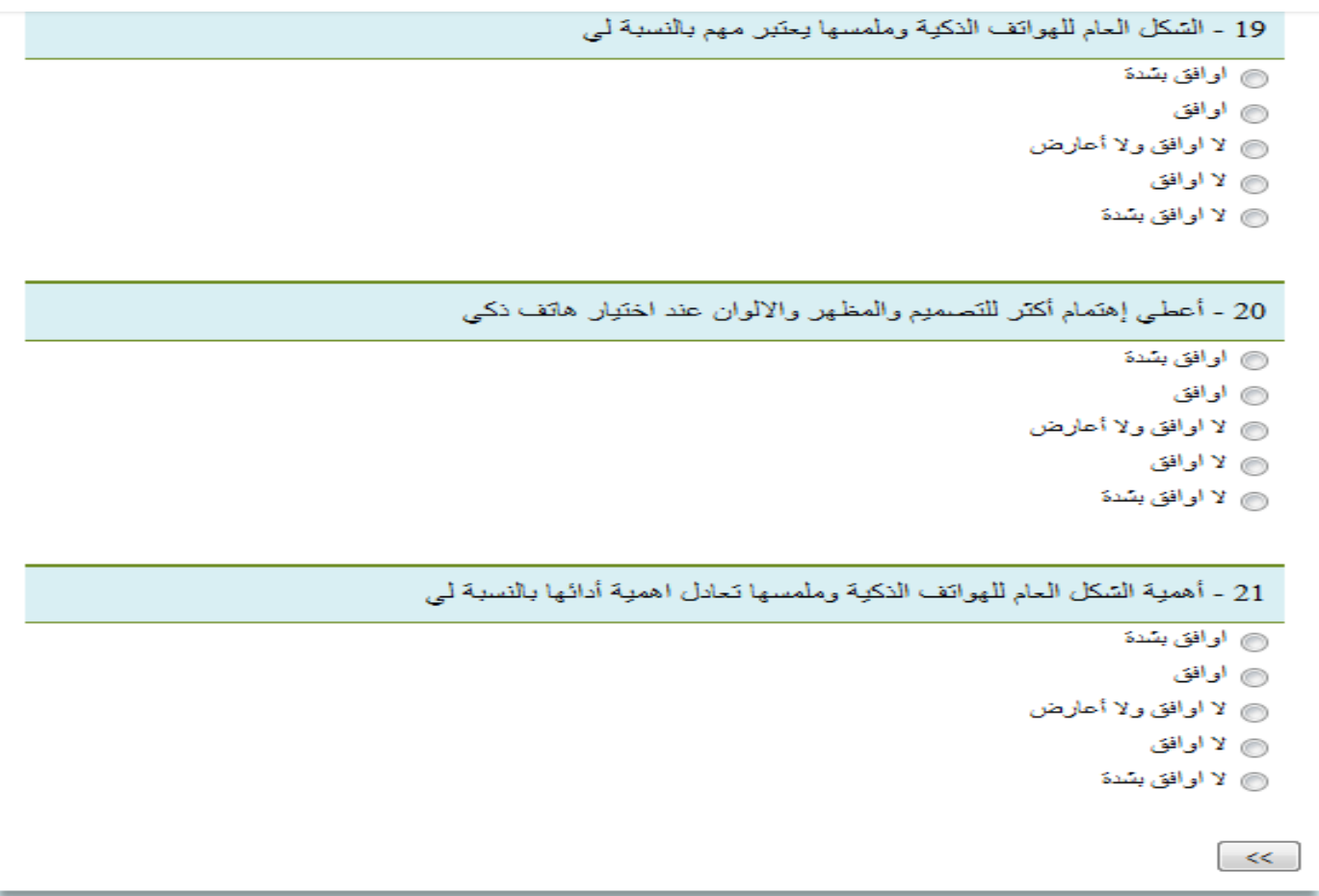




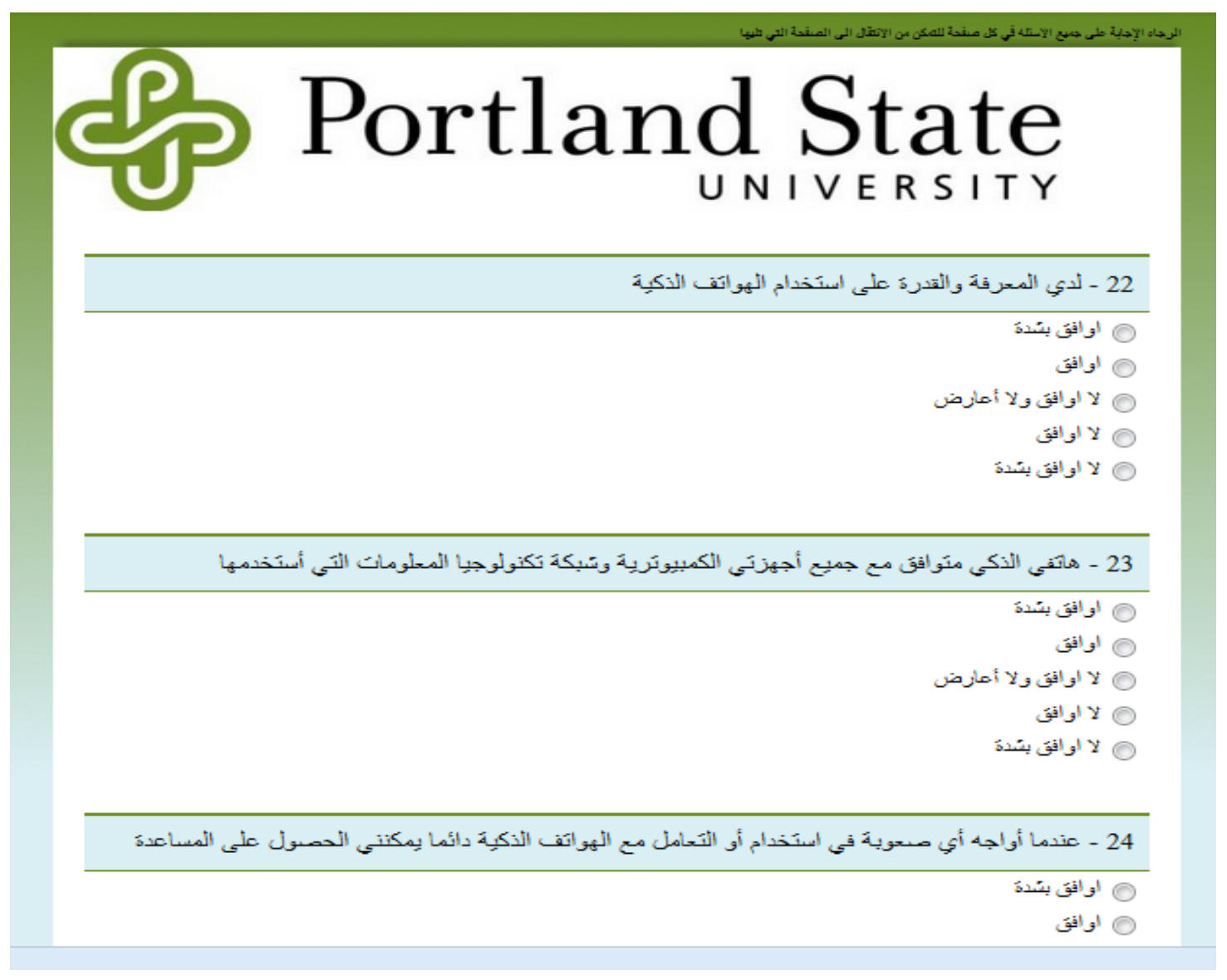




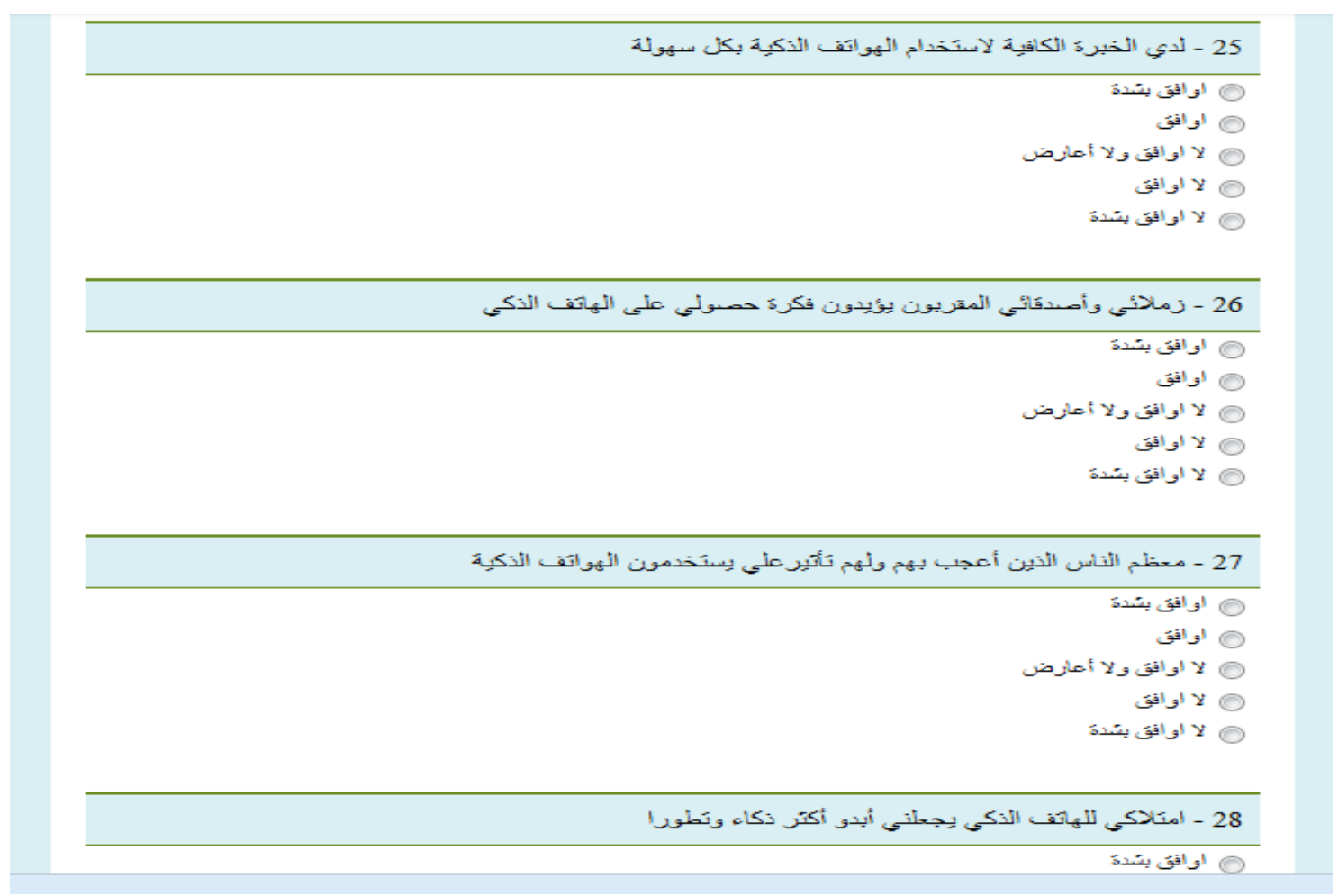




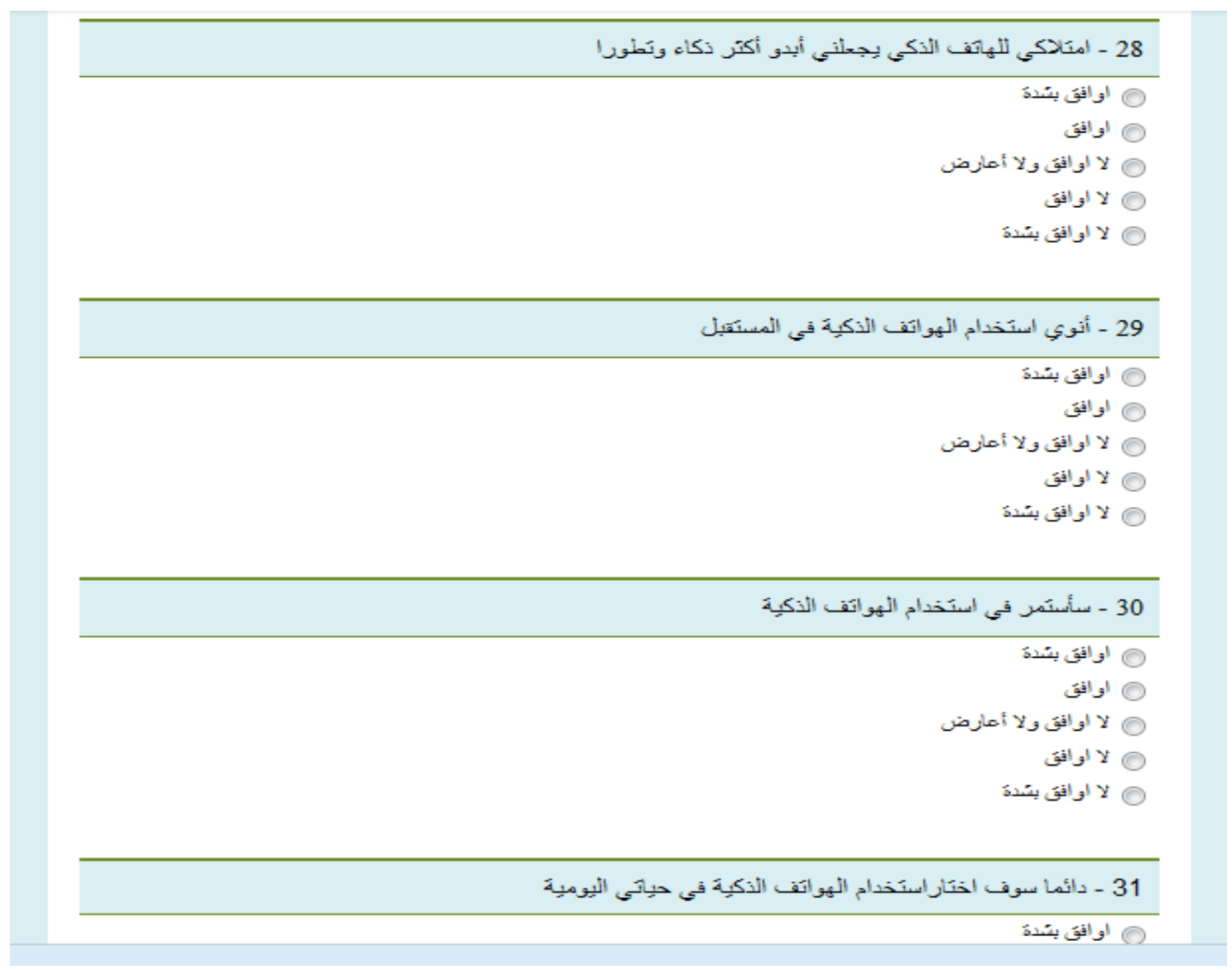




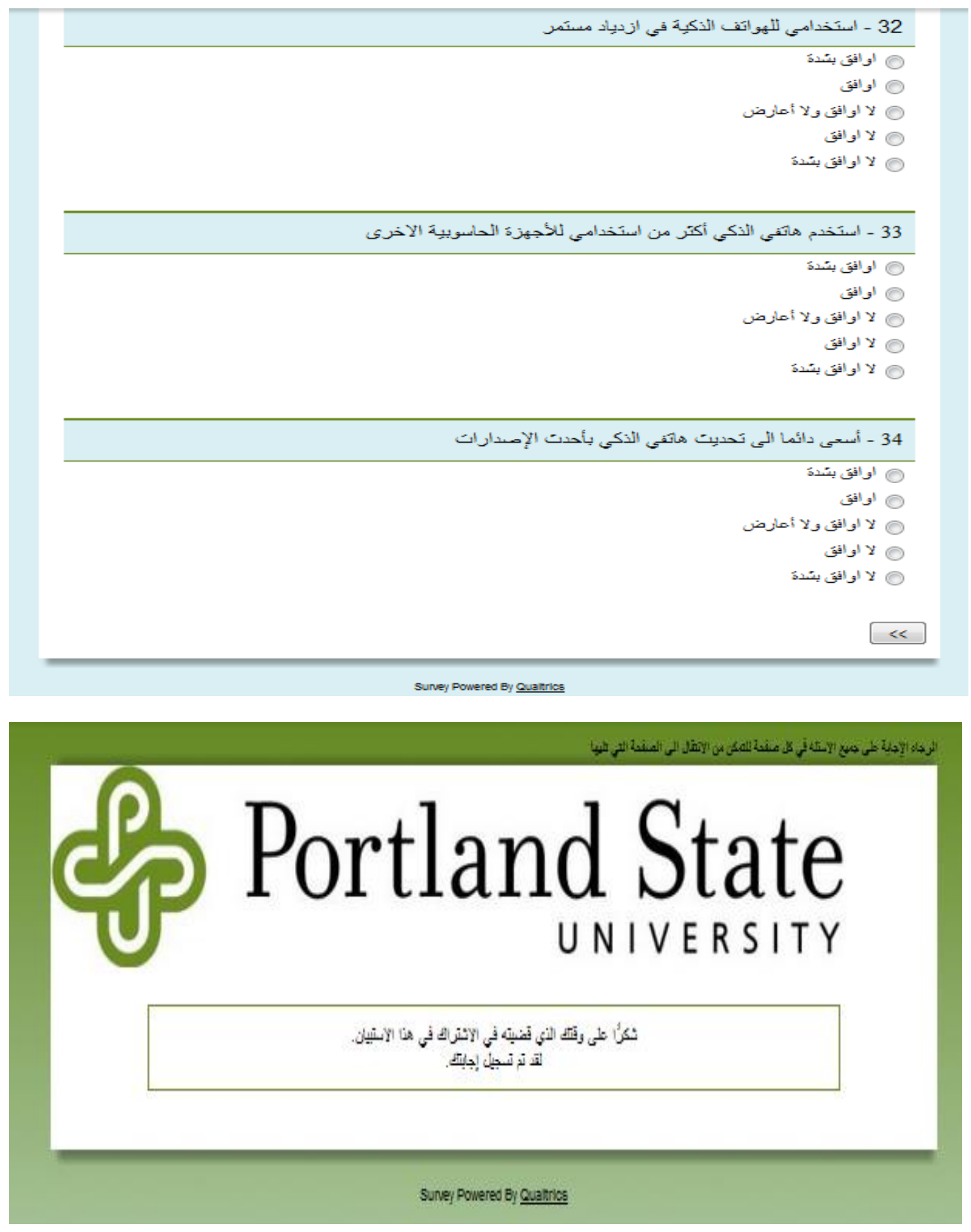




\section{Appendix J: Survey Items English Version}

\begin{tabular}{|c|c|}
\hline $\begin{array}{l}\text { Variables to } \\
\text { be measured }\end{array}$ & Items/Questions \\
\hline 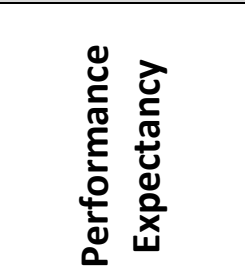 & $\begin{array}{l}\text { 1. I find the smartphone to be useful in my daily life. } \\
\text { 2. Using a smartphone enables me to accomplish more tasks quickly. } \\
\text { 3. Using a smartphone increases my overall productivity. } \\
\text { 4. Use of smartphones improves my performance in many of my } \\
\text { daily activities }\end{array}$ \\
\hline 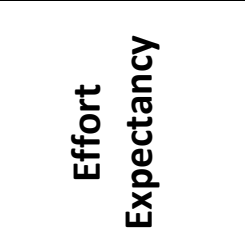 & $\begin{array}{l}\text { 5. Using a smartphone is easy for me. } \\
\text { 6. It is easy for me to learn how to use a smartphone. } \\
\text { 7. Using a smartphone and operating its functions is easy for me. }\end{array}$ \\
\hline 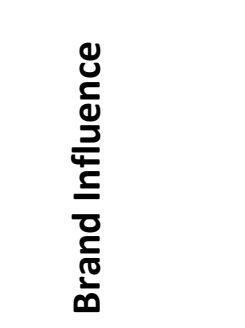 & $\begin{array}{l}\text { 8. The brand name of a smartphone is important to me when } \\
\text { choosing one. } \\
\text { 9. I am very attracted to one particular smartphone brand more } \\
\text { than other. } \\
\text { 10. I would most likely buy only a specific brand of smartphones that } \\
\text { I trust its quality. }\end{array}$ \\
\hline 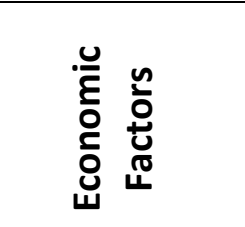 & $\begin{array}{l}\text { 11. Smartphone devices are reasonably priced to me. } \\
\text { 12. The cost of smartphones services is reasonable to me. } \\
\text { 13. Smartphones have many benefits for its cost to me. } \\
\text { 14. At the current price, smartphones provide a good value. }\end{array}$ \\
\hline 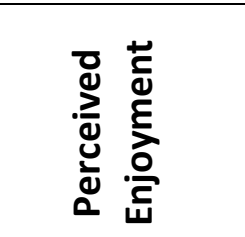 & $\begin{array}{l}\text { 15. I enjoy having a smartphone. } \\
\text { 16. It is fun for me to use smartphones } \\
\text { 17. I use smartphones to make my free time more enjoyable. } \\
\text { 18. Smartphones provide me with many entertainment options }\end{array}$ \\
\hline$\frac{5}{5}$ & $\begin{array}{l}\text { 19. The overall look and feel of smartphones is important to me. } \\
\text { 20. I pay more attention to the design, appearance and colors when } \\
\text { choosing a smartphone. } \\
\text { 21. The overall look and feel of smartphones is as important as its } \\
\text { functionality to me. }\end{array}$ \\
\hline
\end{tabular}




\begin{tabular}{|c|c|}
\hline 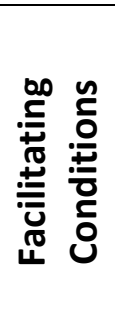 & $\begin{array}{l}\text { 22. I have the knowledge and capability to use smartphones. } \\
\text { 23. My smartphone is compatible with all of my computing devices } \\
\text { and IT network that I use. } \\
\text { 24. I always can get help when any difficulty using or dealing with } \\
\text { smartphones arises. } \\
\text { 25. I have sufficient experience to comfortably use smartphones. }\end{array}$ \\
\hline 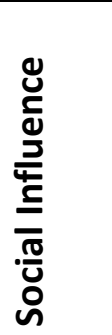 & $\begin{array}{l}\text { 26. My peers and close friends support the idea of me having a } \\
\text { smartphone. } \\
\text { 27. Most people I admire and am influenced by are using } \\
\text { smartphones. } \\
\text { 28. Having a smartphone makes me look more intelligent and } \\
\text { modern. }\end{array}$ \\
\hline 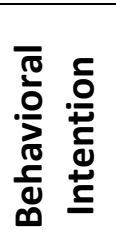 & $\begin{array}{l}\text { 29. I intend to use smartphones in the future. } \\
\text { 30. I will continue to use smartphones. } \\
\text { 31. I will always choose to use smartphones in my daily life. }\end{array}$ \\
\hline 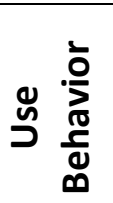 & $\begin{array}{l}\text { 32. My use of smartphones continues to increase. } \\
\text { 33. I use my smartphone more than my other computing devices. } \\
\text { 34. I always update my smartphone with latest version. }\end{array}$ \\
\hline
\end{tabular}




\section{Appendix K: Survey Items Arabic Version}

\begin{tabular}{|c|c|}
\hline $\begin{array}{l}\text { Variables to } \\
\text { be measured }\end{array}$ & Items/Questions \\
\hline 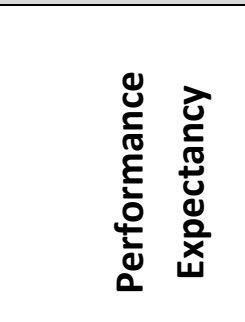 & 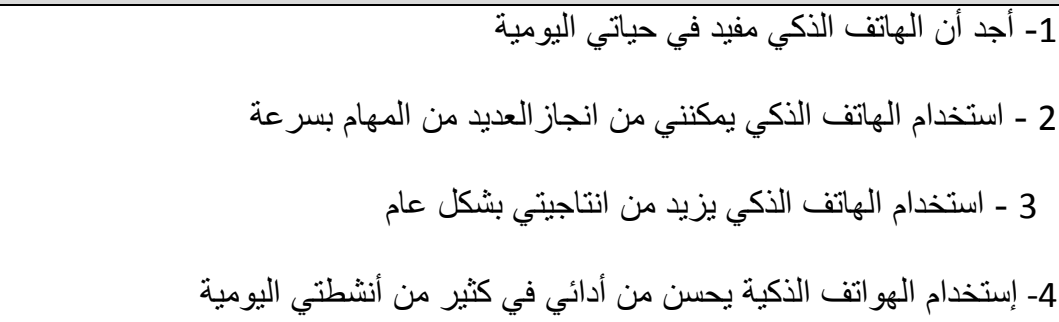 \\
\hline ț & 6 - 5 - إستخدام الهاتف الذكي سهل بالنسبة لي 1 - استخدام الهاتف الذكي وتشغيل وظائفه سهل بالنسبة لي تيفية استخدام الهاتف الذكي \\
\hline 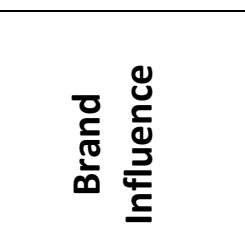 & 10 - 10 - عند اختبار هاتف ذكي فان اسم العلامة التجارية مهم بالنسبة لي العلامات التجارية لهاتف ذكي, بالنسبة لي, أكثر جاذبية من غيرها \\
\hline 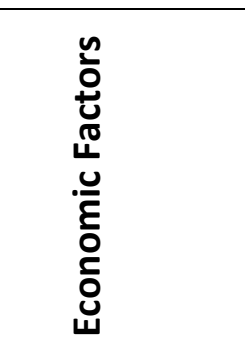 & 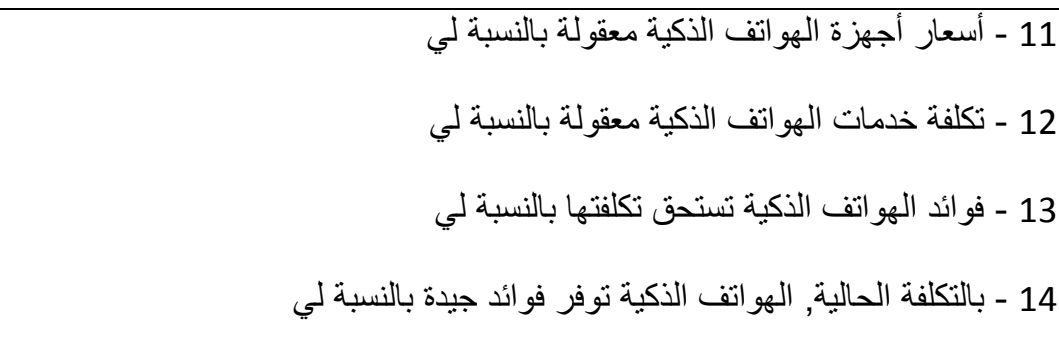 \\
\hline 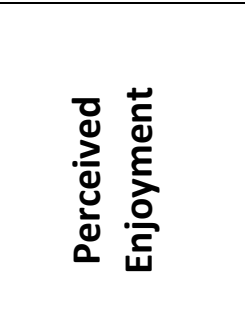 & 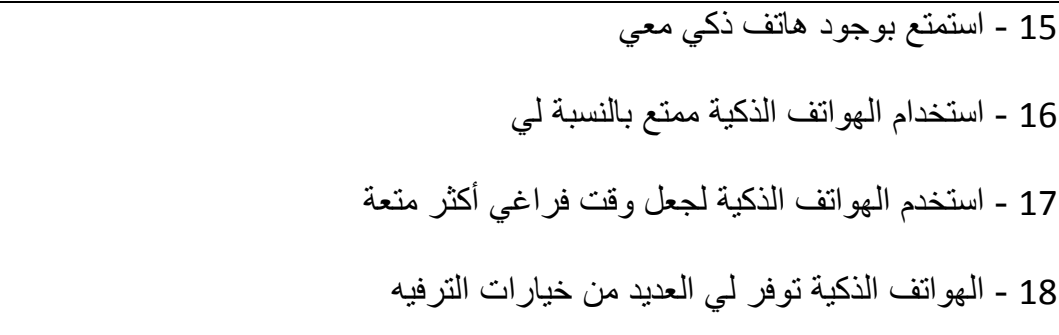 \\
\hline$\frac{.}{\frac{.00}{4}}$ & 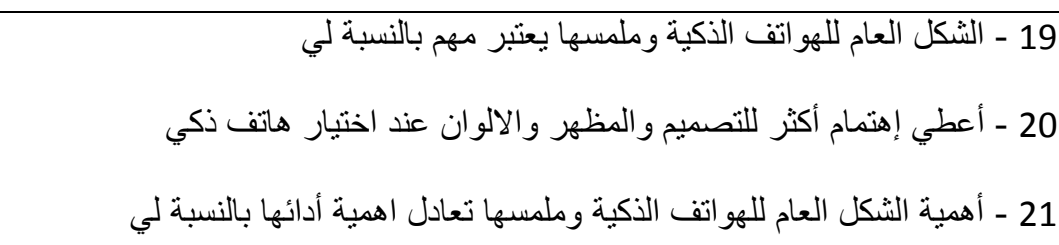 \\
\hline
\end{tabular}




\begin{tabular}{|c|c|}
\hline 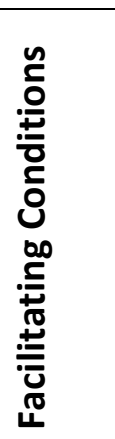 & 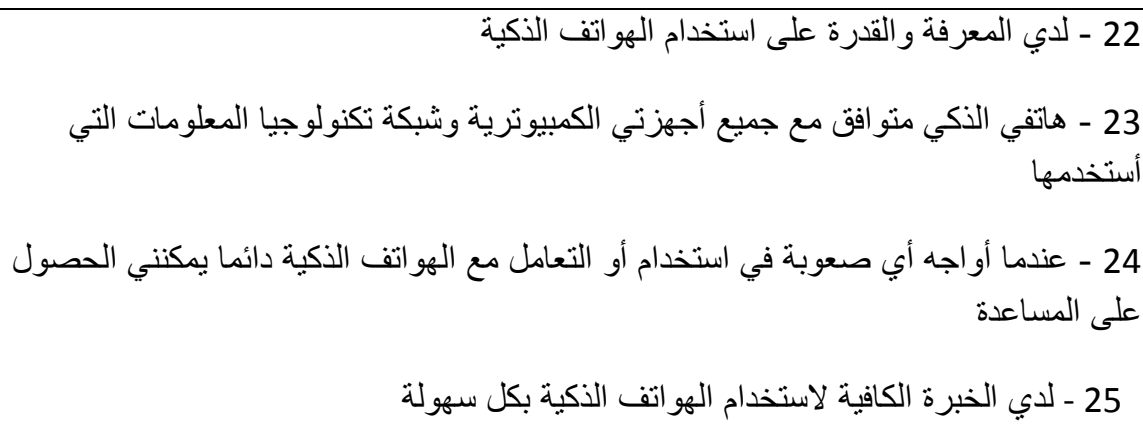 \\
\hline 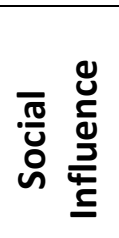 & 27 - 26 - زملائي و أصدقائي المقربون يؤيدون فكرة حصولي على الهاتف الذكي \\
\hline 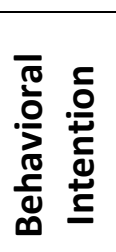 & 30 - 31 - أنوي استخدام الهواتف الذكية في المستقبل 1 - دائما سوف اختار استخدام الهو اتف الذكية في حياتي اليومية الذية الذية \\
\hline 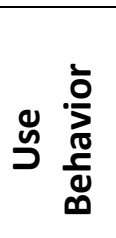 & 33 - 33 - استخدامي للهو اتف الذكية في ازدياد مستمر هاتفي الذكي أكثر من استخدامي للأجهزة الحاسوبية الاخرى دائما الى تحديث هاتفي الذكي بأحدث الإصدارات \\
\hline
\end{tabular}

